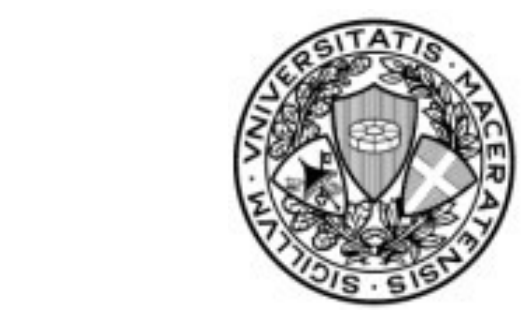

UNIVERSITÀ DEGLI STUDI DI MACERATA

DEPARTMENT OF POLITICAL SCIENCES, COMMUNICATION, AND INTERNATIONAL RELATIONS

\author{
Ph.D. Course in
}

Global Studies. Justice, Rights, Politics

Cycle XXXIII

\title{
VIOLENCE AGAINST WOMEN IN ARMED CONFLICT
}

IHL NORMS FROM A GENDER PERSPECTIVE

Academic Supervisors

Professor Natascia Mattucci

Professor Paolo Palchetti

Scientific Coordinator

Professor Benedetta Barbisan
Ph.D. Candidate

Rachele Marconi

Academic Year 



\section{Table of Contents}

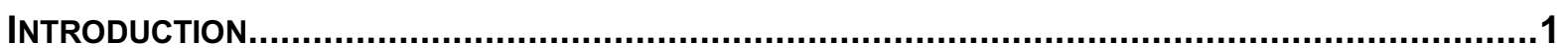

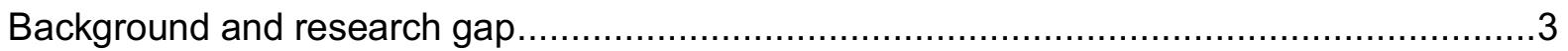

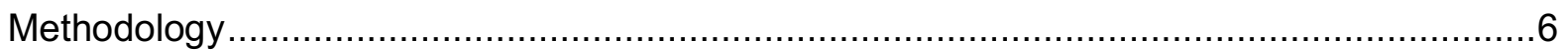

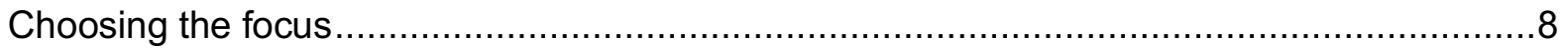

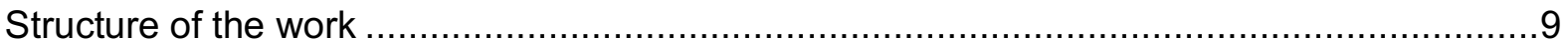

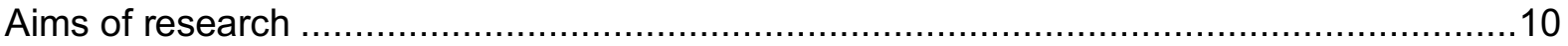

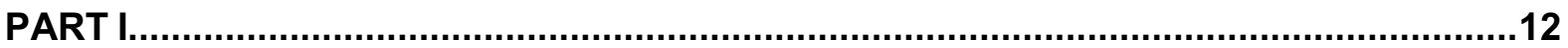

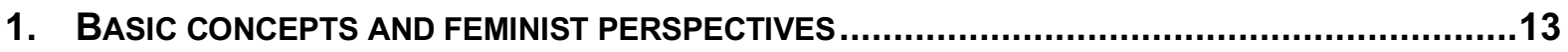

1.1. THE CONCEPT OF "GENDER” AND ITS RELEVANCE IN INTERNATIONAL LAW .........................13

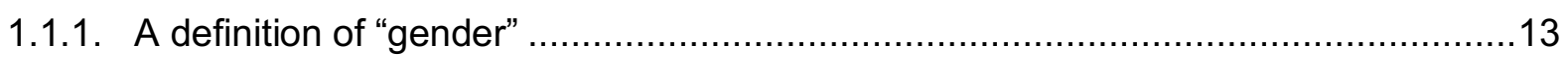

1.1.2. Gender, armed conflict and international humanitarian law................................ 15

1.2. DEFINITION OF CONFLICT-RELATED VIOLENCE AGAINST WOMEN ..................................18

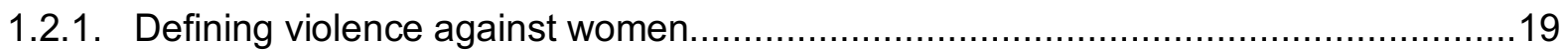

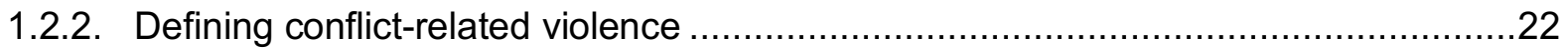

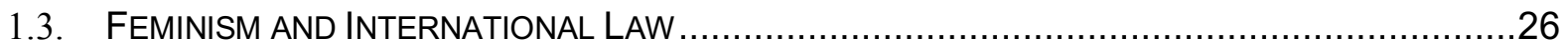

1.3.1. Some remarks on the feminist approaches to International Law ..........................27

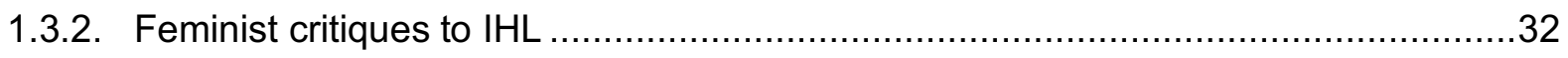

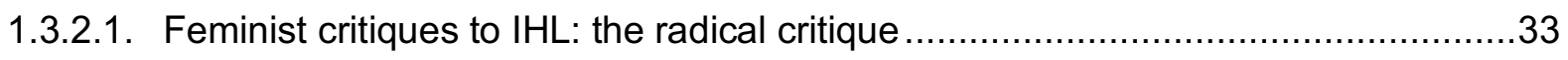

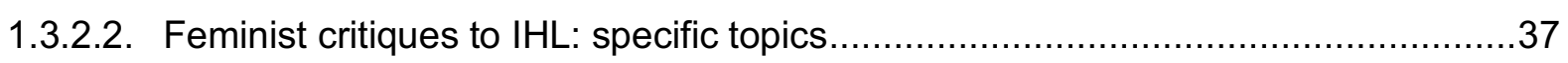

1.3.2.3. Feminist critiques to the international criminal adjudication ...............................41

1.3.2.4. The "revisionist" and the "enforcement" schools: the potential of $\mathrm{IHL} \ldots \ldots \ldots \ldots \ldots . . . . . . . .45$

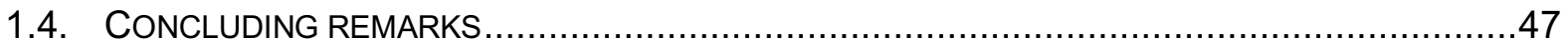

2. WOMEN IN SITUATIONS OF ARMED CONFLICT UNDER IHL TREATIES ..............................50

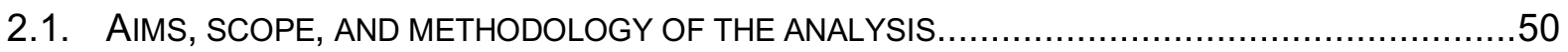

2.2. THE PRINCIPLE OF NON-DISCRIMINATION AGAINST WOMEN .....................................53

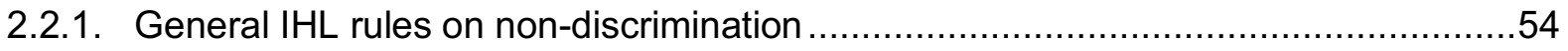

2.2.2. The principle of non-discrimination and the law of occupation ............................57

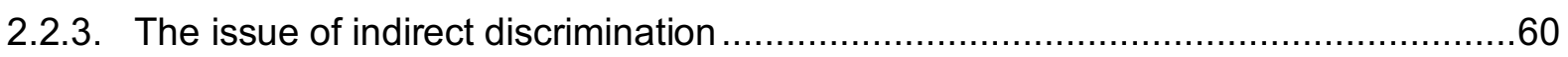

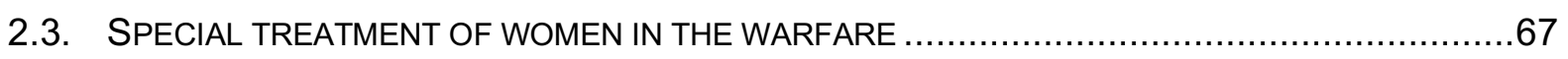

2.3.1. General rules protecting women in the warfare ............................................68

2.3.2. The regime of particular care for pregnant women and mothers of young children ..69 
2.3.3. The system of differentiated treatment for interned women and women prisoners of

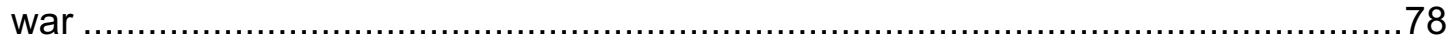

2.4. RULES DEALING WITH ABUSES PARTICULARLY AFFECTING WOMEN .............................87

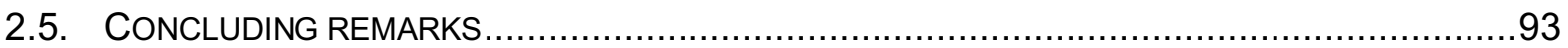

3. ARTICLE 27(2) OF the FOURTH GeneVA CONVENTION: THE CONCEPTS OF "HONOUR" AND "RAPE"

3.1. ARTICLE 27 OF GV IV AND ITS ROLE IN PROTECTING WOMEN AGAINST SEXUAL VIOLENCE.94

3.2. THE CONCEPT OF "HONOUR" FROM A CONTEMPORARY PERSPECTIVE ..........................97

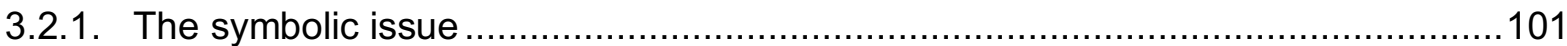

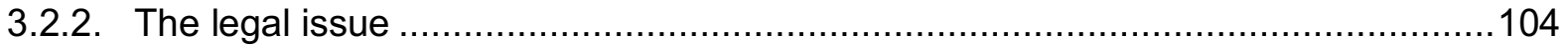

3.2.2.1. Does the concept of honour cover all the forms of conflict-related sexual violence

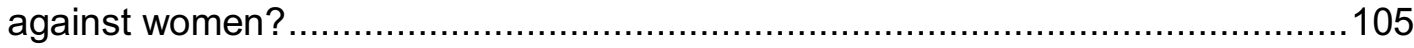

3.2.2.2. Could the concept of honour, as it was traditionally understood, still be useful?..109

3.2.2.3. Is the term honour a generic term subjected to evolutive interpretation? ............112

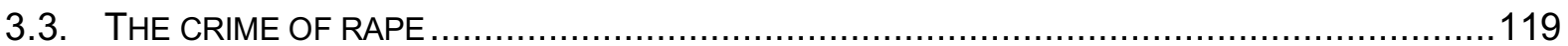

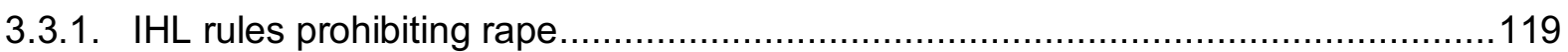

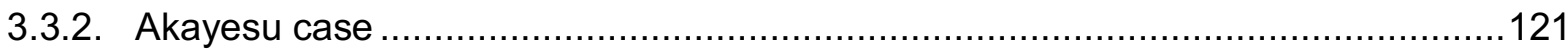

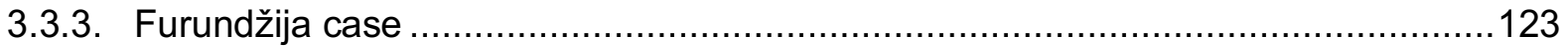

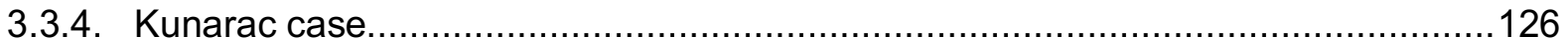

3.3.5. Is the crime of rape a "grave breach" under the Geneva Conventions? ................132

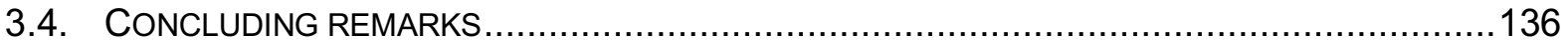

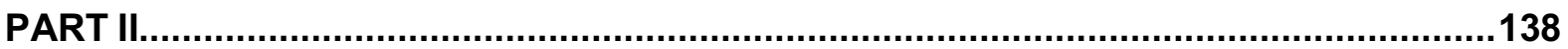

4. REPARATIONS FOR VICTIMS OF ARMED CONFLICT .................................................... 140

4.1. SCOPE OF THE TOPIC AND METHODOLOGICAL REMARKS ........................................140

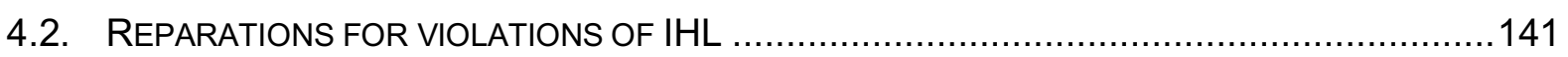

4.2.1. The general obligation to make reparation for violations of $\mathrm{IHL} \ldots \ldots \ldots \ldots \ldots \ldots \ldots \ldots . . . . . . . . . . . . . . . .141$

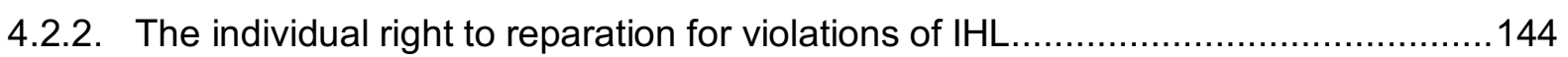

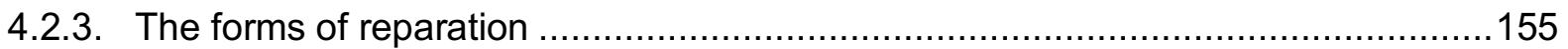

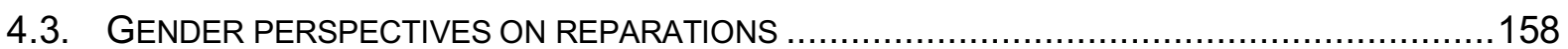

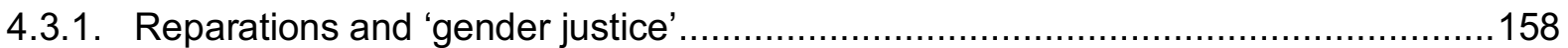

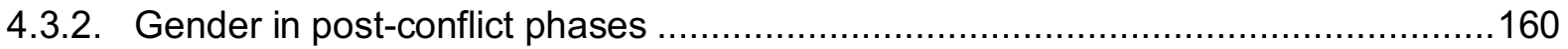

4.3.3. Gender perspectives and the (potential) individual right to reparation..................166

4.3.4. Forms of reparation and transformative justice for crimes against women ............167 


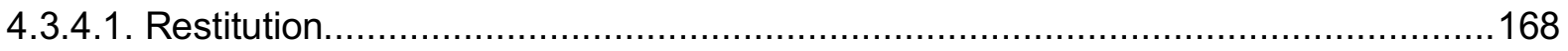

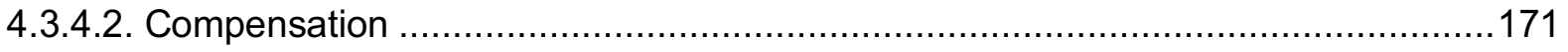

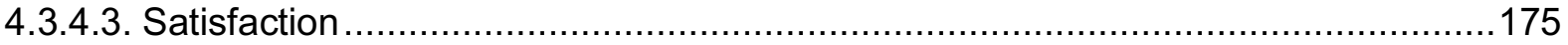

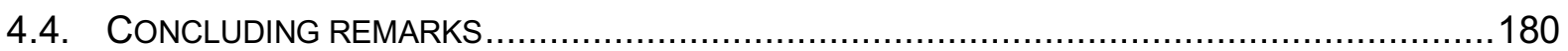

5. REPARATIONS IN THE CASE OF THE KOREAN “COMFORT WOMEN" .................................183

5.1. THE RELEVANCE OF THE CASE FROM A NORMATIVE AND A GENDER PERSPECTIVE...........183

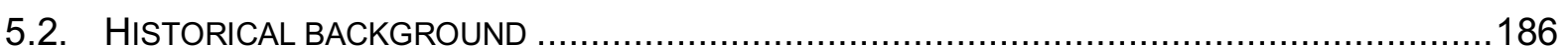

5.3. "COMFORT WOMEN" AS VICTIMS OF IHL VIOLATIONS: THE BASIC ISSUES .......................189

5.4. ISSUES SURROUNDING THE QUESTION OF REPARATION FOR "COMFORT WOMEN"............193

5.4.1. The existence of an individual right to reparation at the time of World War II .........194

5.4.2. The 1965 Settlement Agreement between Republic of Korea and Japan .............197

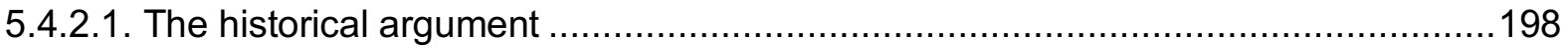

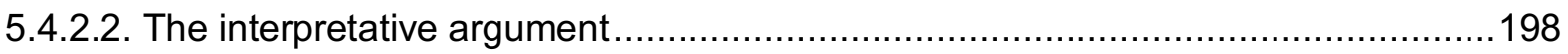

5.4.2.3. The argument of the limited scope of the waiver clause....................................202

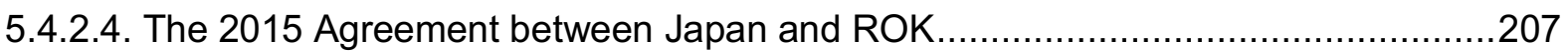

5.5. THE 2021 JUdGement OF the SEOUL CENTRAL DISTRICT COURT AS A TURNING POINT.209

5.6. PUBLIC APOLOGY AND MEMORIALS AS REPARATION FOR "COMFORT WOMEN" AND THEIR

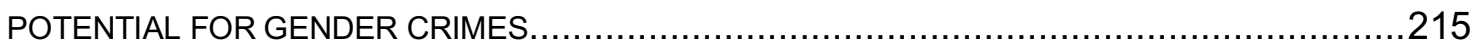

5.6.1. The ambiguous Japanese apologies from the Kato Statement to the 2015

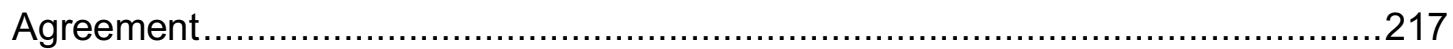

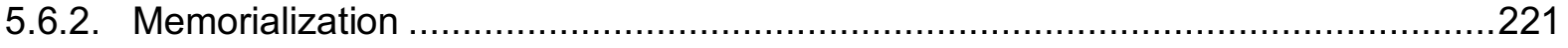

5.7. EXCURSUS: THE INFLUENCE OF INTERNATIONAL HUMAN RIGHTS LAW IN THE "COMFORT

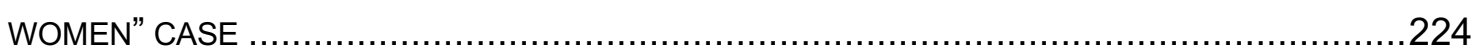

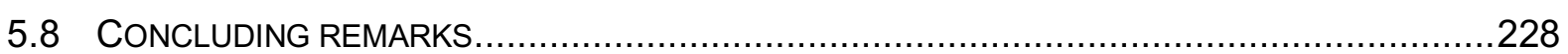

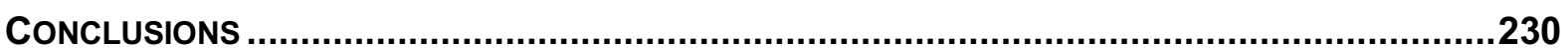

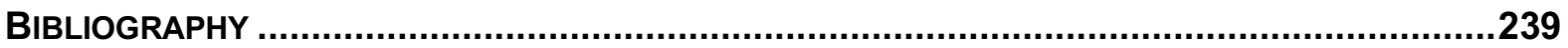




\section{INTRODUCTION}

In 1474, an ad hoc tribunal of twenty-eight judges was convoked by the allied states of the Holy Roman Empire to prosecute Sir Peter von Hagenbach for a series of crimes, including rape of women, girls and nuns. ${ }^{1}$ Sir von Hagenbach was accused for having committed those crimes as governor of the occupied Alsatian territories, serving the Duke Charles of Burgundy, from 1469 to 1474 . In the trial, which is considered the first international criminal prosecution in history ${ }^{2}$ and thus also the first international prosecution for rape, the accused was condemned to death by sword for spreading terror "without first having declared war". 3

More than five and a half centuries after Sir von Hagenbach's case, on 4 February 2021, the Trial Chamber IX of the International Criminal Court (ICC) ${ }^{4}$ condemned Dominic Ongwen, a Ugandan former senior commander of the Lord's Resistance Army, a rebel armed group against the government, for 61 charges, including crimes against humanity and war crimes, committed in Norther Uganda between 1 July 2002 and 31 December 2005. ${ }^{5}$ Among the indictments, Ongwen was found guilty of number sexual and gender-based crimes, such as rape, sexual slavery, forced marriage, forced pregnancy and outrages upon personal dignity committed against seven women, who were abducted to serve in his household. Moreover, the conviction comprised the crimes of forced marriage, torture, rape, sexual slavery and enslavement committed against women and girls that were part of the Sinia brigade. It is worth

\footnotetext{
1 "Multas eciam in civitate Brisacensi mulieres maritatas, virgines, eciam moniales vi oppressisset et contra ipsarum voluntatem, et similia non solum ibi, verum eciam in multis aliis opidis et villis fecisset contra deum, justiciam et omnem honestatem". Knebel, Johannes, Chronicle of the Chaplain Johannes Knebel from the Time of the Burgundian Wars, Bahnmaier, 1851, pp. 86-87. [Cited in Gordon, Gregory S., "The Trial of Peter von Hagenbach", in Heller, Kevin and Simpson, Gerry, The Hidden Histories of War Crimes Trials, Oxford University Press, Oxford, 2013].

${ }^{2}$ Ibid.

${ }^{3}$ Viseur Sellers, Patricia, "The Context of Sexual Violence: Sexual Violence as Violation of International Humanitarian Law", in Kirk McDonald, Gabrielle and Swaak-Goldman, Olivia (eds.), Substantive and Procedural Aspects of International Criminal Law: The Experience of International and National Courts. Volume I: Commentary, Kluwer Law International, The Hague, 2000, p. 267.

4 The International Criminal Court is the first world's permanent international criminal tribunal with complementary jurisdiction over international crimes of genocide, crimes against humanity, war crimes, and the crime of aggression. Established on 17 July 1998 through the Rome Statute, it entered into force on 1 July 2002.

5 ICC-02/04-01/15, 4 February 2021.
} 
noting that the Court entered for the first time a conviction for forced marriage and forced pregnancy. ${ }^{6}$

These two cases may seem quite similar. It is not only that both have a war criminal as defendant, but they also share the nature of the adjudicator, two international criminal tribunals, and the types of criminal charges, comprising crimes committed against women during an armed conflict. In both cases, judges considered unlawful the heinous atrocities against female civilians.

Yet, apart from the temporal dimension, there is a substantial aspect that distinguishes the two decisions. Most importantly, the two cases are separated by the underlying protected interests at stake. Upon closer examination, in the first case the unlawfulness of the acts is produced by the specific circumstances in which the offences against women were committed, that is without a declaration of war. In other words, Sir von Hagenbach would have avoided condemnation had he respected the rules of war and declared war before committing the offences. Since he did not directly declare war, the war was illegitimate and so were his army's acts. To the contrary, in the second case, the illegality of the acts of sexual violence against women committed by Ongwen depends on the nature of the acts. Sexual and gender-based crimes are considered illegal per se and not on the basis on the characterization of the conflict or the specific circumstances in which they are committed. Ultimately, the first case shows that, while judging the military conduct of an individual, priority was given to military considerations over humanitarian considerations, and that compliance with the ius in bello superseded any evaluation of the gravity of the offence against the person. ${ }^{7}$ Contrarily, the main interest at stake in the more recent case is the respect of the physical and sexual integrity of women, being irrelevant any consideration on the violation or not of the rules of war for the impunity of the offender.

The two cases above represent well the motivations and scope of the present investigation. This thesis aims at analysing the ways conflict-related violence against women has become part of the fabric of international humanitarian law (IHL), the system of norms specifically directed to

\footnotetext{
${ }^{6}$ The information sheet of the trial, including all legal documents of the case, are available at: https://www.icccpi.int/Pages/item.aspx? name=pr1564\&fbclid=IwAR2ZeBPwG1atlZC Du8hI2ySdMhjvsNebn1HcXBhlenAEi9ut2E4HuoEBo [last visited, 20 February 2021].

${ }_{7}$ On the existence of some rudimentary norms of respect for the integrity of the person in the pre-modern international humanitarian law, see Viseur Sellers, Patricia, "The Context of Sexual Violence: Sexual Violence as Violation of International Humanitarian Law", in Kirk McDonald, Gabrielle and Swaak-Goldman, Olivia (eds.), Substantive and Procedural Aspects of International Criminal Law..., pp. 262-332.
} 
the regulation of the conduct of war. To what extent IHL protects women from conflict-related violence? This question inspired the investigation behind this thesis.

\section{Background and research gap}

Women, conflict, reparations, and gender are the key concepts of this research. Violence represents the main feature of armed conflict; women are one of the main objects whom this violence is directed to; reparations constitute the means through which the effects of violence may be, at least partially, rectified; and gender is the main category used to analyse the phenomenon of conflict-related violence against women. The relationship among the four is conducted through the lens of IHL.

Traditionally, women were not an active part in war. They did not have the decision-making powers, because they could not be high-rank military personnel, nor could they become combatants according to the majority of national legislations. ${ }^{8}$ However, women have been always experiencing war in many ways. In particular, they have been subjected to many and extremely grievous forms of wartime violence. Conflict-related violence against women is not a new phenomenon. As the example above illustrates, this practice spans centuries and crosses armed conflicts all over the world. Nowadays, the grim forms of violence women experience in the warfare are not only well documented, but also considered potentially present in each situation of armed conflict. ${ }^{9}$

\footnotetext{
${ }^{8}$ Even today, the military is associated to a male institution. However, despite significant resistance, many Eastern and Western countries are facing the progressive push toward the achievement of gender equality in the armed forces. On 17 February 2020, the Indian Supreme Court delivered its decision in support of the equalisation of women officers to their male counterparts in the military, by making them eligible for permanent commissions, which qualifies them to serve as a full tenure. In 1992, the Indian military regime started, to certain extent, to accept women, but before the ground-breaking judgment they were under a special regime, namely the 5-years Short Service Commission, which limited their military career to a maximum of 14 years of service without any possibility to extend it or profiting of the pension benefits. The judgements can be found here: https://main.sci.gov.in/supremecourt/2010/20695/20695 20108150120635 Judgement 17-Feb-2020.pdf [last visited, 27 February 2021].

For a recent overview of the increasing integration of women in the armed forces of NATO States and the challenges faced by the policies of their access to combat positions, see Hagemann, Karen and Campbell, D'Ann, "Post-1945 Western Militaries, Female Soldiers, and Gay and Lesbian Rights", in Hagemann, Karen, Dudink, Stefan and Rose, Sonya O. (eds.), The Oxford Handbook of Gender, War, and the Western World since 1600, Oxford University Press, Oxford, 2020.

9 See ICC, Policy Paper on Sexual and Gender-Based Crimes, 2014, available at: https://www.icc-

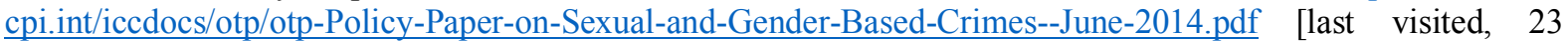
February 2021].
} 
Despite the gravity of the offences suffered, the position of women during armed conflicts remained relatively blurred at national and international law level for centuries. During the last decades, however, a new consciousness raised with regard to the global scale atrocities women face during armed conflicts and, nowadays, the debate around the topic is very lively. ${ }^{10}$ However, the field still harbours many serious challenges for legal scholars. Considering the number of current armed conflicts around the world, their relevance in the global context, ${ }^{11}$ and their great impact on women, ${ }^{12}$ a broader and more systematic analysis is necessary.

Nowadays, the trend of excursions across different regimes of international law - namely international humanitarian law (IHL), international criminal law (ICL), international human rights law (IHRL) and the United Nations law - seem to respond to the need of reconciliation of a fragmented regulation of the issue. At the basis of this holistic approach is the idea that the interaction between regimes may reinforce each one, overcoming the gaps emerging in the application of a single regime and promoting a legal system with a strengthened enforcement capacity.

Conflict-related violence against women is a fertile terrain for this approach. The phenomenon was firstly regulated by IHL, then dealt under the lens of individual criminal responsibility under the jurisprudence of the ad hoc criminal tribunals, ${ }^{13}$ and finally caught the attention of human rights lawyers for the implications of women's rights in the warfare. While great progress has been made in the development of women's legal protection in war under IHL, IHRL, and through the UN Security Council's Resolutions, ${ }^{14}$ a recent academic engagement with the IHL regime and its potentialities lacks.

\footnotetext{
${ }^{10}$ In the last decades, the historical debate particularly focused on one form of conflict-related violence against women, rape. For a study of the mass rapes committed in XIX century, see generally Flores, Marcello (ed.), Stupri di Guerra. La Violenza di Massa contro le Donne nel Novecento, FrancoAngeli, Milano, 2010.

${ }^{11}$ Stockholm International Peace Research Institute, "World military expenditure grows to \$1.8 trillion in 2018", 29 April 2019, available at: https://www.sipri.org/media/press-release/2019/world-military-expenditure-grows18-trillion-2018 [last visited: 21 February 2021]. The report provides that the total world military expenditure reached \$1.8 trillion in 2018.

${ }^{12}$ For a recent analysis of cases of conflict-related sexual violence against women and the operational responses to it enforced by the International Red Cross, see International Committee of the Red Cross, Special Appeal 2020. The ICRC's Response to Sexual Violence, Geneva, March 2020, available at: https:/www.icrc.org/sites/default/files/wysiwyg/Activities/Sexual-violence/2020 specialappeal sv.pdf [last visited: 21 February 2021].

${ }^{13}$ The International Criminal Tribunal for the Former Yugoslavia and the International Criminal Tribunal for Rwanda.

${ }^{14}$ See generally Chinkin, Christine, "Gender and Armed Conflict", in Clapham, Andrew and Gaeta, Paola (eds.), The Oxford Handbook of International Law in Armed Conflict, Oxford University Press, Oxford and New York, 2014.
} 
However, it seems important to focus on IHL for at least three reasons. First, IHL is the main system regulating the conduct of hostilities and the treatment of civilians in armed conflict. This means that the actors of the warfare look at this regime to direct their engagement in armed conflict. As the legal framework to which the parties to the conflict first look at, IHL, and a gender-oriented analysis of its norms, has a great potential to improve the legal and factual position of women in conflict. Second, so far, much of the international legal scholarship has focused on the developments made by the UN Security Council's Resolutions on Women, Peace and Security (WPS) ${ }^{15}$ and is now turning to the interaction of the different legal regimes noted above. ${ }^{16}$ This is not to say that the other regimes will not be of any use for this work. The interplay between the different fields of international law is unavoidable, because of the constant interaction among them. Thus, the work of the international criminal courts ${ }^{17}$ and specialized agencies of the United Nations cannot be underestimated or left outside the scope of this thesis. This is the reason why, although the focus of this research is IHL and its main sources, references to the contributions of other regimes of IL on the development of the protection of women in armed conflict will also be made. Third, while analysing the IHL regime, feminist scholars have usually focused on the criticism to the regime, leaving out its potential to be interpreted in a gender-sensitive way. Although feminist approaches to international law have deeply analyzed and described structural limits and applicative deficits of this legal regime in relation to violence against women in war, the investigation of the potential of the legal regime of IHL may respond to contemporary issues connected with the topic. This thesis aims at filling this gap.

The last point is particularly important for this thesis. The majority of feminist lawyers suggests a substantive reform of the IHL system. In particular, many efforts have been made to introduce a gender-sensitive approach to and a feminist-oriented interpretation of the main IHL sources, namely the Geneva Conventions of 1949. These approaches usually assume that the low enforcement of rules prohibiting violence against women in contexts of armed conflict would

\footnotetext{
${ }^{15}$ See the recent work of Christine Chinkin on Women, Peace and Security and International Law, Cambridge University Press, Cambridge, 2021 (forthcoming).

${ }^{16}$ O'Rourke, Catherine, Women's Rights in Armed Conflict under International Law, Cambridge University Press, Cambridge, 2020. The author suggests that women's organizations and feminist civil society have so far failed to address the protection of women's rights in conflict using the potentialities deriving from the different regimes' interaction.

${ }^{17}$ International criminal law represents a relevant branch of IL for this work to the extent that it constitutes a codification of IHL, in that it determines the behaviours in violation of IHL norms and identifies the wartime offenses warrant prosecution at international level. See David, Erik, Principes de droit des conflits armés, Bruylant, Bruxelles, 2012.
} 
be the result of the non-gender-oriented substance of the norms. Given the incapacity of the norms, as they are written, to fully assume a female perspective and to cover the experience of women in situations of conflict, the regime would be unlikely to fully respond to the various forms of violence to which women are subjected during the conflict.

Moving from this, the point of departure of this thesis is the idea along with feminist approaches have left some space for a positivistic analysis of the IHL norms. In this sense, it is suggested that revisiting the interpretation of the norms - specifically using the traditional means of interpretation listed under the Vienna Convention on the law of treaties of 1969 - is a necessary step for assessing their normative content, and, ultimately, the possibility of a renewed genderoriented interpretation of the regime. If a gender-oriented interpretation is followed, a broader protection of women in conflict situations may be guaranteed.

\section{Methodology}

The topic of conflict-related violence against women can be approached from a variety of different perspectives. While IHL is at the basis of this enquiry, a proper analysis of this topic may also entail an interdisciplinary approach into different fields of study, including philosophy, gender studies, and political science. The contributions of some of these perspectives are considered in this thesis.

If it is true that the need for interdisciplinarity in international law "depends on what one considers to be the proper object of study for international lawyers", or differently said, "on what one considers to be the task of international legal science", ${ }^{18}$ the author cannot ignore the question of whether and for which reasons an interdisciplinary study is necessary for studying the topic of this thesis. First, it seems useful to define what interdisciplinarity stands for.

This thesis approaches conflict-related violence against women from an international humanitarian law perspective. Point of departure of the enquiry is the IHL framework concerning the protection of women during the conflict. This means that it uses as point of reference rules, cases, and State practices on the matter. Interdisciplinarity is here intended as the act of going out of the boundaries of the discipline to unveil and maybe question some of

\footnotetext{
${ }^{18}$ Palchetti, Paolo, “An Interdisciplinary Approach to International Law? Some Cursory Remarks”, in Meccarelli, Massimo (ed.), Reading the Crisis: Legal, Philosophical and Literary Perspectives, Editorial Dykinson, Madrid, 2017, pp. 199-208.
} 
the theoretical assumptions and postulates that form the basis of our understanding of international law. The feminist critics to international humanitarian law will be taken into account to the extent they might help to unmask some critical issues that emerge from the interpretation and the application of the norms. At this stage, other disciplines may be also helpful. One may particularly benefit from gender studies and feminist approaches to international $\operatorname{law}^{19}$ for the identification of the social, economic and cultural influence of the category of gender in contexts of armed conflict. Insights from these disciplines might be helpful to read the law and analyze judicial cases. What does 'honour' mean? What is the intellectual 'package' of this concept? How should we read it to better serve the purpose of the IHL norms that make reference to it? All these are questions where the perspectives of other disciplines might be helpful.

However, caution is needed. While feminist legal scholars often criticize the law of armed conflict based on its lack of effectiveness, the way law is actually applied (or not) cannot be the main, or at least not the only, criterium to evaluate the adequacy of the law to respond to conflict-related violence against women. Considering the numerous political, economic and sociological causes that can influence and affect the effective application of the law, it would be misleading to use non-legal considerations to judge the adequacy of law.

Non-legal considerations will be only used in the first phase, namely the analytical phase, devoted to a better comprehension of the relevant issues often invisible to a strictly legal eye, but not as a methodological tool, that is to demonstrate the adequateness of the IHL regime to respond to issues related to conflict-related violence against women.

The idea at the basis of this methodology is that critical reflections over international law may help shedding light on some particular issues visible only through adopting another perspective. In particular, one can benefit from the idealistic ${ }^{20}$ approach of the feminist perspectives, which offers various insights on the way law ought to be (lex ferenda) in order to better protect women in situations of armed conflict, to reflect on the current status of women's protection under the regime and the numerous issues connected with it.

\footnotetext{
${ }^{19}$ See Charlesworth, Hilary and Chinkin, Christine, The Boundaries of International Law. A feminist analysis, Manchester University Press, Manchester, 2000.

${ }^{20}$ On the tension between the idealistic approach, that is how things ought to be, and the realistic approach, that is how things are, and whether the legal analysis should incorporate the first approach, see Shaw, Malcom N., International Law, Cambridge University Press, Cambridge, 2017, pp. 40-41.
} 
This is why the thesis does not go beyond international law. The author's identity and background remain positivistic, but in a modern, reflective sense. As Cassese put it, the positivistic approach evolved over time, so that "the investigation of legal rules and institutions must not be carried out without a proper contextualization, both socio-politically and ideologically, in order to fully understand the dynamics which spurred their adoption or establishment". ${ }^{21}$

\section{Choosing the focus}

Choices are inevitable in dealing with such a complex field of study. The present investigation is not aimed at covering all aspects concerning with conflict-related violence against women. Certain forms of violence affecting women during the conflict are not treated here. Some could argue that the expulsion from ancestral territories or the demolition of homes should have also been included on this topic. Others would also add modern forms of female sexual enslavement in wartime, peacekeeping agents abuses, or the vulnerable condition of women refugees in (the more and more diffused) refugee camps all over the world.

The selection made here did not mean to reflect any ranking or value judgement of the numerous female experiences of war. This is not to say that the choices are accidental. The criteria for selecting the legal material to be analyzed included its importance in academic literature, the doctrinal interest in its interpretation, and its significance for women in conflict. In particular, the choice of the case of "comfort women" as a leading example in this thesis, to which Chapter 5 is dedicated, reflects the importance of this timely case (a fundamental judgment was issued in January 2021) for the subject. A basic criterion for demarcating the object of investigation was the intention to offer a perspective of critical issues in both of the two basic phases of conflict-rules, jus in bello and jus post bellum.

Of course, ultimately, the way the topic is treated, the forms of violence selected, and the examples used reflect the partial perspective of the author. It cannot be denied the fact that the personal background, made up of the intellectual upbringing, and the texts read influence the way we cope with a topic and the set of presuppositions and assumption we approach it.

\footnotetext{
${ }^{21}$ Cassese, Antonio, Five Masters of International Law: Conversations with R-J Dupuy, E Jiménez de Aréchaga, R Jennings, L Henkin and O Schachter, Hart, Oxford, 2011, p. 258.
} 
Structure of the work

The present investigation consists of two parts. Part I, comprising Chapters One to Three, provides the theoretical background, exploring the gender-oriented perspective at the basis of the feminist critics to IHL, and then turns to the analysis of the legal framework regulating wartime violence against women. Part II, Chapters Four and Five, shifts towards the postconflict phase, with specific regard to the reparation issue. The choice of structuring the thesis into two parts, dealing with subjects apparently distant, responds to the necessity to investigate to what extent IHL accommodates or may accommodate a gender-sensitive approach in the phase of ius in bello first, namely the phase of the hostilities, and in the post bellum phase, that is the phase after the cessation of the hostilities and until a formal settlement.

A gender-sensitive interpretation of the IHL treaties cannot be performed in a theoretical vacuum. The first Chapter explores some key concepts for a gender analysis of the IHL treaties and provides an account of the feminist critiques to the IHL regime. The main argument here is that, so far, less attention has been paid on current impediments in norm application and on the question of whether these weaknesses could be eventually overcome through a renewed interpretation of the norms. Ultimately, the aim is to position this thesis within the broader debate of feminist critique to IHL.

Chapter Two deals with the regulatory analysis of the IHL regime, namely the Hague Conventions, the 1949 Geneva Conventions and the Additional Protocols of 1977, governing the life of civilian women in situations of armed conflict. This Chapter addresses the question of whether the IHL regime is irreversibly gendered or, contrarily, whether it is possible to reinterpret the existing IHL norms in a way that could properly respond to the current issues that women face in contexts of conflict. To this end, a "practical approach" is preferred. In analyzing the number of norms designated to regulate conflict-related violence against women, the provisions are "put to the test" through the use of concrete recent cases that put into question the extent of their applicability to female civilians. The way the provisions react to the interpretative "stress" can affect the level of legal protection women can benefit of. The investigation aims at establishing the feasibility of re-interpreting some parts of IHL in a more gender-sensitive approach.

In Chapter Three, the attention is drawn to the examination of Article 27 of the IV Geneva Convention, related to the prohibition of sexual violence against women in armed conflict. The necessity to specifically focus on this provision has two main reasons. First, the Article 
regulates the most common form of violence against women committed during armed conflicts, namely all acts having a sexual connotation. Since sexual violence usually implies a gender character, the analysis of the Article may also reveal significant aspects on the conception of women under IHL regime. Second, feminist scholars have demonstrated the limits of the norm while using a gender perspective. An investigation over the possibility to interpret in a genderoriented way the provision will shed light on the question whether the limits of the norms may be interpretatively overcome in order to assure a better protection to women from conflictrelated sexual violence.

Chapter Four, the first one of Part II, turns to the post bellum phase, specifically analyzing the mechanism of reparations for violations of IHL norms. An overview of the legal framework of the state obligation to make reparation for breaches of IHL provisions will be first provided. This analysis constitutes the basis for the subsequent examination of the main feminist accounts to reparation, with a specific focus on the question of whether, and eventually how, the category of gender may have a relevance in the determination of the most appropriate forms of reparation in cases of conflict-related violence against women.

Finally, Chapter Five analyzes a specific case of conflict-related violence against women, namely the Korean "comfort women" case, related to the thousands of women from Korea, the Philippines, Indonesia and China who had been forced into government-sanctioned military brothels to act as "comfort women" for Japanese troops during World War II. The case, one of the most disputed ongoing cases of reparation for crimes against women, offers not only numerous legal issues but also a timely and paradigmatic example for the discussion on the relevance of the forms of reparation with regard to the kind of damage suffered by survivors. In particular, the "comfort women" case shows that financial compensation, the currently privileged form of reparation in the international law system, is not always the best solution for victims, especially women survivors, who instead seem to often demand official apology or the construction of monuments. This raises the question of whether, and eventually how, a gender-oriented perspective may influence the choice in the forms of redress for victims of IHL violations.

\section{Aims of research}

The present thesis has three ambitions. First, a systematization of some of the basic IHL rules that concern women in armed conflict. Second, this analysis will suggest a gender-sensitive 
reading of the relevant provisions, namely a legal interpretation that takes into account the specific position of women in war. Third, the limits of this possible interpretation will be explored. This dimension of the thesis will critically assess whether IHL rules can adequately account for the position of women in the warfare or fall short of providing sufficient protection and remedies. 


\section{PART I}

Part I of this thesis is dedicated to an analysis of the core jus in bello rules that address women's condition in armed conflict. Chapter 2 addresses the regulatory analysis of the IHL regime, namely the Hague Conventions, the 1949 four Geneva Conventions and the Additional Protocols of 1977, governing the life of civilian women in situations of armed conflict. Chapter 3 draws the focus to the examination of Article 27 of the IV Geneva Convention, related to the prohibition of sexual violence against women in armed conflict. These two Chapters aim at investigating over the possibility to interpret in a gender-oriented way the provisions, in order to shed light on the question whether the limits of the norms may be interpretatively overcome in order to assure a better protection to women from conflict-related sexual violence. Before that, Chapter 1 sets the scene by offering a brief sketch of the general theoretical ground, exploring some key concepts perspectives of gender-informed critique to IHL. 


\section{BASIC CONCEPTS AND FEMINIST PERSPECTIVES}

In Sections 1.1 and 1.2, this Chapter presents the recurrent categories of "gender" and "conflictrelated violence against women", which are basic analytical tools for the overall thesis. Section 1.3 provides a broad account of the feminist critiques to international humanitarian law (IHL), discussing both their potential contribution to the development of IHL, but also their weaknesses. Section 1. 4 concludes this Chapter by positioning this thesis in the broader debate of feminist criticism to IHL. This thesis, although recognizing that feminist critiques have contributed to revealing the gender biases harbored by many IHL norms, does not side with radical feminist critiques of IHL, which ascribe to it an irreversibly male character. Here, it is rather suggested that many of the valid points of feminist critiques can be accommodated through a gender-sensitive interpretation of the existing rules.

\subsection{The concept of "gender" and its relevance in international law}

The first part of this Chapter discusses whether, and eventually how, the concept of "gender" has contributed to a new approach to IHL, informed the theorization of conflict-related violence against women, and influenced the legal understanding of the issue at international level. Three questions will be at the basis of the investigation: What is "gender"? Why is it important in the context of armed conflicts in general? And how has gender been associated to conflict-related violence against women in particular? In order to address these questions, a definition of "gender" will be first provided, offering an overview of what is subsumed under this concept.

\subsubsection{A definition of "gender"}

Nowadays, the term "gender" is ubiquitous. It is being used extensively in the press, by national and international institutions, and in the academia, both by feminist scholars and by nonfeminist-oriented academics of all disciplines. ${ }^{22}$ Despite its common use, the definition of

\footnotetext{
${ }^{22}$ Braidotti, Rosi, "The Uses and Abuses of the Sex/Gender Distinction in European Feminist Practice", in Griffin, Gabriele and Braidotti, Rosi, Thinking Differently, A Reader in European Women's Studies, Zed Books, London, 2002, 286-306. Braidotti underlines the relevance of international institutions for the spread of the term "gender" much beyond the academia and the feminist circles. In particular, referring to the European Commission, she recognizes that its "stamp of approval" is enormous because it particularly guaranteed "a form of international recognition and therefore of scientific legitimation" to women's studies.
} 
"gender" has been contested. ${ }^{23}$ In many international legal contexts "the terms 'sex' and 'gender' are treated as synonyms" 24 or the concept of "gender" is used with as meaning women's issues in general. ${ }^{25}$

This unclarity surrounding "gender" requires a functional definition that will be taken as basis in the rest of this thesis. For present purposes, the definition offered by the UN Women will be used, which defines "gender" as a concept which

refers to the social attributes and opportunities associated with being male and female and the relationships between women and men and girls and boys, as well as the relations between women and those between men. These attributes, opportunities and relationships are socially constructed and are learned through socialization processes. They are context/time-specific and changeable. Gender determines what is expected, allowed and valued in a woman or a man in a given context. In most societies there are differences and inequalities between women and men in responsibilities assigned, activities undertaken, access to and control over resources, as well as decision-making opportunities. Gender is part of the broader socio-cultural context. ${ }^{26}$

\footnotetext{
${ }^{23}$ One may recall here the disputed definition "gender" given by Article 7, paragraph 3 of the Statute of the ICC: "For the purposes of this Statute, it is understood that the term 'gender' refers to the two sexes, male and female, within the context of society. The term 'gender' does not indicate any meaning different from the above". Many feminist legal scholars have particularly criticised this definition because it would not clearly focus on the relational and culturally contingent aspects that the term should embrace, in so resulting in a synonymous of the term "sex". In this sense, see Charlesworth, Hilary, "Feminist methods in international law", American Journal of International Law, Vol. 93, (1999), p. 394. For this reason the definition of "gender" given by the Rome Statute has been defined as "stunning narrow", see Cossman, Brenda, "Gender performance, sexual subjects and international law", in Canadian Journal of Law and Jurisprudence, Vol. 15, No. 2, (2002) 281 - 296, p. 283; a "failure", see Moshan, Brooke Sari, "Women, War And Words: The Gender Component In The Permanent International Criminal Court's Definition Of Crimes Against Humanity", in Fordham International Law Journal, Vol. 22, No. 4, (1998) 154 - 184, p. 178; "peculiar" in Copelon, Ronda, "Gender crimes as war crimes: integrating crimes against women into International Criminal Court", McGill Law Journal, Vol. 46, (2000), 217-240 p. 236; "restraining", see Lehr-Lehnardt R., "One small step for women: female-friendly provisions in the Rome Statute of the International Criminal Court", in BYU Journal of Public Law, Vol. 16, (2002), 317-354, p. 340; and having "limited transformative edge", Charlesworth, Hilary and Chinkin, Christine, The boundaries of international law...p. 335.

${ }^{24}$ Charlesworth, Hilary, "Foreword", in Harris Rimmer, Susan, and Ogg, Kate (eds.), Feminist Engagement with International Law, Edward Elgar Publishing, Cheltenham, p. xxv.

${ }^{25}$ Venturini, Gabriella, "Diritto internazionale umanitario e diritti umani: una prospettiva di genere", in Di Stefano, Adriana and Sapienza, Rosario (eds.), La tutela dei diritti umani e il diritto internazionale. SIDI - XVI Convegno, Catania, 23-24 giugno 2011, Editoriale scientifica, Napoli, 2012. According to this author: "Di fatto, nel diritto internazionale le questioni di genere sono sinora largamente coincise con la tematica della condizione femminile, lasciando in ombra le relazioni fra genere, sesso, identità e orientamento sessuale" (p. 95). [In fact, in international law, gender issues have so far largely coincided with the issue of the status of women, leaving behind relationships between gender, gender, identity and sexual orientation]. For an overview of the current relevance of "sexual orientation" in international law, see Vitucci, Maria Chiara, "The Protection of Sexual Orientation in International Law: Between the Principles of Non-Discrimination and Human Dignity”, Europa Ethnica, Vol. 76, No 3-4, (2019) 115-119.

${ }^{26}$ UN Women is the United Nations entity dedicated to gender equality and the empowerment of women. UN Women, "Concepts and Definitions", available at: https://www.un.org/womenwatch/osagi/conceptsandefinitions.htm [last visited: 21 February 2021].
} 
This definition reflects the theories that distinguish between sex and gender. ${ }^{27}$ Sex consists in the biological differences between men and women, while gender comprises all aspects of culture and social relations that contribute to have a definition of masculinity and femininity. ${ }^{28}$ This qualification of "gender" and the distinction between "gender" and "sex" have been also adopted by the United Nations ${ }^{29}$ and by the regional human rights systems. ${ }^{30}$

\subsubsection{Gender, armed conflict and international humanitarian law}

Gender, armed conflict, and law are much closer than one may imagine. Gender is now well understood as a "constitutive element of social relationships", and as a "primary way of signifying relationships of power". ${ }^{31}$ This new understanding of the term "gender" 32 - thanks

${ }^{27}$ See, for example, Scott, Joan W., "Gender: a useful category of analysis”, American Historical Review, Vol. 91, (1986) 1053-1075; Flax, Jane, "Postmodernism and gender relations in feminist theory", Signs, Vol. 12, (1987), 621-643, pp. 635-636; Davies, Margaret, "Taking the inside out sex and gender in the legal subject", in Naffine, Ngaire and Owens, Rosemary J. (eds.), Sexing the subject of law, Law Book Company Ltd, Sydney, 1997 , p. 25.

${ }^{28}$ In its Guidance Document entitled 'Addressing the Needs of Women Affected by Armed Conflict', the ICRC writes clearly of this differentiation:

'The term "gender" refers to the culturally expected behaviours of men and women based on roles, attitudes and values ascribed to them on the basis of their sex, whereas "sex" refers to biological and physical characteristics.'

International Committee of the Red Cross (ICRC), Addressing the Needs of Women Affected by Armed Conflict, ICRC, Geneva, 2004, p. 7.

${ }^{29}$ The UN has embraced a clear distinction between sex and gender since the 1990s. "The term 'gender' refers to the ways in which roles, attitudes, values and relationships regarding women and men are constructed by all societies all over the world". Reporting of the expert group meeting on the development of guidelines for the integration of gender perspectives into United Nations human rights activities and programmes, U.N. ESCOR. Comm'n on Hum. Rts, 52d Sess., Agenda Items 9, 21, q 13, U.N. Doc. E/CD.4/1996/105 (1995). A similar definition is given by the Secretary General in 1998: "The term 'gender' refers to the socially constructed roles of women and men that are ascribed to them on the basis of their sex, in public and in private life. The term 'sex' refers to the biological and physical characteristics of women and men [...] Gender roles are learned and vary widely within and between cultures. As social constructs, they can change". Report of the Secretary-General, UN Doc HRI/MC/1998/6 (3 September 1998).

Doubts remain over the true understanding of the distinction in the UN policy and operational activity. See Charlesworth, Hilary, "Not Waving but Drowning: Gender Mainstreaming and Human Rights in the United Nations", Harvard Human Rights Journal, Vol. 18, No. 1, (2005) 1-18, p. 14.

${ }^{30}$ For an account on how gender is understood under the Council of Europe Convention on Preventing and Combating Violence against Women and Domestic Violence (also known as the Istanbul Convention, from the place where it was signed in May 2011), see Niemi, Johanna and Verdu Sanmartin, Amalia, "The Concepts of Gender and Violence in the Istanbul Convention", in Niemi, Johanna, Peroni, Lourdes and Stoyanova, Vladislava (eds.), International Law and Violence against Women. Europe and the Istanbul Convention, Routledge, London and New York, 2020.

${ }^{31}$ Scott, Joan W., "Gender: a useful category of analysis"...p. 1067.

32 The term was in use much before the feminist theorisations with another meaning. The traditional definition of the term "gender" was: "n. a grammatical term only. To talk of persons or creatures of the masculine or feminine gender, meaning of the male or female sex, is either a joculariry (permissible or not according to context) or a blunder”. Fowler's Dictionary of Modern English Usage, Oxford, 1940. 
to the Western feminist theoretical elaborations of the late $1980 \mathrm{~s}^{33}$ - made this concept also an analytical tool "to decode meaning and to understand the complex connections among various forms of human interaction". ${ }^{34}$ With this approach, Joan Scott elevated the concept of "gender" from a neutral term, originating from the differentiation between women and men in biological terms, to the core feminist concept used to explain the structural inequalities between women and men. Gender has become an analytical category with the capacity to redefine traditional paradigms for comprehending human reality. In this way, the concept assumed a scientific value relevant for all social sciences, including law.

Using gender as its central concept, "gender analysis" examines dynamics in all forms of social organization using the specific lens of power relationships between women and men. Since the "state of play in gender relations in a given institution is its gender regime", the spaces of social organization where gender practices take place and develop are more relevant than the moments of individual interaction between men and women. ${ }^{35}$

Armed conflict, as a fundamental human occurrence, cannot escape gender analysis. Indeed, considering that conflict represents one of the ways in which human beings have "interacted" throughout history, gender analysis argues that "gender shapes war and war shapes gender". ${ }^{36}$ Thus, the exclusion of the category of gender from the study of the armed conflict would lead to a partial understanding of the human phenomenon of war. ${ }^{37}$

According to gender approach to war, the armed conflict reproduces and, in certain cases, reinforces the pre-existent social characters culturally associated with masculinity and femininity. Indeed, the "hegemonic masculinity", the privileged masculinity reproducing the characters of power, dominance and strength, and authority, ${ }^{38}$ represents the stereotype of gendered order in warfare. The equation of man as intrepid warrior, on the one hand, and woman as defenseless civilian, on the other hand, have informed the reality and the traditional understanding of the war for centuries, carrying on two opposite and non-interchangeable

\footnotetext{
${ }^{33}$ See for example, K O'Donovan, Katherine, Sexual Divisions in Law, Weidenfeld \& Nicolson, London, 1985.

${ }^{34}$ Scott, Joan W., "Gender: a useful category of analysis"...p. 1070.

${ }^{35}$ Connell, Raewyn W. Gender and Power, Stanford University Press, Stanford, 1987, p. 120.

${ }^{36}$ Goldstein, Joshua, War and Gender: How Gender Shapes the War System and Vice Versa, Cambridge University Press, Cambridge, 2001, p. 1.

${ }^{37}$ For an interdisciplinary analysis of the ways in which war and gender interact, see Sharoni, Simona, Welland, Julia, Steiner, Linda and Pedersen, Jennifer (eds.), Handbook on Gender and War, Edward Elgar Publishing, Northampton, 2016; Nagel, Joane, "Gender, violence and the military", in Shepherd, Laura J. (eds.), Handbook on Gender and Violence, Edward Elgar Publishing, Northampton, 2019.

${ }^{38}$ Connell, Raewyn W. Gender and Power,.....p. 58.
} 
images of the femininity and the masculinity. Therefore, violence, power and control, as expressions of masculinity, have always been the key elements to maintain the gendered order in war. It is only when these characters are not assumed as natural, pre-given characteristics of women and men but as cultural attributes that certain dynamics of the conflict become visible and evaluated according to the sensibility of the time. As Chinkin puts it,

[g]iven the gendered nature of war and the way that conflict is constructed on the basis of gender relations, it can be argued that countering some of the gender asymmetries of conflict could also weaken the very way that war and conflict are constructed. ${ }^{39}$

How about law? One may ask whether and to what extent armed conflict is also a gendered legal setting. To put it differently, the question here is whether the abovementioned gendered aspects of armed conflict have also informed the legal regime regulating armed conflict. If one considers that the law is the system of norms devoted to the regulation of social relationships, and, as it has been said, social interactions in the warfare are intrinsically gendered, it is difficult to imagine that the IHL regime could not have been influenced by the gender assumptions which govern society and war in particular at any given time. ${ }^{40}$

Therefore, gender has emerged as a useful tool also for the analysis of IHL. After decades of feminist scholarship, ${ }^{41}$ gender is currently understood as an essential category for a proper understanding of conflict-related violence. Importantly, gender considerations have been introduced to the realm of IHL through the UN Security Council Women, Peace and Security (WPS) Agenda, which first recognized gender as an analytical tool in conflict situations. ${ }^{42}$ According to this approach, a legal analysis concerning a certain dynamic of war cannot ignore the category of gender. As Durham and O'Byrne put it, a gender perspective on IHL means

first, that where women (and men) participate in war, their experiences should be recognized as valid, rather than being excluded from the discourse or reduced to stereotype; and secondly,

\footnotetext{
${ }^{39}$ Chinkin, Christine, International Law and New Wars, Cambridge University Press, Cambridge, 2017 , p. 414.

${ }^{40}$ See Conaghan, Joanne, Law and Gender, Oxford University Press, Oxford, 2013.

${ }^{41}$ For a review of the "the trajectories of feminist thinking about issues we today subsume under "gender", see Žarkov, Dubravka, "From Women and War to Gender and conflict? Feminist Trajectories", in Ní Aoláin, Fionnuala, Cahn, Naomi, Haynes, Dina Francesca, Valji, Nahla (eds.), The Oxford Handbook of Gender and Conflict, Oxford University Press, Oxford, 2018, pp. 18-29.

42 The UN Security Council Resolution 1325 (2000) establishes the Women, Peace and Security Agenda.

For a critique of the way in which gender has been engaged with the WPS Agenda and how this has reduced certain feminist aspirations, see Otto, Dianne, "Women, Peace, and Security: A Critical Analysis of the Security Council's Vision”, in Ní Aoláin, Fionnuala, Cahn, Naomi, Haynes, Dina Francesca, Valji, Nahla (eds.), The Oxford Handbook of Gender and Conflict, Oxford University Press, Oxford, 2018.
} 
that IHL norms apply to all participants in war, in both a protective and a regulatory sense, regardless of gender. ${ }^{43}$

In this sense, a study about the specific issue of conflict-related violence against women through the lens of IHL cannot disregard the role that gender plays, first, in the actual conduct of those caught up in the hostilities, and, second, in the interpretation and implementation of the law of armed conflict. In more concrete terms, the use of the category of gender to study the issue of conflict-related violence against women aims at exposing the gender causes of certain forms of violence and whether and how specific military conduct harms particularly women. This perspective also entails the analysis of the gendered effects of conflict-related violence against women, such as social ostracism, in order to have both a victim-centric perspective and to acknowledge the real nature and gravity of violence. As it will be discussed later on in this Chapter, a strand of feminist scholarship has focused on the gendered nature of the IHL rules governing such events as well as the gendered logic of the legal concepts and assumptions that underpin legal reasoning.

\subsection{Definition of conflict-related violence against women}

During the last decades, the attention of international law scholars has turned to a great extent to the effects of wartime violence. The introduction of the 1949 Geneva Conventions reflected a new awareness about the necessity to protect human beings also during warfare and paved the way to the process of "humanization of International Humanitarian Law". ${ }^{44}$ For the first time, many forms of violence and brutal atrocities committed during the conflicts, which were before considered as collateral and unavoidable effects of the war, became understood not only as morally regrettable outrages, but also as violations of international legal norms. This development of IHL is also reflected in the new perception of and response to women's experience of the warfare: several forms of violence, to which women have always been subjected to during the war, did not appear tolerable anymore.

\footnotetext{
${ }^{43}$ Durham, Helen and O’Byrne, Katie, "The Dialogue of Difference: Gender Perspectives on International Humanitarian Law", International Review of the Red cross, Vol. 92, No. 877, (2010) 31-52, p. 51.

${ }^{44}$ Meron, Theodor, "The Humanization of Humanitarian Law", The American Journal of International Law, Vol. 94, No. 2, (2000) 239-278.
} 
The concept of "conflict-related violence against women" will be analysed here. Indeed, before addressing the question of whether and how IHL deals with the phenomenon of violence against women in the warfare, a description of the phenomenon seems necessary. The identification of the boundaries of this concept is not only a conceptual-linguistic exercise, but also a legal challenge. Indeed, the way in which international law, and in particular IHL, defines the various forms of "conflict-related violence against women" might influence the interpretation of the legal vocabularies and categories and, consequently, lead to a reduced or more extensive protection of women caught up in the conflict. Furthermore, a definition of the concept seems even more urgent if one considers the current number of terms used interchangeably to describe the phenomenon. ${ }^{45}$

\subsubsection{Defining violence against women}

The term "violence against women" (VAW) has been legally defined in Article 1 of the UN Declaration on the Elimination of Violence against Women as

any act of gender-based violence that results in, or is likely to result in, physical, sexual, or psychological harm or suffering to women, including threats of such acts, coercion or arbitrary deprivation of liberty, whether occurring in public or private life. ${ }^{46}$

As it may be highlighted, this definition qualifies VAW as "gender-based violence". "Genderbased violence against women" (GBV) is defined by the UN Committee on the Elimination of Discrimination against Women as "violence that is directed against women because she is a woman or that affects women disproportionately". ${ }^{47}$ The qualification of VAW as "genderbased violence" expresses the intention to strengthen the gender character of this kind of violence and to consider it "as a social - rather than an individual - problem, requiring comprehensive responses, beyond specific events, individual perpetrators and

\footnotetext{
45 "Conflict-related violence against women" is usually used interchangeably with "wartime sexual violence" and "wartime gender-based violence".

${ }^{46}$ UN Declaration on the Elimination of Violence against Women, General Assembly Resolution 48/104, (1993), available at https://www.un.org/en/genocideprevention/documents/atrocitycrimes/Doc. 21 declaration\%20elimination\%20vaw.pdf [last visited: 21 February 2021]. Article 3 of the 2011 Council of Europe Convention on preventing and combating violence against women and domestic violence (also known as the Istanbul Convention) adds to this definition that "violence against women' is understood as a violation of human rights and a form of discrimination against women", available at https://www.coe.int/en/web/conventions/full-list/-/conventions/rms/090000168008482e [last visited: 21 February 2021].

${ }^{47}$ CEDAW, General Recommendation No. 19 on Violence Against Women, UN GAOR, 1992, Doc. No. A/47/38.
} 
victims/survivors". ${ }^{48}$ This approach to VAW puts the accent on the collective and endemic dimension of the issue, and the gendered correlation between the forms of violence and the group of people (women) specifically affected by them. In this way, VAW started to be understood as a structural phenomenon with deep causes in the gendered division of roles and as the most pervasive manifestation of the patriarchal culture. In other terms, a close relation is highlighted between any form of violence against women and the discriminatory status against women worldwide. ${ }^{49}$

Two considerations must be stressed at this point. The first one regards the distinction between VAW and sexual violence. ${ }^{50}$ Not all forms of VAW are sexualized, and this thesis will deal both with sexualized and non-sexualized violence against women. Some crimes have both a sexualized and a non-sexualized component. For example, the crime of forced marriage has been described by Justice Sebutinde, in her concurrence in the AFRC Judgement, as

the forceful abduction and holding in captivity of women and girls ('bush wives') against their will, for purposes of sexual gratification of their 'bush husbands' and for gender-specific forms of labour including cooking cleaning, washing clothes (conjugal duties). ${ }^{51}$

As the abovementioned definition clarifies, the forced conjugal association involves both sexual and non-sexual acts, which cannot be considered separately because "they are integrated in this form of abuse". 52

48 CEDAW, General Recommendation No. 35 on gender-based violence against women, updating general recommendation No. 19, 14th July 2017, para. 9. The General Recommendation No. 35 is remarkable for its strong assessment that "the prohibition of gender-based violence against women has evolved into a principle of customary international law". For a critique of the CEDAW's positions, see De Vido, Sara, "The Prohibition of Violence Against Women as Customary International Law? Remarks on the CEDAW General Recommendation No. 35”, Diritti Umani e Diritto Internazionale, Vol. 12, Issue 2, (2018) 379-396.

49 The link between the phenomenon of VAW and discrimination against women has been recognized in many international documents: CEDAW, General Recommendation No. 19, UN GAOR, 1992, Doc. No. A/47/38; Vienna Declaration and Programme of Action, as adopted by the World Conference on Human Rights on 25 June 1993 World Conference on Human Rights, UN A/Conf. 157/23, 12 July 1993; Preamble of the UN Declaration on the Elimination of Violence against Women, General Assembly resolution 48/104 of 20 December 1993; Article 3, The Inter-American Convention on the Prevention, Punishment, and Eradication of Violence against Women, 1994 (Convention of Belém do Pará); Article 1, Protocol on the Rights of Women in Africa, 2003 (Protocol of Maputo); Article 3, Council of Europe Convention on preventing and combating violence against women and domestic violence, 2011 (Istanbul Convention).

${ }^{50}$ In order to understand the relevance of the issue, one may quote the 2018 campaign of the international human rights organisation Women's Initiatives for Gender Justice to enhance a better international understanding of sexual violence. See Women's Initiatives for Gender Justice (WIJG), 'Civil Society Declaration on Sexual Violence', 2019, available at https://4genderjustice.org/wp-content/uploads/2019/11/English-Civil-SocietyDeclaration-on-Sexual-Violence.pdf [last visited: 21 February 2021].

${ }^{51}$ AFRC Trial Judgement, Concurring Opinion of Justice Sebutinde, para. 12.

${ }^{52}$ Special Court for Sierra Leone, Prosecutor v. Taylor, Case No. SCSL-03-0I-T, Trial Chamber, Judgment, 18 May 2012 ("Taylor case"), para. 424. 
The second consideration concerns the preference of the term "violence against women" instead of "gender-based violence" in this thesis. At least two reasons support this choice. First, despite the fact that the term "gender" is usually meant to imply women (or "female"), genderspecific harms can actually affect both women and men. Forms of GBV against men may include, among others, being harassed, beaten or killed for non-conformity to the dominant stereotype of masculine identity as well as forms of sexual violence such as rape, enforced sterilization, enforced nudity, enforced masturbation and genital violence. ${ }^{53}$ The ad hoc International Criminal Tribunals recognized the existence of cases of sexual violence against men $^{54}$ also committed by female perpetrators. ${ }^{55}$ The ICRC has incorporated this aspect of men's experience in warfare in recent Commentaries to the Geneva Conventions, ${ }^{56}$ and an increased number of research demonstrates gender implications in these kinds of violence against men. ${ }^{57}$ While recognizing the relevance of gender violence for both women and men, this thesis deals only with the women's experience of violence in situations of armed conflicts.

Second, the concept "violence against women" is preferred over "gender-based violence" also because it is usually broader. As it is already implied by the definition of gender given above, a gendered harmful act is a violent act reflecting or committed on the basis of socially attributed differences between men and women. However, the gender of the victim, in the sense of the social construction, is not always relevant to the commitment of the violent act against women. Women may be harmed also irrespectively of their gendered attributes. For example, not any

\footnotetext{
${ }^{53}$ Sivakumaran, Sandesh, "Sexual Violence Against Men in Armed Conflict”, European Journal of International Law, Vol. 18, No. 2, (2007) 253-276.

${ }^{54}$ See, for example, ICTR, Prosecutor v. Pauline Nyiramasuhuko, Case No. ICTR-98-42-T; ICTY, Prosecutor $v$. Cesić, Sentencing Judgment, IT-95-10/1-S, 11 March 2007, paras 13-14; ICTY, Prosecutor v. Milomir Stakić, Trial Judgment, IT-97-24. For a critique on the failure of the ad hoc Tribunals, the ICC and domestic courts to recognize the sexual nature of the majority of cases involving acts of sexual violence against men, see International Center for Transitional Justice, "When No One Calls It Rape: Addressing Sexual Violence Against Men and Boys in Transitional Contexts", (2016), available at: https://www.ictj.org/sites/default/files/ICTJ Report SexualViolenceMen 2016.pdf [last visited, 23 October, 2020].

55 See for example, ICTY, Prosecutor v. Biljana Plavšić, IT-00-39\&40/1-S.

${ }^{56}$ In particular, some examples of this new understanding of gender-based violence can be found in The Geneva Conventions of 12 August 1949, Commentary to the Third Geneva Convention relative to the Treatment of Prisoners of War, Geneva, 2020. "Today, however, the prohibition of sexual violence is recognized to encompass violence not only against women and girls, but any person, including men and boys". (Commentary to Article 3 , para 736). "Practice has also shown that men in prisoner-of-war camps are also subjected to rape and other forms of sexual abuse, such as being stripped naked in public, subjected to genital violence or forced sterilization". (Commentary to Article 13, para. 1578).

${ }^{57}$ A recent research conducted in the post-conflict Sri-Lanka reveals that many men and boys were abducted and arrested by the Sri-Lankan security forces after the end of the conflict in 2009 because suspected to be somehow linked with the Liberation Tigers of Tamil Eelam (LTTE) and sexually abused. It is sustained that the acts of sexual violence against men constituted part of an institutional policy of torture. Touquet, Heleen, "Unsilenced: Male Victims of Sexual Violence in Sri Lanka”, International Truth and Justice Project, (Johannesburg, 2018).
} 
case of force displacement of a group of female civilians must be gendered. The female civilians may be displaced independently of their gender or socially ascribed role in society.

\subsubsection{Defining conflict-related violence}

When is an act of violence against women "conflict-related"? The answer to this question is necessary in order to determine whether IHL is applicable. There is not a single definition of armed conflict and the relevant definitions "fleshed out over the years through state practice, international case law, and the writings of scholars". ${ }^{58}$

In any case, IHL recognizes two kinds of armed conflicts, namely international (IACs) and non-international (NIACs). ${ }^{59}$ This thesis deals with acts of violence against women in both of these situations of armed conflict. The distinction is relevant for two reasons: first, for the different thresholds for the application of the IHL regime and, second, for the content of law relevant to each type of conflict. ${ }^{60}$ For the purpose of this thesis, the definitions of IAC and NIAC given by the International Criminal Tribunal for the Former Yugoslavia (ICTY) in the Tadic decision are used. According to this approach, IAC is "an armed conflict [...] whenever there is resort to armed force between States" $"$, while a NIAC is defined as "protracted armed violence between governmental authorities and organized armed groups or between such groups within the State". ${ }^{62}$ Furthermore, the decision indicates the different thresholds for the application of IHL in IACs and NIACs as well as the geographical and temporal scope of the two kinds of armed conflicts:

\footnotetext{
${ }^{58}$ Akande, Dapo, "Classification of Armed Conflicts", in Saul, Ben and Akande, Dapo (eds.), The Oxford Guide to International Humanitarian Law, Oxford University Press, Oxford, 2020, p. 56.

${ }^{59}$ For some considerations on the historical reasons to distinguish between IACs and NIACs, see generally Fleck, Dieter, "The Law of Non-International Armed Conflict", in Fleck, Dieter, The Handbook of International Humanitarian Law, Oxford University Press, Oxford, 2013.

${ }^{60}$ Article 2 common to the four Geneva Conventions states that the Conventions apply to "all cases of declared war or of any other armed conflict which may arise between two or more High Contracting Parties". Only one provision, common Article 3 to all four Geneva Conventions, extended its application to "armed conflict not of an international character occurring in the territory of one of the High Contracting Parties". Nowadays, also the Additional Protocol II (AP II), related to "The protection of victims of Non-International Armed Conflicts" and Article $8(2)(\mathrm{c})$ and (e) of the ICC Statute are applicable to NIACs. By contrast, the treaty rules applicable to IACs are much more and establish a detailed regime. In particular, the conduct of hostilities is regulated by the so called "Hague Law", and the protection of persons who do not take part, or no longer take part, to the hostilities by the "Geneva Law".

${ }^{61}$ Additional Protocol I to the Geneva Conventions (API) includes in the category of IACs also the so called "wars of national liberation", defined as armed conflicts "in which peoples are fighting against colonial domination and alien occupation and against racist regimes in the exercise of their right to self-determination". Article 1(4), AP I. ${ }^{62}$ ICTY, Prosecutor v. Tadic, Decision on Defence Motion for Interlocutory Appeal on Jurisdiction, IT-94-1AR72, 2 October 1995, para 70.
} 
International humanitarian law applies from the initiation of such armed conflicts and extends beyond the cessation of hostilities until a general conclusion of peace is reached; or in the case of internal conflicts, a peace settlement is achieved. Until that moment, international humanitarian law continues to apply to the hole territory of the warring State or, in the case of internal conflicts, the whole territory under the control of a party, whether or not actual combat takes place there.

Without entering the debates over the thresholds and the temporal and geographical grounds for the application of IHL in IACs and NIACs, ${ }^{63}$ it may be said here that NIACs require a higher threshold, namely a certain intensity of the hostilities, expressed in the words "protracted armed violence", and a certain level of organization of the groups involved. The NIAC may also extend over internal contexts and "may have a cross-border dimension". ${ }^{64}$

However, not all acts of violence committed during an armed conflict are conflict-related. For an act to be relevant under IHL, there must be a link to the conflict. The nexus criterion, established by the jurisprudence of the ICTY and the ICTR ${ }^{65}$ and adopted as a requisite element for all war crimes under the Statute of the $\mathrm{ICC}^{66}$, has been described as a "fifth cumulative requirement for IHL to apply", ${ }^{67}$ because it applies in addition to the four general IHL requirements of material, geographical, temporal and personal scope of application of the conduct. ${ }^{68}$ Thus, the existence of the nexus criterium is necessary for triggering the applicability of IHL, so as to distinguish domestic crimes from international crimes, and isolated crimes from war crimes. ${ }^{69}$ According to the UN Secretary general, "conflict-related" violence encompasses "all forms of physical, sexual and psychological violence perpetrated by

\footnotetext{
${ }^{63}$ See, generally, Greenwood, Christopher, "Scope of Application of Humanitarian Law", in Fleck, Dieter (eds.), The Handbook of International Humanitarian Law, Oxford University Press, Oxford, 2008; Crawford, Emily, "The Temporal and Geographical Reach of International Humanitarian Law", in Saul, Ben and Akande, Dapo (eds.), The Oxford Guide to International Humanitarian Law, Oxford University Press, Oxford, 2020, pp. 57-75. ${ }^{64}$ Akande, Dapo, "Classification of Armed Conflicts", ...p. 56.

${ }^{65}$ For the ICTY and ICTR jurisprudence on the nexus criterion see, among others: ICTY, Prosecutor v. Tadic, Case No. IT-94-1-AR72, Decision on the Defence Motion for Interlocutory Appeal on Jurisdiction of 2 October 1995, paras 67, 70; ICTY, Prosecutor v. Kunarac et al., Case No. IT-96-23, Judgment of 12 June 2002 (Appeals Chamber), paras 55 ss; ICTR, Prosecutor v. Rutaganda, Case No. ICTR-96-3, Judgment of 26 May 2003 (Appeals Chamber), para. 569.

66 The nexus criterium is expressed in the ICC Elements of Crimes for all crimes as follow: ' $[\mathrm{t}] \mathrm{he}$ conduct took place in the context of and was associated with an international armed conflict [or a NIAC]'. See ICC, Elements of Crimes, from Articles 8(2)(a) to 8(2)(e).

${ }^{67}$ Sassòli, Marco, International Humanitarian Law Rules, Controversies, and Solutions to Problems Arising in Warfare, Edward Edgar Publishing, Cheltenham, 2019, p. 201.

${ }^{68}$ For an analysis of the nexus criterium, see Cassese, Antonio, "The nexus requirement for war crimes", Journal of International Criminal Justice, Vol. 10, No. 5, (2012) 1395-1417.

${ }^{69}$ See, for example, ICTY, Prosecutor v. Mrkšić et al., Case No. IT-95-13/1, Trial Judgment, 27 September 2007, para. 423.
} 
both State and non-State actors"70 and that is "linked, directly or indirectly (temporally, geographically or causally) to a conflict" ${ }^{\prime 71}$.

Some clarifications should be offered with regard to this definition. First, conflict-related violence against women varies in forms, including

murder, unlawful killings, torture and other cruel, inhuman or degrading treatment or punishment, abductions, maiming and mutilation, forced recruitment of women combatants, rape, sexual slavery, sexual exploitation, involuntary disappearance, arbitrary detention, forced marriage, forced prostitution, forced abortion, forced pregnancy and forced sterilization. ${ }^{72}$

As apparent from the list, many forms of conflict-related violence against women also constitute sexual violence, which is probably the most common form of violence against women in the warfare. However, as noted above, the concept of "conflict-related violence against women" is broader that "conflict-related sexual violence against women", because it also covers forms of violence which are not sexualized, such as a form of torture that do not involve acts against the female sexual organs.

Second, for violence to be considered conflict-related a sufficient personal, temporal, and geographical nexus with the conflict must exist. The personal link occurs when the agent of the violence is an armed actor affiliated to a party of the conflict, being a state or non-state actor. This means that, for example, some ill-treatment committed by a civilian against his wife inside the domestic walls cannot be considered a conflict-related act, even if that conduct occurs in a place where there is an ongoing armed conflict. As for the temporal link, the violence must be committed during or in the immediate aftermath of an armed conflict, "provided that it was committed in furtherance of, or at least under the guise of, the situation created by the armed conflict". ${ }^{73}$ The geographical link is satisfied when the violence is perpetrated close to the warfare area, which does not need to comprise the battlefield area, but at least a place "substantially related" to this area, which comprises the entire territory under control of the belligerent parties. ${ }^{74}$

\footnotetext{
${ }^{70}$ Report of the Secretary-General on In-depth study on all forms of violence against women, A/61/122/Add.1, 6 July 2006, para. 143.

${ }^{71}$ Report of the Secretary-General on Conflict-related sexual violence, S/2015/203, 23 March 2015, para. 2.

72 Report of the Secretary-General on In-depth study on all forms of violence against women, A/61/122/Add.1, 6 July 2006, para. 143.

${ }^{73}$ ICTY, Prosecutor v. Orić, Case No. IT-03-68, Trial Judgment, 30 June 2006, para. 256.

${ }^{74}$ ICTY, Prosecutor v. Stakić, Case No. IT-97-24-A, Judgement of 22 March 2006, (Appeals Chamber), para. 342; citing ICTY, Prosecutor v. Kunarac et al., Case No. IT-96-23, Judgment of 12 June 2002 (Appeals
} 
The last link, namely the scope or functional link, concerns the political or military intent of that violence. In other words, it refers to the question whether the act of violence should be functional to the achievement of a political or military goal. This aspect is not always present, so it is not necessary to have such a link to classify an act of violence as conflict-related. Anyways, many forms of conflict-related violence against women do serve specific military purposes. In particular, sexual violence and rape during armed conflict have been perpetrated over time for many reasons, such as, among others, as a form of torture, to dishonour women and, consequently, to humiliate and destroy communities, as well as to spread venereal diseases or to force entire populations to escape their lands. ${ }^{75}$

The UN Secretary general identified some conditions which may concretely demonstrate the link of the act of violence to the conflict, such as

the perpetrator's status as a belligerent party; the proliferation and use of small arms and light weapons; the breakdown of law and order; the militarization of sites of daily activity such as fuel and water collection; cross-border consequences such as displacement, trafficking or economic disruption; the (sometimes deliberate) spread of HIV; and the targeting of ethnic, sectarian or other minorities or of populations in contested territory affording an economic, military or political advantage, including in violation of a ceasefire agreement. ${ }^{76}$

In any case, international criminal courts' jurisprudence conveys that a causal link between the armed conflict and the crime is not necessary in order to satisfy the nexus requirement. The nexus requirement is fulfilled when the armed conflict has played a "substantive role" in permitting the perpetrator to commit it or to decide to commit it or to give him or her the purpose and the manner to commit it. ${ }^{77}$

In sum, conflict-related violence against women is here understood as violence that occurs against female subjects - girls and women - during or in the immediate aftermath of armed conflict, international or not, and which has a nexus with the conflict as described above.

This definition of conflict-related violence against women immediately shows that it is a subject that calls for an interdisciplinary approach. On the one hand, it covers acts that might

\footnotetext{
Chamber), paras 60, 64. In the same vein, ICC, Prosecutor v. Jean-Pierre Bemba Gombo, Case No. ICC-01/0501/08-3343, Trial Judgement, 21 March 2016, para. 142.

${ }^{75}$ Report of the Secretary-General on In-depth study on all forms of violence against women, A/61/122/Add.1, 6 July 2006, para. 144.

${ }^{76}$ Report of the Secretary-General on the implementation of Security Council Resolutions 1820 (2008) and 1888 (2009), A/65/592-S/2010/604, 24 November 2010, para. 5.

${ }^{77}$ ICTR, Prosecutor v. Nyiramasuhuko et al., Case, No. ICTR-98-42, Trial Judgment, 24 June 2011, para. 6153; ICTR, Prosecutor v. Setako, Case No. ICTR-04-81, Appeals Judgment 28 September 2011, para. 249; ICTY, Prosecutor v. Jovica Stanišić and Franko Simatović, Case No. IT-03-69-T, Trial Judgement, 30 May 2013, para. 956.
} 
call for the application of IHL norms, an issue for legal interpretation. On the other hand, the specificity of these acts, as being committed against women, requires their investigation from a perspective that focuses on their gender dimension. The need to connect these two discourses gave rise to important discussions and feminist critiques to IHL, within the broader framework of feminist approaches to international law. The next Section turns to this issue, broadly sketching this important field of research.

\subsection{Feminism and International Law}

The overall aim of feminist approaches to international law has been in line with feminist approaches to law in general. As noted by Thomas and Boisseau,

[w]omen have used the law historically as a vehicle to obtain personal and societal change. Even more, women used feminist theory to transform the law itself to incorporate an appreciation of gendered realities. ${ }^{78}$

The idea that law can be an instrument to achieve advancements in the women condition is applicable to any setting that is particularly sensitive for women, thus also in the context of conflict-related violence against women. Feminist scholars and activists were the pioneers in the process of bringing conflict-related violence against women to the foreground. The recognition of the structural and systematic nature of the violence against women during armed conflicts constituted the basis for the legal understanding of this phenomenon in international law. It is very likely that none of the legal advancements in the understanding of the women's protection in situations of armed conflict could have been possible without the development of the theoretical feminist framework. In other terms, international feminist scholars brought the "woman question" into the field of IHL. According to Bartlett,

In law, asking the woman question means examining how the law fails to take into account the experiences and values that seem more typical of women than of men, for whatever reason, or how existing legal standards and concepts might disadvantage women. ${ }^{79}$

Thus, it is essential to make a brief overview of the feminist trajectories in international law, and, specifically, in the theorization of conflict-related violence against women. After a brief

\footnotetext{
78 Thomas, Tracy A., and Boisseau, Tracy Jean (eds), Feminist legal history: essays on women and law, New York University Press, New York, 2011, p. 1.

${ }^{79}$ Bartlett, Katharine T., "Feminist Legal Methods", Harvard Law Review, Vol. 103, (1989) 829-888, p. 837.
} 
overview of the feminist approaches to international law, the analysis turns then to the study of the feminist encounters with IHL, with a particular attention to the critical scrutiny that feminist internationalist scholars have made in evaluating the law of armed conflict.

\subsubsection{Some remarks on the feminist approaches to International Law}

From the 1990s, the feminist legal and political commitment to gender equity and justice moved from the national level to the international arena. ${ }^{80}$ The milestone essay that sanctioned the entry of the feminist approaches in the international legal scholarship is, without doubt, the article "Feminist Approaches to International Law" of Hilary Charlesworth, Christine Chinkin, and Shelley Wright, published in 1991 in the American Journal of International Law. ${ }^{81}$ According to Juan M. Amaya Castro, "this event was by no means the first feminist engagement with the field, but it marked feminism's entrance through the front door of the international legal academic establishment". Indeed, twenty years after the publication of this article, the co-authors reveal that at the time they did not feel like adding anything to feminist theories, but rather they perceived themselves as "professional borrowers" and described their work as "using feminist insights to illuminate our discipline". ${ }^{82}$

After the publication of this piece come to life "in a haphazard way", 83 a proliferation of articles in the 1990s broadened the path to feminism in international law. Feminist legal scholars started their "excursions" 84 in the analysis of international law and international institutions with a multi-dimensions "despair about the apparent imperviousness of international law to

\footnotetext{
${ }^{80}$ This is not to say that feminist activism in international law and politics cannot be also traced before that date. Feminist international agenda developed since the women pacifist movement during the World War I. See in this regard, Wiltsher, Anne, Most Dangerous Women: Feminist Peace Campaigners of the Great War, Pandora, London, 1985. For an analysis of the difficulties of the feminist engagement with humanitarianism and peace for the gender hierarchy informing the international politics in the first half of the Twentieth century, see Sluga, Glenda, "Gender, Peace, and the New Politics of Humanitarianism in the First Half of the Twentieth Century", in Hagemann, Karen, Dudink, Stefan, and Rose, Sonya O., The Oxford Handbook of Gender, War, and the Western World since 1600, Oxford University Press, Oxford, 2020.

${ }^{81}$ Charlesworth, Hilary, Chinkin, Christine and Wright, Shelley, "Feminist Approaches to International Law", American Journal of International Law, Vol. 85, (1991) 613-645.

${ }^{82}$ Charlesworth, Hilary, Chinkin, Christine and Wright, Shelley, "Looking back on Feminist Approaches", (October, 2012), available at: http:/www.intlawgrrls.com/2012/10/looking-back-on-feminist-approaches.html [last visited, 31 October 2020].

${ }^{83} \mathrm{Ibid}$.

${ }^{84}$ Charlesworth, Hilary and Chinkin, Christine, The Boundaries of International Law, Manchester University Press, Manchester, 2000, p. 59. The book constitutes a real turning point in the history of feminist approaches to international law, being the first volume that analytically and critically examines the main pillars of international law from a feminist perspective.
} 
feminist perspectives", ${ }^{85}$ based on the idea that the structure of international law reflects the patriarchal system of a "masculine world" ${ }^{86}$ and reproduces male values and assumptions at international level. ${ }^{87}$ Driven by the presupposition that international law is a gendered system that has always excluded women, the feminist approaches aim at giving voice to women in international lawmaking, judiciary, and political mechanisms. ${ }^{88}$ It is worth underlining that a number of feminist strands exist, and that is why here the term "approaches" (in the plural form) is being used here. In particular, one may recall here the Third Word approach as an internal feminist strand that criticized the idea of a common women experience. ${ }^{89}$ This approach distinguished the western female condition from that in Third World countries one, where the element of colonialism has generated a "double jeopardy" for women..$^{90}$

Despite the great variety of sensibilities, theoretical backgrounds, and sometimes competitive visions within the feminist scholarship, ${ }^{91}$ resulting in a heterogeneity as an "unavoidable and accepted feature of the movement"92, at least two common characters may be identified in this field. First, a distinguishable feminist method of commitment with international law is the convergence of research and political legal strategy. Put another way, the feminist approaches to international law aim at unveiling the fundamental male-centered categories and structures of international law, combining a critical interpretation of legal practices with ethical and

\footnotetext{
${ }^{85}$ Otto, Dianne, "Feminist Approaches to International Law", in Orford, Anne and Hoffmann, Florian, The Oxford Handbook of the Theory of International Law, Oxford University Press, 2016, p. 489.

${ }^{86}$ Charlesworth, Hilary, Chinkin, Christine and Wright, Shelley, "Feminist Approaches to International Law",...p. 621.

${ }^{87}$ For a valuable overview of the feminist approaches to international law, see Chinkin, Christine, "Feminism, Approach to International Law", in Wolfrum, Rüdiger (ed.), The Max Plank Encyclopedia of Public International Law, Oxford University Press, 2010, available at: https://opil.ouplaw.com/view/10.1093/law:epil/9780199231690/law-9780199231690-e701.

${ }^{88}$ Hilary Charlesworth affirms that the invisibility of women in the international arena constitutes a human right issue as the principle of substantive equality is concerned. It "means that no challenge is offered to the status quo of imbalance in favour of men's representation. The imbalance appears normal and indeed inevitable, and maintains the necessity of "natural' supportive female roles". Charlesworth, Hilary, "Transforming the United Men's Club: Feminist Futures for the United Nations", Transnational Law \& Contemporary Problems, Vol. 4, No. 2, (1994) 421-454, p. 440.

${ }^{89}$ For an overview of the Third World approaches and critical race feminist approaches to international law, see Wing, Adrien K., "International Law and Feminism", in West, Robin and Grant Bowman, Cynthia (eds.), Research Handbook on Feminist Jurisprudence, Edward Elgar Publishing, Cheltenham, 2019, pp. 477-484.

${ }^{90}$ Oloka-Onyango J and Tamale, Sylvia, “"The Personal is Political' or Why Women's Rights Are Indeed Human Rights: An African Perspective on International Feminism”, Human Rights Quarterly, Vol. 17, (1995) 691-731.

${ }^{91}$ For a valuable overview of the feminist theories of law engaged in the understanding of international law, see Lacey, Nicola, "Feminist legal theory and the rights of women", in Knop, Karen (eds.), Gender and human rights, Oxford University Press, Oxford, 2004, pp.17-19. Lacey identifies four axes of differentiation among the feminist theories of law: 1) the methodology and written style; 2) the theories of sexual violence; 3) the substantive of methodological continuities with other legal and social theories; 4) the political orientation.

${ }^{92}$ Bianchi, Andrea, International Law Theories. An Inquiry into Different Ways of Thinking, Oxford University Press, Oxford, 2017, p. 185.
} 
political stances. ${ }^{93}$ The critical engagement with the law's gendered languages and practices becomes instrumental to the advancement of women's rights and instances. The theoretical engagement served feminist scholars to pursue their political agenda "by opening up new spaces for legal arguments that would otherwise not have had any significant currency, by imposing new parameters on the way international lawyers saw their discipline, their legal regimes and institutions". 94

Second, feminist approaches are also characterized for their debunking methodology. This methodology consists in critically questioning categories, concepts, and values usually considered irrefutable and almost "natural" realities. ${ }^{95}$ Feminist approaches question the alleged objectivity and universality of basic international structures, such as sovereignty and the use of force ${ }^{96}$, considering them as expressions of a patriarchal model of social organization. ${ }^{97}$ In particular, feminist scholars put into question the well-established concept of State under international law, ${ }^{98}$ expressing the idea that

[s]tates are patriarchal structures not solely in the sense of the exclusion of women from elite positions and decision-making roles, but also in the assumptions as to the concentration of power and control in an elite and the domestic legitimation o the use of force to maintain that control. These assumptions are reinforced by international legal principles of sovereign equality, political independence and territorial integrity and the legitimate use of force to defend those attributes. ${ }^{99}$

\footnotetext{
93 The "tension" of the feminist agenda consists in a "both academic and political" dedication. Charlesworth, Hilary and Chinkin, Christine, The Boundaries of International Law,...p. 21. In the same vein, Charlesworth explains that "feminism can be understood as a political ambition, but it is also an intellectual method which challenges claims to objective and impartial knowledge in various disciplinary traditions". Charlesworth, Hilary, "Foreword", in Harris Rimmer, Susan, and Ogg, Kate (eds.), Research Handbook on Feminist Engagement with International Law, Edward Elgar Publishing, Cheltenham, 2019, p. xxiv.

${ }^{94}$ Amaya Castro, Juan M., "Feminism and International Law: 20 years after Charlesworth, Chinkin and Wright", Runnymede Lecture, Universiteit van Amsterdam, 9 June 2011, p. 5.

${ }^{95}$ One of the latest examples in this direction is the feminist scholars' project to re-write judgements of a particular relevance in international law in a feminist perspective. See Hodson, Loveday and Lavers, Troy (eds.), Feminist Judgements in International Law, Hart, Oxford, 2019.

96 For a valuable analysis of the gendered assumptions behind the use of force and its prohibition, the contemporary understanding of the role of violence under international law, see Heathcote, Gina, The Law on the Use of Force. A Feminist Analysis, Routledge, London and New York, 2012.

${ }^{97}$ Charlesworth, Hilary, Chinkin, Christine and Wright, Shelley, "Feminist Approaches...p. 622.

${ }^{98}$ See Charlesworth, Hilary, "The sex of the State in international law", in Naffine, Ngaire and Owens, Rosemary J. (eds.), Sexing the subject of law, Law Book Company, Sydney, 1997.

99 Chinkin, Christine, "A Gendered Perspective to the International Use of Force", Australian Year Book of International Law, Vol. 12, No. 1, (1992) 279-293, pp. 285-286.
} 
According to these views, the supposed neutrality of the international concept of "State"100 actually hides a male-dominated conception of the world. ${ }^{101}$ The feminist "demystifying" attitude towards fundamental milestones of international law is considered the only possible strategy to undermine the persistent patriarchal distinction between private and public spheres. ${ }^{102}$ This distinction, in turn, is understood as a gendered division that positions men lives in the public world and women lives in the private/domestic one, which "continues to be a manifestation of legal privilege that dispenses licenses along gender lines"103 and "impairs the successful participation of women in democratic life". ${ }^{104}$

The transposition of this insight in the international legal system has two main manifestations. First, it has been argued that the strict distinction between acts within the domestic jurisdiction of States and those involving the international responsibility of States is an expression of the public/private dichotomy - and this has consequences for women. Considering that the majority of harms affecting women occur in the private domestic sphere, States cannot be held accountable under the traditional rules of State responsibility because private actions are not imputable to the State, with the consequence that a global issue is underestimated at international level. ${ }^{105}$ Second, the distinction between public and private spheres would have always excluded women from the political (public) sphere, with the consequence of a lack of

\footnotetext{
100 The feminist scholars assume the Grotian analogy of rules governing the conduct of states and of individuals. Lauterpacht, Hersch, "The Grotian Tradition in International Law”, British Year Book of International Law, Vol. 23, No. 1, (1946), pp. 26-30.

${ }^{101}$ Evans has well expressed that
}

\begin{abstract}
$[\mathrm{t}]$ he work of feminist social scientists $[\ldots]$ has shown that there is no such thing as a gender-neutral social institution. This does not mean that the institution (or the structure) is actually deliberately designed for men (although the history of many social institutions is that they have been designed by men) but that the assumptive world of masculinity permeates the design and the working of the particular structure. In short, feminists have constructed an overwhelming case to demonstrate the way in which the formal, institutional world works according to the expectations and assumptions of men, and generally men of the white middle class.
\end{abstract}

Evans, Mary (ed.), Feminism. Critical concepts in literary and cultural studies, Routledge, London and New York, 2001, p. 16.

102 MacKinnon, Catharine, Toward a Feminist Theory of the State, $2^{\text {nd }}$ edition, Harvard University Press, Cambridge, 1991.

${ }^{103}$ Romany, Celina, "State responsibility goes private: a feminist critique of the public/private distinction in International Human Rights Law", in Cook, Rebecca (ed.), Human rights of women. National and international perspectives, University of Pennsylvania Press, Philadelphia, 1994, p. 90.

104 Ibid, p. 94.

${ }^{105}$ Charlesworth, Hilary, "Words Apart: Public/Private Distinctions in International Law", in Thornton, Margaret (ed.), Public and Private: Feminist Legal Debates, Oxford University Press, Oxford, 1995, pp. 252-254. On how the operation of the public/private distinction in international human rights law operates to the detriment of women, see Charlesworth, Hilary and Chinkin, Christine, "The Gender of Jus Cogens", Human Rights Quarterly, Vol. 15, No. 1, (1993) 63-76. 
women involvement in the development of international law. The still visible numeric disproportion of women in international decision-making fora, ${ }^{106}$ as well as in international judicial bodies ${ }^{107}$ has become one of the major strands in feminist legal scholarship. ${ }^{108}$ Feminist legal scholars qualify the issue of the underrepresentation of women as a human rights issue, also on the basis that it constitutes a violation of the principle of substantial equality, ${ }^{109}$ which postulates that "they [women] as a group [...] should be able to make the decisions that affect their lives". ${ }^{110}$ As it will be shown in the following, this is a very important insight that can have important consequences in addressing the international rules on reparations.

106 Charlesworth, Hilary, Chinkin, Christine, The boundaries of international law...,p. 171. See also, Charlesworth, Hilary, "Law-Making and Sources", in Crawford, James and Koskenniemi, Martti (eds.), The Cambridge Companion to International Law, Cambridge University Press, 2012, p. 188. The issue of the female under representation in international bodies is not new. See, for example, the Report of the Fourth World Conference on Women, Beijing, 4-15 September 1995, UN Doc. A/CONF.177/20, 17 October 1995, para. 142(b), where governments as well as international and regional intergovernmental institutions are asked to take actions «aim for gender balance when nominating or promoting candidates for judicial and other positions in all relevant international bodies, such as the United Nations International Tribunals for the former Yugoslavia and for Rwanda and the International Court of Justice, as well as in other bodies related to the peaceful settlement of disputes»». Available at: https://www.un.org/en/ga/search/view doc.asp?symbol=A/CONF.177/20. A similar request came from the UN General Assembly Resolution on the "Improvement of the status of women in the United Nations system", UN Doc. A/RES/56/127, 30 January 2002, where member States were encouraged «to identify and nominate more women candidates for appointment or election as judges or other senior officials in international courts and tribunals». Available at: http:/www.un.org/en/ga/search/view doc.asp?symbol=A/RES/56/127. The UN Security Council Resolution dealt with the issue in its Resolution 1325 (2000), 31 October 2000.

107 A comparative survey of representative processes for the selection and nomination of candidates in 12 international judicial bodies has been carried out by Linehan, Jan, "Women and public international litigation", (2002), online version available at: http://www.iccnow.org/documents/WomenIntlPublicLitigation.pdf [last visited: 30 September 2020].

${ }^{108}$ The feminist calls for sex representative adjudicators is part of the broader feminist debate over the international adjudication, concerning, among others, questions about the extent to which international adjudication is a useful tool for achieving equality for and eradicating the subordination of women and how international adjudication can be improved. For a valued overview of the way feminist scholarship has engaged and enriched the debate over the international adjudications and for further references, see Grossman, Nienke, "Feminist Approaches to International Adjudication", in Ruiz Fabri, Hélène (ed.), Max Planck Encyclopedia of International Procedural Law, Oxford University Press, 2019, online version available at: https://opil.ouplaw.com/view/10.1093/lawmpeipro/e3350.013.3350/law-mpeipro-e3350 [last visited, 06 October 2020].

109 Charlesworth, Hilary, "Transforming the United Men's Club: Feminist Futures for the United Nations", Transnational Law \& Contemporary Problems, Vol. 4, (1994) 421-454, p. 440.

${ }^{110}$ Knop, Karen, "Re/Statements: feminism and state sovereignty in International Law", Transnational Law \& Contemporary Problems, Vol. 3, (1993) 293-344, pp. 306-307. The marginal presence of women in international institution makes them "aliens within the states, aliens within an international exclusive club that constitutes international society” (p. 309). It must be underlined that feminist arguments for women's participation in international institutions diverge. Knop examines the main three feminist approaches: equality, "different voice" and collective autonomy. The controversial "different voice" approach, along with female voice would be inherently different, is based on the work of Gilligan, Carol, In a different voice: psychological theory and women's development, Harvard University Press, Cambridge, 1982. MacKinnon particularly criticised Gilligan's reasoning: "For women to affirm difference, when difference means dominance, as it does with gender, means to affirm the qualities and characteristics of powerlessness. [...] I do not think that the way women reason morally is morality 'in a different voice'. I think it is morality in a higher register, in the feminine voice". MacKinnon, Catharine, Feminist unmodified: discourses on life and law, Harvard University Press, Cambridge, 1987, pp. 3839. Nowadays, the most recognized approach seems to be the one which understands the representativeness of the court in the sense of actively seeking "different viewpoints" as the inclusion of different perspectives strengthens 
The insights that feminists have brought to general international law and, especially, to the field of human rights law ${ }^{111}$ have a great deal to offer to the study also of other fields of international law. ${ }^{112}$ The law of armed conflict was not exempt from this influence. Here, one of the major tasks of feminist legal scholars has been to identify features of the existing legal regime of human rights that take no account of the realities of women's lives and to apply them to IHL. In doing so, they have drawn on theoretical insights developed by feminists working within the framework of human-rights discourse, which characterizes legal systems based on Western liberal ideals. ${ }^{113}$ Thus, the intellectual engagement of feminist international legal scholars with the legal treatment of women during the warfare, the impact of the IHL regime on their status, as well as the analysis of the gender-bias of some provisions of IHL constitute part of the far-reaching feminist critique of the whole structure of international law.

\subsubsection{Feminist critiques to IHL}

An introduction to the main feminist critiques to IHL seems essential as they offer a crucial tool to address the object of this thesis. Feminist insights aim at understanding the gender

the legitimacy of the courts and from this it follows greater respect and observance of international law as interpreted and applied by them. Grossman, Nienke, "The Effect of The Participation of Women Judges On The Legitimacy Of International Courts And Tribunals", Proceedings of the American Society of International Law Annual Meeting, Vol. 105, (2011) 452-455.

111 A condensing overview of the feminist scholarship on human rights with a focus on the strategies used to approach this regime and to introduce a new interpretation and substance to international human right law, and the main results of this international struggle of the 1990s, see Kouvo, Sari and Pearson, Zoe, Gender and International Law. Critical Concepts in Law. Volume II, Doing Gender and International Law: Human Rights, Routledge, London and New York, 2014. For a more recent discussion on the influence of international human rights law for the protection of women as well as the relevance of the most important international human right law document related to women, Convention on the Elimination of all Forms of Discrimination Against Women (CEDAW), see Nussbaum, Martha C., "Women's Progress and Women's Human Rights", in Fassbender, Bardo and Traisbach, Knut (eds.), The Limits of Human Rights, Oxford University Press, Oxford, 2019, pp. 231-265.

112 The recent volume of Papanicolopulu represents a valid example of the international doctrinal interest on the issue of the relationship between gender, feminist approaches, women and specific branches of IL, the law of the sea in this case. The author dismantles the two assumptions along with women has little to do with the sea and the law of the sea is a gender-neutral legal regime. The main gender considerations with regard to the law of the sea are here understood in terms of gender equality and protection of women in vulnerable position on the one hand, and empowerment and participation of women in maritime activities on the other hand. Papanicolopulu, Irini, Gender and the Law of the Sea, Brill/Nijhoff, Leiden, 2019. For further perspectives on the current feminist engagement with international law, see Kouvo, Savi and Pearson, Zoe (eds.), Feminist Perspectives on Contemporary International Law: Between Resistance and Compliance, Hart Publishing, 2014; Harris Rimmer, Susan, and Ogg, Kate, Feminist Engagement with International Law, Edward Elgar Publishing, Cheltenham, 2019, "Engaging feminist dialogues on contemporary issues within international law, outside of a focus on women's issues" (p. 71).

113 One of the first feminist scholars dealing with the issue of women and IHL, Judith Gardam, started her article in 1997 with these words: "The aim of this article is to extend the critique of human right law by feminist scholars to humanitarian law". Gardam, Judith, "Women and the Law of Armed Conflict: Why the Silence?", International and Comparative Law Quarterly, Vol. 46, (1997) 55-80, p. 55. 
implications of IHL. The recent feminist engagement with the IHL regime and with international law led to a new understanding of the many forms of violence that women experience during conflict. ${ }^{114}$ Thus, feminist critiques may be a useful point of departure for the following study of the IHL provisions related to women.

Despite the author's interest for feminist critiques to IHL, this Section cannot analyze them all in detail. It would have been impossible to do justice to the numerous feminist thoughts, theories, analytical responses to the issue of conflict-related violence against women. This Section focuses on some of the basic criticisms, main tenets, and common questions that the feminist critics addressed and have been addressing during the last decades. In so doing, the feminist theories of international law are left apart to better consider the number of insights offered by feminist analysis. Indeed, irrespective of the great variety of stances within the international feminist scholarship, some recurrent themes may be identified.

The rest of this Section covers both general criticisms, namely the literature that addresses IHL as a legal regime (Subsection 1.3.2.1.), and specific criticisms, namely the views of authors who focus on specific categories of IHL, such as the principle of military necessity or the concept of women's honor under IHL (Subsection 1.3.2.2.).

Both general and specific criticisms can be radical or not. As radical are here understood feminist criticisms arguing that IHL as a regime or some of its basic concepts are irreversibly gendered. That means that they cannot be read in a way that accommodates the concerns of feminist critiques - their gender bias cannot be interpreted away. On the other pole, there are feminist critiques that claim that problematic IHL features can be addressed though a gendersensitive interpretation and implementation of the relevant provisions. These two ways to group together feminist critiques are reflected in the distinction between the 'revisionist' and the 'enforcement' schools of thought. This thesis argues that there are significant merits in the second school and that IHL leaves significant rooms for interpretation to allow addressing basic feminist concerns from within its system of norms and jurisprudence (Subsection 1.3.2.3.).

1.3.2.1. Feminist critiques to IHL: the radical critique

\footnotetext{
114 Chinkin, Christine, "Gender and Armed Conflict", in Clapham, Andrew and Gaeta, Paola, The Oxford
} Handbook of International Armed Conflict, Oxford University Press, Oxford, 2014, pp. 675-699. 
For some feminist international lawyers IHL, as a branch of international law, is an irreversibly gendered regime, so even the "label 'humanitarian law' is a misnomer". ${ }^{115}$ At the basis of this critique of IHL is often a feminist critique of militarism as a form of gender oppression, ${ }^{116}$ in that it reproduces and reinforces gendered roles, and as a form of "objectification perfected", because it transfers in the battlefield the process of objectification of the other, which is common in the traditional relationship between men and women. The authorities and the methods used to oppress women within the State are the same that exercise their control internationally towards weaker States. ${ }^{117}$ These elements are then necessarily reflected also in the law that seeks to govern war, namely IHL. If war is a gendered social context, some feminist legal scholars argue, then the phenomenon of conflict-related violence against women is a product of their unequal structural status. ${ }^{118}$ The offences that affect women in the warfare represent an extension, "a continuum of violence", of the gender-based discrimination they suffer in peacetime. ${ }^{119}$ Therefore, discrimination that women experience worldwide is the main cause of the different impact of armed conflict on women. ${ }^{120}$ Furthermore, the grim gender

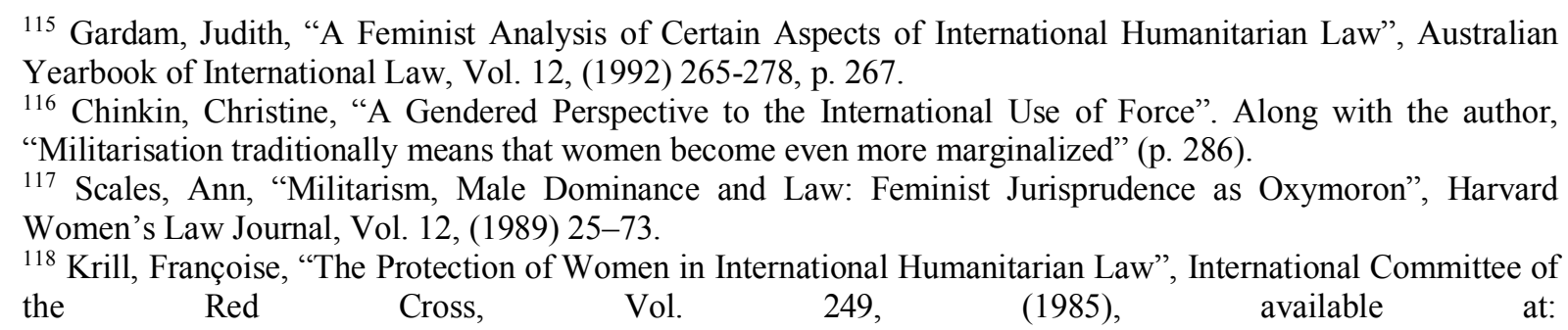
https://www.icrc.org/en/doc/resources/documents/article/other/57jmfj.htm [last visited, 07 October 2020].

${ }^{119}$ For a discussion on the link between the peacetime condition of women and the egregious forms of violence affecting them during the warfare, see Swaine, Aisling, Conflict-Related Violence against Women: Transforming Transition, Cambridge University Press, 2018. In identifying a spectrum of forms of gender violence in the three different contexts of Liberia, Northern Ireland and Timor-Leste, the author analyses their occurrence, and the relationship between them, within and across different points of pre-, mid- and post-conflict, with the aim of discovering whether the structural harms in peacetime provide a basis for conflict-time gendered harms. On how the constant violence affecting women from their private lives to the public sphere, from peacetime to warfare demonstrates the structural gender inequalities and the male supremacy over women, see for example Moser, O. Caroline, "The Gendered Continuum of Violence and Conflict: An Operational Framework", in Moser, O. Caroline, and Clark, Fiona (eds.), Victims, Perpetrators or Actors? Gender, Armed Conflict and Political Violence, Zed Books Ldt., New York, 2001; Cockburn, Cynthia, "The Continuum of Violence: A Gender Perspective on War and Peace", in Giles, Wenona and Hyndman, Jennifer (eds.), Sites of Violence: Gender and Conflict Zones, University of California Press, Berkeley and Los Angeles, 2004, pp. 24-44. For a critique to the "continuum thesis", see Wood, Elisabeth Jean, "Conflict-related sexual violence and the policy implications of recent research", International Review of the Red Cross, Vol. 96, (2014) 457-478. The author tries to demonstrate that it is not possible to reduce the complex phenomenon of the conflict-related sexual violence to a mono-casual theory, suggesting that the dynamics of connection among pre-war sexual violence, conflict-related sexual violence and post-war sexual violence may vary in forms and depending on the settings.

${ }^{120}$ Nowadays, the impact of structural gender inequalities and discrimination on the wartime violence against women is well recognized at international level. In this regard, the recent UN Security Council resolution S/RES/2467, 23 April (2019) expresses it as follows:

Recognizing that the disproportionate impact of sexual violence in armed conflict and post-conflict situations on women and girls is exacerbated by discrimination against women and girls and by the under- 
inequalities in conflict not only reflect the unequal condition of women in peacetime, but are supposed to exacerbate during the conflict. ${ }^{121}$

Based on this line of argument, a group of feminist legal scholars denounce the IHL regime's systemic failure to address the issue of conflict-related violence against women as an expression of a broader problem: the IHL's deficiency in tackling with the systematic gender inequalities affecting women globally. According to their views, if the problem is broader and transcends IHL, IHL cannot offer a partial resolution, focusing on solutions for some forms of violence only, such as rape. From the perspective of this systemic critique, only an analysis of the profound economic, health, judicial and social disparities between men and women could help explain and address the much more vulnerable condition of female civilians in situations of armed conflict. As Judith Gardam expresses this point, "in a world where women are not equals of men [...] a general category of rules that is not inclusive of the reality for women cannot respond to their situation". ${ }^{122}$ If any, the role of IHL should be to address the broader problems that shape women's condition. As the warfare expresses the structural inequalities between men and women already existing in our societies, IHL could be a means to face them. As conflict could also represent an opportunity for subverting the social structures and rethinking the role of women in patriarchal societies, IHL role could be to activate the equality process. In this sense, the degree of effectiveness of the IHL rules in the protection of women in the warfare may also provide for a litmus test revealing the capacity of this legal system in responding to the unequal condition of women and men in general.

This feminist perspective to IHL is both systemic, in the sense that it addresses IHL as a regime, and radical, as it focuses on the in-built gender biases of IHL. The feminist legal scholars'

\footnotetext{
representation of women in decision-making and leadership roles, the impact of discriminatory laws, the gender-biased enforcement and application of existing laws, harmful social norms and practices, structural inequalities, and discriminatory views on women or gender roles in society, and lack of availability of services for survivors, and further affirming the importance of promoting gender equality by addressing these and other root causes of sexual violence against all women and girls as part of conflict prevention, conflict resolution and peacebuilding.
}

For some examples of the literature on the matter, see Lindsey, Charlotte, "Women Facing War: ICRC Study on the Impact of Armed Conflict on Women", ICRC, Geneva, 2001; Rehn, Elisabeth and Johnson Sirleaf, Ellen, "Women, War and Peace: The Independent Experts' Assessment on the Impact of Armed Conflict on Women and Women's Role in Peace-building", UNIFEM, New York, 2002.

121 Gardam, Judith and Charlesworth, Hilary, "Protection of Women in Armed Conflict", Human Rights Quarterly, Vol. 22, No. 1, (2000) 148-166, p. 150. See also, Chinkin, Christine, "A Gendered Perspective to the International Use of Force",...p. 286. "Militarisation traditionally means that women become even more marginalized".

122 Gardam, Judith G. and Jarvis, Michelle J., Women, Armed Conflict and International Law, Kluwer Law International, Boston, 2001, p. 93. 
frustration for the absence of a social analysis on the root causes of gender inequalities shows, in general, a certain conception of IHL as a branch of law which should transcend its mere legal boundaries ${ }^{123}$ so as to also investigate sociological or any other non-legal features and take them into account for the analysis of legal phenomena and for the interpretation and application of law. In other terms, it is sustained that IHL is uncapable to properly deal with the numerous forms of conflict-related violence against women in so far as it does not recognize and even address the generally unequal women's condition.

This feminist scholarship is right in pointing to "a continuum of violence framework" as "a key tool to expose the complexity of GBV [gender-based violence], its structural, socioeconomic root causes and the links between GBV in 'war' and 'peace'". ${ }^{124}$ It is also essential in that it helps to develop a certain sensibility over the women's perspective on war and the way war has been regulated through law. In this sense, it could be said that feminist theories of IHL offer women's viewpoint on a phenomenon basically conceived and developed by men over centuries.

The main problem with this approach is its broad scope. By suggesting that IHL can be the fuel for transforming societal mechanisms, these theories overestimate the potential tasks of IHL ${ }^{125}$ and risk to give priority to political achievements over legal considerations. Indeed, many of these criticisms - directly connected with the assumption that the violence against women is a form of discrimination against women ${ }^{126}$ - emphasize "the tensions between the pragmatic and limited aims of IHL and the range of expectations placed upon this area of law". ${ }^{27}$ This is not to say, however, that IHL cannot contribute to societal change. The potential of IHL to go beyond conflict and to also address underlying socio-economic and patriarchal causes of VAW

\footnotetext{
${ }^{123}$ The opposite Kelsenian perspective of legal science, according to which law is only positive law and the legal science should only deal with the analysis of the norms, does not accept the use of values and criteria external to the positive law. In this sense, considerations others than the legal ones are to be considered outside the legal science. Kelsen, Hans, Pure Theory of Law, second edition, University of California Press, 1967).

${ }^{124}$ Chinkin, Christine and Neenan, Joanne, "International Law and the Continuum of Gender-based Violence", LSE Women, Peace and Security Working Paper Series, (2017), https://blogs.1se.ac.uk/wps/2017/04/06/international-law-and-the-continuum-of-gbv/.

${ }^{125}$ Sassoli, Marco, International Humanitarian Law Rules, Controversies, and Solutions to Problems Arising in Warfare, pp. 558-559.

${ }^{126}$ CEDAW, General Recommendation No. 19, UN GAOR, 1992, Doc. No. A/47/38, para. 1. See also, Council of Europe Convention on preventing and combating violence against women and domestic violence, 11 May 2011, Article 3. The preamble of the Convention states "violence against women is a manifestation of historically unequal power relations between women and men, which have led to domination over, and discrimination against, women by men and to the prevention of the full advancement of women".

${ }^{127}$ Durham, Helen, "International Humanitarian Law and The Protection of Women", in Helen and Gurd, Tracey (eds.), Listening to the Silence: Women and War, Koninklijke Brill, Leiden, 2005, p. 97, note 14.
} 
may be particularly relevant in the post bellum phase. Feminist scholars have used the concepts of "transformative justice" and "transformative reparations" to describe how reparation may be used to address gendered structural inequalities. This potential of IHL will be described in more detail in Chapter 4.

\subsubsection{Feminist critiques to IHL: specific topics}

The feminist critics of IHL often target specific concepts, categories, and institutions of IHL. One of them is the distinction between combatants and civilians. The distinction between the abovementioned categories is a cornerstone of IHL. ${ }^{128}$ According to the principle, " $[\mathrm{t}]$ he Parties to the conflict shall at all times distinguish between the civilian population and combatants". ${ }^{29}$ The principle distinguishes between combatants, who are members of armed forces representing a party of an international armed conflict (IAC) $)^{130}$, and civilians, defined in opposition to the first as persons who are not members of armed forces. The distinction between these two categories is essential in that a certain protection and different legal consequences of the conduct of the person are associated to each legal status. In particular, combatants are the only ones that can directly participate in the hostilities. This means that, if they act within the rules limiting the means and methods of warfare defined by IHL, they cannot be punished even if their conduct is contrary to the enemy's domestic legislation. At the same time, combatants can be always the object of military attacks. Conversely, the status of civilian attributes immunity from military violent attacks. ${ }^{131}$ Thus, attacks against the civilian population or against individual civilians are generally prohibited. However, civilians cannot take part to the hostilities, otherwise they can be punished by the enemy's relevant domestic legislation.

According to feminist legal scholars, the distinction between combatants and civilians is a deeply gendered one, representing the traditional male-female differentiation in roles. ${ }^{132}$ The

\footnotetext{
${ }^{128}$ In its Advisory Opinion on the Legality of the Threat or Use of Nuclear Weapons, the International Court of Justice (ICJ) qualifies this distinction as the "cardinal principle". Legality of the Threat or Use of Nuclear Weapons, (Advisory Opinion), July 8, 1996, (1996) ICJ Reports 226, para. 257.

129 Article 48 of the 1977 Additional Protocol I.

${ }^{130}$ In non-international armed conflicts (NIACs) the legal concept of "combatant" does not exist. For a brief examination of the difference between IACs and NIACs, see later on the chapter.

${ }^{131}$ Article 51 of the 1977 Additional Protocol I.

${ }^{132}$ For an overview of the main gender problems with the principle of distinction, especially connected with a certain (masculine and Eurocentric) vision of the war, see Stern, Orly Maya, Gender, Conflict and International Humanitarian Law. A Critique of the "Principle of Distinction", Routledge, Abingdon-New York, 2019. The author sustains that:
}

The law fails women in new wars, first and foremost because it is not functioning properly. However, in addition to the ways it fails everyone, it also fails women in specific ways. Those failings pertaining to 
activity of the combatant, devoted to the use of force in the interest of the national security, is usually performed by male warriors. On the contrary, civilians are mainly women. The IHL regime has been conceived to prioritize combatants, so, given that the majority of combatants are men, while women usually constitute the civilian population, the IHL rules incorporates a "gendered hierarchy". ${ }^{133}$ In this way,

[w]omen suffer under a double disability in comparison with combatants: their status and treatment are not only inferior as civilians but doubly so as women civilians. ${ }^{134}$

The gender inequality expressed in such rules is conceived as "inherent", because it would be the result of a system of values and assumptions that are far from being dismantled. ${ }^{135}$

The criticized assumptions of the combatants' prioritization are also reflected in another core principle of IHL, the principle of military necessity. ${ }^{136}$ The principle of military necessity postulates the use of measures which are necessary to fulfil a legitimate military purpose and which are not proscribed by international humanitarian law. The legitimate military purpose is to weaken the military capacity of the enemy in order to achieve the main military interest and the ultimate goal of the final victory of the State. Even where the rules of IHL provide protection for victims of armed conflict, humanitarian considerations succumb to the military necessity doctrine. ${ }^{137}$ As Gardam puts it,

Far from being a neutral yardstick, military necessity in fact incorporates a hierarchy of values. It assumes [makes natural] that the military victory of the State is pre-eminent. From this flows the seemingly logical value judgement, that the life of the combatant is more important than that of civilian, even more so if that civilian belongs to the enemy State. [...] The military resists strongly the notion that combatants should assume risks to protect the civilian population. But their position is not immune to challenge. It assumes that war is inevitable and that soldiers are performing a necessary, thankless public duty. ${ }^{138}$

everyone and those pertaining to women are interrelated. The organising principle of IHL[the principle of distinction] assumes males as the primary actors. Bringing in women as actors destabilises the entire construct of IHL. We are left with a destabilised law, operating in conflicts that by their very nature push IHL beyond its field of comfortable operation.

${ }^{133}$ Gardam, Judith, "Women and the Law of Armed Conflict: Why the Silence?”,...p. 56.

${ }^{134}$ Ibid. p. 64.

135 Ibid. p. 70.

${ }^{136}$ On military necessity, see generally Salvadego, Laura, Struttura e funzioni della necessità militare nel diritto internazionale, Giappichelli, Torino, 2016.

${ }^{137}$ This idea was expressed much before the feminist legal scholarship's debate over the IHL regime. In this regard see for example, Jochnick, Chris af and Normand, Roger, "The legitimation of violence: a critical history of the laws of war", Harvard International Law Journal, Vol. 35, No. 1, (1994) 49-96. The authors suggest that "the laws of war have been formulated deliberately to privilege military necessity at the cost of humanitarian values" ( $p$. 50 ), and that "in the development of the law of armed conflict, humanitarian considerations have always taken second place to military necessity, especially when the restraints are to protect non-combatants" (p. 62).

138 Gardam, Judith, "Women and the law of armed conflict: why the silence?", International and Comparative Law Quarterly, Vol. 46, Issue 1, (1997) 55-80, p. 72. 
According to ta feminist critical perspective, this hierarchization of considerations inherent in the concept of military necessity is ultimately detrimental to women. As predominantly civilians, their life and interests will always rank after the target of military victory of the State and its pursuance by (male) combatants.

Third, feminist scholars reject as a typically male approach the distinction between international armed conflicts (IACs) and non-international armed conflicts (NIACs). IACs are conflicts between States. ${ }^{139}$ They include either conflicts in which States are directly involved with their armed forces and conflicts in which States indirectly control armed groups fighting against the government of another State, as well as belligerent occupation, even when there is not armed resistance. Conversely, NIACs are conflicts occurring between one or more States, on the one hand, and a sufficient organised armed group, on the other hand, or between organised armed groups that do not fight under state authority. As also noted above, for a NIAC to exist, a certain intensity of violence must arise between the parties. The distinction between IACs and NIACs is relatively recent. Indeed, before the introduction of the 1949 Geneva Conventions, conflicts within the State were basically conceived as a national affair, in line with the Westphalian concept of the State as having the monopoly of the use of force within its territory. Today, most treaty IHL rules apply to IACs, while NIACs are regulated only by Article 3 of the 1949 Geneva Conventions (common Article 3), and, when other supplementary conditions are accomplished, by the 1977 Additional Protocol II. Cassese explained the reluctance of all parties involved, both insurgents and States, to provide NIACs with the same IHL rules of IACs, stating

[i]n practice, insurgents are not willing to live up to international standards they have not accepted. What is even more important, States engaged in an international armed conflict do not readily concede that civil strife calls for the application of international regulations. ${ }^{140}$

Thus, when the distinction between IACs and NIACs was made, it was not well accepted that IHL is binding for States also in NIACs. Nowadays, NIACs constitute the vast majority of armed conflicts. Despite "the slow but steady merger of the IHL of NIACs and the IHL of

\footnotetext{
${ }^{139}$ In particular, the International Criminal Tribunal for the former Yugoslavia (ICTY) suggested a definition of IAC in Tadic case: "an armed conflict exists whenever there is a resort to armed force between States". ICTY, Prosecutor v. Dusko Tadic, Decision on the Defence Motion for Interlocutory Appeal on Jurisdiction, IT-94-1-A, 2 October 1995, para. 70.

${ }^{140}$ Cassese, Antonio, "The Status of Rebels under the 1977 Geneva Protocol on Non-International Armed Conflict", International \& Comparative Law Quarterly, Vol. 30, (1981) 416-439, p. 425.
} 
IACs", ${ }^{141}$ especially thanks to the jurisprudence of the international courts, ${ }^{142}$ it remains still more difficult to prosecute violations of the conduct of hostilities in NIACs than in IACs. ${ }^{143}$ The distinction between IACs and NIACs is contested today: many scholars argue that it has no reason to exist anymore and that a unique regime applicable both to IACs and NIACs would be preferable. ${ }^{144}$

According to the feminist critique, the diminished protection for civilians resulting from the less detailed regime of NIACs affects mainly women, who form the majority part of the civilian population. Moreover, the distinction would result in a "construct that obscures both the human suffering created by, and the causes of, 'internal' conflict". ${ }^{145}$

Such feminist criticisms against the distinction between combatants and non-combatants, and IACs and NIACs have been rejected by some authors. As for the distinction between combatants and civilians and the claim that the IHL regime would protect the first and not the second, the counterargument is that the current weak position of the civilians in conflict is basically due to a non-compliance with the rules instead of a lack of the rules themselves. Besides, the feminist critique to the distinction between IACs and NIACs has been considered not valid in that it would erroneously ascribe such distinction within a gendered dimension. ${ }^{146}$

Fourth, feminist legal scholars also criticise the way women are represented under the Geneva Conventions of 1949. First, they condemn the use of an outdated language within the body of IHL. In particular, when specific forms of conflict-related sexual violence against women are addressed, the IHL regime treats them as acts against honour and not as acts of violence. In this way, they seem to be concerned "about the men who were harmed by the attack on this honour" and "not about women — qua women — as subjects of international law". ${ }^{147}$ Chapter III will deal in greater detail with the feminist critiques related to the qualification of sexual violent acts as crimes against honour. Here it suffices to underline that the use of an outdated language in the identification of the crime of sexual violence is considered to have

\footnotetext{
${ }^{141}$ Sassoli, Marco, International Humanitarian Law Rules, Controversies, and Solutions...p. 17.

${ }^{142}$ In particular, the ICTY stated in Tadić case that many IHL rules of IACs are also applicable for NIACs, and that the concept of war crimes is also applicable in NIACs. ICTY, Prosecutor v. Dusko Tadić, IT-94-1-AR72, Appeals Chamber, Decision, 2 October 1995, para. 96-136.

143 Ibid. p. 18.

${ }^{144}$ See, among others, Crawford, Emily, The Treatment of Combatants and Insurgents Under the Law of Armed Conflict, Oxford University Press, Oxford, 2010.

145 Charlesworth, Hilary, "Feminist Methods in International Law", American Journal of International Law, Vol. 93, No. 2, (1999) 379-394, pp. 389, 394.

${ }^{146}$ Sassoli, Marco, International Humanitarian Law Rules, Controversies, and Solutions...p. 558.

${ }^{147}$ Ibid. pp. 379, 386-387.
} 
consequences on the legal understanding of the gravity of the crime, mischaracterizing the nature of the offence, ${ }^{148}$ and to diminishing its "gravest dimension"149.

A related point concerns the fact that the women-specific IHL norms are expressed in terms of "protection" rather than "prohibition", fostering, and somehow crystallizing, a certain narrow idea of women as vulnerable subjects in need of protection. ${ }^{150}$ This narrative seems difficult to change because it "is also disruptive of the gendered ways of thinking that have served to legitimate armed conflict (as 'manly') and silence alternative ways of thinking (as feminine or 'wimpish')". ${ }^{151}$ Feminist critics also point that the women-specific IHL provisions are basically designed to protect women primarily in their relationship with others, and not as individuals. Indeed, the majority of the female-specific norms would not have the women as the primary target for protection but the children. ${ }^{152}$ After analyzing the regime of particular care for pregnant women and mothers of young children, Chapter II will offer an overview of this specific feminist critique in order to understand its current relevance.

\subsubsection{Feminist critiques to the international criminal adjudication}

Feminist critiques not only challenge substantive norms and concepts of IHL, but also institutional/procedural elements. Given the importance of the criminal prosecution to implement IHL's provisions by punishing the acts of violence committed against women during the armed conflict, the feminist critique of the limits of the international criminal adjudication is a critical part of the overall feminist critiques to IHL.

Developments under the "new born" international criminal law (ICL) provided crucial milestones in the recognition of conflict-related violence against women in the 1990s. The UN Security Council's (UN SC) institution of the International Criminal Tribunal for the former Yugoslavia (ICTY) ${ }^{153}$ and the International Criminal Tribunal for Rwanda (ICTR) ${ }^{154}$ marked an unprecedent step in the awareness of the impact of armed conflicts on women. These two

\footnotetext{
${ }^{148}$ Askin, Kelly D., "Women and International Humanitarian Law", in Askin, Kelly D. and Koenig, Dorean (eds.), Women and International Human Rights Law, Vol. 1, Transnational Publishers, Inc., New York, 1999, p. 55.

${ }^{149}$ Copelon, Rhonda, "Surfacing Gender: Re-engraving Crimes Against Women in Humanitarian Law", Hastings Women's L. J., Vol. 5, (1994) 243-266, p. 249.

150 Gardam, Judith, and Jarvis, Michelle J., Women, Armed Conflict, and International Law, Kluwer Law International, The Hague, 2001, pp. 107-112.

151 Otto, Dianne, "Women's Rights", in Moeckli, Daniel, Shah, Sangeeta and Sivakumaran, Sandesh (eds.), International Human Rights Law, Oxford University Press, Oxford, 2013, p. 321.

152 Gardam, Judith, "Women and the Law of Armed Conflict: Why the Silence?", International and Comparative Law Quarterly, Vol. 46, (1997) 55-80, p. 57.

${ }^{153}$ UN SC Resolution 827 (1993).

154 UN SC Resolution 955 (1994).
} 
ad hoc tribunals were the first in history to focus on the large-scale atrocities committed against women, predominantly sexual violence and rape, in the two respective war settings.

The outcome of this judicial effort to prosecute crimes against women is twofold. First, it produced a landmark jurisprudence, which criminalised sexual violence offences and declared them as constitutive acts of the crimes against humanity and the most egregious war crimes. Second, it paved the way to the recognition of the gender crimes in the text of the Statute of the International Criminal Court (ICC), adopted by 120 States in Rome on 17 July 1998 (for this reason usually referred to as the Rome Statute) and entered into force on 1 July $2002 .{ }^{155}$

The recent developments in international criminal law have led to a shift of feminist debates. On the one hand, feminist legal scholars have recognized the relevance of international criminal tribunals in advancing the proscription and the criminalization of wartime violence against women as well as in contributing to put the issue of tactical sexualized violence against women under the spotlight. On the other hand, they have also pointed that this approach, based on the criminalization of VAW, has its limits. Feminist legal scholars were concerned about the fact that the jurisprudence of the ad hoc international criminal tribunals' treatment of rape as a communal harm strictly connected to violent nationalism might conceal its real nature as a crime against the (female) person and underestimate the correlation of rape with pre-existent and systematic gender inequalities. ${ }^{156}$ According to this view, the ICTY's and ICTR's focus on mass rape - basically understood within an unquestioned ethnical dimension - would oversimplify the complexity of violence against women. ${ }^{157}$ The approach of the ad hoc

\footnotetext{
${ }^{155}$ In particular, the Rome Statute is the first international criminal law text to have explicitly recognized rape, sexual slavery, forced prostitution, forced pregnancy, forced sterilization, and other forms of sexual violence as distinct types of war crimes. It also expanded the list of sexual and gender crimes that constitute crimes against humanity so to include not only rape but also other forms of sexual violence and persecution on the basis of gender (Article 7 (1) (g)). Moreover, it represents the first international legal document which expressly includes various forms of sexual and gender-based crimes as constitutive acts of crimes against humanity and war crimes committed in international and non-international armed conflicts (Article 8 (2) (b) (xxii) and 8 (2) (e) (vi)). The Statute authorizes the Court to exercise its jurisdiction over sexual and gender crimes if they constitute acts of genocide or other acts constitutive of crimes against humanity or war crimes. Article 7, paragraph 3 of the Statute has been dedicated to defining the term "gender": "For the purposes of this Statute, it is understood that the term 'gender' refers to the two sexes, male and female, within the context of society. The term 'gender' does not indicate any meaning different from the above". Finally, Article 21, paragraph 3 of the Statute includes gender, as defined in Article 7 (3), among the criteria that cannot be used to discriminate in the application and interpretation of the law.

156 Chinkin, Christine, "Rape and Sexual Abuse of Women in International Law", European Journal of International Law, Vol. 5, (1994) 326-341.

${ }^{157}$ Doris E. Buss, "The Curious Visibility of Wartime Rape: Gender and Ethnicity in International Criminal Law," Windsor Yearbook of Access to Justice, Vol. 25, No. 1, (2007) 3-22; Doris E. Buss, "Sexual Violence, Ethnicity, and the Limits of Intersectionality in International Criminal Law," in Grabham, Emily, Cooper, Davina,
} 
international criminal tribunals on "rapes as extensions of nationalism" and "rape as one modality of ethnic harm" 158 has been accused to have created "a pre-established framework for describing wartime rape in all settings". 159

In more recent times, feminist legal scholarship has even shifted to denounce the "elevation of war rape to the position of ultimate violence against women". ${ }^{160}$ In particular, feminist internationalists have criticized the tendency of the international criminal courts' jurisprudence to hierarchize the forms of violence that women can be subject to. While the emphasis on sexual violence as the quintessential harm of war could be seen as reflecting "the victory of particular feminist positions", ${ }^{161}$ other feminist scholars argue that the focus on sexual violence has obscured the complex range of forms of violence that affects women's life in situations of armed conflict, and, in general, has covered a number of other aspects connected with gender and conflict. ${ }^{162}$ According to this view, the "prioritization" of rape and sexual violence could lead to a partial and narrow understanding of the multifaceted women's experience of war, and

Krishnadas, Jane, Herman, Didi (eds.), Intersectionality and Beyond Law, Power and the Politics of Location, Routledge-Cavendish, Abingdon, 2008.

${ }^{158}$ Buss, Doris E., "The Curious Visibility of Wartime Rape",... p. 22.

${ }^{159}$ Eriksson Baaz, Maria and Stern, Maria, Sexual Violence as a Weapon of War? Perceptions, Prescriptions and Problems in the Congo and Beyond, Zed Books, London and New York, 2013, pp. 42-43.

Zarkov sustains that, in the early years of the wars in the former Yugoslavia and in Rwanda, feminist scholarship was not exempt from the trend of the "essentializing of ethnicity", in so privileging this category of difference over other possible factors and in so creating "geographies of violence". Zarkov, Dubravka, "From Women and War to Gender and Conflict?: Feminist Trajectories", in Ní Aoláin, Fionnuala, Cahn, Naomi, Haynes, Dina Francesca, and Valji, Nahla (eds.), The Oxford Handbook of Gender and War, Oxford University Press, Oxford, 2018, pp. 26-27.

${ }^{160}$ Zarkov, Dubravka, "From Women and War to Gender and Conflict?: Feminist Trajectories",...p. 28.

${ }^{161}$ Engle explains that the process leading to the problematic narrative of sexual violence as the quintessential harm of war dates back to the early Nineties, when women's human rights advocacy started to gain their recognition at international level. The author sustains that the focus on the dominant understanding of the centrality of sexual violence in conflict was useful to the feminist cause for two main reasons. First, it facilitates the mediation among the numerous feminist internal currents, in so converging them around a common issue; and second, it led the feminist having a central role in the development of the emerging international criminal law. Engle, Karen, "A Genealogy of the Centrality of Sexual Violence to Gender and Conflict", in Ní Aoláin, Fionnuala, Cahn, Naomi, Haynes, Dina Francesca, and Valji, Nahla (eds.), The Oxford Handbook of Gender and War, Oxford University Press, Oxford, 2018. In this sense, it has been sustained that the focus on rape and sexual violence represents a victory for the radical feminists, whose main project with regard to law concerns the revision of the legal system through the legal recognition of the harms particularly affecting women, such as rape and sexual violence, in so subverting the male control over women's sexuality and slowly improving the social relationship between women and men and women's condition generally. See MacKinnon, Catharine, "Feminism, Marxism, method, and the State: toward a feminist jurisprudence", Signs, Vol. 8, No. 4, (1983) 635-658; West, Robin, "Jurisprudence and gender", University of Chicago Law Review, Vol. 55, No. 1, (1988) 1-72. At international level, the radical feminist scholars promoted the inclusion of the crime of rape among the human rights' violations. See MacKinnon, Catharine, "Rape, Genocide, and Women's Human Rights." Harvard Women's Law Journal, Vol. 17, No. 5, (1994) 5-16.

${ }^{162}$ Engle, Karen, “A Genealogy of the Centrality of Sexual Violence to Gender and Conflict”, ...p. 141. The author is also worried that the focus on the criminalisation of the sexual violence "allied feminists with the police and with penal systems at the international and domestic levels". (p. 141). 
reinforce the idea of women as victims in need of protection. ${ }^{163}$ For example, in this context it has been sustained that no due consideration has been given to acts of violence such as the demolition of the home, the destruction of water sources, the steal of the land or the expulsion from the ancestral territory. ${ }^{164}$ Apart from that, the undue focus on sexual violence and its treatment by international criminal justice could result in a "misleading" sense of progress for women in terms of advancements in IHL, and, a Judith Gardam notes,

indifference in all quarters, including among feminists themselves, to the potential benefits that might ensue from developments in the law and its interpretation to take account of the overall different experience of women in armed conflict beyond sexual violence. ${ }^{165}$

Some feminist authors have gone even further, addressing the mainstream corpus of literature and international criminal jurisprudence on gender-based violence as a manifestation of the "fragmentation of gender law reform". ${ }^{166}$ Indeed, not only these "successes" in the criminalization of sexual violence would result in a "little feminist engagement with the nature, form, and operation of international criminal law", but they would also "remain fragmented from mainstream developments and emerge predominantly through the work of specialist gender actors and scholarship" rather than developing as a fertilizing component informing legal outputs within the realm of the discipline. ${ }^{167}$ The ultimate risk of this focus on certain aspects of women's experience of war would be the perpetuation of certain stereotypes attributed to women and the legitimation of some categories that the feminist scholarship wanted to fight. 168

Some scholars have claimed that certain limits of the international criminal justice find their main roots in the criminal adjudication process and in its limited attention to victims. ${ }^{169}$ In this

\footnotetext{
${ }^{163}$ Buss, Doris E., "The Curious Visibility of Wartime Rape".

164 Žarkov, Dubravka, "From Women and War to Gender and conflict? Feminist Trajectories", in Ní Aoláin, Fionnuala, Cahn, Naomi, Haynes, Dina Francesca, Valji, Nahla (eds.), The Oxford Handbook of Gender and Conflict, Oxford University Press, Oxford, 2018, p. 28.

165 Gardam, Judith, "The Silences in the Rules That Regulate Women during Times of Armed Conflict", in Ní Aoláin, Fionnuala, Cahn, Naomi, Haynes, Dina Francesca, and Valji, Nahla (eds.), The Oxford Handbook of Gender and War, Oxford University Press, Oxford, 2018, p. 42.

${ }^{166}$ Heathcote, Gina, Feminist Dialogues on International Law: Success, Tensions, Futures, Oxford University Press, Oxford, 2019, p. 85.

167 Ibid.

${ }^{168}$ For an overview of the internal feminist critique to the mainstream narrative of women and war and its possible risks for the achievement of the feminist agenda, see Mégret, Frédéric, "Féminisme et Droit International: Le 'Féminisme de Gouvernance' à l'Epreuve du 'Féminisme Critique", in Tourme Jouannet, Emmanuelle, Bourgorgue-Larsen, Laurence, Muir Watt, Horatia, and Ruiz Fabri, Hélène (eds.), Féminisme(s) et Droit International. Etudes du Réseau Olympe, Société de legislation compare, Paris, 2016, pp. 417-424.

${ }^{169}$ On the potentialities of the international criminal judicial bodies for enhancing the individual right to access to justice and their increasing attention to victims of international crimes, see Marchegiani, Maura, "La condition juridique de la victime à travers le prisme des juridictions pénales internationalisées”, in in Kamto, Maurice and
} 
sense, it has been argued that prosecutions are primarily based on the imperative of "orderbuilding", aiming at "obtaining convictions against the most legally and morally culpable, for the worst possible crimes, in the shortest possible time, with the fewest possible witnesses". This logic would obfuscate the female 'subjectivity' in international law. ${ }^{170}$ These critiques had a double effect. On the one hand, feminist scholars and practitioners underline the importance of developing international criminal law through the shaping of the relevant procedures of adjudication and the interpretation of criminal law provisions related to sexual and gender-based violence. ${ }^{171}$ On the other hand, they note the limits of international criminal courts in implementing IHL ${ }^{172}$ and also suggest additional forms of "international recognition" for women victims of conflict-related violence. ${ }^{173}$

\subsubsection{The "revisionist" and the "enforcement" schools: the potential of IHL}

Already from the discussion above, a tension emerges within feminist legal scholars as for the possible contribution of IHL to the adequate recognition of women's experience of war. ${ }^{174}$ In particular, two main feminist schools of thought may be identified with respect to the role of IHL in addressing the situation of civilian women caught in armed conflict and the best way to achieve the goal of a better protection of women civilians in conflict settings. ${ }^{175}$

On the one hand, the "enforcement school" argues that the "tragic plight of women does not primarily result from a lack of humanitarian rules to protect them but rather from a failure to coherently interpret and implement existing rules". ${ }^{176}$ This approach - also promoted by the

Tyagi, Yogesh (eds.), The Access of Individuals to International Justice, Brill Nijhoff, Leiden Boston, 2019, pp. 341-377.

170 Dixon, Rosalind, "Rape as a crisme in International Humanitarian Law: where to from here?", European Journal of International Law, Vol. 13, No. 3, (2002) 697-719, p. 705.

${ }^{171}$ Engle, Karen, "Feminism and Its (Dis)contents: Criminalizing Wartime Rape in Bosnia and Herzegovina", American Journal of International Law, Vol. 99, No. 4, (2005) 778-816. Sellers, Patricia, "Gender Strategy is Not Luxury for International Courts”, Journal of Gender, Social Policy \& the Law, Vol. 17, No. 2, (2009) 301-25.

172 Bennoune, Karima, "Do We Need New International Law to Protect Women in Armed Conflict?", Case Western Reserve Journal of International Law, Vol. 38, (2006-2007), p. 386.

${ }^{173}$ Dixon, Rosalind, "Rape as a crime in International Humanitarian Law: where to from here?”, ...p. 709.

${ }^{174}$ On the inherent incoherence of the feminist legal scholarship as for theoretical arguments, political goals and the role to attribute to international law, see Charlesworth, Hilary, "The Women Question in International Law", Asian Journal of International Law, Volume 1, Issue 1, (2011), pp. 33 - 38. The author wonders how "most of the debate and engagement with feminist ideas in international law comes from other feminists. So, while the rest of the discipline ignores us, feminists have created a veritable industry of internal critique, pointing to the problematic assumptions and approaches of other feminists" (p. 35).

${ }^{175}$ For a valuable overview of the feminist debate over the adequateness of the female-specific IHL provisions, see Oosterveld, Valerie, "Feminist Debates on Civilian Women and International Humanitarian Law", Windsor Yearbook of Access to Justice, Vol. 27, (2009) 385-402.

176 See 'Advancement of Women and Implementation of the Outcome of the Fourth World Conference on Women', statement by the ICRC to the UN General Assembly, 53rd Session, Third Committee (15 October 1998), 
ICRC - aims at focusing on the effective implementation of the IHL provisions, overcoming the unwillingness and ineptitude of the international community in implementing the existent legislation. ${ }^{177}$ Strategically, this approach is informed by the consideration that "this is not the ideal time politically to mount a challenge to IHL". ${ }^{178}$ Instead, it is suggested to make a "reflection upon the existing IHL norms within a gender perspective" 179 in order to have a system effectively implemented instead of risking that a revision of the Geneva Conventions would weaken the whole regime. ${ }^{180}$

On the other hand, the second school of thought is deeply convinced that the problem of an effective protection of the civilian women in war cannot be really addressed by the existent IHL regime, because it is inherently discriminatory and it contains a dated conception of women. ${ }^{181}$ Oosterveld classifies this approach as the "revisionist school", because feminist scholars from this side are firmly convinced that only an amendment of some of the main IHL female-specific provisions could modernize this legal regime and make it responsive to women's need in the warfare. Some authors could be classified in both schools of thought as they suggest that, while the idea of redrafting IHL treaties to include the current understanding of conflict-related violence against women would be now a "high stake project", it could be may only be "realistic as a long-term goal". ${ }^{182}$

Nowadays the "enforcement" school approach seems to prevail in terms of influence. As Gardam put it,

available at: https://www.icrc.org/en/doc/resources/documents/statement/57ipep.htm [last visited, 24 September 2020].

${ }^{177}$ Lindsey, Charlotte, "Women and War - An Overview”, International Review of the Red Cross, no. 839, (2000), available at: https://www.icrc.org/en/doc/resources/documents/article/other/57jqq3.htm [last visited, 02 October 2020].

${ }^{178}$ Gardam, Judith, "The Neglected Aspect of Women and Armed Conflict-Progressive Development of The Law", Netherlands International Law Review, Vol. 52, Issue 2, (2005) 197-219, p. 216.

${ }^{179}$ Durham, Helen and O’Byrne, Katie, "The Dialogue of Difference: Gender Perspectives on International Humanitarian Law",...p. 37.

180 ICRC, "Overview of Operations 2003", p. 2, available at: www.icrc.org/Web/eng/siteeng0.nsf/htmlall/5GVEKF/\$File/OVER2003 bkmk.pdf [last visited，02 October 2020] Gaggioli, Gloria, "Sexual violence in armed conflicts: A violation of international humanitarian law and human rights law", International Review of the Red Cross (2014), 96 (894), 503-538.

${ }^{181}$ Gardam, Judith and Charlesworth, Hilary, "Protecting Women in Armed Conflict" Human Rights Quarterly, Vol. 22, (2000), 148, p. 160. See also, Gardam, Judith, "Women and Armed Conflict: The Response of International Humanitarian Law" in Durham, Helen and Gurd, Tracy (eds.), Listening to the Silences: Women and War, Martinus Nijihoff Publishers, Leide, 2005, p. 123.

${ }^{182}$ Bennoune, Karima, “Do We Need New International Law to Protect Women in Armed Conflict?”, ...p. 388. 
It is also worth bearing in mind that much can be achieved though the reinterpretation of existing provisions of LOAC, rather that understanding the hazardous path of persuading states to adopt new law. ${ }^{183}$

This approach of the "enforcement" school is also broadly shared by this thesis, offering the theoretical background for the rest of the investigation. Feminist scholarship's incursions in IHL provide such legal regime with at least three important insights. First, feminist legal scholars made clear that an adequate interpretation of the IHL regime not only allows, but also necessitates gender considerations. A deep understanding of the gendered dynamics which inform the armed conflict was at the basis of the legal recognition of the many forms of violence which affect women during the warfare and the starting point for an international prosecution of the relevant crimes. Therefore, when interpreting the relevant norms of IHL we need to have recourse to these underlying gender dynamics in order to do justice to their telos, their purpose and objective. Second, feminist scholars demonstrate how a certain interpretation and application of the relevant provisions actually affect the level of the protection of women caught in armed conflicts. When more than one possible interpretation is possible, feminist approaches make us sensitive to their real impact on women and can thus guide us to select some over others. Third, feminist theories shed light on the connection between the condition of women in conflict and the structural discrimination women suffer worldwide, and demonstrate how the IHL regime can have some disciplinary impact effects on actual conducts in war, at least by avoiding the reproduction of certain aspects of gendered social behaviours. All these three contributions can be delivered by adopting a perspective closer to the "enforcement" school. A revision of the IHL regime is neither desirable nor required since feminist stances may be satisfied by the interpretation of the existing norms.

\subsection{Concluding remarks}

The focus of this thesis is on conflict-related violence against women. Of course, not all forms of conflict-related violence against women have a prominent gender aspect, because in some cases only the biological element is involved. However, it is common that gender roles and assumptions intensify biological differences. It is also common that "gender-based violence against women is affected and often exacerbated by [...] militarisation, foreign occupation,

\footnotetext{
${ }^{183}$ Gardam, Judith, "The Silences in the Rules That Regulate Women during Times of Armed Conflict”, p. 43.
} 
armed conflict, violent extremism and terrorism" 184 . Therefore, gender is here considered a key concept for a proper understanding of IHL violations involving women.

This Chapter also provided an overview of the most important engagements of feminist critics with international law and IHL in particular. As feminist international lawyers have demonstrated, the use of a gender-sensitive lens in the study of IHL may contribute to an interpretation of the relevant provisions that leads to a better protection of those who the regime aims to protect, in this case women. The feminist lessons sketched in this Chapter are thus very important and may be translated to new understandings of the relationship between war, IHL regime, and women.

It is true that, from a historical perspective, IHL was made by men, in a world governed by men. It is also true that, to a certain extent, IHL still endorses certain gendered biases as, among others, the outdated language used in some provisions and the symbolical opposition through which the masculinity and the femininity are being constructed. However, this thesis does not follow the more radical feminist approach often implied in the "revisionist school", according to which IHL is an irreversibly male regime that ideologically can only express male interests and it is thus not even "truly humanitarian". This thesis is rather based on an understanding that the flexibility inherent in many parts of IHL allows interpretations that accommodate to a great extent feminist concern and its three basic contributions as presented above. Therefore, many of the aims of the feminist critiques, it is here submitted, can be approached by a humane treatment-oriented ${ }^{185}$ reinterpretation of the current rules of IHL rather than a complete overhaul of the regime that ultimately undermines its validity.

Starting from these premises, the following chapters will try to put some of the basic femalerelevant rules of IHL under question and to investigate whether they can be interpreted in a way that accommodates insights from feminist critiques. This will be pursued using recent cases of conflict-related violence against women both in bello and post bellum. Chapters 2 and 3 will apply a gender-sensitive approach on the relevant rules of the Geneva Conventions. Chapters 4 and 5 will use insights from the theories discussed above to interpret from a gender

\footnotetext{
${ }^{184}$ General Recommendation No. 35 on gender-based violence against women, updating general recommendation No. 19, CEDAW, 14th July 2017, para. 14.

185 The idea that the principle of humane treatment "is in truth the leitmotiv of the four Geneva Conventions" was expressed by Jean Pictet in 1958. Pictet, Jean S. (ed.), Commentary on the Fourth Geneva Convention, ICRC, 1958, p. 204.
} 
perspective the system of reparations available to women who have suffered serious violations of IHL rules. 


\section{WOMEN IN SITUATIONS OF ARMED CONFLICT UNDER IHL TREATIES}

This Chapter analyzes the set of norms of international humanitarian law, which deals with the situation of women in armed conflicts. It essentially addresses the following questions: does international humanitarian law (IHL) deal with conflict-related violence against women, and how is conflict-related violence against women eventually conceptualized in this body of law? In order to answer these questions, the first Section (2.1.) is devoted to delimitating the scope of the analysis, introducing the methodological approach applied to study the object of the research. The Chapter continues with an examination of the IHL provisions of relevance to women, with special focus on the principle of non-discrimination (2.2) and the system of special protection for women (2.3). The final Section (2.4.) is devoted to the set of IHL norms addressing all civilians but dealing with abuses particularly affecting women.

\subsection{Aims, scope, and methodology of the analysis}

The analysis of the legal rules that have women in conflict as their explicit or implicit subject is important on multiple grounds. First, from a doctrinal/descriptive perspective, it sheds light to States' obligations with regard to the protection of women during the conflict. Second, from a critical perspective, the analysis of the applicable law shows potential gaps and limits, inviting considerations of how to address them. A comprehensive understanding of the norms is thus essential for assessing the representation of women's experience in warfare encapsulated in international humanitarian law. The issue of how women are represented and constructed in international humanitarian law is directly linked to the question of whether the Geneva Conventions of 1949 incorporate a gendered-sensitive approach. Indeed, if these norms are proven to be based on misleading assumptions of women, they could lead to an insufficient consideration of the female experience of war and ultimately to an inadequate protection of women during wartime.

With regard to the scope of this Chapter, two remarks should be premised already at the beginning. First, the examination will include both the general and the specific protection afforded to women under international humanitarian law. This means that the analysis also covers some provisions that do not specifically mention women but are nevertheless particularly relevant for women. Second, the examination will focus on international 
humanitarian law, but it will also cover certain rules from other bodies of international law that protect women in situations of armed conflict, such as human rights law, international criminal law, and refugee law.

The most relevant treaty rules are included in the Hague Regulations on Land Warfare of 1899 and 1907, the 1929 Geneva Convention relative to the Treatment of Prisoners of War, the four 1949 Geneva Conventions, and their Additional Protocols of 1977 and 2005. In order to give an as full as possible overview of the protection of women under the Geneva Conventions, the articles' examination will include a discussion of the historical origins of the norm and its contemporary scope of application. To that end, the International Committee of the Red Cross' (ICRC) Commentaries, both the first ${ }^{186}$ and the updated ${ }^{187}$ version, offer an essential source of authoritative interpretation of the provisions. A brief overview of the history of these provisions, mainly using les travaux préparatoires of the Geneva Conventions, will be also helpful in the understanding of the content of the norms. ${ }^{188}$ References to customary international law, especially as identified by the ICRC in its 2005 study $^{189}$, and to the jurisprudence of the international criminal courts offer the current status of international

\footnotetext{
186 Pictet, Jean S. (ed.), The Geneva Conventions of 12 August 1949, Commentary, Volume I, First Geneva Convention for the Amelioration of the Condition of the Wounded and Sick in Armed Forces in the Field, Geneva, 1952, [therein: Commentary, Vol. I]; The Geneva Conventions of 12 August 1949, Commentary, Volume II, Second Geneva Convention for the Amelioration of the Condition of Wounded, Sick and Shipwrecked Members of Armed Forces at Sea, Geneva, 1960, [Commentary, Vol. II]; The Geneva Conventions of 12 August 1949, Commentary, Volume III, Third Geneva Convention relative to the Treatment of Prisoners of War, Geneva, 1960, [Commentary, Vol. III]; The Geneva Conventions of 12 August 1949, Commentary, Volume IV, Fourth Geneva Convention Relative to the Treatment of Civilian Persons in Time of War, Geneva, 1958, [Commentary, Vol. IV]. 187 The ICRC Commentaries to the first three 1949 Geneva Conventions have been recently updated. Dörmann, Knut, Lijnzaad, Liesbeth, Sassòli, Marco, and Spoerri, Philip (eds.), Commentary on the First Geneva Convention: Convention (I) for the Amelioration of the Condition of the Wounded and Sick in Armed Forces in the Field, Cambridge University Press, Cambridge, 2016 [therein: Commentary, Vol. I, 2016]; Commentary on the Second Geneva Convention: Convention (II) for the Amelioration of the Condition of Wounded, Sick and Shipwrecked Members of Armed Forces at Sea, Cambridge University Press, Cambridge, 2017, [Commentary, Vol. II, 2017]; Commentary on the Third Geneva Convention: Convention (III) relative to the Treatment of Prisoners of War. Geneva, 12 August 1949, Cambridge University Press, Cambridge, 2020, [Commentary, Vol. III, 2020].

188 Article 32 of the Vienna Convention on the Law of Treaties considers the travaux préparatoires a supplementary means of interpretation to which recourse is possible for confirming a meaning deriving from the use of general rules of interpretation; or in cases in which general rules may not determine the meaning of an ambiguous or obscure phrase, or they would lead to manifestly absurd or unreasonable meanings.

189 The study on customary international humanitarian law, conducted by the International Committee of the Red Cross (ICRC), began in 1996. The first Part of the study identifies 161 rules of customary IHL that constitute the common core of humanitarian law binding on all parties to all armed conflicts; the second Part contains the underlying practice for the rules listed in Part land it is updated on a regular basis. The full text, originally published by Cambridge University Press, is available at the official ICRC website: https://ihldatabases.icrc.org/customary-ihl/eng/docs/home [last visited: 21 February 2021]. Henckaerts, Jean-Marie and Doswald-Beck, Louise (eds.), Customary International Humanitarian Law: Volume 1, Rules/Volume 2, Practice, Cambridge University Press, 2005. [Therein: ICRC, Customary International Humanitarian Law, Vol. 1/Vol. 2].
} 
humanitarian law. The jurisprudence of the ad hoc tribunals and the International Criminal Court and the ICRC database of customary IHL is essential in order to evaluate the current validity of feminist critics and, in general, to assess the adaptability and the adequacy of the system of norms in responding to women experience in warfare.

When it comes to the systematization of this legal material, scholars usually study the fortytwo norms of IHL related to women ${ }^{190}$ by dividing them in three main groups: first, general non-discrimination provisions; second, those dealing with the specific protection for civilian women against sexual violence; and, third, the specific rules on the protection of pregnant women and mothers.

This categorization will be partially used also here to systematize the basic different situations which women may face in war. In particular, the analysis will follow this scheme:

- Norms related to the principle of non-discrimination against women (Section 2.2.);

- The special treatment of women in the warfare, concerning two specific sets of norms (Section 2.3.):

a. the regime of particular care for pregnant women and mothers of young children;

b. the system of differentiated treatment for interned women and women prisoners of war.

- Rules not explicitly directed to women but dealing with abuses particularly affecting women (Section 2.4.).

This systematization corresponds to the core legal aspects associated with the female experience of war and permits to start from a study of the most general norms and principles and continue to the more specific rules concerning women. The regime of specific protection for civilian women against sexual violence will be the object of a specific investigation in the following Chapter 3.

In terms of methodology, the starting point is a doctrinal legal analysis, addressing the scope and gaps of the relevant treaty frameworks. This will offer the basis to frame the contemporary application of IHL to women. Illustrative examples are particularly important in contextualizing the main contested IHL norms. To put it differently, the examination of

\footnotetext{
190 This is the number of IHL norms specifically mentioning women in the 1949 Geneva Conventions and the
} 1977 Additional Protocols. 
concrete cases makes it possible to see the importance of the relevant provisions for the current forms of violence that women experience in conflict settings.

The analysis of the relevant norms has also a critical dimension, reflecting on the main criticisms against the adequacy of the women-related provisions of IHL, with special focus on arguments expressed by scholars with a feminist background. In particular, starting from the basic feminist postulate according to which the international legal framework cannot be gender neutral, because it was conceived in an era in which many forms of discrimination were not even perceived as such, ${ }^{191}$ a basic hypothesis of the following is whether it is possible to aspire to a gender-sensitive reading of IHL through a reinterpretation of its provisions. The challenge of this study will be to bring together the feminist critics to IHL regime and a legal examination of the body of norms which regulate the women's experience of war.

An analysis of the main developments of IHL - especially through the jurisprudence of the $a d$ hoc tribunals and the International Criminal Court and the ICRC database of customary IHL is essential in order to evaluate the current validity of these critics and, in general, to assess the adaptability and the adequacy of the system of norms in responding to women experience in warfare.

\subsection{The principle of non-discrimination against women}

This section introduces the principle of non-discrimination as manifested in general provisions of the IHL regime (2.2.1). ${ }^{192}$ Although the list of prohibited criteria for discrimination is not exhausting and it has changed over time, ${ }^{193}$ the explicit prohibition of any discrimination based on sex in each of the Geneva Conventions and the Additional Protocols demonstrates the awareness about the different and discriminatory treatment to which women and men can be affected in armed conflict settings. Here, particular attention is given to the principle of non-

\footnotetext{
${ }^{191}$ Charlesworth, Hilary, "Feminist Methods in International Law", American Journal of International Law, Vol. 93, No. 2, (1999) 379-394.

192 The principle of non-discrimination, as a means for achieving equality, has been at the foundation of the human rights law regime. For an analysis of the human right law framework on discrimination and its understanding by the regional human rights courts, see Sjöholm, Maria, Gender-sensitive Norm Interpretation by Regional Human Rights Law Systems, Brill, 2018, pp. 191-227.

${ }^{193}$ For example, the list of Article 12 of GC I provides the following anti-discriminatory criteria: "sex, race, nationality, religion, political opinions, or any other similar criteria"; while Article 75 of the AP I: "race, colour, sex, language, religion or belief, political or other opinion, national or social origin, wealth, birth or other status, or on any other similar criteria".
} 
discrimination and the law of occupation (2.2.2). The analysis will then turn to the case of indirect discrimination, which is of particular relevance for women (2.2.3). The issue will be discussed with reference to the specific regime of the law of occupation, with the concrete example of the status of women in the occupied part of Cyprus, the Turkish Republic of Northern Cyprus (TRNC).

\subsubsection{General IHL rules on non-discrimination}

The Geneva Conventions of $1949^{194}$ and their Additional Protocols of $1977^{195}$ prohibit any discrimination on the basis of sex. In other words, no distinction, exclusion or restriction can be made on the basis of sex under the IHL regime, because it would impair or nullify the recognition, enjoyment or exercise of a certain status or protection to women or men. These general non-discrimination provisions cover all categories of persons involved or affected by the warfare. Thus, all women can benefit from the non-discriminatory clause.

Article 12 of the GC I and II guarantees respect and protection in all circumstances for, respectively, the wounded and sick and the members of the armed forces at sea who are wounded, sick or shipwrecked. They shall be "treated humanely" and "without any adverse distinction founded on sex". The principle of equality of treatment must be also respected with regard to women who are prisoners of war, both during their detention ${ }^{196}$ and in the execution of penalties ${ }^{197}$. The Fourth Geneva Convention provides for the prohibition of discrimination against women belonging to protected persons, ${ }^{198}$ namely all persons of foreign nationality and persons without any nationality, who find themselves in the power of the enemy in own or occupied territory. Furthermore, Article 13 states that the set of norms providing for a general

\footnotetext{
${ }^{194}$ GCs, common Art 3; GC I, Art. 12; GC II, Art 12; GC III, Arts 16 and 88(2); GC IV, Arts 13 and 27(3).

195 AP I, Art 75; AP II, Art 4.

196 GC III, Article 16: "Taking into consideration the provisions of the present Convention relating to rank and sex, and subject to any privileged treatment which may be accorded to them by reason of their state of health, age or professional qualifications, all prisoners of war shall be treated alike by the Detaining Power, without any adverse distinction based on race, nationality, religious belief or political opinions, or any other distinction founded on similar criteria".

197 GC III, Article 88(2): “A woman prisoner of war shall not be awarded or sentenced to a punishment more severe, or treated whilst undergoing punishment more severely, than a woman member of the armed forces of the Detaining Power dealt with for a similar offence.

In no case may a woman prisoner of war be awarded or sentenced to a punishment more severe, or treated whilst undergoing punishment more severely, than a male member of the armed forces of the Detaining Power dealt with for a similar offence".

198 GC IV, Article 27(3): "Without prejudice to the provisions relating to their state of health, age and sex, all protected persons shall be treated with the same consideration by the Party to the conflict in whose power they are, without any adverse distinction based, in particular, on race, religion or political opinion".
} 
protection against some consequences of war covers, "without any adverse distinction", the whole population, thus also female members of the civilian population belonging to the belligerents' party. ${ }^{199}$ Article 9(1) of the Additional Protocol I of 1977 and Article 2(1) of the Additional Protocol II of 1977 specify that the provisions of the Protocols shall apply "without any adverse distinction founded on", among others, sex. Article 75 of the Additional Protocol I of 1977 - the so called "summery of the law" 200 - extends some fundamental guarantees, "without any adverse distinction" based on, inter alia, sex, also in cases in which the prisonerof-war or protected person status under the Fourth Geneva Convention are denied. ${ }^{201}$ Thus, in IACs, the prohibition of discrimination applies, for example, to women who are mercenaries and to women civilians not covered by the status of protected person. Finally, common Article 3 of the four Geneva Conventions obliges the Parties of a non-international armed conflict to treat in all circumstances "persons taking no active part in the hostilities" humanely, without any adverse discrimination. ${ }^{202}$ The system of equality provided for NIACs by common Article 3 is basically reproduced in Article 4(1) of the Additional Protocol II of $1977 .{ }^{203}$

\footnotetext{
${ }^{199}$ GC IV, Article 13: "The provisions of Part II cover the whole of the populations of the countries in conflict, without any adverse distinction based, in particular, on race, nationality, religion or political opinion, and are intended to alleviate the sufferings caused by war". It must be underlined that the list of adverse distinction is only declarative and not limitative, so that the list has a non-exhaustive nature.

${ }^{200}$ Pilloud, Claude, Sandoz, Yves, Swinarski, Christophe, and Zimmermann, Bruno (eds), Commentary on the Additional Protocols: of 8 June 1977 to the Geneva Conventions of 12 August 1949, Martinus Nijhoff Publishers, Geneva, 1987, para. 3007.

${ }^{201}$ AP I, Article 75(1): "In so far as they are affected by a situation referred to in Article 1 of this Protocol, persons who are in the power of a Party to the conflict and who do not benefit from more favourable treatment under the Conventions or under this Protocol shall be treated humanely in all circumstances and shall enjoy, as a minimum, the protection provided by this Article without any adverse distinction based upon race, colour, sex, language, religion or belief, political or other opinion, national or social origin, wealth, birth or other status, or on any other similar criteria. Each Party shall respect the person, honour, convictions and religious practices of all such persons".

${ }^{202}$ GCs, common Article 3: "In the case of armed conflict not of an international character occurring in the territory of one of the High Contracting Parties, each Party to the conflict shall be bound to apply, as a minimum, the following provisions:

(1) Persons taking no active part in the hostilities, including members of armed forces who have laid down their arms and those placed ' hors de combat ' by sickness, wounds, detention, or any other cause, shall in all circumstances be treated humanely, without any adverse distinction founded on race, colour, religion or faith, sex, birth or wealth, or any other similar criteria".

${ }^{203}$ AP II, Article 4(1): "All persons who do not take a direct part or who have ceased to take part in hostilities, whether or not their liberty has been restricted, are entitled to respect for their person, honour and convictions and religious practices. They shall in all circumstances be treated humanely, without any adverse distinction. It is prohibited to order that there shall be no survivors".
} 
The International Committee of the Red Cross (ICRC) has qualified the principle of nondiscrimination as a norm of customary international law applicable in both international and non-international armed conflicts. ${ }^{204}$

The general principle of non-discrimination is generally a subsidiary obligation, in that it is auxiliary to the satisfaction of another primary humanitarian obligation. Examples of the subsidiarity of the non-discrimination requirement can be found in Articles 12 of the I and II GC and Article 16 of the III GC. ${ }^{205}$ In particular, the subsidiarity of the non-discrimination requirement to the principle of humanitarian treatment is well expressed in the ICRC Commentary to common Article 3, which suggests that

[w]hile the legal obligation of humane treatment under common Article 3 is absolute; the ways to achieve such treatment must be adapted to a person's specific needs. Humane treatment accorded to one person is not necessarily sufficient to constitute humane treatment for another person. Therefore, common Article 3 does not prohibit differentiated treatment that is actually necessary in order to achieve humane treatment. ${ }^{206}$

Article 13 of the IV GC is the only provision in which the principle of non-discrimination is considered a primary obligation, because there it works as a rule of interpretation: all provisions of the Part II of the Convention must be interpreted and applied without discrimination.

Is there any gap in these non-discrimination rules? As it has been observed, "these provisions are all located in the Law of Geneva dealing with the victims of armed conflict, and none are found in the rules regulating the actual conduct of hostilities". ${ }^{207}$ One may then ask whether anti-discriminatory clauses should have been also introduced in the conventions governing the conduct of hostilities, namely the Law of the Hague, and whether this gap could specifically affect women in situations of warfare. For instance, one may refer to the law of occupation ${ }^{208}$

\footnotetext{
${ }^{204}$ ICRC, Customary IHL, Rule 88 states: “Adverse distinction in the application of international humanitarian law based on race, colour, sex, language, religion or belief, political or other opinion, national or social origin, wealth, birth or other status, or on any other similar criteria is prohibited".

${ }^{205}$ In articles 12 of the I and II GCs and Article 16 of the III GC, the requirement of non-discrimination if subsidiary to the requirement of, respectively, "be treated humanely and cared" and "be treated alike". Rona, Gabor, and McGuire, Robert J., "The Principle of Non-Discrimination", in Clapham, Andrew, Gaeta, Paola, Sassoli, Marco (eds.), The 1949 GC: A Commentary, Oxford University Press, Oxford, 2015, pp. 191-206.

${ }^{206}$ ICRC, Commentary on the First Geneva Convention: Convention (I) for the Amelioration of the Condition of the Wounded and Sick in Armed Forces in the Field, Cambridge University Press, Cambridge, 2016, Article 3, para. 576.

${ }^{207}$ Gardam, Judith, "The Silences in the Rules", in Clapham, Andrew, and Gaeta, Paola (eds.), The Oxford Handbook of International Armed Conflict, Oxford University Press, Oxford, 2014, p. 38.

208 Article 42 of The Hague Regulations of 1907 defines occupation in the following terms: "Territory is considered occupied when it is actually placed under the authority of the hostile army. The occupation extends only to the territory where such authority has been established and can be exercised." Three elements should coexist for the law of occupation to apply. First, a State effectively have control over the territory of another State. Second, the territorial State has lost effective control over that territory. Third, the inexistence of the territorial
} 
- the branch of IHL which regulates the partial or total occupation of a territory by a hostile army - whose regime is specifically regulated by the Hague Regulations of 1907, the Fourth Geneva Convention of 1949 and Additional Protocol I of 1977. ${ }^{209}$

\subsubsection{The principle of non-discrimination and the law of occupation}

As it has been said, the anti-discriminatory clauses introduced in the Geneva Conventions cover also situations of occupation, as a "subcategory of the rules on civilians in the power of the enemy"210. Thus, civilians who find themselves under the occupation of a hostile army should be treated by the occupying Power without any adverse distinction based, inter alia, on sex. Moreover, the occupying Power has the active duty to abrogate any discriminatory law in force in the occupied territory. ${ }^{211}$ This means that the occupying Power is being given the active role of ascertaining the eventual pre-existence of any discriminatory rule and the power and duty to intervene for the abolition of the discriminatory regime. In this sense, in case of occupation, the role of the occupying Power could be considered instrumental to the effectiveness of the principle of non-discrimination.

A critical question is the scope of this active duty of the occupying Power. In particular, one may ask whether the active duty covers all branches of domestic law such as penal law, civil law, and administrative law. In accordance with Article 43 of the Hague Regulation of 1907, the occupying Power should respect the "law in force" in the occupied territory "unless absolutely prevented". ${ }^{212}$ Beyond that, the Occupying Power is potentially allowed "to legislate in almost all aspects of life in the occupied territory". ${ }^{213}$ The provision is complemented by

\footnotetext{
State's consent on the State's presence in that territory. Ferraro, Tristan (ed.), ICRC Expert Meeting, "Occupation and Other Forms of Administration of Foreign Territory", ICRC 2012, pp. 17-23.

${ }^{209}$ In particular, the law of occupation is contained in Section III of the Hague Regulations of 1907 - Articles 42 to 56 - and Sections I (concerning rules for protected persons both in own and occupied territory), III (related to specific regime for occupied territories) and IV (on civilians internees) of Part III of the IV Geneva Convention. ${ }^{210}$ Sassoli, Marco, International Humanitarian Law Rules, Controversies, and Solutions to Problems Arising in Warfare, Edward Edgar Publishing, Cheltenham, 2019, p. 231.

211 Commentary, Vol. IV, comment to Art. 27(3), p. 207.

212 Article 43, Hague Regulation of 1907. The expression "empêchement absolu" is commonly interpreted as "necessity", following the language of Article 3 of the 1874 Brussels Draft International Declaration on the Laws and Customs of War. For an overview of the origin of Article 43 of the 1907 Hague Convention and an analysis of the provision, see Arai-Takahashi, Yutuka, The Law of Occupation: Continuity and Change of International Humanitarian Law, and Its Interaction with International Human Rights Law, Martinus Nijhoff, Leiden-Boston, 2009, pp. 93-113.

${ }^{213}$ Spoerri, Philip, "The Law of Occupation", in Clapham, Andrew and Gaeta, Paola (eds.), The Oxford Handbook of International Law in Armed Conflict, Oxford University Press, Oxford, 2014, p. 195.
} 
Article 64, IV Geneva Convention. ${ }^{214}$ Indeed, the Commentary to the IV Geneva Convention supports the existence of the occupant's power to legislate in the occupied territory by quoting the first paragraph of Article 64, IV Geneva Convention. After stating the general rule according to which the occupying Power must administrate using the penal law in force in the occupied territory, the provision inserts the possibility of repealing or suspending the penal law rules "in cases where they constitute a threat to its security or an obstacle to the application of the present Convention". ${ }^{215}$ Thus, penal rules which discriminate on the base of sex must be abrogated by the occupied Power, to the extent they present an obstacle to the application of the anti-discrimination principle. As it has been suggested, despite the language of right of the provision ("may be repealed or suspended"), Article 64 should be interpreted as proclaiming a duty over the occupying Power. Indeed, it should be recalled that States parties are bound under Article 1 of the IV Geneva Convention " to respect and to ensure respect" for the Convention "in all circumstances", so also during an occupation. ${ }^{216}$ In addition, it is clear that the contracting party "may not invoke the provisions of its internal law as justification for its failure to perform a treaty". ${ }^{217}$ The occupying Power is bound to this rule with regard to its own country, and "a fortiori to the domestic laws in force in an occupied territory". ${ }^{218}$

According to the ICRC, the reference to the penal legislation contained in Article 64, IV Geneva Convention must be broadly interpreted. Indeed, "the whole of the law" must be considered here as relevant. Thus, on the one hand "there is no reason to infer a contrario that the occupation authorities are not also bound to respect the civil law of the country, or even its constitution", ${ }^{219}$ and, on the other hand, the occupying Power has an active duty to abrogate

\footnotetext{
${ }^{214}$ Gutteridge expressed the idea along with Article 64 is an "amplification and clarification" of Article 43 of the Hague Regulation. Gutteridge, Joyce A.C., "The Geneva Conventions of 1949", British Yearbook of International Law, Vol. 26, (1949) 294-326, p. 324.

${ }^{215}$ Article 64(1) of the IV Geneva Convention reads: "The penal laws of the occupied territory shall remain in force, with the exception that they may be repealed or suspended by the Occupying Power in cases where they constitute a threat to its security or an obstacle to the application of the present Convention. Subject to the latter consideration and to the necessity for ensuring the effective administration of justice, the tribunals of the occupied territory shall continue to function in respect of all offences covered by the said laws".

${ }^{216}$ Dinstein, Yoram, The International Law of Belligerent Occupation, Cambridge University Press, Cambridge, 2019, p. 124.

${ }^{217}$ Vienna Convention on the Law of Treaties, art. 27, May 23, 1969, 1980 U.N.T.S. 332.

${ }^{218}$ Dinstein, Yoram, The International Law of Belligerent Occupation, ...p. 125.

${ }^{219}$ Commentary, Vol. IV, Article 64, p. 335. See also Gasser, Hans-Peter, "Protection of the Civilian Population", in Fleck, Dieter, The Handbook of International Humanitarian Law, Oxford University Press, Oxford, 2008, pp. 286-287. The author states that "although Article 46 mentions only criminal law which remains in force, the entire legal system of the occupied territories is actually meant under this rule. Incidentally, Article 43 Hague Reg speaks unambiguously and without restriction of 'the law in force in the country'. The express reference to criminal law in the IV Geneva Convention can be explained by the fact that, during the World War II, occupying powers
} 
also discriminatory civil law rules in force in the occupied territory. A gender-sensitive interpretation of Article 64, IV Geneva Convention would also support a broad interpretation.

The existence of an active duty of the occupying Power to abrogate any discriminatory civil law rule in force in the occupied territory is particularly relevant for women for a number of reasons. First, women, especially in patriarchal societies, are often absent or almost absent both in the phase of occupation and during the negotiation process, ${ }^{220}$ and they are usually devoted to the private sphere. The consequence is that they are particularly affected by rules governing the private life, namely civil law, family law, and inheritance law. ${ }^{221}$ Second, the law of occupation has been conceived for safeguarding the status quo ante, in that it is designed to be a temporary regime to be applied over a short-term period of time (conservatory principle of the law of occupation). ${ }^{222}$ However, the reality of the contemporary forms of occupation regimes reveals that this system of military control by an external force may protract for years or decades, such as in the cases of Cyprus, Israel-Palestine, Iraq, Afghanistan, Western Sahara, and the Crimea. This means that the law of occupation's principles and rules, usually

interfered in a particularly scandalous manner with the criminal laws of occupied territories. Other areas of law, however, are not thereby excluded".

${ }^{220}$ See Bell, Christine and O'Rourke, Catherine, "Peace Agreements or Pieces of Paper? The Impact of UNSC Resolution 1325 on Peace Processes and Their Agreements", International \& Comparative Law Quarterly, Vol. 59, No. 26, (2010) 941-980, p. 948. The authors studied that the 99\% of peace mediators are men. The situation does not seem much evolved in recent years. As for the 2019 Report of the UN Secretary General, "Women from diverse settings, including Afghanistan, the Central African Republic, Libya, South Sudan, the Sudan and Yemen have faced and continue to face steep obstacles, direct resistance and great personal risks in their efforts to ensure their participation in processes pertaining to the future of their countries, and we must recognize that, too frequently, we fall short of our ambitions. Collectively, the United Nations, Member States, regional organizations and other actors supporting peace processes are not on track to attain sufficient concrete progress in the area of the women and peace and security agenda by 2020. Although the United Nations has ensured, since 2012, that all United Nations mediation teams include women, the participation of women in negotiating delegations has not improved in recent years. In 2018, of six active processes led or co-led by the United Nations, women were included in 14 out of 19 delegations, although the percentage of female delegates remained low".

Women's absence in mediation processes affects the decision-making power of women in post-conflict areas, resulting in a low consideration of women's rights and gender equality in peace agreements:

"Between 1990 and the end of 2018, according to the Peace Agreements database only 353 of 1,789 agreements (19.7 per cent), relating to more than 150 peace processes, included provisions addressing women, girls or gender. In 2018, of 52 agreements across a range of issues included in that database, only 4 ( 7.7 per cent) contained provisions relating to gender, down from 39 per cent in 2015. The data underline that the vast majority of agreements do not explicitly address gender equality or the rights of women". Report of the Secretary General, Women and Peace and Security, UN Doc. S/2019/800, 9 October 2019, paras. 14-15.

${ }^{221}$ In the context of Palestinian people, the Israeli occupation of Sinai, Gaza and the West Bank particularly affects Palestinian women. While recognizing the role of Palestinian women in the struggle for self-determination, Charlesworth and Chinkin underline that women's political participation remains marginal. This is also due to discriminatory legal restrictions on, among others, land-holding, inheritance, and workforce, as well as certain husband rights over his wife. See Charlesworth, Hilary and Chinkin, Christine, The Boundaries of International Law. A feminist analysis, Manchester University Press, Manchester, 2000, pp. 155-162.

${ }^{222}$ In this regard, see Article 43 of the Hague Regulations of 1907 and Article 64 of the IV Geneva Convention, which state as a general rule that the occupying Power has to respect the law in force in the country. 
considered as transitory and peripherical, could become essential for guiding the occupying Power's approach to the administration of the occupied territory, with great repercussions on the civilian's, and particularly women's, life.

\subsubsection{The issue of indirect discrimination}

Under the current interpretation of the IHL, the principle of non-discrimination refers not only to direct discrimination but also to indirect discrimination. According to the ICRC Commentary,

In order to be fully effective, the prohibition of 'any adverse distinction' under common Article 3 must be understood to comprise not only measures that single out certain persons protected under common Article 3 for adverse treatment, but also seemingly neutral measures that have the effect of adversely affecting certain persons. For persons falling within the protective scope of common Article 3, it makes no difference whether they are directly selected for inhumane treatment, or whether their inhumane treatment is the indirect consequence of general policies. When adopting general policies, a Party to a non-international armed conflict will therefore need to take into account the potential consequences of these policies on all persons protected under common Article 3 who are affected by them. ${ }^{223}$

Thus, the prohibition of discrimination under the Geneva Conventions of 1949 and the Additional Protocols of 1977 encompasses both direct and indirect discrimination. This means that IHL prohibits not only rules which differentiate a treatment on the basis of sex, in so reducing or excluding women from the enjoyment of the same treatment as men, but also rules that do not consider the discrimination deriving from the application of a seemingly neutral rule to women and men. In the latter case, an apparently neutral provision has a discriminatory effect when implemented because it does not take into account the pre-existing inequalities between the sexes or the gender roles that influence the female and male behaviors. ${ }^{224}$

As noted above, the occupying Power generally administrates the occupied territory, balancing its security need with the interest of the population to be protected. In this sense, it could be very difficult to imagine the occupying Power as a transformative authority, which assumes the responsibility to revise the eventual discriminatory civil law regime. While such a limited role of the occupying Power may not have great implications in the short term, the situation

\footnotetext{
${ }^{223}$ Commentary, Vol. I, 2016, Article 3, para. 573.

${ }^{224}$ The concepts of direct and indirect discrimination are linked to the concept of "gender-neutral norm", which is a provision drafted in universal terms that perpetuates sex and gender-based discrimination in not considering the influence of gender and a reality made of different power relations between men and women. For a definition of direct and indirect discrimination, see the Glossary \& Thesaurus of the EIGE (European Institute for Gender Equality) official website, https://eige.europa.eu/thesaurus/overview [last visited: 21 February 2021].
} 
can become especially detrimental for women civilians when the occupation protracts over time. As Christine Chinkin puts it,

Women's rights become caught between the politics and ideologies of the occupier and the liberation goals of the occupied - including those of occupied women. The roles of women vis$\grave{a}$-vis their own people in occupation also depend upon the social and political status of women in the occupied territory prior to occupation. ${ }^{225}$

Thus, while it is impossible to make sweeping generalizations on the situation of women in contexts of occupation, it is clear that the fact to be under a regime of occupation constitutes, per se, a potential factor of discrimination for women. In particular, it has been demonstrated that the women's lives can be negatively affected by the under-regulation of the private sphere in contexts of occupation continuing over a long period and occurring in patriarchal societies.

In analyzing the situation of women under the "frozen" occupation of the North of Cyprus by the Turkish army, Nì Aoláin underlines that, on the one hand, “women's non-status in the military has broader effects on their status and power in the civic and political affairs of the Island", ${ }^{226}$ and, on the other hand, "the lack of common legal system across Cyprus and Occupied Territory is a formidable barrier to the resolution of family and women's rights issues and enables a range of gendered abuses". ${ }^{227}$ In particular, many difficulties appear in cases of contentious family, marriage and divorce proceedings concerning parties who live in different zones of the Island, one in the Greek Cypriot part and the other one in the Turkish part. Since judicial acts issued in the Turkish Republic of Northern Cyprus (TRNC) are not binding in the Greek Cypriot-ruled Republic of Cyprus, ${ }^{228}$ the parties of the controversy are not incentivized to comply with the court's decisions. Considering that women are usually the economically and socially weaker part, ${ }^{229}$ the difficulties and, often, the impossibility to enforce courts'

${ }^{225}$ Chinkin, Christine, International Law and New Wars, Cambridge University Press, Cambridge, 2017, p. 371. Chinkin makes some different examples of women civilians under situations of occupation, explaining that in certain circumstances they have a social active role of resistance and/or activism against the occupied Power.

${ }^{226}$ Nì Aoláin, Fionnuala, "Gendering the Law of Occupation: The Case of Cyprus", Minnesota Journal of International Law, Vol. 27, No. 1, (2018) 107-141, p. 122.

227 Ibid. p. 130.

${ }^{228}$ Since the Occupied Northern Territory does not have international legal recognition, any decision issued by a Turkish Cypriot court is not binding nor enforceable outside the occupied territory.

229 The gender equality index published by the Gender Equality Institute in 2017 reveals that, despite many advancements, Cyprus has still much to do in the domain of work due to continue gender segregation. https://eige.europa.eu/publications/gender-equality-index-2017-cyprus [last visited, 11 March 2020]. In order to understand how much gender roles are rooted in the patriarchal Cypriot society and how gender stereotypes still influence the legal regime in the Republic of Cyprus, one can refer to the Constitution of the Republic of Cyprus, which reads in Article 2, paragraph 7: (a) a married woman shall belong to the Community to which her husband belongs. (b) a male or female child under the age of twenty-one who is not married shall belong to the Community to which his or her father belongs, or, if the father is unknown and he or she has not been adopted, to the Community to which his or her mother belongs. The patriarchal logic embedded in the Article seems to have been 
decisions have generally even more negative repercussions on women, who are left with little or no access to the financial resources of marriage, including property. ${ }^{230}$

The women's situation in Cyprus offers a good example of a form of indirect discrimination and how it can inform the interpretation of positive law. The civil and family law regime in force in Cyprus became discriminatory when applied by the occupying Power, in this case Turkey, because it does not consider that the social and economic weaker position of women in that society is exacerbated under the regime of prolonged occupation.

As noted above, the principle of non-discrimination also covers indirect discrimination. It has been also explained that the non-discrimination principle applies with regard to penal provisions as well as to civil provisions. Following this interpretation, any discrimination against women deriving from the implementation of civil and family norms in force in the occupied territory would potentially fall within the scope of the active duty of the occupying Power. However, if a conservative principle of the law of occupation is followed, according to which the occupying Power must govern the occupied territory maintaining the status quo ante, it could be difficult to conceive an active duty of the occupying Power to abolish non-openly discriminatory civil law provisions, such as those described before. Therefore, a gendersensitive interpretation would support the broader view rather than the second one. Indeed, in

overcome by the subsequent developments of the family law regime. For an overview of the main sources of family law and a description of the historical developments of the family law regime in the Republic of Cyprus, Plevri, Anna, "Cyprus", in Ruggeri, Lucia, Kunda, Ivana, and Winkler, Sandra (eds.), Family Property and Succession in EU Member States National Reports on the Collected Data, 2019, pp. 94-97, available at https://www.euro-family.eu/documenti/news/psefs_e book compressed.pdf [last visited, 03 April 2020]; and Hatzimihail, Nikitas E., "Reconstructing Mixity: Sources of Law and Legal Method in Cyprus", in Palmer, Vernon Valentine, Mattar, Mohamed Y. (eds.), Mixed Legal Systems, East and West, Routledge, New York and London, 2016, pp. 91 ss. Nevertheless, the recent case law of the ECtHR demonstrates that gender equality between women and men has not been achieved yes in the Republic of Cyprus. In particular, one may refer to the case Vrountou v. Cyprus, in which the applicant complained the discriminatory treatment on the basis of sex in the dispersal of housing assistance between the children of displaced men and those of displaced women. In its judgement, the ECtHR observed that "the principal justification the Government have advanced for the difference in treatment is the socio-economic differences which were said to exist in Cyprus in 1974, notably that men were the traditional breadwinners at that time [...]. However, this is precisely the kind of reference to 'traditions, general assumptions or prevailing social attitudes' which provides insufficient justification for a difference in treatment on grounds of sex because it derives entirely from the man's primordial role and woman's secondary role in the family". ECtHR, Case no. 33631/06, 2016, para. 76. Then, the Court underlined the impressive reluctance of Cyprus in changing its discriminatory legal regime stating that "it is particularly striking that the scheme continued on the basis of this difference in treatment until 2013, nearly forty years after it was first introduced. The fact the scheme persisted for so long, and yet continued to be based solely on traditional family roles as understood in 1974, means that the State must be taken to have exceeded any margin of appreciation it enjoyed in this field. Very weighty reasons would have been required to justify such a long-lasting difference in treatment. None have been shown to exist. There is accordingly no objective and reasonable justification for this difference in treatment" (para. 80).

${ }^{230}$ Nì Aoláin, Fionnuala, “Gendering the Law of Occupation”...p. 135. 
interpreting the active duty of the occupying Power to abrogate discriminatory provisions of the occupied territory's legal regime, scholars usually refer to directly discriminatory provisions in apartheid regimes or racial legislations. ${ }^{231}$

Even if once accepts that the occupying Power is not entitled to legislate as a territorial sovereign over the population of the occupied territory, ${ }^{232}$ the legislative powers of the occupant may be assessed differently in case of long-term occupation. As Sassoli indicates,

[s] uggestions to adopt special rules for long-term or transformative occupations are unrealistic because States would never accept such rules and they would lead to never-ending classification disputes. Nevertheless, an occupation continuing over a long period of time impacts the way an occupying power's duties and obligations under IHL are interpreted. ${ }^{233}$

This author suggests that the longer the occupation lasts, the more duties and obligations the occupying Power has under IHL. The statement can have an impact on the distinction between what the occupying Power may or must do with regard to the existing legislation which is inconsistent with IHL, and, particularly, with the principle of non-discrimination. Following this line of thinking, at least in long-term occupations, thus, the occupying Power is required to abrogate not just the openly discriminatory penal and civil law provisions, but also existing civil law rules which indirectly discriminate women.

The situation of Northern Cyprus can offer other reflections with regard to the condition of women under an occupation regime and the forms of discrimination to which they can be subject. The fact that TRNC is a self-declared State, recognized as an independent State only by Turkey, has particular repercussions on women's life. In particular, the international nonrecognition of the TRNC affects the recognition of validity of the judicial and administrative acts of the entity in question insofar as they are produced by an unrecognized State. Indeed, some States assume the position along with the judiciary must be in line with the executive power's exercise of non-recognition. This means that also the acts of marriages, divorces and deaths registered by the TRNC authorities could be considered invalid by third countries.

This issue emerged in Emin v. Yeldag (2002) 1 F.L.R. 956. ${ }^{234}$ The case concerned a Turkish Cypriot woman who asked an English court for the recognition of her divorce, issued by a

\footnotetext{
${ }^{231}$ Fleck, Dieter, The Handbook of International Humanitarian Law...p. 287.

232 Pellet, Alain, "The Destruction of Troy Will Not Take Place", in Playfair, Emma (ed.), International Law and the Administration of Occupied Territories, Clarendon Press, Oxford, 1992, p. 201.

233 Sassoli, Marco, International Humanitarian Law Rules, ...pp. 324-325.

234 The decision of the case Emin v. Yeldag (2002) 1 F.L.R. 956 is available at: http://www.uniset.ca/microstates/20021FLR956.htm [last visited, 4 April 2020].
} 
TRNC court. The applicant was especially requesting the leave to apply for financial relief. The judge of the Family Division departed from the previous English law non-exceptions approach and, for the first time, recognized the validity of the judicial act of divorce stemmed from an entity non-recognized as State by the United Kingdom. The case created a precedent in the English law, in that it recognized the applicability of the exception to the general rule of invalidity of acts of unrecognized States to matters of divorces and marriages. ${ }^{235}$ The case offers an example of the obstacles that Turkish-Cypriot citizens face, obstacles that are particularly relevant for women because of their abovementioned specific economic and social vulnerability in the Northern Cypriot society. Considering that Turkish-Cypriot women are usually economically dependent on their husbands, not every woman can afford a judicial proceeding for the recognition of acts of divorce. In addition, the recognition of an act of divorce by a third State has, in the majority of cases, greater impact for a Turkish-Cypriot woman than for her former husband, because the woman usually needs her former husband's economic support or the financial reliefs that a single woman can eventually ask for.

In this case, the source of the discrimination against women is not the application of any provision of the TRNC's legal regime per se. Rather, the discriminatory treatment results as a consequence of the overall legal status of the northern part of Cyprus under international law. The Turkish political choice not to formally proclaim itself as the Northern Cyprus' occupant and to support, against international law, the creation of the professed State of the TRNC that remains unrecognized has concrete repercussions on women's lives. Despite a developing international approach aiming at the acknowledgment of the effects of acts issued by unrecognized entities, ${ }^{236}$ the case mentioned above shows that it is still potentially possible for

\footnotetext{
${ }^{235}$ Ronen, Yael, "Recognition of divorce without recognition of statehood", Cambridge Law Journal, Vol. 63, No. 2, (2004) 268-271.

${ }^{236}$ This approach was firstly expressed by the Supreme Court of the United States in the well-known case Texas v. White, 72 U.S., (7 Wall) 700, 733, 1878, p. 240. Despite the illegality and the unrecognition of the Confederate States established during the Civil War, the Supreme Court stated that "acts necessary to peace and good order among citizens, such, for example, as acts sanctioning and protecting marriage and domestic relations, governing the course of descends, regulating the conveyance and transfer of property real and personal, and providing remedies for injuries to person and estate and other similar acts which would be valid if emanating from a lawful government, must be regarded in general as valid when proceeding from an actual, though unlawful government". The International Court of Justice (ICJ) endorsed this position in its famous Advisory Opinion in the Namibia case regarding the effects and recognition of acts issued by the illegal South African administration in Namibia. Despite the declaration of illegality under international law of the South African occupation in Namibia, the Court stated that "while official acts performed by [South Africa with respect to Namibia] are illegal and invalid, this invalidity cannot be extended to those acts such as, for instance, the registration of birth, death and marriages, the effects of which can be ignored only to the detriment of the inhabitants of the Territory". Advisory Opinion on Legal Consequences for States of the Continued Presence of South Africa in Namibia (South West Africa), Notwithstanding Security Council Resolution 276 (1970) [1971] I.C.J. Reports 16, para. 125. The ECtHR followed and developed the legal reasoning of the ICJ in its Cyprus v. Turkey judgement of 2001. The Court's
} 
States to consider invalid acts of marriage and divorce deriving from an entity non-recognized as a State, such as TRNC.

To conclude, it is here suggested that different forms of discrimination affect women in situations of prolonged belligerent occupation. The aforementioned examples on the application of family law are only one symptom of how a conflict enters the domestic sphere. They represent one of the challenges that the law of occupation and, in general, IHL face with respect to circumstances which were probably not conceived during the writing of the norms.

While much has been said on the extent of the occupant's discretional power to repeal or suspend existing legislation and the legitimacy of the acts which are the products of the exercise of this power, ${ }^{237}$ the nature of the active duty of the occupant to change discriminatory provisions remains insufficiently explored and must be read also in light of the specific effects it has on women, especially in situations of prolonged belligerent occupation. As it has been demonstrated above, a broad interpretation of the principle of non-discrimination can support a broader legislative power in the hands of the occupant and in favor of the occupied Territory's population. Indeed, it is here argued that the occupying Power is not only entitled to revise the local laws in accordance with the changes of the social needs, ${ }^{238}$ but it is also required to

statement shows an increasing concern for human rights of individuals: "In situations similar to those arising in the present case, the obligation to disregard acts of de facto entities is far from absolute. Life goes on in the territory concerned for its inhabitants. That life must be made tolerable and be protected by the de facto authorities, including their courts; and, in the very interest of the inhabitants, the acts of these authorities related thereto cannot be simply ignored by third States or by international institutions, especially courts, including this one. To hold otherwise would amount to stripping the inhabitants of the territory of all their rights whenever they are discussed in an international context, which would amount to depriving them even of the minimum standard of rights to which they are entitled. [...] For the Court, the conclusion to be drawn is that it cannot simply disregard the judicial organs set up by the "TRNC" in so far as the relationships at issue in the present case are concerned. It is in the very interest of the inhabitants of the "TRNC", including Greek Cypriots, to be able to seek the protection of such organs; and if the "TRNC" authorities had not established them, this could rightly be considered to run counter to the Convention. Accordingly, the inhabitants of the territory may be required to exhaust these remedies, unless their inexistence or ineffectiveness can be proved - a point to be examined on a case-by-case basis.

For an overview of the current national and international "nuanced" attitude to the recognition of occupation measures by third countries, with a specific focus of the emerging sensibility on the legitimate expectations of individuals living in the occupied territory, see Benvenisti, Eyal, The International Law of Occupation, Oxford University Press, Oxford, 2012, pp. 299-317.

237 See Dinstein, Yoram, "Legislation Under Article 43 of the Hague Regulations: Belligerent Occupation and Peacebuilding", Harvard University, Occasional Papers Series, No. 1, (2004), pp. 8-10. The author suggests a litmus test to analyze the legitimacy of the welfare measures taken by the occupant Power. "I believe [...] that the litmus test for distinguishing between legitimate and illegitimate concern for the welfare of the civilian population - under Article 43 - should hinge on whether the Occupying Power shows similar concern for the welfare of its own population. Differently put, if the Occupying Power enacts a law - say, against cruelty to animals in the occupied territory - the crux of the issue is whether a parallel (not necessarily identical) law exists back home. If the answer is negative, the ostensible concern for the welfare of the civilian population deserves being disbelieved".

${ }^{238}$ In this sense, Takahashi underlines that the system of duties and powers of the occupying Power has been enlarged by the GCIV in comparison to the regime of the Hague Regulations. "The GCIV requires the occupying 
promote a non-discriminatory legislative regime. The occupant must prohibit any kind of direct and indirect discrimination against women in its Constitution, with a language that clearly contains specific norms on gender equality and provides equal rights and opportunities for men and women. It must also take all appropriate legislative measures to ensure that both direct and indirect discrimination are fought on issues concerning, for example, maternity, parental leave and marital status.

This broad interpretation of the principle of non-discrimination, according to which the occupant State is requested to take positive actions to guarantee substantial equality in the occupied territory, seems also in line with the trend of a "righting of the law of occupation", to the extent that human right norms, and in particular women's rights norms, should not only apply in occupied territories, but also be used as "the standard for judging the actions of occupying powers". ${ }^{239}$ The ICJ, in its 2004 advisory opinion on the Wall in the Occupied Palestinian Territory, seems to upheld this approach in that it considered the relevant human rights treaties binding and applicable under the Israeli occupiers' regime. ${ }^{240}$ The Court did not give any explanation on the possible relationship between the IHL regime, in particular occupation law, and international human rights law. However, one may argue that this reference to human rights obligations would reinforce the argument of a broad interpretation of the principle of non-discrimination, according with the wide scope of the principle under international human rights treaties.

The principle of non-discrimination seems, ultimately, a valuable legal means to guarantee sufficient flexibility to the law of occupation and, in general, to the IHL regime. It provides answers to some of the legal challenges deriving from contemporary occupations, in particular

power to assume the role of regulator of socio-economic issues and provider of services to meet need of local population. The duties on the occupant are not merely of negative nature, but also of positive nature encompassing the duty to prevent and protect the inhuman treatment". Arai-Takahashi, Yutuka, The Law of Occupation...p. 116. ${ }^{239}$ Gross, Aeyal, The Writing on the Wall: Rethinking the International Law of Occupation, Cambridge University Press, Cambridge, 2017, p. 341. The term "righting" was borrowed by the author from Karen Knop and used to described the current "convergence" process of IHRL and IHL in the law of occupation. On the broad support to the application of the IHRL regime to the law of occupation, see also, among others, Tristan Ferraro, "The Law of Occupation and Human Rights Law: Some Selected Issues”, in Kolb, Robert and Gaggioli, Gloria (eds.), Research Handbook on Human Rights and Humanitarian Law, Edward Elgar, Cheltenham, 2013, 279.

240 The Court would observe that, while the jurisdiction of States is primarily territorial, it may sometimes be exercised outside the national territory. Considering the object and purpose of the International Covenant on Civil and Political Rights, it would seem natural that, even when such is the case, States parties to the Covenant should be bound to comply with its provisions.

ICJ, Legal Consequences of the Construction of a Wall in the Occupied Palestinian Territory, Advisory Opinion, 2004 ICJ Reports 136, 9 July 2004, para. 109. At para. 112, the Court also recognizes the applicability of the International Covenant on Economic, Social and Cultural Rights to the Occupied Palestinian Territory (OTP). 
it can assure a humanitarian response to practical problems women face in long-terms occupations. This is also in line with the fact that IHL prohibits "adverse distinction". This means that it is possible to introduce a different regime on the basis of sex as long as it is more advantageous for the underprivileged group. This regime legitimizes the existence of the set of norms comprised both in the four Geneva Conventions of 1949 and in their Additional Protocols of 1977, which provide for a special treatment for women. These norms are the object of the following analysis.

\subsection{Special treatment of women in the warfare}

The special treatment of women in the warfare is not only consistent with the principle of nondiscrimination, but is also a specification of it. According to the ICRC,

[t]he notion of 'adverse distinction' implies that while discrimination between persons is prohibited, a distinction may be made to give priority to those in most urgent need of care. ${ }^{241}$

In application of this principle, the States parties to the Geneva Conventions of 1949 violate the principle of non-discrimination not only when treating persons differently on the base of sex, but also when they fail to treat differently women in those circumstances when they face specific disadvantages because of their sex. The "tension" 242 between the rules prohibiting any adverse distinction based on sex and the regime of special protection for women is thus addressed by the assumption that, under certain conditions and especially during the warfare, women are more vulnerable than men, and for this reason they need special respect and protection. In this sense, the regime of specific protection for women aims at going beyond formal equality towards promoting substantial equality.

The reasons adduced to justify the special treatment of women are based on objective biological differences between women and men, such as the female experience of pregnancy, and (alleged) psychological and physical disparities between the sexes, which could justify, for example, the special protection for women against sexual violence. While the first category of reasons are objective vulnerabilities, grounded on undeniable physiological needs, the second category appears more relative and sometimes less justifiable. On this basis, it has been argued

\footnotetext{
${ }^{241}$ ICRC, Customary International Humanitarian Law, Vol. 1, Chapter 32, Section B, p. 299, online version available at: https://ihl-databases.icrc.org/customary-ihl/eng/docs/v1 rul rule88 [last visited, 07 May 2020].

242 Sassoli, Marco, International Humanitarian Law Rules, ...p. 281.
} 
that IHL rules, granting special protection to women on the basis on a supposed generic psychophysical weakness, may indeed reinforce a certain stereotype of women as defenseless and always in need of protection. ${ }^{243}$

The system of rules awarding special protection to women can be divided into two categories. First, there are general rules, requiring that women must be treated with "all consideration due to their sex" (2.3.1). Second, there are specific groups of provisions granting a particular legal status to pregnant women and mothers of young children, and providing for a differentiated treatment for interned women and women prisoners of war (2.3.2). The third category of norms specifically dealing with women, namely the special regime of protection for civilian women against sexual violence, requires special attention due to its importance and will be examined in the following Chapter.

\subsubsection{General rules protecting women in the warfare}

The regime of special protection for women in the warfare is established by general provisions contained in each of the four Geneva Conventions. ${ }^{244}$ These provisions address women in general, regardless of their specific condition or situation using expressions such as "regard" or "special respect" or "consideration due to women on account to their sex". Article 12, paragraph 4 of the First Geneva Convention, for example, referring to women who are wounded or sick members of the armed forces, states that "[w]omen shall be treated with all consideration due to their sex". The same protection is afforded to female wounded, sick or shipwrecked members of the armed forces at sea, ${ }^{245}$ women prisoners of war, ${ }^{246}$ and women civilians. ${ }^{247}$ Women are "the object of special respect", along with the Additional Protocol I. ${ }^{248}$ As for the general principle of non-discrimination, the special protection for women is extended to NIACs through common Article 3.

The special "regard" due to women is not defined. However, in identifying the elements to consider for the application of the special provisions for women in detention, the ICRC

\footnotetext{
${ }^{243}$ In this sense, see for example, Gardam, Judith, "The silences of the rules", in Ní Aoláin, Fionnuala, Cahn, Naomi, Haynes, Dina Francesca, Valji, Nahla (eds.), The Oxford Handbook of Gender and Conflict, Oxford University Press, Oxford, 2018, p. 40.

${ }^{244}$ GC I, Article 12(4); GC II, Article 12(4); GC III, Article 14(2); GC IV, Article 27(2).

245 GC II, Article 12(4).

${ }^{246}$ GC III, Article 14(2).

${ }^{247}$ GC IV, Article 27(2).

${ }^{248}$ AP I, Article 76(1).
} 
Commentary lists the following points: (a) weakness; (b) honour and modesty; (c) pregnancy and child-birth. ${ }^{249}$ Here, the original intention of the Parties seems to be the introduction of a protection regime based on old-fashioned assumptions on women as defenseless, in need of protection for the preservation of their modesty, and as child bearers. The 2016 ICRC Commentary to the First Geneva Convention updates this approach, in specifying that "the distinct set of needs of and particular physical and psychological risks facing women, including those arising from social structures, have to be taken into account in order to comply with the obligation in paragraph 4 [Article 12]". ${ }^{250}$ Thus, the protection provided by the Article seems to be very broad, in that it recognizes not only physical and psychological vulnerabilities of women, but also specific weaknesses stemming from "social, economic, cultural, and political structures in a society". 251

These general rules need to be further specified. On their own, the provisions in relation to 'regard', 'consideration', or 'special respect' are "statements of general principle and impose no concrete obligations". ${ }^{252}$ This means that specific provisions are required to specify the precise obligations on the Parties and, consequently, the extent of protection for women. These specific provisions are the object of the following analysis.

2.3.2. The regime of particular care for pregnant women and mothers of young children

IHL acknowledges the exclusive female experience of bearing children through a series of provisions specifically devoted to the protection of pregnant women and mothers of young children. These ruled cover women even if they fall outside the notion of protected persons, when they are in the power of an adverse party, in situations of occupation, and, in general, when they can likely suffer the effects of the hostilities.

IHL assimilates pregnant women or maternity cases to the wounded and sick. The principle is expressed under Article 16, Fourth Geneva Convention, related to the wounded and sick, which provides that "the wounded and sick, as well as the infirm and expectant mothers, must be the

\footnotetext{
${ }^{249}$ Commentary Vol. III, Article 14(2), p. 147.

${ }^{250}$ Commentary, Vol. I, 2016, Article 12, para. 1429.

251 Ibid. para. 1428.

${ }^{252}$ Gardam, Judith, "The silences of the rules”, in Ní Aoláin, Fionnuala, Cahn, Naomi, Haynes, Dina Francesca, Valji, Nahla (eds.), The Oxford Handbook of Gender and Conflict,...p. 38.
} 
object of particular protection and respect". This rule is also contained in Article 8(a), Additional Protocol I. ${ }^{253}$ The association of expectant mothers to the wounded and sick reflects the common element of "neutrality". The assumption is that both categories of persons cannot take part in conflict because of their vulnerable condition, so they cannot be considered enemies. $^{254}$

While the concept of "pregnant women" is very clear, that of "mother having dependent infants" or "mother of young children" is particularly generic. In order to delineate the scope of application of the provisions containing such or similar expressions, it is important to identify the age in which children are considered "dependent" to their mother. Since national rules or customs cannot be decisive here, the ICRC Commentary to the GCs suggests that the age of seven years - already expressed in some Articles of the Geneva Conventions ${ }^{255}-$ is the age under which the provision must be mandatorily applied. Thus, children under the age of seven are always considered dependent to their mothers, and these women can benefit of some specific guarantees. ${ }^{256}$ However, the age of seven must be considered as a minimum. In fact, children often depend on their mother well beyond that age.

Thus, pregnant women and mothers of young children are the beneficiaries of a number of provisions. In particular, IHL provides for priority in medical care, ${ }^{257}$ preferential rescue, ${ }^{258}$ privileged delivery in the consignment of food and essential clothing, ${ }^{259}$ and preferential treatment - under the criterion of treatment as nationals - for non-repatriated pregnant women or mothers of children under seven years old. ${ }^{260}$ They must also be given priority in repatriation, return to the residency or accommodation in a neutral country. ${ }^{261}$ In situations of occupation, the occupying power has the duty to maintain the eventual former preferential regime provided for them. ${ }^{262}$ The Additional Protocols also provide for preferential judicial treatment, stating

\footnotetext{
${ }^{253}$ AP I, Article 8(a): "For the purposes of this Protocol: a) 'wounded' and 'sick' mean persons, whether military or civilian, who, because of trauma, disease or other physical or mental disorder or disability, are in need of medical assistance or care and who refrain from any act of hostility. These terms also cover maternity cases, newborn babies and other persons who may need immediate medical assistance or care, such as the infirm or expectant mothers, and who refrain from any act of hostility".

${ }^{254}$ Commentary, Vol. IV, p. 134.

255 GC IV, Article 38.

${ }^{256}$ GC IV, Articles 14, 132, 76(2)(3).

${ }^{257}$ GC IV, Articles 14, 23(1), 91(2), 127(3). The medical assistance guaranteed by GC IV, Articles 23(1), 91(2) and $127(3)$ deals only with pregnant women.

${ }^{258}$ GC IV, Articles 21, 22(1), 23.

${ }^{259}$ GC IV, Articles 23, 89(5); AP I, Article 70(1).

${ }^{260}$ GC IV, Article 38.

${ }^{261}$ GC IV, Article 132(2).

262 GC IV, Article 50(5).
} 
that judicial cases concerning pregnant women and mothers with dependent children must be considered with "utmost priority", ${ }^{263}$ and prohibiting the condemnation to death penalty for the same categories of women both in IACs ${ }^{264}$ and in NIACs. ${ }^{265}$

Apart from the final provision mentioned above, no supplementary norm for the protection of women can be found in the Additional Protocol II, dealing with NIACs. Nevertheless, there are at least two reasons why these rules should also apply to NIACs. First, the human-treatment requirement under common Article 3, the rules stated in Article 4 of the Additional Protocol $\mathrm{II},{ }^{266}$ as well as the principle of separation of women and men in detention, affirmed in Article 5 of the Additional Protocol II, incorporate "by analogy, all of these specific provisions [addressing specific women needs] because they merely clarify and specify the primary obligations of the Conventions". ${ }^{267}$ Considering that Protocol II is informed by the principle of human treatment stated under common Article 3 of the four Geneva Conventions, ${ }^{268}$ it can be considered as indirectly including the obligations deriving from this principle. Second, the ICRC recognized the special protection for women in the warfare as a norm of customary international law under Rule 134, which states: "The specific protection, health and assistance needs of women affected by armed conflict must be respected". This general recognition seems to cover also NCIAs.

The content of the specific medical assistance for pregnant women and mothers is very controversial. In particular, it is contested whether this special medical treatment also includes a State's obligation to provide (safe) abortion services ${ }^{269}$ to expectant mothers raped and impregnated in armed conflict, thus prioritizing women's health and recognizing their right of choice. In this sense, access to abortion would be part of the medical treatment for rape. This is an issue of great practical importance. The United Nations Population Fund (UNFPA)

\footnotetext{
${ }^{263}$ AP I, Article 76(2).

264 AP I, Article 76(3).

265 AP II, Article 6(4).

${ }^{266}$ Namely, the respect for the person and honor requirement and the prohibition of outrages upon personal dignity. ${ }^{267}$ In this sense, but referring only to Common Article 3, Rona, Gabor, and McGuire, Robert J., "The Principle of Non-Discrimination", in Clapham, Andrew, Gaeta, Paola, Sassoli, Marco (eds.), The 1949 GC: A Commentary...p. 201.

${ }^{268}$ The idea that Additional Protocol II is a development and a supplement of common Article 3 of the four Geneva Conventions is stated under Article 1(1), AP II.

269 The World Health Organization (WHO) defines "Unsafe abortion" as "a procedure for terminating an unintended pregnancy, carried out either by persons lacking the necessary skills or in an environment that does not conform to minimal medical standards, or both". See: WHO, "Safe abortion care: the public health and human rights rationale", in Safe abortion: technical and policy guidance for health systems, 2nd ed., Geneva, 2012, p. 18, available at: http://apps.who.int/iris/bitstream/10665/70914/1/9789241548434 eng.pdf [last visited, 17 June 2020].
} 
supported around 7.3 million women with sexual and reproductive health services, including clinical management of rape in 2019. In 2020, it has been estimated that approximately 4 million of pregnant women will need maternal care assistance in conflict-affected and humanitarian settings. ${ }^{270}$ In some cases, wartime rape is even committed with the specific purpose of impregnating women of a particular ethnic group and this is the reason why women are sometimes detained until it would be too late to legally abort. ${ }^{271}$ Considering that about three fifths of all maternal deaths worldwide occur in countries that are considered fragile because of conflict or disaster ${ }^{272}$ one may also ask whether the non-recognition of abortion services also impinge the right to life in conflict-affected areas. ${ }^{273}$

The extent of the medical care to wartime-raped women has always been a particularly thorny issue. Article 7(2) of the International Criminal Court (ICC) Statute qualifies forced pregnancy as a crime against humanity only if the "intent of affecting the ethnic composition of any population or carrying out other grave violations of international law" can be proved. This supplementary intent - an element not required for the other offences to constitute a crime against humanity - clearly expresses the relevance of religious and moral motivations in addressing the issue of wartime rape and, conclusively, related abortions. Indeed, the definition of forced pregnancy "shall not in any way be interpreted as affecting national laws relating to pregnancy". ${ }^{274}$ As Chinkin notes,

\footnotetext{
${ }^{270}$ United Nations Population Fund (UNFPA), "Humanitarian action: 2020 overview”, New York, 2020, available at https://www.unfpa.org/sites/default/files/pub-pdf/HAO 2020 publication Lo Res 10 Feb.pdf [last visited, 29 May 2020]. The Report particularly refers to Yemen, the Central Sahel Region (Burkina Faso, Mali and Niger), and the Democratic Republic of Congo.

${ }^{271}$ In this regard, the case of Bosnian Muslim women during the conflict in the former Yugoslavia is emblematic. Bosnian Muslim women were impregnated, mainly by Bosnian Serbs, and detained for months so that it would have been impossible to obtain an abortion along with national laws. See UN Doc. S/1994/674/Add.2 (Vol. V), 28 December 1994, Rape and Sexual Assault, Final Report of the UN Commission of Experts Established Pursuant to Security Council Resolution 780, (1992), p. 6-8. In the Karadzic and Mladic decision, the Trial Chamber stated: "It would seem that the aim of many rapes was enforced impregnation; several witnesses also said that the perpetrators of sexual assault - often soldiers - had been given orders to do so and that camp commanders and officers had been informed thereof and participated therein." Prosecutor v. Karadzic and Mladic, supra note 714, Transcript, p. 960.

272 UNFPA, State of World Population 2015: Shelter from the Storm. A transformative agenda for women and girls in a crisis-prone world, New York, 2015, available at: https://www.unfpa.org/sites/default/files/sowp/downloads/State of World Population 2015 EN.pdf $\quad$ [last visited, 28 May 2020].

${ }^{273}$ See Schabas, "The right to life", in Clapham, Andrew and Gaeta, Paola (eds.), The Oxford Handbook of International Law in Armed Conflict, Oxford University Press, Oxford, 2014.

${ }^{274}$ Rome Statute of the International Criminal Court (Rome Statute) 1998, 2187 UNTS 90, Art. 7(2)(f).
} 
the continuing insistence that control is maintained over women's reproductive capacity has subjugated gender identity to ethnic identity or other international law imperatives. ${ }^{275}$

International human rights law is also not particularly useful on that matter. Indeed, when it comes to reproductive rights, the first explicit mention of abortion in an international law document has been included in the Protocol to the African Charter on Human and Peoples' Rights on the Rights of Women in Africa, better known as the Maputo Protocol. ${ }^{276}$ Moreover, while international human rights bodies seem to have recognized the women's right to access to abortion, regional human rights courts' jurisprudence still appear cautious on the matter. ${ }^{277}$

Moving to states' practice, this is also not univocal on the scope of medical assistance for pregnant women. US policy deserves particular attention in this context due to the importance of US humanitarian aid in conflict zones. US aid policy seems not to recognize that the IHL preferential medical care regime for pregnant women and the obligation of non-discriminatory medical treatment provided by the Geneva Conventions also require the Parties to provide safe abortion services. ${ }^{278}$ These abortion-restrictions policy - known as Mexico City Policy censored aid organizations' activity in conflict areas, effectively obliging them not to discuss the abortion option with raped survivors in order not to lose access to U.S. aid. The U.S. attitude to the issue 279 - quietly changed during the President Obama administration ${ }^{280}$ and again under

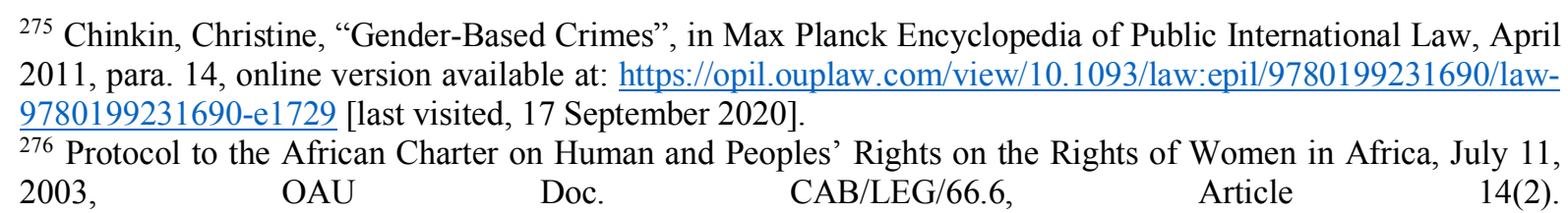

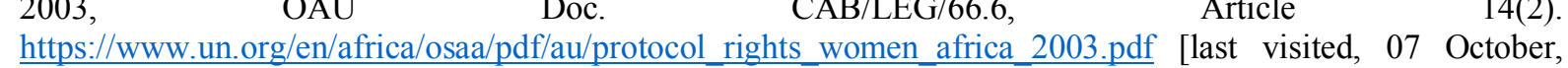
2020].

${ }^{277}$ For recent updates on the regional human rights courts' jurisprudence on the issue of reproductive rights and access to abortion, see Sjöholm, Maria, Gender-sensitive Norm Interpretation by Regional Human Rights Law Systems,...pp. 519-563.

${ }^{278}$ The Helms amendment to the Foreign Assistance Act of 1961, adopted in 1973 and still in force, does not directly prohibit U.S. funding for abortion services in cases of life endangerment, incest, or rape. However, it states that no U.S. aid can fund providers of abortion "as a method of family planning". Further, the Helms Amendment contains a provision that prohibits abortion speech, stating that none of the funds can be used to "motivate or coerce any person to practice abortions". Helms Amendment to the Foreign Assistance Act, Section 104(f)(1), 22 U.S.C. \$2151(b)(f)(1)(1973). In 1984, President Ronald Reagan introduced the Global Gag Rule, also known under the name of the Mexico City Policy, which institutes a ban on federal funding flowing to international family planning institutions that offer, among other services, advice and counselling on abortion.

${ }^{279}$ For an overview of previous U.S. actions threating to international agreements on women's rights, see Allen, Louise and Shepherd, Laura J., "In Pursuing A New Resolution On Sexual Violence Security Council Significantly Undermines Women's Reproductive Rights", LSE Women, Peace and Security blog, (25 April, 2019), available at: https://blogs.lse.ac.uk/wps/2019/04/25/in-pursuing-a-new-resolution-on-sexual-violencesecurity-council-significantly-undermines-womens-reproductive-rights/ [last visited, 25 April 2020].

${ }^{280}$ President Barack Obama rescinded the Mexico City Policy on January 23, 2009. However, as the Helm Amendment of 1973 remained in force, "USAID [U.S. Agency for International Development] is prohibited from providing funds to pay for the performance of abortion as a method of family planning or to motivate or coerce 
revision with the signature of the recent new President Biden's memorandum ${ }^{281}$ - was confirmed, and in a way strengthened, by the President Trump administration.

US stance was especially expressed in the context of the negotiation over UN Security Council Resolution 2467, the latest and ninth SC Resolution on "Women, Peace and Security" (WPS), adopted on 23 April 2019.282 The Trump administration raised the threat of veto to this Resolution, essentially expressing its opposition to the use of the proposed words "sexual and reproductive health" (SRH), which connote abortion as one of the possible health services for wartime raped women. ${ }^{283}$ Tumultuous negotiations led the SC Members to reach a compromise on the Resolution 2467 language. ${ }^{284}$ The result of the debates is a text which lacks direct references to women's rights on SRH. ${ }^{285}$ However, appropriate healthcare for women survivors of wartime rape is contained in a number of operative paragraphs. ${ }^{286}$ In particular, paragraph 16, while encouraging the adoption of a survivor-centred approach and restating nondiscrimination, focuses on groups "particularly vulnerable [...] and notably in the context of their health". In paragraph 16(a), the Parties are called to provide the survivors of sexual and gender-based violence the "care required by their specific needs" and "without any

any person to practice abortion, as stipulated by the Helms Amendment enacted in 1973". This and all other statutory and policy requirements relating to family planning remain in effect. For further information, see the official USAID website: https://www.usaid.gov/news-information/press-releases/president-obama-rescindsmexico-city-policy [last visited, 19 May 2020].

${ }^{281}$ On the $31^{\text {st }}$ January 2021, the newly-elected President Joe Biden signed a memorandum to rescind the Mexico City Policy, in so giving a clear message of rupture from the work of the previous administration. Anyways, it is still early to say whether his approach to the matter will be as fearless as it now appears or more cautious. https:/edition.cnn.com/2021/01/28/politics/biden-abortion-executive-orders/index.html

${ }^{282}$ The UN Security Council Resolution 2467 was adopted with 13 votes in favour, and abstentions from Russia and China. The text of the UN Security Council Resolution is available at: https://undocs.org/S/RES/2467(2019). ${ }^{283}$ The US position with regard to "sexual and reproductive health" controversy does not seem changed so far. In a letter to the UN Secretary General Antonio Guterres, the now former Trump's acting administrator for the US agency for international development (USAID), John Barsa, urges the UN "to stay focused on life-saving interventions" which does not include abortion as an essential healthcare service. The text of the letter is available at: https://www.usaid.gov/news-information/press-releases/may-18-2020-acting-administrator-john-barsa-unsecretary-general-antonio-guterres [last visited: 10 November, 2020].

${ }^{284} \mathrm{https}$ ://www.theguardian.com/world/2019/apr/22/us-un-resolution-rape-weapon-of-war-veto.

${ }^{285}$ Only the Preamble recognises "the need for survivors of sexual violence to receive non-discriminatory access to services such as medical and psychosocial care to the fullest extent practicable and need to be free from torture and cruel, inhuman or degrading treatment, and that violations of the obligations on the treatment of victims can amount to serious violations of international law".

${ }^{286}$ In this sense, see Chinkin, Christine and Lees, Madelaine, Commentary on Security Council Resolution 2467. Continued State Obligation and Civil Society Action on Sexual Violence in Conflict, Centre for Women Peace and Security, London School of Economics and Political Science, London, (2019), available at: https://www.un.org/sexualviolenceinconflict/wp-content/uploads/2019/09/report/commentary-on-securitycouncil-resolution-2467/19 0496 WPS Commentary Report online.pdf [last visited, 19 May 2020]. The authors sustain that the Resolution at issue, as well as the others WPS Resolutions, have binding legal force, at least when they reiterate or incorporate existing law. With specific regard to sexual and reproductive rights, it is stated that the Resolution 2467 guarantees full access to appropriate healthcare also for raped women who choose not to give birth. 
discrimination". Paragraph 17 recalls the right to an effective remedy and assistance for the survivors of sexual violence, while paragraph 18 recognizes the "specific needs" of women and girls who become pregnant as a result of sexual violence in armed conflict. In mentioning women "who choose to become mothers", it is implied the possibility of raped women to choose whether or not to continue with their unwanted pregnancy.

In sum, the most recent legal instrument dealing with the healthcare of pregnant women raped during conflict, UN SC Resolution 2467, seems to recognize safe abortion as part of the nondiscriminatory healthcare services which must be guaranteed to wartime rape survivors. Considering the strong disagreements during the negotiations, however, the adoption of the Resolution without unanimity, in so breaking a "19 years of consensus on a critical issue",287 as well as the ambiguous language used in the Resolution, doubts remain over the future interpretation of the abovementioned indirect references to SRH. Future state practice will be extremely relevant in this respect.

In conclusion, the historical interpretation of the Geneva Conventions' special regime of medical care for pregnant women caught up in the conflict seems at least ambivalent as to its scope. It is particularly under discussion whether the Parties to the conflict must also guarantee safe abortion services to survivors of wartime rape. The Geneva Conventions do not specify the content of the preferential medical treatment for pregnant women, and it is not widely accepted that the non-discriminatory medical care obligations contained in the GCs Articles compel States Parties to provide for abortion services for wartime rape survivors. However, there seems to be some room for legal interpretation that accounts for women's medical needs in this context. First, these provisions have a purely humanitarian character. This means that their purpose is to bring relief to victims, and, as such, they must be interpreted as to guarantee vulnerable civilians, in these case pregnant women, the maximum protection and assistance. Access to safe abortion represents an essential medical supply which may prevent further traumas to psychologically, and usually also physically, offended women. For this reason, it would be difficult to conclude that this special regime of medical protection for pregnant women does not include a legal obligation to provide for abortion to raped survivors. In this sense, a refusal of providing abortion for wartime raped women and girls would amount to a breach of the State Party's obligation of guaranteeing a preferential medical care to pregnant

\footnotetext{
${ }^{287}$ Report of the Secretary General, Women and Peace and Security, UN Doc. S/2019/800, 9 October 2019, para. 41.
} 
women under Articles 14, 23(1), 91(2), 127(3) of the Fourth Geneva Convention, and, in general, a violation of the principle of non-discriminatory medical care under common Article 3.

Some authors go even further, asserting that medical humanitarian assistance programs without any reference to safe abortion services violate the States' obligation to guarantee human treatment and to prohibit torture, cruel and inhuman treatment under common Article 3. This assertion is supported by many valid arguments. First, the lack of adequate medical attention is among the acts that have been considered cruel by the ICTY. ${ }^{288}$ The refusal to provide a safe abortion in cases of wartime rape may be fully considered a "lack of adequate medical attention" in this sense. Second, the definition of cruel treatment includes not only physical, but also mental suffering. ${ }^{289}$ The impossibility to have access to abortion after a war rape definitely causes such suffering in that it forces the rape survivor to revive the physical humiliation suffered. Third, it is well recognized that "the prohibition [of violence to life and person under common Article 3] must also be understood as comprising omissions under certain circumstances", for example, letting persons "continue to suffer from wounds or sickness by failing to provide medical care". ${ }^{290}$ In this case, the non-provision of safe-abortion assistance for raped survivors may lead them to prolonged suffering. If one considers that rape is expressly prohibited under IHL, ${ }^{291}$ lack of assistance may amount to torture and its terrible effects continue much beyond on the victims. ${ }^{292}$ In this sense, "the denial of abortion services to girls and women raped and impregnated aggravates the harm suffered and subjects these victims to further cruel, inhuman and degrading treatment". ${ }^{293}$ This position has been also assumed by the UK government. In recognizing the restrictions placed on the use of aid for the purpose of abortion as a violation of common Article 3, the UK also claimed the State's role in ensuring that the humanitarian aid services comply the Geneva Conventions' obligations. ${ }^{294}$ Indeed, any potential conflicts with domestic law do not exclude States obligations under

\footnotetext{
288 See for example ICTY, Prosecuto v. Mrkšić, Trial Judgment, 2007, para. 517.

289 See for example ICTY, Prosecutor v. Naletilić and Martinović, Trial Judgment, 2003.

${ }^{290}$ Commentary III, 2020, Article 3, para. 629.

${ }^{291}$ GC IV, Article 27(2); AP I, Article 76(1); ICRC, Customary IHL, Rule 93.

${ }^{292}$ Prosecutor v. Zejnil Delalic, Zdravko Mucic, Hazim Delic and Esad Landzo (“Čelebići” judgment), Case No. IT-96-21-10, Judgment, (November 16, 1998) paras. 495-496.

${ }^{293}$ See, the NGO Global Justice Centre Report on "The Right to Abortion for Girls and Women Raped in Armed Conflict. States' positive obligation to provide non-discriminatory medical care under the Geneva Conventions", available at: http://globaljusticecenter.net/documents/LegalBrief.RightToAnAbortion.February2011.pdf [last visited, 18 May 2020].

${ }^{294}$ Debate of 9 January 2013, Vol. 750, col. 124-126, available at: https://hansard.parliament.uk/Lords/2013-1209/debates/13120911000076/ViolenceAgainstWomen [last visited, 17 June 2020].
} 
common Article 3, being the Parties obliged to respect and to ensure respect for IHL. ${ }^{295}$ This means that States cannot adduce national laws prohibiting abortion internally ${ }^{296}$ as a reason for not fulfilling their obligations under common Article 3.297

As stated above, this set of norms providing pregnant women and women mothers of young children with a specific protection recognizes biological differences between women and men related to the pregnancy. However, two basic criticisms have been raised against this special regime from a gender perspective. First, some feminist scholars underline that these norms tend to protect women primarily in their relationship with others and not as individuals. According to this view, the primary target for protection of the rules discussed above would seem to be the children and not the women. ${ }^{298}$ Moreover, these rules harbor a risk of confusion between regimes that operate for women and those that cater for children, so that women may be "infantilized". ${ }^{299}$ With respect to this criticism, one can observe that, even admitting the prior intention of the Parties to protect children, ${ }^{300}$ the special treatment for pregnant women and

\footnotetext{
${ }^{295}$ Common Article 1, GCs. On the quasi-constitutional nature of common Article 1, see Boisson de Chazournes, Laurence and Condorelli, Luigi, "Common Article 1 of the Geneva Conventions revisited: Protecting collective interests", International Review of the Red Cross, No. 837, (31 March 2000), available at: https://www.icrc.org/en/doc/resources/documents/article/other/57jqcp.htm [last visited, 30 May 2020].

${ }^{296}$ It has been reported that only $32 \%$ of countries allow or permit abortion at the woman's request with no requirement for justification, while $46 \%$ of countries allow or permit abortion where the pregnancy is the result of rape. https://pubmed.ncbi.nlm.nih.gov/30572956/ [last visited, 30 May 2020].

${ }^{297}$ The concept is expressed in the 2020 Commentary to the Third Geneva Convention as follows:

Authorizing torture or other forms of ill-treatment based on prevailing circumstances is contrary to the absolute nature of the prohibitions, dilutes the prohibitory effect of common Article 3, and increases the risk of subsequent violations. Indeed, this is a proverbial door that must remain locked; use of these forms of ill-treatment in any circumstances tends to induce the search for justifications to engage in prohibited conduct, making the escalation of these practices almost unavoidable (the so-called 'slippery slope' argument). It may also undermine respect for common Article 3 among the Parties to the conflict, as it may signal to them that these prohibitions are qualified, while they are absolute under common Article 3.
}

Commentary, Vol. III, 2020, Article 3, para. 650. The opposite view is expressed by Gaggioli in: Gaggioli, Gloria, "Is There a Right to Abortion for Women and Girls Who Become Pregnant as a Result of Rape? A Humanitarian and Legal Issue", Vulnerabilities in Armed Conflicts: Selected Issues, $14^{\text {th }}$ Bruges Colloquium - October 17 and 18, (2013), available at: https://www.icrc.org/en/doc/assets/files/2013/abortion-sexual-violence-bruges-10-20132.pdf [last visited, 17 June 2020]. The author sustains the idea that, along with the principle of non-discrimination, "if abortion is legally available in case of rape, the State must ensure that all women and girls in this situation have access to it". In other words, only "in countries where abortion is permitted in such situations (in case of rape), women and girls must have access to it if they so wish. It does not mean however that IHL imposes abortion in such situations independently of the choice of women and girls or independently of what domestic law provides",

${ }^{298}$ In this regard, see Gardam, Judith, "Women and the Law of Armed Conflict: Why the Silence?", International and Comparative Law Quarterly, Vol. 46, (1997) 55-80, p. 57; Kuper, Jenny, International Law Concerning Child Civilians in Armed Conflict, Clarendon Press, Oxford, 1997.

${ }^{299}$ Bennoune, Karima, "Do We Need New International Law to Protect Women in Armed Conflict?", Case Western Reserve Journal of International Law, Vol. 38, No. 2, (2007) 363-391, p. 377.

${ }^{300} \mathrm{GC}$ IV, Article 50(5)- which prohibits the Occupying Power to abrogate any preferential measures in regard to food, medical care and protection against the effects of war adopted prior to the occupation and which also covers pregnant women and mothers of young children - is titled "Children". The Pictet Commentary to Article 
mothers of young children results in an important protection aiming at reducing women suffering. The obligation to assist "safe abortion", which has been discussed above, is of particular relevance here. As argued, there are convincing arguments why an obligation to assist "safe abortion" to women raped and impregnated in armed conflict should be regarded as part of the obligation to provide medical care for pregnant women in conflict. This interpretation prioritizes women's health and recognizes their right of choice.

The second feminist claim against the IHL regime of particular care for pregnant women and mothers of young children focuses on their reflection of a fixed gender role of women as childbearers. In other words, the specific regime for maternal care may reinforce the established gender roles, which attribute only to mothers the role of caretakers of children. ${ }^{301}$ Undoubtedly, these norms tend to acknowledge the reality in times of conflict, in which women are usually the main responsible for children. Moreover, to an important extent, they do reflect the real biological difference of giving birth. However, there is a valid point in this critique. A gender approach to these issues would require to disassociate the category of caretaker from that of woman. This would mean that we need to recognizing both the underestimated conflict-related violence against fathers and the male role of caretakers of children and award them an equivalent level of protection.

2.3.3. The system of differentiated treatment for interned women and women prisoners of war

The second category of special protective rules for women are related to cases of deprivation of liberty as prisoners of war (POWs) or civilian internees. POWs are defined by Article 4 of the III Geneva Convention as persons "fallen into the power of the enemy" and are members of the armed forces of a Party to the conflict or members of militias or volunteer corps forming part of the armed forces or of organized resistance movements; civilians that accompany the armed forces or that take up the arms against the invaders and respect IHL rules; members of the crew. ${ }^{302}$ Civilian internees are civilians detained in IACs by reason of their activity being potentially a serious risk to the security of the detaining authority. Since this form of detention

91, GC IV reveals that "The reference to maternity cases was inserted in the text at the request of the International Union for Child Welfare". Commentary, Vol. IV, p. 400.

301 Gardam, Judith and Jarvis, Michelle, Women, Armed Conflict and International Law, Kluwer Law International, 2001, p. 93.

302 GC III, Article 4. 
is not for criminal allegations but for security reasons, it can last only as long as those reasons exist, and civilian internees are provided an extensive protection by IV Geneva Convention of 1949 and Additional Protocol I of 1977. For the purposes of this Section, the term "detainees" will be used to designate all persons deprived of their liberty in both IACs and NIACs, thus encompassing both POWs and civilian internees.

Article 119, IV Geneva Convention generally lists "sex" among the relevant grounds for special account granted internees, and Article 14, paragraph 2, III Geneva Convention states that due regard must be given to the specific needs of women prisoners of war and forbids any discriminatory treatment of them. Furthermore, a set of specific rules provides interned women and women POWs with a system of differentiated treatment during the period of reclusion. In particular, separate sleeping quarters and toilet facilities ${ }^{303}$ must be provided for women POWs ${ }^{304}$ for women detainees, ${ }^{305}$ even while undergoing a disciplinary punishment. ${ }^{306}$ The requirement of separate quarters must be superseded in case of detention or internment of the family unit. ${ }^{307}$ Women POWs in disciplinary punishment regime ${ }^{308}$ or on whom a sentence has been pronounced ${ }^{309}$, and women internees undergoing a disciplinary punishment are also entitled to female "immediate supervision". ${ }^{310}$ Article 75, paragraph 5 of the Additional Protocol I extends this guarantee to all interned women. ${ }^{311}$ The differentiated treatment of separation on the basis of sex and female direct supervision is also provided for interned women in NIACs. ${ }^{312}$

The Commentaries to the four 1949 Geneva Conventions and their Additional Protocols reveal the purpose of these provisions. The principle of differentiated treatment for interned women and women POWs appears to be the outcome of a dated conception of "the most elementary rules of decency"313 aimed to "protect the honour and modesty" of women POWs and interned

\footnotetext{
303 The requirement of "separate toilet facilities" for women prisoners of war requires the detaining power to comply with two main requirements: the toilet facilities in camps must be "for the exclusive use of women prisoners of war", and they must "have safe (e.g. only with women guards) and regular access to them day and night". Commentary III, Article 29, 2020, para. 2206.

${ }^{304}$ GC III, Articles 25(4), 29(2), 108(2).

305 GC IV, Article 76(4), 85; AP I, Article 75(5).

${ }^{306}$ Respectively, GC III, Article 97; GC IV, Article 124.

${ }^{307}$ GC IV, Articles 82(3), 85(4); AP I, Article 75(5).

${ }^{308}$ GC III, Article 97(4).

${ }^{309}$ GC III, Article 108(2).

${ }^{310}$ GV IV, Article 124.

311 AP I, Article 75(5).

312 AP II, Article 5(2)(a).

${ }^{313}$ Commentary, Vol. III, Article 29, p. 207.
} 
women. ${ }^{314}$ In other words, the special female treatment in case of detention or internment was not conceived to preserve women's right to integrity, security and privacy, but to respect the moral concept of "women's honor". ${ }^{315}$ A different language is adopted under the Commentary to Article 5(2)(a) of the 1977 Additional Protocol II, which describes the special protection for interned women in NIACs as an "essential element" to fulfil the "absolute obligations" of the prohibition of "outrages upon personal dignity, in particular humiliating and degrading treatment, rape, enforced prostitution and any form of indecent assault" laid down in Article 4, paragraph $2 .{ }^{316}$ Along with a renewed centrality of the person, the Parties to the Additional Protocol II conceived the guarantee of a differentiated dormitories and sanitary facilities and the supervision of female guards as methods of protection from a number of forms of violence to which women can be affected during the detention or the internment. This prisoner-centred approach seems to be confirmed in the 2020 Commentary to the III GC, which, in illustrating the detaining power obligation to provide for separate dormitories, states that "in all circumstances, the Detaining Power must be guided by the overarching obligations to ensure the humane treatment and safety of the prisoners, to provide living conditions that are not prejudicial to their health and to take into account their habits and customs". ${ }^{317}$ Indeed, the requirement of separate quarters may also cover other categories of persons having special exigencies or at risk of specific harms and the lack of this intervention would violate the obligation of humane treatment. ${ }^{318}$

While this regime uses a dated language and it may corroborate the gender stereotype of women's vulnerability, ${ }^{319}$ it nonetheless represents a reality in which an interned woman or a female POW is usually double vulnerable: because she is a woman and because she is in the power of the enemy. In this sense,

On peut parler, dans ce cas, d'un ensemble de normes visant à assurer, d'un coté, un standard minimum de civilisation dans des circonstances exceptionnelles liées à la guerre, voies la cohabitation dans les camps de prisonniers, lieux d'internement, infirmeries et tendant, de

\footnotetext{
${ }^{314}$ Commentary, Vol. III, Article 97, p. 465.

315 Commentary, Vol. IV, Article 85, p. 388.

316 Pilloud, Claude, Sandoz, Yves, Swinarski, Christophe, and Zimmermann, Bruno, Commentary on the Additional Protocols...p. 1390, para. 4583.

${ }^{317}$ Commentary Vol. III, Article 25, 2020, para. 2100. The same sentence, without the final part "and to take into account their habits and customs" can be also found in Commentary III, Article 108, 2020, para. 4211.

${ }^{318}$ Commentary, Vol. III, 2020, Article 108, para. 4215.

${ }^{319}$ Commentary to Article 14 of the III GC refers to the rules providing for "separate dormitories, separate places of detention" as a "special treatment for persons of the weaker sex". Commentary Vol. III, Article 14(2), p. 146.
} 
l'autre coté, à éviter que certaines catégories plus vulnérables de femmes subissent les effets des hostilités. ${ }^{320}$

It is a matter of fact that men are the majority of persons deprived of their freedom. ${ }^{321}$ This means that detention facilities are quite often not designed to satisfy women needs in terms of privacy, safety, hygienical, and healthcare conditions. ${ }^{322}$ In addition, women face higher risk of sexual violence during their internment, ${ }^{323}$ a risk which increases because of the usual presence of exclusively male detention staff $^{324}$ or the accommodation with male codetainees. ${ }^{325}$ That being so, IHL rules acknowledge the fact that women do not have the same experience of internment or detention as men, thus admitting the potential discrimination against women in times of deprivation of their liberty. As specified by the 2020 Commentary to the Third Geneva Convention, ${ }^{326}$ addressing Article 14, by providing for special protection to women in detention

is not to be understood as implying that women have less resilience, agency or capacity within the armed forces, but rather as an acknowledgement that women have a distinct set of needs and may face particular physical and psychological risks. ${ }^{327}$

In this sense, the system of differentiated treatment for interned women and women prisoners of war actually gives effect to the absolute principle of humane treatment under common Article 3. The principle of differentiate accommodation for women deprived of their liberty has been recognized by the ICRC database of customary IHL as a norm of customary international law applicable in both international and non-international armed conflicts. ${ }^{328}$

\footnotetext{
${ }^{320}$ Deteseanu, Daniela-Anca, "La protection des femmes en temps de conflit armé", in Sorel, Jean-Marc, and Popescu, Corneliu-Liviu (eds.), La protection des personnes vulnérable en temps de conflit armé, Bruylant, Bruxelles, 2010, p. 272.

${ }^{321}$ However, it must be stressed that the 2020 Commentary to the Third Geneva Convention recognizes as a premise the fact that women's number in the army is growing, with a consequent "increased risk of capture". Commentary III, Article 25, 2020, para. 1679.

${ }^{322}$ Lindsey-Curtet, Charlotte, Holst-Roness, Florence Tercier and Anderson, Letitia, "Addressing the Needs of Women Affected by Armed Conflict. An ICRC Guidance Document”, ICRC, March 2014, pp. 119ss.

323 Ivi. p. 125.

${ }^{324}$ Ivi. p. 169.

${ }^{325}$ ICRC, Protecting People Deprived of their Liberty, Geneva, 2016, p. 42.

${ }^{326}$ On the significant gender shifts developments in the 2020 updated Commentary to GCIII, see O'Rourke, Catherine, "Geneva Convention III Commentary: What Significance for Women's Rights?", Just Security, (October 21, 2020), available at: https://www.justsecurity.org/72958/geneva-convention-iii-commentary-whatsignificance-for-womens-rights/?fbclid=IwAR1XN2u-P8ZcLruDJlx7Fk6DG9X9-cGz0qENM2 FRC4Edjo6Ho6-Hdp5L0 [last visited, 26 October 2020].

327 Commentary, Vol. III, 2020, Article 14, para. 1692.

${ }^{328}$ ICRC, Customary IHL, Rule 119 states: "Women who are deprived of their liberty must be held in quarters separate from those of men, except where families are accommodated as family units, and must be under the immediate supervision of women". ICRC, Customary International Humanitarian Law,... Vol. 1, chapter 37. The 2020 Commentary to the Third Geneva Convention also mentions the UN Rules for the Treatment of Women
} 
Despite the guarantees of the above-mentioned regime of differentiated treatment for interned women and women POWs, some issues still remain open with regard to certain abuses disproportionately affecting or having a gender-specific impact on women. ${ }^{329}$ One of the most recent examples of widespread sexual violence perpetrated in detention has been registered in the Syrian conflict, where government forces have subjected both male and female detainees to different forms of violence at all stages of detention as part of a wider policy between 2011 and 2016. ${ }^{330}$ Beyond Syria, one of the most recurrent forms of conflict-related violence against women during the last decades have been gender-based forms of arbitrary detention or de facto arbitrary detention, especially in NIACs and committed by Armed Non-State Actors (ANTAs). The most heinous expression of these forms of detention is the case of the foreign minor brides, ${ }^{331}$ namely female juveniles who become spouses of an adult or minor male member of an armed group and thus become affiliated ${ }^{332}$ with that armed group. ${ }^{333}$ For instance, many

Prisoners and Non-custodial Measures for Women Offenders (known as the Bangkok Rules) - approved with the GA Res 65/229, 16 March 2011 - as a relevant step forward in that direction. Commentary, Vol. III, 2020, Article 25 , note 47.

${ }^{329}$ This is not to suggest that forms of gender-based violence are not perpetrated against men and boys in conditions of detention. After providing for data on widespread violence against men in facilities for detainees in both IACs and NIACs, Bradley underlines a substantial gap in the protection of male detainees under the IHL regime, criticizing an unjustifiable discrepancy in treatment between women and men and suggesting a more gender-neutral prohibition of sexual violence. Bradley, Samantha Frances, "Protection of Detainees from Sexual Violence under International Humanitarian Law”, Journal of Conflict \& Security Law, Vol. 25 No. 3, (2020) 381422.

${ }^{330}$ ICRC, “Sexual Violence in Detention”, (2017), available at https:/www.icrc.org/en/publication/4293-sexualviolence-detention [last visited 16 September 2020].

331 The phenomenon of child marriage covers predominantly girls and, to a less extent, boys. UNICEF, "Child Marriage: Latest Trends and Future Prospects", available at: https://data.unicef.org/resources/child-marriagelatest-trends-and-future-prospects/ [last visited 16 September 2020]. The UN General Assembly has stated that "deep-rooted gender inequalities and stereotypes, harmful practices, perceptions and customs, and discriminatory norms are [...] among the root causes of child, early and forced marriage". UNGA, Res. 71/175, UN Doc. A/RES/71/175, 19 December 2016. Anyways, conflict settings increase the risk of child marriages. See in this regard, Girls Not Brides, "Child Marriage in Humanitarian Settings", 2018, available at: https://www.girlsnotbrides.org/wp-content/uploads/2016/05/Child-marriage-in-humanitarian-settings.pdf [last visited, 18 September 2020]. For an updated overview of the phenomenon of child marriage, see Mazurana, Dyan, Marshak, Anastasia and Spears, Kinsey, "Child Marriage in Armed Conflict", International Review of the Red Cross, Vol. 101, No. 911, (2019) 575-601.

${ }^{332}$ For an overview of the different forms of affiliation of women to ANSAs, see ICAN/UNDP, Invisible Women. Gender dimension of Return, Reintegration and Rehabilitation from Violent Extremism, 2019, p. 27, available at: https://www.undp.org/content/undp/en/home/librarypage/womens-empowerment/invisible-women.html [last visited 16 September 2020].

${ }^{333}$ The phenomenon of forced marriages is widespread in different conflict settings. The first international tribunal dealing with cases of forced marriages is the Special Court for Sierra Leone (SCSL). In the context of Sierra Leone conflict, the so called "bush wives" experienced particularly traumatizing and harsh conditions. "The use of the term 'wife' by the perpetrator was deliberate and strategic. The word 'wife' demonstrated a rebel's control over a woman. His psychological manipulations of her feelings rendered her unable to deny him his wishes. [...] 'Bush wives' were expected to carry out all the functions of a wife and more. A 'bush wife' carried her 'husband's' possessions on her head and trekked across the countryside with him; she was expected to gratify her 'husband's' sexual wishes whenever he so desired without question; she cooked for him when food was available, did his laundry and generally protected his possessions in his absence; she was expected to show undying loyalty to her 
sources reported the case of the female students kidnapped by Boko Haram ${ }^{334}$, a jihadist group acting in Nigeria ${ }^{335}$, in $2014^{336}$ and in $2018^{337}$. In both episodes, these young women were taken hostages, forced to live together with terrorists, subjected to threatens and violence, and

husband for his protection and reward him with 'love and affection'; she was not expected to attempt to escape as this was deemed disloyal. Punishment for disloyalty was always severe and so, women were led to believe, in most cases would be met with death". SCSL, Prosecutor v. Brima and Others, Trial Chamber II, SCSL-2004-16T, (8 August 2005), pp. 15-16, available at: http://www.rscsl.org/Documents/Decisions/AFRC/365/SCSL-04-16T-369.pdf [last visited, 23 September 2020]. There are also more recent cases of forced marriages. "Many groups, including Islamic State in Iraq and the Levant (ISIL) and Boko Haram, use the promise of marriage and access to sex to incentivize recruitment of men and boys, engage in trafficking and other gendered practices that promote and reinforce violent masculinities, and perpetuate sexual and gender-based violence and the persecution of individuals on the basis of their sexual orientation or gender identity". Report of the Secretary-General, Conflictrelated sexual violence, U.N. Doc. S/2018/250, 23 March 2018, para. 13. The practice of forced marriages by armed groups during conflicts is increasing. See Committee on the Elimination of Discrimination against Women, General Recommendation No. 30, Women in conflict prevention, conflict and post-conflict situations, CEDAW/C/GC/30, (1 November 2013), para. 62, available at: https://tbinternet.ohchr.org/ layouts/15/treatybodyexternal/Download.aspx?symbolno=CEDAW/C/GC/30\&Lan $\mathrm{g}=$ en [last visited, 18 September 2020].

${ }^{334}$ It should be underlined that not all women affiliated with Boko Haram have been abducted. Both who joined the ANSAs voluntary and those abducted are housed in military camps for the displaced, at risk of sexual abuse and stigmatized by the communities from which they originally came. UNICEF, "In Nigeria's restive northeast, fate of thousands of abducted women remains unknown", 2016, available at: https://news.un.org/en/story/2016/04/526752-nigerias-restive-northeast-fate-thousands-abducted-womenremains-unknown-un\#.VxDC43CQyGB [last visited 16 September 2020].

${ }^{335}$ A well-documented analysis of the NIACs in Nigeria, against the non-state armed groups Boko Haram and the Islamic State in West Africa Province (ISWAP), with an historical overview and the parties to the conflicts can be found at: RULAC (Rule of Law in Armed Conflicts), "Non-International Armed Conflicts in Nigeria", available at: http://www.rulac.org/browse/conflicts/non-international-armed-conflict-in-nigeria\#collapse3accord [last visited, 16 September 2020].

${ }^{336}$ Amnesty International, ' Our Job Is to Shoot, Slaughter and Kill': Boko Haram's Reign of Terror in NorthEast Nigeria', 14 April 2015, available at: https://www.amnesty.org/en/documents/afr44/1360/2015/en/ [last visited 16 September 2020]; Amnesty International, Nigeria: abducted women and girls forced to join Boko Haram attacks, (2015), available at: https://www.amnesty.org/en/latest/news/2015/04/nigeria-abducted-womenand-girls-forced-to-join-boko-haram-attacks/ [last visited 16 September 2020]; CNN, "Officials: Boko Haram kidnaps 185 women and children, kills 32 people", (18 December 2014) available at https://edition.cnn.com/2014/12/18/world/africa/nigeria-boko-haram-kidnapping/index.html, [last visited 16 September 2020].

${ }^{337}$ CNN, "UNICEF: Boko Haram has kidnapped more than 1000 children in Nigeria" (13 April 2018), available at: https://edition.cnn.com/2018/04/13/africa/boko-haram-children-abduction-intl/index.html [last visited, 16 September 2020]; Amnesty International, "Nigeria: Security forces failed to act on warnings about Boko Haram attack hours before abduction of schoolgirls", 2018, available at: https://www.amnesty.org/en/latest/news/2018/03/nigeria-abduction-of-schoolgirls-security-forces-failed-to-actboko-haram/ [last visited, 16 September 2020]. 
abducted to become victims of sexual slavery ${ }^{338}$ or forced marriages. ${ }^{339}$ Leaving aside the issues related to the qualification of the crime of forced marriage, ${ }^{340}$

The crucial element of "forced marriage" is the imposition, by threat or physical force arising from the perpetrator's words or other conduct, of a forced conjugal association by the perpetrator over the victim. ${ }^{341}$

Under the IHL framework on IACs, these girls would qualify as falling under one of the two categories of civilian prisoners of war, namely "civilian followers", under Article 4(A)(4) of the GC III, as they are usually "responsible for the welfare" services for members of an armed force without being members thereof. The concept of "civilian follower", however, is not included in the IHL framework on NIACs. If the Parties to a NIAC, such as those in the Nigerian conflict, decide to sign a special agreement under Article 3(3) common to the Geneva Conventions $^{342}$ with the purpose of applying the GC III, the girls associated to the fighting group, including brides, may be recognized the status of "civilian followers" under Article 4(A)(4) and be entitled the POWs status - even if the combatant status, immunity or privileges are not accorded to them. ${ }^{343}$ Considering that the GC III does not distinguish between prisoners

\footnotetext{
${ }^{338}$ Sexual slavery is a form a slavery. For an overview of the contemporary legal framework prohibiting slavery, forced labour and other forms of exploitation of humans by humans, see Borelli, Silvia and Vitucci, Maria Chiara, "From chattel slavery to 'modern slavery': The role for human dignity in the struggle against contemporary forms of human exploitation”, Questions of International Law, (December 24, 2019), available at: http://www.qilqdi.org/from-chattel-slavery-to-modern-slavery-the-role-for-human-dignity-in-the-struggle-againstcontemporary-forms-of-human-exploitation/ [last visited, 10 September 2020].

${ }^{339}$ ICC, Office of the Prosecutor, Report on Preliminary Examination Activities (2018), 5 December 2018, para 225, available at: https://www.icc-cpi.int/itemsDocuments/181205-rep-otp-PE-ENG.pdf [last visited 15 September 2020]. See also, ICC, Office of the Prosecutor, Report on Preliminary Examination Activities (2016), 14 November 2016, paras. 292-296.

${ }^{340}$ For an examination of the term "forced marriage", how it has been defined in international criminal law by the Special Court for Sierra Leone, and a critique of its "judicial legislation", see Eboe-Osuji, Chile, International Law and Sexual Violence in Armed Conflicts, Martinus Nijhoff Publishers, Leiden, 2012. For a comparison between the case law of the Special Court for Sierra Leone and the Extraordinary Chambers in the Courts of Cambodia, and the issues related to the definition and the content of the concept, see Oosterveld, Valerie, "Forced Marriage during Conflict and Mass Atrocity", in Ni Aolain, Fionnuala, Cahn, Naomi, Haynes, Dina Francesca and Valji, Nahla (eds), The Oxford Handbook of Gender and Conflict, Oxford University Press, Oxford, 2018. For an historical overview of the legislative process leading to the criminalisation of forced marriage in times of armed conflict under the Statute of the International Criminal Court, with particular references to the driving actors influencing the understanding of the crime and a critique to the cultural assumptions behind its final definition, see Baumeister, Hannah, Sexualised Crimes, Armed Conflict and the Law. The International Criminal Court and the Definitions of Rape and Forced Marriage, Routledge, Abingdon, 2018.

${ }^{341}$ SCSL, Prosecutor v. Brima and Others, Trial Chamber II, Judgement, SCSL-04-16-T, (20 June 2007), Partly Dissenting Opinion of Judge Doherty, para 53.

342 "The Parties to the conflict should further endeavour to bring into force, by means of special agreements, all or part of the other provisions of the present Convention".

${ }^{343}$ Arai-Takahashi, Yutaka, "War Crimes relating to child soldiers and other children that are otherwise associated with armed groups in situations of non-international armed conflict. An incremental step toward a coherent legal framework?", Questions of International Law, (23 September, 2019), available at: http://www.qil-qdi.org/warcrimes-relating-to-child-soldiers-and-other-children-that-are-otherwise-associated-with-armed-groups-in-
} 
of war who are combatants and those who are civilians, ${ }^{344}$ the recognition of the status of "civilian followers" to the abducted girls would mean that all provisions of GC III would be applicable to them, like for POWs in IACs. This means, in particular, that the detaining power would be allowed to protract the detention of these girls until the end of the conflict in accordance with the relevant rules for POWs. ${ }^{345}$ Where there is no such agreement between the Parties to the conflict, the full discipline regulating the NIACs would apply, where "there is no universal treaty provision on the release of persons deprived of their liberty". ${ }^{346}$ However, the practice established from numerous agreements, the legislation of some States, as well as from Resolutions of the Security Council, the General Assembly and regional organisations seems to confirm the existence of a customary rule, according to which such persons deprived of their liberty held in a NIAC "must be released as soon as the reasons for the deprivation of their liberty cease to exist". ${ }^{347}$ Another possibility would be to consider persons such as the young brides of the members of the ANSA as civilians. The status of civilians, regulated under the IV Geneva Convention, would allow their special treatment, especially with regard to release or repatriation. In particular, the brides under the age of 18 would fall into the category of "young children", for whom Article 132 of the IV GC provides a mechanism encouraging the parties to conclude agreements to release or repatriate certain vulnerable categories of civilians even when the hostilities are still in progress. ${ }^{348}$ Thus, in cases of NIACs such as the Nigerian conflict, girls forcibly married to armed actors would profit more from the conclusion of an agreement between the Parties to the conflict for the application of Article 132 of the IV GC, which would guarantee them the possibility to be released whenever safely feasible even before the end of the conflict.

To conclude, the difficulties in the qualification of girls abducted and forced to marriages with their offenders and the consequent level of their protection may be ascribed to the general issue

$\underline{\text { situations-of-non-international-armed-conflict-an-incremental-step-toward-a-coherent-legal// }}$ [last visited, 17 September 2020].

${ }^{344}$ The Geneva Conventions of 12 August 1949, Commentary to the Third Geneva Convention relative to the Treatment of Prisoners of War, Geneva, 2020, para. 1046, available at: https://ihldatabases.icrc.org/applic/ihl/ihl.nsf/Comment.xsp?action=openDocument\&documentId=1796813618ABDDA06C 12585850057AB95\# Toc42431489 [last visited, 17 September 2020].

345 Article 118, GC III.

${ }^{346}$ Fleck, Dieter, "The Law of Non-International Armed Conflict", in Fleck, Dieter, The Handbook of International Humanitarian Law, Oxford University Press, Oxford, 2013, p. 604.

${ }^{347}$ ICRC, Customary IHL, Rule 128.

${ }^{348}$ IV GC, Article 132: "The Parties to the conflict shall, moreover, endeavour during the course of hostilities, to conclude agreements for the release, the repatriation, the return to places of residence or the accommodation in a neutral country of certain classes of internees, in particular children, pregnant women and mothers with infants and young children, wounded and sick, and internees who have been detained for a long time". 
of the outdated dichotomy between international and non-international armed conflict. Indeed, the lack of an adequate regime on the release of persons deprived of their liberty in NIACs, which represent the most common war settings of the phenomenon of forced marriages, leaves the parties free to regulate the treatment of brides and to decide about their release.

The qualification of the associated girls in case they violated IHL by participating in the perpetration of one or more international crimes is still an open issue. They could be considered as victims of forced marriage and sexual enslavement, which would place their acts within a non-consent-based environment, or as perpetrators. In this regard, it must be noted that the issue has recently come in the spotlight because of the UN Security Council Resolution 2396 (2017), which acknowledged the necessity to avoid generalizations, emphasizing that

women and children associated with foreign terrorist fighters returning or relocating to and from conflict may have served in many different roles, including as supporters, facilitators, or perpetrators of terrorist acts, and require special focus when developing tailored prosecution, rehabilitation and reintegration strategies, and stress[ing] the importance of assisting women and children associated with foreign terrorist fighters who may be victims of terrorism, and to do so taking into account gender and age sensitivities. ${ }^{349}$

Finally, it should be noted that the failure to adequately separate men and women in detention centres does not constitute a criminal violation of IHL, namely a violation that may give rise to the individual criminal responsibility of a commander. One of the consequences of this is that military commanders have not a legal obligation to report this violation to the competent authority. The Geneva Academy and the ICRC 2019 Guidelines on "Investigating violations of international humanitarian law: law, policy and good practice" suggests that also in situations of non-criminal violations of IHL "it would still be desirable to maintain a reporting obligation" 350 , in that the reporting phase is recognized as a relevant operational step to start an investigation. Thus, the introduction of such an obligation is left to domestic military manuals. Considering the non-mandatory duty to report these violations, it may be expected that the commander, as the competent authority to prosecute the failure to adequately separate men and women in a detention center, would carry out an investigation and promptly intervene to eliminate the violation and to prevent its reoccurrence only if no other incidents need to be prioritized in that moment. In other words, it is likely that the clear obligations to make an

\footnotetext{
${ }^{349}$ UN SC Res 2396 (2017), para 31.

${ }^{350}$ Lubell, Noam, Pejic, Jelena and Simmons, Claire, "Investigating Violations of International Humanitarian Law: Law, Policy and Good Practice", (September 2019), para. 90, available at: https://www.icrc.org/en/document/guidelines-investigating-violations-ihl-law-policy-and-good-practice [last visited, 21 September 2020]).
} 
enquiry on cases concerning deaths or serious injuries of detainees provided by the GC III ${ }^{351}$ could overshadow instances of lack of separation of women and men in detention centers.

\subsection{Rules dealing with abuses particularly affecting women}

The special IHL provisions explicitly covering women are a clear recognition of the relevance of sex and gender in conflict, expressing the understanding that women and men have a different experience of the war. However, these are not the only relevant norms for women in conflict. Some norms, even if not explicitly referred to women, cover abuses particularly affecting women. Although prima facie these rules apply equally to both men and women, de facto they belong to the specific corpus of rules that address the condition of women in conflict. Some of these norms will be the object of the following analysis.

Due to the actual allocation of roles in war, women usually ${ }^{352}$ fall under the category of civilian. ${ }^{353}$ As such, they mainly benefit from the norms protecting civilians caught up in the conflict. In this sense, the general principle of distinction - according to which belligerents shall at all times make a distinction between civilians and combatants and refrain from intentionally attacking the former ${ }^{354}$ - is the main form of legal guarantee in the warfare for female subjects. The principle of distinction has been clearly described by the International Court of Justice in its 1996 Advisory Opinion on Nuclear Weapons as one of the "cardinal principles contained in the texts constituting the fabric of humanitarian law", which aims at

the protection of the civilian population and civilian objects and establishes the distinction between combatants and non-combatants; States must never make civilians the object of attack and must consequently never use weapons that are incapable of distinguishing between civilian and military targets. ${ }^{355}$

\footnotetext{
${ }^{351}$ GC III, Articles 120-121.

352 The Beijing Platform for Action claimed that "civilian victims, mostly women and children, often outnumber casualties among combatants". Fourth World Conference on Women, Beijing, P.R.C., Sept. 4-15, 1995, Beijing Declaration and Platform for Action, 135, U.N. Doc. A/CONF. 177/20 (September 15, 1995), para. 133.

${ }^{353}$ The definition of "civilian" is laid down in Article 50(1) of Additional Protocol I: "a civilian is any person who does not belong to one of the categories of persons referred to in Article 4(a)(1), (2), (3) and (6) of the Third Convention and in Article 43 of this Protocol'. Thus, this negative formulation clarifies that civilians are basically individuals who are not combatants.

354 AP I, Article 48.

355 ICJ, Legality of the Threat or Use of Nuclear Weapons, Advisory Opinion, (1996), Rep 226, 257. The precept of distinction constitutes the first Rule of customary IHL. ICRC, Customary International Humanitarian Law, Vol. I, p. 3.
} 
In case of doubt, a person must be presumed to be a civilian. ${ }^{356}$ The implementation of this fundamental pillar of the IHL regime requires a number of specific rules, ${ }^{357}$ such as those on "protection of the civilian population" established under Article 51 of the Additional Protocol I. After a general statement confirming the customary nature of the principle of "civilian immunity", ${ }^{358}$ Article 51, paragraph 2 prohibits "acts or threats of violence the primary purpose of which is to spread terror among the civilian population". ${ }^{359}$ The rule forms part of the contemporary customary IHL. 360

The protection of civilians through the principle of distinction "transcends the contours of direct or even indiscriminate attacks" ${ }^{\prime 361}$ concerning also the central principle of proportionality which prohibits "[a]n attack which may be expected to cause incidental loss of civilian life, injury to civilians, damage to civilian objects, or a combination thereof, which would be excessive in relation to the concrete and direct military advantage anticipated". ${ }^{362}$ This rule is part of the contemporary customary IHL. ${ }^{363}$ The principle of proportionality, also known as the prohibition of excessive collateral damage to civilians or civilian objects, requires a preliminary military assessment of the direct and concrete military advantage of the attack in relation to the predictable collateral damage that the attack may provoke to the civilian population. Thus, an attack is forbidden if the resulted collateral damage will be excessive compared to the expected military advantage. While it is presumed that not all inconveniences to civilians may be avoided and IHL regime may only reduce loses, ${ }^{364}$ the principle forms part of the rules which positively affect women civilians in situations of conflict.

An important question in this context is whether specific forms of violence against women should (also) be treated as attacking them in a military way. This would mean that civilian women are being treated as military targets in violation of the principle of distinction. Wartime rape and other forms of sexual violence against women have been often treated as acts which can constitute "tactic of war" to "deliberately target civilians" and often used, inter alia, to

\footnotetext{
${ }^{356}$ AP I, Article 50(1).

357 AP I, Articles 48-58.

358 AP I, Article 51(1).

${ }^{359}$ AP I, Article 51(2); AP II, Article 13(2).

${ }^{360}$ ICRC, Customary IHL, Rule 2.

361 Dinstein, Yoram, "The Principle of Distinction and Cyber War in International Armed Conflicts", Journal of Conflict \& Security Law, Vol. 17, No. 2, (2012), p. 269.

362 AP I, Article 51(5)(b) and AP I, Article 57.

${ }^{363}$ ICRC, Customary IHL, Rule 14.

${ }^{364}$ Kalshoven, Frits, Reflections on the Law of War: Collected Essays, Martinus Nijhof, Leiden, 2007, p. 109.
} 
"instill fear" 365 or to implement a strategy of "expulsion through terror" in civilian members of a community or ethnic group. ${ }^{366}$ There is no doubt that wartime rape and sexual violence are often used with the primary purpose to spread the terror among civilians. ${ }^{367}$ However, as it will be discussed in the following Chapter, rape and sexual violence in war are prohibited per se, and not on the basis of an evaluation of the intent of the acting Parties to the conflict. Moreover, while the application of Article 51, paragraph 2 is conditional on the fulfillment to the requirement that these acts of violence do not offer "substantial military advantage", ${ }^{368}$ rape and sexual violence are always prohibited, irrespective of the military advantage that the Party could eventually take from it.

The principle of distinction prohibits not only deliberate attacks against civilians, but also "indiscriminate attacks", that is, attacks that do not aim at a particular military objective, or that employ a method or means of combat directed to indiscriminate targets, or which employ means of combat whose effects cannot be limited as required by IHL rules. ${ }^{369}$ This norm represents a significant limitation to the principle of military necessity and, as a consequence, a safeguard for the wide number of women civilians often casually close to conflict areas. ${ }^{370}$ Once again, it is important to underline that the norm is not referred to cases of rape and sexual

365 UN Security Council Resolution S/RES/1820, 19 June (2008). The Security Council has recognized the "political motivations" which often move the sexual attacks to women in the warfare in: UN Doc S/PRST/2013/, 12 February 2013, available at: https://www.securitycouncilreport.org/atf/cf/\%7B65BFCF9B-6D27-4E9C8CD3-CF6E4FF96FF9\%7D/s_prst_2013_2.pdf [last visited 24 March 2021]. The Secretary General of the UN Security Council has also recognized the use of sexual violence as a tactic of war and terrorism in Nigeria, as a tactic of war in the Central African Republic, para. 35 and also as a tactic that has been used to induce displacement. UN Security Council, Report of the Secretary General on "Conflict-related Sexual Violence", S/2019/280, 29 March 2019, paras. 13, 35, 137, available at: https://www.securitycouncilreport.org/atf/cf/\%7B65BFCF9B-6D27-4E9C-8CD3CF6E4FF96FF9\%7D/s 2019 280.pdf [last visited, 28 May 2020].

366 ICTY, Prosecutor v. Kunarac et al., Judgement, No. IT-96-23/T (2001), para. 579. The Court found that Bosnian Serbs used rape in the context of a widespread and systematic attack on civilians with the ultimate goal to drive the Muslims out of the region of Foča. In general, the extensive investigations and prosecutions of wartime sexual violence led by the ICTY raised a new consciousness about the power of rape as an effective tool of war for the intimidation and the persecution of the enemy.

367 The independent international fact-finding mission on Myanmar, established by the Human Rights Council, described the acts of rape and sexual violence committed by the Tatmadaw targeting the civilian population in Rakhine, Kachin and Shan States since 2011 as "hallmark", part of a deliberate strategy to intimidate, terrorize or punish a civilian population and they are used as tactic of war. See Human Rights Council, Report of the independent international fact-finding mission on Myanmar, 12 September 2018, A/HRC/39/64 para 79.

368 Pilloud, Claude, Sandoz, Yves, Swinarski, Christophe, and Zimmermann, Bruno, Commentary on the Additional Protocols...p. 618, para. 1940.

${ }^{369}$ AP I, Article 51(4)(a)(b)(c).

${ }^{370}$ It would be better to say that, nowadays, the conflicts are closer and closer to the civilians. A recent ICRC Report reveals the trend of the "urbanization of the armed conflicts". ICRC Report, "International Humanitarian Law and the Challenges of Contemporary Armed Conflicts", 2019, available at: https://www.icrc.org/sites/default/files/document/file list/challenges-report the-needs-of-civilians-inincreasingly-long-conflicts.pdf [last visited, 26 May 2020]. 
violence. It is true that these forms of violence against women could be a tactical or strategic way to weaken the enemy, in so often referred as "weapons of war" or "methods of warfare". 371

However, these characterizations are not used in a legal meaning. While a unique definition of "weapon" does not exist, the Weapons Law Encyclopedia of the Geneva Academy of International Humanitarian Law and Human Rights defines it as follows:

A weapon is a device that is construed, adapted or used to kill, injure, disorient, or threaten a person or to inflict damage on a physical object. A weapon may act through kinetic energy or by other means, such as transmission of electricity, diffusion of chemical substances or biological agents or sound, or direction of electromagnetic energy". ${ }^{372}$

The expression "method of warfare", which is used in the same sense as "means of combat" or "means of warfare", generally describes the way in which weapons are used by parties to an armed conflict. ${ }^{373}$ The description of rape and sexual violence as "weapons of war" or "methods of warfare", while potentially highlighting certain systematic violent practices of the combatants, may be confusing in the understanding of these two legal concepts and, consequently, misleading in the application of the law, ${ }^{374}$ as well as potentially obstructive for

\footnotetext{
371 The UN used the concept many times. See i.e. General Assembly Resolutions 48/143 (1993); Res. 49/196 (1995), 16; Res. 50/192 (1996), 1-3; Res. 51/115 (1997). It UN Doc. A/RES/48/143; Statement by the President of the Security Council, S/PRST/2004/46, 14 December 2004; Statement by the President of the Security Council, S/PRST/2005/25, 21 June 2005; Office of the High Commissioner for Human Rights, "Rape: Weapon of War", available at: www.ohchr.org/en/newsevents/pages/rapeweaponwar.aspx [last visited 26 March 2021]; UNICEF, "Sexual Violence as a Weapon of War", available at: www.unicef.org/sowc96pk/sexviol.htm [last visited, 26 March 2021]. See also, Gardam, Judith, "Women and the Law of Armed Conflict: Why the Silence?", International and Comparative Law Quarterly, Vol. 46, No. 1, (1997) 55-80, p. 59. For an understanding of the assumptions, the ontologies, the composition and the limits of the "rape as a weapon of war" discourse, see Eriksson Baaz, Maria and Stern, Maria, Sexual violence as a weapon of war? Perceptions, prescriptions, problems in the Congo and beyond, Zed Books, London-New York, 2013. The concept of rape as a "weapon of war" entered the collective imaginary and the common language, in so representing a good example of the international Community relevance in making visible world-scale issues and in conceptualizing them. Nowadays, the concept is well known and used all over the world, see, for example,. https://www.britannica.com/topic/rape-crime/Rapeas-a-weapon-of-war [last visited: 28 May 2020].

372 Weapons Law Encyclopedia, "Weapon", available at: http://www.weaponslaw.org/glossary/weapon [last visited, 26 March 2021]. Another, narrower, definition of "weapon" is given by the Program on Humanitarian Policy and Conflict Research, Harvard University, Manual on International Law Applicable to Air and Missile Warfare, 2009, p. 6: a weapon is "a means of warfare used in combat operations, including a gun, missile, bomb or other munitions, that is capable of causing either (i) injury to, or death of, persons; (ii) damage to, or destruction of, objects". See also the definition suggested by the ICRC: "weapon" refers to (i) an object, material, instrument, mechanism, device or substance that is used to (ii) kill, injure, damage, threaten or destroy". ICRC, "A Guide to the Legal Review of New Weapons, Means and Methods of Warfare: Measures to Implement Article 36 of Additional Protocol I of 1977', ICRC, Geneva, 2006, p. 9, fn. 17.

373 Pilloud, Claude, Sandoz, Yves, Swinarski, Christophe, and Zimmermann, Bruno, Commentary on the Additional Protocols...p. 621, para. 1957.

${ }^{374}$ For general debates over the use of the notion of methods of warfare to describe sexual violence, see e.g. Meger, Sara, "The Problematic Evolution of UN Resolutions on Women, Peace and Security", e-International Relations, (1 November 2012), available at: https://www.e-ir.info/2012/11/01/the-problematic-evolution-of-unresolutions-on-women-peace-and-security/ [last visited, 26 March 2021].
} 
the investigations. ${ }^{375}$ In any case, while rules on the prohibition of rape and sexual violence concern the treatment of persons in the hands or power of the enemy, the application of the principle of distinction requires an examination of the lawful or unlawful use of weapons and methods of war in the conduct of hostilities. ${ }^{376}$ Thus, weapons and methods of warfare are considered unlawful on the basis of an evaluation of their indiscriminate nature; on the contrary, rape and sexual violence are as such contrary to the basic principle of human treatment of persons, and prohibited by IHL per se. Since these forms of violence are always committed against persons hors de combat and they are proscribed in any case, no further analysis on whether they cause superfluous injury or unnecessary suffering ${ }^{377}$ is required.

In other words, the narrative of rape and sexual violence as weapons of war or means of war has undoubtedly contributed to a better understanding of this endemic wartime phenomenon, often not limited to single and isolated episodes but systematically designed as a "deliberate policy"378 and often translated in a "political event" 379 . In this sense, the use of these terms aptly evokes the strategical function and the military utility that these forms of violence against women may assume in the warfare, contributing to their international stigmatization, ${ }^{380}$ and becoming "common bridge" concepts "between academia and other worlds of politics, policy and media" 381 . However, the "universalizing composition" 382 of the rape as a weapon of war risks not only to reduce a complex problem to fixed linguistic expressions that do not always

\footnotetext{
375 The narrative of rape as a weapon of war presumes the existence of a certain level of military collective intentionality and functionality of the act, which is not always present in the warfare.

376 See in this regard, Gaggioli, Gloria, "Sexual violence in armed conflicts: A violation of international humanitarian law and human rights law", International Review of the Red Cross, Vol. 96, No. 894, (2014) 503538, p. 518.

377 AP I, Article 35; ICRC, Customary IHL, Rule 70.

${ }^{378}$ Niarchos, Catherine N., "Women, war, and rape: Challenges facing the International Tribunal for the Former Yugoslavia", Human Rights Quarterly Vol. 17, No. 4, (1995) 649-690, p. 658.

${ }^{379}$ Seifert, Ruth, "War and rape: A preliminary analysis", in Stiglmayer, Alexandra (ed.), Mass rape: The war against women in Bosnia-Herzegovina, University of Nebraska Press, Lincoln,1994, p. 68.

${ }^{380}$ Benshoof, Janet, "The Other Red Line: The Use of Rape as an Unlawful Tactic of Warfare", Global Policy, Vol. $5, \quad$ No. 2, (May 2014), available at: http://www.globaljusticecenter.net/documents/JB $\% 20$ Global $\% 20$ Policy $\% 20$ Article.The $\% 20$ Other $\% 20$ Red $\% 20$ Line\%205.21.14.pdf [last visited: 31 May 2020]. The author sustains that addressing strategic rape under the IHL regime governing the legality of weapons and tactics used in war would increase its stigmatization. Thus, she suggests to distinguish the opportunistic rape from the strategic rape in order to effectively deterring from the use of the latter in war.

${ }^{381}$ Zarkov, Dubravka, "Conceptualizing Sexual Violence in Post-Cold War Global Conflicts", in Hagemann, Karen, Dudink, Stefan and Rose, Sonya O. (eds.), The Oxford Handbook of Gender, War, and the Western World since 1600, Oxford University Press, Oxford, 2020, p. 729.

${ }^{382}$ Eriksson Baaz, Maria and Stern, Maria, Sexual violence as a weapon of war? Perceptions, prescriptions, problems in the Congo and beyond,...p. 109.
} 
represent the full reality, ${ }^{383}$ but also to confuse the application of norms related to the conduct of the hostilities - which also requires an impact and injury assessment - with the rules concerning the treatment of individuals. In other terms, the categorization of rape as a weapon of war or a method of war not only offers a partial account of this form of wartime sexual violence, leading to a "problematic homogenization" of a complex phenomenon, ${ }^{384}$ but also do not properly express a legal concept. From a gender perspective, thus, it does not appear necessary to adopt an extensively broad interpretation of the IHL concepts of "weapon" or "method of warfare" so to include rape and other forms of sexual violence.

Together with the abovementioned principles, women also benefit of a series of norms not specifically addressed to them but related to civilians, protected persons, prisoners of war. One may refer, for example, to the general norms of the third Geneva Convention for the protection of the prisoners of war, "to which the principle [along with women should in general receive more favourable treatment] is applicable, although it has not been explicitly mentioned".385 These norms are: Article 13, paragraph 2, concerning the protection of prisoners of war against insults and public curiosity; Article 17, introducing relevant guarantees for the prisoners of war during the questioning; Article 26, stating the principal duty of the Detaining Power to provide prisoners with food; Article 27, regarding the provision of adequate clothing in case of need; Article 38, affirming the Detaining Power duty to ensure the practice of intellectual, educational, and recreational pursuits, sports and games amongst prisoners; Article 46, concerning the minimal conditions for the transfer of prisoners; and Article 79, regulating the practice of prisoners' representatives.

\footnotetext{
${ }^{383}$ Not all rape and other forms of sexual violence in war are tactical: they may also be part of micro-dynamics of violence in war. Even when they are conceived as a tactic of war, the strategic character of rape and sexual violence may vary over time and in different war settings from cases in which rape assumes the role of safeguarding the commanders' positions to cases in which it is built as a non-strategy. Wood, Elisabeth Jean, "Sexual violence during war: variation and accountability", in Smeulers, Alette (ed.), Collective Violence and International Criminal Justice, Intersentia, Antwerp, 2010. The author also makes a distinction between a strategy and a tactic. The former is described as a military plan formulated by high-ranking military leaders and would employ military units for the achievement of certain objectives, in a top-down logic. The tactic consists of a bottom-across logic means used by low-ranking military units to implement the strategy (pp. 316-318). See also, Leiby, Michele, "Wartime sexual violence in Guatemala and Peru", International Studies Quarterly, Vol. 53, No. 2, (2009) 445-468.

${ }^{384}$ Buss, Doris E., "Rethinking 'Rape as a Weapon of War"', Feminist Legal Studies, Vol. 17, (2009), 145-163, p. 161. After offering an updated debate on the ways wartime sexual violence and rape have been conceptualized over the past decades, Zarkov sustains that the "rape as a weapon of war" narrative also supports certain geopolitical assumptions along with the rapist is always the non-Western man. In this way, sexual violence against women in war may be used as a justification for the Western military interventions around the world. See Zarkov, Dubravka, "Conceptualizing Sexual Violence in Post-Cold War Global Conflicts".

${ }^{385}$ Commentary, Vol. III, p. 147.
} 


\subsection{Concluding remarks}

This Chapter analysed the system of the IHL norms related to women's condition during armed conflict. These can be either rules that explicitly have women as their subject or rules that are de facto particularly relevant for women. Emphasis has been given to the study of those rules whose application appears particularly critical from a gender perspective.

In particular, it emerged that some limits in the application of IHL norms to women are strictly connected with the challenges that the IHL regime generally faces in modern war. For example, the principle of non-discrimination against women has not been conceived to face the consequences of situations of prolonged occupation. This is a problem that transcends the condition of women in war - but also disproportionate affects women. The analysis showed that on many occasions, such as for the health treatment of pregnant women in war, IHL norms are sufficiently broad to encompass the various forms of violence women are subjected to in the warfare. Read from a gender-sensitive perspective, basic IHL norms may be interpreted as to provide for an adequate treatment and protection for women.

Ultimately, the analysis suggested that, despite the existence of limitations in the wording of the norms, the normative framework does leave "room for new insights and perspectives generated by new contexts". ${ }^{386}$ State practice may play a relevant role in strengthening the IHL regime protecting women in situations of conflicts by using a gender-sensitive interpretation, providing an effective implementation of the relevant provisions, and elevating the standards of protection. An interpretation of IHL norms that takes into account the specificities of the female experience of war seems not only to shed light to the female experience of war, but also to constitute the basis for a reinterpretation and even a general development of this body of law. It is here suggested that the process of gender-oriented interpretation of IHL norms may even trigger broader reflections for IHL and help confronting some of the major issues of the modern conflicts, such as prolonged occupation.

\footnotetext{
${ }^{386}$ Bartlett, Katharine T., "Feminist Legal Methods", Harvard Law Review, Vol. 103, (1989) 829-888, pp. 852-
} 853. 


\section{Article 27(2) of The Fourth Geneva Convention: The CONCEPTS OF "HONOUR" AND "RAPE"}

The Geneva Conventions contain only few specific provisions related to the protection of women against sexual violence during armed conflict: Article 27 of the Fourth Geneva Convention, Articles 75 and 76 of the First Additional Protocol to the Geneva Conventions, and Article 4 of the Second Additional Protocol to the Geneva Conventions. The first provision in Section I of Part III of the Forth Geneva Convention, Article 27, opens the Part related to the "status and treatment of protected persons", which establishes a specific and more detailed regime in favor of certain categories of persons. As it has been noted during the Diplomatic Conference of 1949, Part III "constitutes the main portion" of the Convention. ${ }^{387}$ This Chapter focuses on Article 27 of the Fourth Geneva Convention (CG IV), and especially its second paragraph, which is central for understanding the position of women in IHL and displaying the potential of an evolutive interpretation of the norms addressing the female experience in war. First, a general introduction on Article 27 of CG IV is offered (3.1.). Then, the Chapter turns to two concepts provision that are critical for women in armed conflict and have been thoroughly discussed and criticized by feminist scholars: "honour" (3.2.) and "rape" (3.3.). The Chapter concludes that Article 27 of CG IV is a prime example of how IHL norms can be interpreted to accommodate insights from a gender perspective and overcome approaches and language harbouring gender bias.

\subsection{Article 27 of GV IV and its role in protecting women against sexual violence}

According to Article 27,

Protected persons are entitled, in all circumstances, to respect for their persons, their honour, their family rights, their religious convictions and practices, and their manners and customs. They shall at all times be humanely treated, and shall be protected especially against all acts of violence or threats thereof and against insults and public curiosity.

\footnotetext{
${ }^{387}$ Federal Political Department of Switzerland, Final Record of the Diplomatic Conference of Geneva of 1949, Berne, Vol. II, Section A, p. 821 [therein: Final Record, Vol. II].
} 
Women shall be especially protected against any attack on their honour, in particular against rape, enforced prostitution, or any form of indecent assault.

Without prejudice to the provisions relating to their state of health, age and sex, all protected persons shall be treated with the same consideration by the Party to the conflict in whose power they are, without any adverse distinction based, in particular, on race, religion or political opinion.

However, the Parties to the conflict may take such measures of control and security in regard to protected persons as may be necessary as a result of the war.

As it has been noted, ${ }^{388}$ the first paragraphs of this Article stem from Article 3 of the 1929 Geneva Convention on the prisoners of $w^{389}{ }^{389}$ and Article 46 of the Hague Regulations ${ }^{390}$. Following the structure of Article 3 of the 1949 Geneva Convention, a first general provision requiring for protected persons the respect for fundamental rights - related to "their person, their honour, their family, and religious convictions and practices, and their manners and customs" - and human treatment in all circumstances is followed by a specific paragraph related to the treatment for women.

"Protected persons" are "those who, at a given moment and in any manner whatsoever, find themselves, in case of a conflict or occupation, in the hands of a Party to the conflict or Occupying Power of which they are not nationals". ${ }^{391}$ This means that protection is accorded to all persons of foreign nationality and to persons without any nationality. On the one hand, nationals of a Party to the conflict or Occupying Power do not fall within the scope of application of the provision, confirming, thus, the traditional idea according to which international law should not interfere with state relationship with its own nationals. The ad hoc tribunals have adopted, however, a broad interpretation of Article 4 of GV IV leading to an enlargement of the category of protected persons. Based on the object and purpose of Article 4 of GC IV, which is directed "to the protection of civilians to the maximum extent possible", the ICTY considers the applicability of the provision not depending "on formal bound and

\footnotetext{
${ }^{388}$ Commentary, Vol. IV, p. 201.

${ }^{389}$ Article 3 of the 1929 Geneva Convention states: "Prisoners of war are entitled to respect for their persons and honour. Women shall be treated with all consideration due to their sex".

390 Article 46 of the Hague Regulations states: "Family honour and rights, the lives of persons, and private property, as well as religious convictions and practice, must be respected private property cannot be confiscated". ${ }^{391}$ GC IV, Article 4.
} 
purely legal relations" but on "the substance of relations". ${ }^{392}$ The broad reading of Article's 4 personal scope notwithstanding, it should be noted that the Fourth Geneva Convention covers only international armed conflicts, so that its concrete applicability is significantly reduced.

One of the noticeable elements of this Article is that the generality of the norm is "interrupted" by a paragraph dealing exclusively with a specific category of persons: women. The members of Committee III of the Diplomatic Conference decided to dedicate a special protection to women as "an equally general principle [to the general principle of protection laid down in paragraphs 1 and 3] respect due to women". ${ }^{393}$ Why did Committee III need to introduce a special provision related to the protection of women? Was the protection assured by paragraphs 1 and 3 inadequate to women's condition in warfare?

The Commentary to Article 27 reveals that a new consciousness about the heinous acts that women experience during war universally developed after the World War II. A new understanding of the brutal treatment women were subjected to by troops "revolt[ed] the conscience of all mankind" and made clear "the necessity of proclaiming that women must be treated with special consideration". ${ }^{394}$ The introduction of a specific paragraph for women civilians signals an evolving awareness concerning female experience of war: the main set of rules regarding the protection of civilians in international humanitarian law could not ignore it anymore. In so doing, IHL recognized that the commitment of acts of violence during armed conflicts specifically against women is legally relevant, thus making a millenarian phenomenon internationally visible. Thereafter, such acts of violence would constitute not only morally regrettable behaviors, but also specific violations of international humanitarian law. It must be underlined that this understanding was not a spontaneous achievement, but a result of indirect

\footnotetext{
392 ICTY, The Prosecutor v Dusko Tadić on the Defence Motion for Interlocutory Appeal on Jurisdiction, IT-941-AR72, Appeals Chamber, Decision, 2 October 1995, para 166. Indeed, "it would be incongruous with the whole concept of human rights, which protect individuals from the excesses of their own governments, to rigidly apply the nationality requirement of article 4". ICTY, The Prosecutor v Zejnil Deladić et al (Čelebići camp), Trial Judgment, IT-96-21-A, 16 November 1998, para 266.

As a result, the identification of nationals or not national has been determined not only on the basis of the formal tie of nationality, but also using other criteria, such as ethnicity and allegiance. The adoption of this approach led the courts to qualify as 'protected persons' also victims of the same nationality of their perpetrators but with different ethnicity or allegiance. Other rulings expressing this comprehensive interpretation of the term 'national' see ICTY, The Prosecutor v. Zlatko Aleksovky, Appeals Chamber Judgment, IT-94-1-A, 15 July 1999, para 146; ICTY, The Prosecutor v. Zejnil Deladić et al (Čelebići camp), Appeals Chamber Judgment, IT-96-21-A, 20 February 2001, para 73; ICC, The Prosecutor v. Thomas Lubanga Dyllo, Pre-Trial Chamber, Decision on the confirmation of charges, ICC-01/04-01/06, 29 January 2007, paras 277-80; ECCC, The Prosecutor v. Duch, No 001/18-07-2007/ECCC/TC, Judgment, 26 July 2010, paras 425-6.

${ }^{393}$ Final Record, Vol. II, p. 821.

${ }^{394}$ Commentary, Vol. IV, p. 205.
} 
but resolute intervention of women's groups. Indeed, the Final Record of the Diplomatic Conference of Geneva reveals that the second paragraph follows exactly the text proposed to the International Committee of the Red Cross by the International Women's Congress and the International Federation of Abolitionists.

Article 27, paragraph 2 represents per se a real advancement in the protection of women during armed conflict, because it is the first provision which deals with women in conflict situations as special protected persons and attributes legal relevance to women's experience during situations of conflict. Nevertheless the concrete application of this rule and whether it provides an adequate protection for women has raised important discussions. From this perspective, two critical aspects of the norm need to be analyzed: the use of the term "honour" as an allegedly outdated concept; and the nature of the crime of rape in the international legal system.

\subsection{The concept of "honour" from a contemporary perspective}

Article 27, paragraph 2 first guarantees women special protection against "any attack on their honour" and then it gives a short list of acts that are particularly representative of this kind of violence. The use of the concept of "honour" has been criticized for being inadequate to express the physical and psychological violence that women are subjected to in time of war. In particular, this line of reasoning points out that "honour" embodies a gendered idea of sexual violence against women. It addresses this kind of violation as a family and social harm more than a violation of the individual integrity of the woman, thus, inadequately reflecting the gravity of the offence. ${ }^{395}$

\footnotetext{
395 This critique to the tenor of Article 27, paragraph 2 can be found in many feminist texts. Hilary Charlesworth and Christine Chinkin think that, by "designating rape as a crime against 'honour' rather than one of violence, the provision [in the Fourth Geneva Convention] presents women as male and family property". Charlesworth, Hilary, and Chinkin, Christine, The Boundaries of International Law: A Feminist Analysis, Manchester University Press, Manchester, 2000, p. 314. Ronda Copelon argues that considering sexual violence as an attack to honor risks to reinforce "the social view, internalized by women, that the raped woman is dishonorable". Copelon, Rhonda, "Surfacing Gender: Re-engraving Crimes Against Women in Humanitarian Law", Hastings Women's Law Journal, Vol. 5, No. 2, (1994) 243-266, p. 249. The same position is assumed by Gardam, Judith, "Women and the Law of Armed Conflict: Why the Silence?", International and Comparative Law Quarterly, Vol. 46, No. 1, (1997) 55-80; Gardam, Judith and Jarvis, Michelle, Women, Armed Conflict and International Law, Kluwer Law International, The Hague, 2001; Niarchos, Catherine N., "Women, War and Rape: Challenges Facing the International Tribunal for the Former Yugoslavia", Human Rights Quarterly, Vol. 17, No. 4, (1995) 649-690, p. 671; and Gardam, Judith, "Women, Human Rights and International Humanitarian Law", Int'l Rev. Red Cross, Vol. 25, No. 839, (1998) 324-421; Bennoune, Karima, "Do We Need New International Law to Protect Women in Armed Conflict?", Case Western Reserve Journal of International Law, Vol. 38, No. 2, (2006-2007) 363-392.
} 
The Geneva Conventions do not provide a definition of "honour". In order to better understand the meaning of the term "honour", one should first turn to a systematic interpretation, looking at the other provisions that expressly contain the term. The term "honour" is used a number of times in international humanitarian law Conventions. Apart from Article 27 of the Fourth Geneva Convention and Article $46^{396}$ of the 1907 Hague Convention which deals with the respect of "family honour", the word is associated with men combatants and prisoners. In particular, Articles $10^{397}$ and $12^{398}$ of the Hague Convention (II) of 1989, the respectively Articles 10 and 12 of Hague Convention (IV) of 1907, and Article 21 of the Third Geneva Convention of 1949 permit prisoners to be released if they promise on parole and rest "bound on their personal honour" to the engagements contracted - otherwise they lose their right to be treated as prisoners of war. Article 35 of the Hague Convention IV of 1907 requires the contracting parties to consider rules of "military honour" in cases of capitulations. Article 3 of the Geneva POW Convention of 1929 and Article 14 of the Third Geneva Convention of 1949 deal with the treatment of prisoners of war who are "entitled to respect for their persons and honour". The term also occurs with regards to honorable burial in Article 76 of Geneva POW Convention of 1929, Articles 17, 120 and 130 of, respectively, the First, the Third and the Fourth Geneva Convention of 1949. Dealing with the fundamental guarantees, Articles 75 and 76 of, respectively, First and Second Additional Protocols to the Geneva Conventions entitle persons who are deprived of certain rights during detention to "respect for their person, honour".

Despite these many references, the content of honour is not settled. The Conventions of international humanitarian law use the term with different connotations depending on the context and the subject to whom they refer. Commonly, "honour" has been employed for combatants as synonymous of the military bravery and virtue, which men must express in the warfare. In this sense, the concept embodies a set of practices and rules which go back to the ancient Romans ${ }^{399}$ and are rooted in the centenarian chivalry military tradition governing the

\footnotetext{
${ }^{396}$ For the text of the norm, see note 386.

${ }^{397}$ Hague Convention II, Article 10: "Prisoners of war may be set at liberty on parole if the laws of their country authorize it, and, in such a case, they are bound, on their personal honor, scrupulously to fulfill, both as regards their own Government and the Government by whom they were made prisoners, the engagements they have contracted".

${ }^{398}$ Hague Convention II, Article 12: “Any prisoner of war, who is liberated on parole and recaptured, bearing arms against the Government to whom he had pledged his honor, or against the allies of that Government, forfeits his right to be treated as a prisoner of war, and can be brought before the Courts".

${ }^{399}$ Cicero states: "Nature has made us, as I have said before - it must often be repeated — enthusiastic seekers after honor, and once we have caught, as it were, some glimpse of its radiance, there is nothing we are not prepared to
} 
combatants in the battlefield. ${ }^{400}$ Currently, the concept of chivalry - intended to incapsulate military honour and embodied in a set of norms mandated both by national military codes and law of war and by military cultural training - seems to face a crisis among military circles. ${ }^{401}$ Some authors express negatively with regard to the recent process of rejection of the concept, considering it still helpful for the maintenance of some of the positive requirements that it encloses, ${ }^{402}$ for the its core meaning of respect for the person's "self-worth and also the value of that person in the eyes of others", 403 as well as for conceptualizing and "imposing certain demanding ethical-legal soldierly duties". ${ }^{404}$ In any case, honour is a code by which many men and women are raised, and by which they define and lead their lives. Therefore, the concept of honour is more complex than merely a 'value' term". 405

bear and go through in order to secure it. It is from this rush, this impulse from our soul towards true renown and reputation that the dangers of battle are encountered; brave men do not feel wounds in the line of battle, or if they feel them prefer death rather than move one step from the post that honor has appointed". Tusculanae Disputationes II.58 [translation in: Olsthoorn, Peter, Honor in Political and Moral Philosophy, SUNY Press, 2015 , p. 21].

${ }^{400}$ For a comprehensive analysis of the relevance of chivalry in relation to warfare past and present, the possibility to consider it as a principle of IHL and its relationship to the law of armed conflict, see Gill, Terry, "Chivalry: A Principle of the Law of Armed Conflict?", in Matthee, Mariëlle, Toebes, Brigit, Brus M.M.T.A. (eds.), Armed Conflict and International Law: In Search of the Human Face, T.M.C. Asser Press, The Hague, 2013. For a more limited concept of chivalry, see Fenrick, William J., "The Rule of Proportionality and Protocol I in Conventional Warfare”, Military Law Review, Vol 98, No. 1, (1982) 91-127, p. 94.

401 Wallach, Evan, "Pray Fire First Gentlemen of France: Has 21st Century Chivalry Been Subsumed by Humanitarian Law?", Harvard National Security Journal Vol. 3, (2012) 431-469, pp. 431-444.

${ }^{402}$ Wallach identifies five current chivalric requirements: courage, trustworthiness, mercy, courtesy and loyalty. Ibid. pp. 443-459. The author suggests that the main difference between chivalry and IHL is that the first "mandates actions and punishes inactions that IHL can only recommend". Ibid. p. 460.

${ }^{403}$ Arman particularly focuses on the prisoner's honor, supporting the idea along with the term honor has not lost its relevance today. Despite the challenging in interpreting the concept, namely that concept of honour has become outdated, or that is necessarily sexist, or that it has a culture-specific meanings, it is worth to find a modern meaning to the concept according to the fundamental protections provided by the Third Geneva Convention. Arman, Jemma, "GCIII Commentary: Protecting the Honour of Prisoners of War", ICRC's Humanitarian Law \& Policy blog, (September 3, 2020), available at: https://blogs.icrc.org/law-and-policy/2020/09/03/gciiicommentary-honour-prisoners-of-war/\# ftn3 [last visited, 26 October 2020].

${ }^{404}$ Bohrer, Ziv, "Divisions over Distinctions in Wartime International Law", in Bohrer, Ziv, Dill, Janina and Duffy, Helen, (eds.), Law Applicable to Armed Conflict, Max Planck Trialogues on the Law of Peace and War (Anne Peters and Christian Marxsen series eds.), Vol. 2, Cambridge University Press, Cambridge, 2020, 106-196, p. 189. The author analyses the concept of chivalry as an example to demonstrate the benefits which can occur in case of application of existing IHL rules instead of promoting an IHRL wartime application and a rights-oriented reading of IHL. In particular, the increased influence of IHRL on IHL could lead to an extreme approach to the right to life that, associated with a "first-soldier position", would paradoxically affect the protection of civilians in the warfare.

${ }^{405}$ Lindsey, Charlotte, “The impact of armed conflict on women”, in Durham, Helen and Gurd, Tracey (eds.), Listening to the silence: women and war, Brill, Leiden, 2005, p. 33. 
The chivalric connotations of "honour" have had some influence in shaping the specific meaning of the term with regard to women, where it is related to the preservation of the female modesty, chastity and purity. ${ }^{406}$ As Gardam and Jarvis put it,

The notion of women's honour that we find in IHL is a masculine construct that bears little relation to the reality of sexual violence for women. Christian and chivalric principles have contributed much to the "honour" of women in IHL. ${ }^{407}$

The defence of women's honour demands the combatants not to rape or commit indecent assaults. From this perspective, the term "honour" seems indeed gender-oriented in that it reflects the social construction of what male and female should be and how combatants must behave to preserve this categorisation.

Some scholars seem to support this approach, arguing that the concept of honour applied in relation to women should be conceptualized separately, as a special type of honour "held exclusively by women". ${ }^{408}$ This assertion would be reinforced by the Commentary to Article 27, which states "woman should have an acknowledged right to special protection, the special regard owed to women being, of course, in addition to the safeguards laid down in paragraph 1". ${ }^{409}$ This additional honour-based protection for women would be associated with the alleged character of sexual purity as inherent quality of women's honour. Pictet's words seem to confirm this linkage between women's honour as modesty and the need of a special protection: "women [...] have an absolute right to respect for their honour and their modesty, in short, for their dignity as women". 410

That said, what did the State parties to the Geneva Conventions intend for "women's honour" at the time of the ratification of the Conventions? It seems realistic to say that the parties conceived the term honour in terms of respect for purity and chastity, when they used it with regard to women. In this sense, Article 27, paragraph 2 of the IV Geneva Convention seems to

\footnotetext{
406 Gardam and Jarvis note that "Christian and chivalric principles have contributed much to the 'honour' of women in IHL [...] Knights were the 'natural' protectors of women who, in a portrayal that continues today [...] were weak modest, docile, incapable of looking after themselves, and thus condemned to highly stylized inferior role in society". See Gardam, Judith and Jarvis, Michelle, Women, Armed Conflict...p. 108.

${ }^{407}$ Ibid.

${ }^{408}$ Crowe, Anna, "'All the regard due to their sex': Women in the Geneva Conventions of 1949", Harvard Research Working Paper Series, HRP 16-001, (December 2016), p. 13, available at: http://hrp.law.harvard.edu/wp-content/uploads/2016/12/Anna-Crowe HRP-16 001.pdf [last visited 15 March 2019].

${ }^{409}$ Uhler, Oscar M., Coursier, Henri, Commentary. IV Geneva Convention...p. 205.

${ }^{410}$ Ibid. p. 206 (emphasis added).
} 
suffers from «an approach still limited to protect honour and not the person as such». ${ }^{411}$ Even if true, this would not exclude, however, the development of the concept of honour beyond these original conceptualizations.

In order to address the issue of what honour means today, one needs to identify and specify the problems associated with this meaning. Why does it matter if honour is a concept associated primarily with a gender stereotype or if it can be given a meaning beyond this? The concept of honour could indeed raise two types of problems: a symbolic issue and a legal issue. The symbolic problem involves the importance of using the concept of honour to deal with crimes against women from a linguistic and symbolic perspective. As for the second issue, namely the legal issue, it must be clarified whether, and eventually how, the use of "honour" affects the legal protection of women in the warfare.

\subsubsection{The symbolic issue}

The symbolic issue requires a brief examination of the symbolic consequences that could derive from the use of the term honour in a norm protecting women from conflict-related sexual violence. For this purpose, a brief analysis of the etymology of the term honour and its relevance in human history could be supportive.

The word "honour" comes from the Latin honos (the form used by Cicero) and later honor ${ }^{412}$ and it is connected to the word honestus. While its meaning and relevance for the societies using it changed over time and across cultures, ${ }^{413}$ an older and a modern concept of the term could be distinguished.

The older meaning of honour - which can still be found in some groups and in the military links a certain status and, consequently, the reputation of a person, to his/her ability to use force. In this case, violence is the means to preserve society's structures and the honour codes

\footnotetext{
${ }^{411}$ La Rocca, Simona, "Le violenze di genere nei conflitti armati: nome e politiche di contrasto", in La Rocca, Simona (ed.), Stupri di guerra e violenza di genere, Ediesse, Roma, 2015, p. 50. [translation of the author from the Italian original text: "un approccio ancora limitato a tutelare l'onore e non la persona in quanto tale"].

${ }^{412}$ Online Etymology Dictionary, 'Honor', available at: https://www.etymonline.com/word/honor [last visited, 26 March 2021].

${ }^{413}$ An overview of the philosophy around the concept of honour from Cicero to Amartya Sen can be found in: Olsthoorn, Peter, Honor in Political and Moral Philosophy, SUNY Press, New York, 2015, cap 1. In particular, the author explains the idea along with, even in democratic societies - more individualistic and less constrained in specific rules of honour - honour can still play a role.
} 
are the representation of "the blatant stratification of the violent over the unviolent". ${ }^{414}$ As a consequence, "because violence has historically been the responsibility of men, honor has often been synonymous with masculinity itself". ${ }^{415}$ Analysing this culture of honour from a gender perspective, it can be said that it helped sustaining patriarchal regimes, based on the rigid distinction between the public sphere, dominated by men, and the private sphere, designated to women, and as "a manifestation of legal privilege that dispenses licenses along gender lines" ${ }^{416}$ Seen from this perspective, the use of the term honour in Article 27 of the IV Geneva Convention could create a problem of symbolisms and gendered language in that it could perpetuate the gender stereotype, according to which women's honour - which cannot be expressed in terms of her ability to use force - is strictly connected to the passive status of chastity and pureness of females.

In recent times, the concept of honour is treated by some as obsolete. Its reduced use should be basically attributed to the development of the culture (and language) of dignity. Indeed, the concept of dignity has supplanted in many contexts the notion of honour because of its more democratic and universalistic scope ${ }^{417}$ Leaving aside the philosophical debate on the distinction between dignity and honour, a group of philosophers and sociologists argue that there is a modern concept of honour that can still play a relevant role in our societies - including the interpretation of the law. According to this view, since codes and cultures of honour have always been relevant for regulating human life in communities, it is preferable to focus on amending the grounds of honor and modifying the honour codes, ${ }^{418}$ rather than abandoning the concept altogether or fighting against its use. There is indeed an import function for honour in

\footnotetext{
${ }^{414}$ Collins, Randall, Violence: A micro-sociological theory, Princeton Univ. Press, Princeton, 2008, p. 233.

415 Black, Donald, Moral time, Oxford Univ. Press, New York, 2011, p. 72.

416 Romany, Celina, "State responsibility goes private: a feminist critique of the public/private distinction in International Human Rights Law", in Cook, Rebecca (eds.), Human rights of women. National and international perspectives, University of Pennsylvania Press, Philadelphia, 1994, p. 90.

417 Olsthoorn well clarifies the philosophical foundation of the Kantian concept of dignity, as intrinsic character of all rational beings, regardless of their social status. Kant distinguishes dignity from honour, considered a hierarchical concept because connected with the behaviour or the character of the person. Olsthoorn, Peter, Honor in Political and Moral Philosophy,... pp. 134 ss.

${ }^{418}$ Appiah, Kwame Anthony, The honor code: How moral revolutions happen, Norton, New York, 2010, pp. $137-$ 172. In studying some sociological and moral revolutions, the author expresses the idea of changing the ground of honour instead of leaving the concept aside especially with regards to struggles against practices of violence against women. He sustains the idea that many forms of violence against women are connected with a wrong idea of honour, so that only reforming the concept of honour it would be possible to fight against gender violence. For example, sustaining the idea that violence against women is a form of dishonor will transform such acts in shameful practices.
} 
our vocabularies as well as in social and legal practice. As Simone Weil aptly expresses this idea,

Honour is a vital need of the human soul. The respect due to every human being as such, even if effectively accorded, is not sufficient to satisfy this need, for it is identical for every one and unchanging; whereas honour has to do with a human being considered not simply as such, but from the point of view of his social surroundings. This need is fully satisfied where each of the social organisms to which a human being belongs allows him to share in a noble tradition enshrined in its past history and given public acknowledgment. ${ }^{419}$

Weil's definition of honour makes clear the close connection between each human being and his/her community, its social surroundings. Honour appears to define human beings' life by contributing to shaping our identities. But honour cannot be reduced to a mere concern for reputation and public recognition, because the concept is concerned with "the self-respect of those seeking honor as much as the respect of others". ${ }^{420}$ In that regard, a renewed understanding of the concept of honour, disconnected from a code of violence, would be useful to help identifying the fundamental character of each human being considered as a social being.

Coming back to the text of Article 27, paragraph 2 of the IV Geneva Convention, the concept of honour needs to be read critically in light of its significance at the symbolic level. There is merit in the view suggested above that a more modern understanding of honour is possible and actually preferable to abandoning its use altogether. Of course, in the context of Article 27, paragraph 2 of the IV Geneva Convention abandoning 'honour' is not possible, as it forms part of the text of the rule. One thus needs to be aware of the connotations and symbolic repercussions of using an outdated version of the term, connected with a patriarchal idea of subordination of women and a male-controlled society. This understanding of the term honour does not respond anymore to the current conception of violence against women as a crime against the integrity of the person. As Cherif Bassiouni put it, the apparent connection between sex and morality interferes on our view of rape and sexual violence in two ways: victims are not believed and rape is not considered a harmful act. On the second issue,

\footnotetext{
${ }^{419}$ Weil, Simone, The Need for Roots. Prelude to a Declaration of Duties towards Mankind, Routledge, London and New York, 2001, p. 18. [Original text: L'honneur est un besoin vital de l'âme humaine. Le respect dû à chaque être humain comme tel, même s'il est effectivement accordé, ne suffit pas à satisfaire ce besoin ; car il est identique pour tous et immuable ; au lieu que l'honneur a rapport à un être humain considéré, non pas simplement comme tel, mais dans son entourage social. Ce besoin est pleinement satisfait, si chacune des collectivités dont un être humain est membre lui offre une part à une tradition de grandeur enfermée dans son passé et publiquement reconnue au-dehors. Weil, Simone, L'enracinement. Prélude à une déclaration des devoirs envers l'être humain. Paris : Les Éditions Gallimard, 1949].

${ }^{420}$ Appiah, Kwame Anthony, The honor code...p. 134.
} 
Violent crimes are viewed generally as more serious than crimes to property or nonviolent crimes. The violence inherent in rape is often difficult to detect. First, the physical signs of rape are often internal and not readily visible. Secondly, rape and sexual assault do not always leave lasting physical signs even internally. Thus, rape and sexual assault are often referred to as crimes of "honour," which do not sound as serious. Though the language throughout international law concerning women's honour may reflect a sensitivity to the fact that victims are punished a second time by societies that value women's chastity as a measure of worth, it obscures the fact that rape and sexual assault are violent crimes that cause lasting physical and psychological harm. ${ }^{421}$

In this respect, the use of the term honour in Article 27 could indeed support some gender stereotypes that connect women's morality to chastity and purity, and that consider sexual assaults to women as a source of women's dishonor and shame. Thus, when interpreting or applying Article 27, paragraph 2 of the IV Geneva Convention one needs to be conscious of these inherent issues and put this concept in a context that reinforces the more modern understanding sketched above.

\subsubsection{The legal issue}

In order to understand whether the critics to the concept of honour have a merely symboliclinguistic relevance or whether they could also have a legal relevance, it is necessary to examine whether its strict interpretation could negatively affect the level of protection guaranteed to women in warfare. In other terms, one may ask whether the scope of application of the norm (Article 27, paragraph 2 of the IV Geneva Convention) would be reduced in case of interpretation of the term honour in merely terms of chastity and purity.

To this end, three issues should be addressed. First, it the core essence of the norm must be identified in order to ascertain which behaviours are prohibited by Article 27, paragraph 2 of the IV Geneva Convention (3.2.2.1). Secondly, one may ask whether the concept of honour could be still useful when addressing the contemporary condition of women in situations of armed conflict. In other words, it shall be clarified whether honour can be still valuable for a legal understanding of the different forms of sexual violence against women in situations of armed conflict (3.2.2.2). And finally, it should be analysed whether the vagueness of this term could permit an evolutive interpretation of its meaning, which better responds to the current understanding of the women's experience of warfare (3.2.2.3).

\footnotetext{
${ }^{421}$ Cherif Bassiouni, Mahmoud, Crimes Against Humanity: Historical Evolution and Contemporary Application, Cambridge University Press, Cambridge, 2011, pp. 425-426, note 338.
} 
3.2.2.1. Does the concept of honour cover all the forms of conflict-related sexual violence against women?

The concept of honour seems to encapsulate the different forms of conflict-related sexual violence against women that Article 27, paragraph 2 of the IV Geneva Convention explicitly prohibits. Indeed, the text of the provision states that "[w]omen shall be especially protected against any attack on their honour, in particular against...". First, the phrase "in particular" shows that the short list which follows the sentence represents an indicative specification of the kinds of attacks on women's honour that can occur in the warfare. The listing is thus not exclusive. Second, this list includes an open-ended clause, namely "any form of indecent assault". ${ }^{422}$ Rape and enforced prostitution are expressly prohibited by the provision. It must be underlined that these two forms of sexual violence are probably the cruellest but, by using an indicative listing and an open-ended clause covering against any form of indecent assault, the norm also covers less brutal sexual practices and behaviours. The ICRC Study on Customary International Humanitarian Law confirms that the expression "any form of indecent assault" refers to any form of sexual violence. ${ }^{423}$

In order to understand which conducts are prohibited under Article 27, paragraph 2 of the IV Geneva Convention, it seems useful to compare the text of the norm with Article 8, paragraph 2 (b)(xxii) of the Rome Statute, one of the most recent relevant international provisions, which prohibits war crimes and introduces a longer list of proscribed forms of conflict-related sexual violence. In identifying the acts constituting serious violations of the laws and customs applicable in international armed conflicts, Article 8, paragraph 2 (b)(xxii) enlists the commission of "rape, sexual slavery, enforced prostitution, forced pregnancy [...], enforced sterilisation, or any other form of sexual violence also constituting a grave breach of the Geneva Convention". 424

\footnotetext{
422 The statement of protection against "any form of indecent assault" can be also found in other provisions of the Additional Protocols. With regard to the Additional Protocol I, three Articles can be listed. Article 75(2)(b) mentions 'any form of indecent assault' among the acts which "are and shall remain prohibited at any time and in any place whatsoever, whether committed by civilians or by military agents'. In Article 76(1), it is provided protection for women from "rape, forced prostitution and any other form of indecent assault". Finally, in Article 77(1), which provides that children shall be protected 'against any form of indecent assault'. In the Additional Protocol II, Article 4(2)(e) considers "humiliating and degrading treatment, rape, enforced prostitution and any form of indecent assault" as "outrages upon personal dignity".

${ }^{423}$ ICRC CIHL Study, Rule 93.

${ }^{424}$ Rome Statute of the International Criminal Court (Rome Statute) 1998, 2187 UNTS 90, Art. 8, paragraph 2 (b)(xxii).
} 
Article 8, paragraph 2 (b)(xxii) of the Rome Statute seems more modern than Article 27, paragraph 2, IV Geneva Convention in several aspects. First, it qualifies the enlisted conducts as sexual violence and not as (merely) attacks on women's honour. Second, it distinguishes between enforced prostitution and sexual slavery, acknowledging the difference between the perpetrator who, respectively, gets/expects to get or does not get a pecuniary or other advantage from the victim. ${ }^{425}$ Third, it enlarges the list of prohibited conducts, probably showing greater consciousness $^{426}$ about the different forms of sexual violence committed against women.

Despite the differences in the wording of the two provisions, however, it seems plausible to say that Article 27, paragraph 2 of the IV Geneva Convention and Article 8, paragraph 2 (b)(xxii) of the Rome Statute have the same scope of application. In providing an indicative list of prohibited conducts and in introducing a final open-ended clause, both articles prohibit all forms of conflict-related sexual violence against women and cover a wide range of sexual conducts. As Sellers and Rosenthal note with regard to the scope of application of Article 27, paragraph 2 of the IV Geneva Convention,

Indecent assault conduct would encompass, inter alia: vaginal, labial, penile, testicular, breast, and anal mutilations; insertions of objects and liquids into the genitals and anus; burning of pubic hair; insertion of genitalia into one's own or another person's orifice, or into an animal, plant, tree, or inanimate object; rape (e.g., gang rapes, rape of children, rape of pregnant women, rapes prior to execution); compelled sexual acts between protected persons, especially family members, members of the same sex, internees, the aged, sick, disabled, military comrades or with the deceased; forced nudity, forced public display while nude, forced performance of duties while nude; forced masturbation, forced masturbation of other protected persons or members of Detaining Power; being compelled to watch infliction of sexual violence on others; or sexual insults, threats, intimidation, coercion, punishment, or threats of sexual violence; forced circumcision; forced abortion; forced pregnancy; forced birth; or mutilation of a pregnant womb. ${ }^{427}$

Thus, the short listing provided by the provision does not seem to limit the scope of application of Article 27, paragraph 2 of the IV Geneva Convention. Any form of conflict-related sexual violence appears to be covered by the text of the provision. In this sense, the existence of the final open clause "any form of indecent assault" is actually preferable to a list which would

\footnotetext{
${ }^{425}$ De Brouwer, Anne-Marie, Supranational Criminal Prosecution of Sexual Violence: The ICC and the Practice of the ICTY and the ICTR, Intersentia, Antwerp, 2006, p. 142.

${ }^{426}$ Along with Steains, "the ultimate inclusion of rape, sexual slavery, enforced prostitution, enforced sterilization and other forms of sexual violence as grave breaches and serious violations of Article 3 common to the four Geneva Conventions proceeded smoothly, reflecting the widespread acceptance of the fact that the listing of these crimes was merely codifying the current state of international law". Steains, Cate, "Gender Issues", in Roy S. Lee (ed.), The International Criminal Court: The Making of The Rome Statute: Issues, Negotiations, Results, Kluwer Law International, The Hague, 1999, p. 365.

${ }^{427}$ Viseur Sellers, Patricia and Rosenthal, Indira, 'Rape and other sexual violence', in Clapham, Andrew, Gaeta, Paola, Sassòli, Marco, The 1949 Geneva Conventions. A Commentary, Oxford Univ. Press, Oxford 2015, p. 356, note 86 .
} 
have restricted the proscribed conducts in a limited or exhausted catalogue of forms of sexual violence.

Since Article 27, paragraph 2 of the IV Geneva Convention can potentially cover any form of sexual violence, one may ask whether the use of the concept of "honour" may have a limiting function, excluding some conducts from the space of protection for women in situations of armed conflict. In other words, could a narrow interpretation of the term honour, strictly understood as connotating women's chastity and purity, exclude the applicability of Article 27 on certain behaviors which, despite violating the physical and sexual integrity of the woman, are accepted by the society as safeguard conducts for the associated family and community honour? For example, one could here think of female genital mutilation practices, which are accepted and inflicted to young girls in some parts of the world as a marriageability (honourrelated) procedure associated with a certain cultural ideal of feminine and chastity. ${ }^{428}$ Could a soldier committing such practices be eventually absolved from responsibility on the basis of a strict interpretation of the term honour? Furthermore, could certain types of effects resulting from the criminal sexual conduct committed against a female subject during the warfare be accepted in order to restore the good reputation of the woman and the one of the family/community to which she belongs? One could here refer to the killings of women for non-honorable sexual behaviors, the so called "honour crimes" 429 , or forced marriages of

${ }^{428}$ For a comprehension of the scale of this worldwide issue, see WHO, Female genital mutilation, (3 February 2020), available at: https://www.who.int/news-room/fact-sheets/detail/female-genital-mutilation [last visited: 21 February 2021]. In 2015, European Institute for Gender Equality (EIGE) developed and published the first stepby-step guide to estimate the number of girls at risk of female genital mutilation in the European Union. From 20 February 2020, EIGE is on the lookout for a service provider to estimate the number of girls at risk of female genital mutilation (FGM) in four countries: Denmark, Spain, Luxembourg and Austria, see EIGE, Estimation of the number of girls at risk of female genital mutilation in the EU, (3 February 2020), available at: https://eige.europa.eu/procurement/eige-2020-oper-01\%20\#procurement [last visited: 21 February 2021].

429 "Honour crimes" are "honour killings" that

involve the murder or attempt murder of a woman by close relatives for having brought dishonour on the family and are one of the manifestations of male notions of proprietary ownership over the female body, possessiveness, and sexual jealousy which contributes to the global problem of violence against women. shameful conduct can include talking to a male, having a pre-marital relationship, or dressing provocatively.

Cane, Peter and Conaghan, Joanne (eds.), The New Oxford Companion of Law, Oxford University Press, Oxford, 2008, p. 544.

Also defined as "crimes committed in the name of the so-called honour", these crimes are considered "harmful practices", persistent practices and forms of behaviour that are grounded in discrimination on the basis of, among other things, sex, gender and age, in addition to multiple and/or intersecting forms of discrimination that often involve violence and cause physical and/or psychological harm or suffering. The harm that such practices cause to the victims surpasses the immediate physical and mental consequences and often has the purpose or effect of impairing the recognition, enjoyment and exercise of the human rights and fundamental freedoms of women and children. There is also a negative impact on their dignity, physical, psychosocial and moral integrity and development, participation, health, education and economic and social status. 
women with their offenders in order to "repair" the wrong done by rape, the so called "chastity reparations", ${ }^{430}$ which avoid disreputable embarrassment and shame for the families of the woman. ${ }^{431}$ The narrow interpretation that conflict-related sexual violence against women is a crime against the women's honour could also lead to a misrepresentation and, consequently, to a limitation of the possible victims of this kind of crimes. For example, in reporting cases of prosecution of sexual and gender-based crimes during World War I, Schabas mentions a French academic report in which, among war crimes, were considered "deliberate violations of the honour of young girls". ${ }^{432}$ The explicit reference to the age of the victims, using the term "young girls", could suggests that only women before the transition to adulthood could be affected by violations of their honour, undoubtedly because of the erroneous belief according to which sexual violence is basically an offence against the purity and the chastity of the woman. From a legal perspective, this would imply a legal relevance of the criterium of the age for the qualification of the crime, with the consequence of a possible inapplicability of the

See Committee on the Elimination of All Forms of Violence Against Women and Committee on the Rights of the Child, Joint General Recommendation No. 31 (November 14th, 2014) on Harmful practices, CEDAW/C/GC/31$\mathrm{CRC} / \mathrm{C} / \mathrm{GC} / 18$, para. 15. For a comprehensive understanding of the inclusion of the "crimes of honour" within the international framework of violence against women, rather than connecting these abuses to specific cultures and communities, see Welchman, Lynn and Hossain, Sara (eds), Honour: Crimes, Paradigms and Violence Against Women, Zed Books, London, 2005. An annotated bibliography - both general and regional - of "crimes of honour", see https://www.soas.ac.uk/honourcrimes/bibliography/file54988.pdf [last visited: 21 February $2021]$.

430 This kind of marriages were very common in the past and recognized not only by society codes of honour but also by national criminal codes. For example, under article 544 of the Italian criminal code was recognized the so called matrimonio riparatore. The norm was abolished only in 1981. Anyway, this practice seems far from outdated. On January $16^{\text {th }} 2020$, the Turkish's ruling party proposed a draft law which would give men amnesty for child sex offences if the two parties get married and the age difference of the two parties is less than ten years. In post-conflict contexts this practice seems to be even more accepted. The 2016 Report of the Secretary-General on conflict-related sexual violence denounced that customary courts in South Sudan require rape victims to marry the perpetrator as a form of settlement in about the 90 per cent of such cases. In north-east Nigeria and in Somalia, marriage is a "restitution" widely accepted by victims" families in order to avoid "shame", and in Myanmar, "reparation marriages" are a traditional remedy for rape. Report of the Secretary-General on conflict-related sexual violence, UN Doc. S/2016/361, 20 April 2016, para.10.

${ }^{431}$ Appiah refers to a passage in Deuteronomy to explain the old idea behind this honour rule:

If a man finds a damsel that is a virgin, which is not betrothed, and lay hold on her, and lie with her, and they be found; Then she shall be his wife; because he hath humbled her, he may not put her away all his days. [Deuteronomy 22:28-29].

Appiah, Kwame Anthony, The Honor Code: How Moral Revolutions Happen, Norton, New York, 2010, p. 97.

${ }^{432}$ Schabas refers to the 'Inquiry into the Penal Liabilities of the Emperor Wilhelm ii', in Report on the Responsibility of the Authors of the War and on the Enforcement of Penalties, Minutes of the Commission, USNA F.W. 181.1201/16, pp. 39-41, pp. 4-18, at p. 5 (emphasis added). Schabas, William A., "International Prosecution of Sexual and Gender-Based Crimes Perpetrated during the First World War", in Martin Böse, Michael Bohlander, André Klip and Otto Lagodny, Justice Without Borders. Essays in Honour of Wolfgang Schomburg, Brill, Nijhoff, Leiden, 2018, p. 401. 
norm and, subsequently, the exclusion of liability in cases in which the offence is committed against a "non-pure" and "non-chaste" woman.

From a hypothetical perspective, it could be possible to interpret the term honour in a narrow sense in order to allegedly preserve its traditional meaning at the time of the drafting of the Fourth Geneva Convention. Adopting such an interpretation of Article 27, paragraph 2 would leave a space of non-protection for women either in cases in which a behavior is not being seen as conflicting with the female honor and in cases in which a conduct is aimed at restoring the woman's honour or her family's honour. Finally, a rigid interpretation of the term honour could lead to a disqualification of the crime of conflict-related sexual violence as a crime against the chastity of the woman, in so excluding the existence of the offence for non-young women.

Nevertheless, there are at least three important arguments why such an interpretation would not be acceptable, meaning that the concept of honour cannot have the limiting function described above. First, giving the concept of honour such a limiting function would be contrary to the overall purpose of Article 27, paragraph 2 of the Fourth Geneva Convention, which is to protect women caught in conflict. Second, the intention of the Parties to cover a broad spectrum of acts is well indicated by the use of the indicative list and an open-ended clause, as discussed above. Third, and most important, the concept of "honour" should not be treated as "frozen" in time but, as it will be discussed in the following, as an evolving concept, that needs to be read in the light of contemporary circumstances and perceptions about women. As noted above, studies looking at this concept from gender-perspective have revealed its potential biases and suggested ways to read it in a "modern" way that accounts for the contemporary position of woman in society and war. Considering those point, one cannot support a limiting function of the concept of honour within the context of Article 27, paragraph 2 of the IV GC.

3.2.2.2. Could the concept of honour, as it was traditionally understood, still be useful? Even if not harmful, as shown above, there is a different question surrounding the concept of honour: Could it be actually useful in the legal treatment of women in conflict. Here, one may ask whether the term honour could have its own importance still today. In particular, it may be suggested that this concept serves a certain purpose in those societies that recognize honour as a rule of societal relationships. 
So far, international courts have never dealt with the interpretation of the term honour under Article 27 of the IV Geneva Convention. ${ }^{433}$ However, useful insights can be derived by looking at the jurisprudence of international courts related to the concept of honour outside Article 27 of the IV Geneva Convention. One of the best examples in this context is the Krstic case, decided by the International Criminal Tribunal for the former Yugoslavia (ICTY). Although concerning a different provision of international law and set in a different context, this case shows how the concept of honour has been indirectly utilized by a court to capture specific social arrangements which are the expression of honour rules particularly affecting women.

In the Krstic case, when assessing the existence of the crime of genocide ${ }^{434}$ for the events of Srebrenica, the ICTY considered the patriarchal structure of Bosnian society in the context of legally evaluating the killing of almost all Bosnian Muslim men and the associated condition of those Bosnian Muslim women who survived the attack. The Court considered that "the Bosnian Serb forces could not have failed to know, by the time they decided to kill all the men, that this selective destruction of the group would have a lasting impact upon the entire group" 435 . In particular, a "strong indication of the intent to destroy the group" 436 was found in the act of concealment of the bodies in mass graves, with the majority of men of Srebrenica being listed as missing. Since "for Bosnian Muslim women it is essential to have a clear marital status, whether widowed, divorced or married: a woman whose husband is missing does not fit within any of these categories" ${ }^{\prime 37}$, the disappearance of two or three generations of men had the catastrophic effect of making it impossible for women to start a new life in Srebrenica. ${ }^{438}$

This case may be seen as an example of the influence of a societal code based on the concept of honour over military strategies. Indeed, the honour of women - embodied in the female devotion and loyalty to the husband - was a key factor in the choices of Serbian military plans, and the related factual findings played a significant role in the Court's acknowledgment that

\footnotetext{
433 The only reference to the term in this sense will be mentioned in the following pages.

${ }^{434}$ For a definition of the crime of genocide, see Article 6, Rome Statute of the International Criminal Court.

${ }^{435}$ ICTY, The Prosecutor v Radislav Krstić, Trial Judgment, IT-98-33, 2 August 2001, para. 595.

436 Ibid. para. 596.

${ }^{437}$ Ibid. para. 93.

${ }^{438}$ The Appeal Chamber subsequently confirmed the decision of the Trial Chamber and recognized the genocidal design in the Serbs' plan. The main reason of the forcible deportation, rather than killing, of women, children and elderly was found in the fact that the area of Srebrenica was under the international spotlight at that time, so the Serb forces wanted to minimize the risks in their genocidal project. ICTY, The Prosecutor v Radislav Krstić, Appeal Judgment, IT-98-33-A, 19 April 2004.
} 
the elements of the crime of genocide were met. ${ }^{439}$ This example shows that, embedded into concrete cases and reflecting specific cultural codes, the concept of honour could be still useful for a proper comprehension of certain situations in "some states, and amongst conservative military officials" in which "the concept of honour, as used in Article 27 paragraph 2, resonates strongly". ${ }^{440}$

The international recent recognition of the link between the status of women and the honorability of the group led to a new awareness of the role sexual violence practices have in the warfare. In particular, it has been acknowledged that wartime rape is not only an act of aggression against the person, but also a "crime against the community" ${ }^{441}$ Since the aftermath of the war in the former Yugoslavia, it has become clear that the conflict-related sexual violence against women is often foreordained and directed to humiliate the community to which the woman belongs and to destroy the sense of identity of the group. ${ }^{442}$ In particular, rape assumes the "characteristics of a method of warfare with aims similar to the deliberate targeting of the civilian population: the destruction of its culture and moral". ${ }^{443}$

In this sense, it is only a deep understanding of the relevance of the concept of honour - as a category informing the life of individuals and influencing their behaviors especially on the base of their sex - that could permit a full comprehension of the magnitude of the wartime acts of sexual violence against women. Indeed, since in particular geographical and temporal context "the honour of the group is linked to the status its women" 444 , honour emerges as a concept with an important potential in addressing also the community dimensions of violence against women.

\footnotetext{
${ }^{439}$ For an analogous example on the implicit relevance of the concept of female honour in the jurisprudential identification of the existence of the elements of the crime of genocide, see ICTR, Prosecutor v. Akayesu (Case No. ICTR-96-4-T), Trial Chamber, Judgment, 2 September 1998, para. 507. In this case, the ICTR considered the situation in which female members of a group part of a society whose membership was dependent on the identity of the father, were raped by men of another group:

«In patriarchal societies, where membership of a group is determined by the identity of the father, an example of a measure intended to prevent births within a group is the case where, during rape, a woman of the said group is deliberately impregnated by a man of another group, with the intent to have her give birth to a child who will consequently not belong to its mother's group»».

${ }^{440}$ Viseur Sellers, Patricia and Rosenthal, Indira, "Rape and other sexual violence", in Clapham, Andrew, Gaeta, Paola, Sassòli, Marco, The 1949 Geneva Conventions. A Commentary, Oxford Univ. Press, Oxford 2015, p. 350. 441 Eriksson, Maria, Defining Rape: Emerging Obligations for States under International Law?, Brill, Leiden/Boston, 2011, p. 139.

${ }^{442}$ Seifert, Ruth, "War and Rape: A Preliminary Analysis", in Stiglmayer, Alexandra (ed.), Mass Rape: The War against Women in Bosnia-Herzegovina,...pp. 54-72, 62-63.

${ }^{443}$ Gardam, Judith, "Women and the Law of Armed Conflict: Why the Silence?"...p. 60.

${ }^{444}$ Eriksson, Maria, Defining Rape...p. 140.
} 
Of course, this does not mean to suggest forgetting the consequences of such heinous acts on the person as individual - this would bring us close to the traditional understanding of honour that has been criticized above. It rather serves to acknowledge that sexual violence in war is characterized by specific causes and implications. Neglecting or ignoring the existence of the culture of honour may lead to underestimate the broader repercussions of certain sexual crimes. Understanding the way through which honour works and expresses in the lives of individuals and communities is thus the only possible way to really understand how it can still affect women in situations of armed conflicts.

\subsubsection{Is the term honour a generic term subjected to evolutive interpretation?}

The third issue that needs to be addressed in this context is intimately related to the two questions above. It pertains the possibility of the term honour being interpreted in a new way, reflecting the current understanding and sensibility regarding acts of violence against women. In other words, considering the prevailing (at least symbolic) inconveniency in addressing the issue of violence against women merely in terms of honour, one may ask whether the interpretation ${ }^{445}$ of the concept permits a less outdated meaning of the term. This issue raises the general question of evolutive interpretation method, that is "an interpretation where a term is given a meaning that changes over time" ${ }^{446}$, in so "casting away or reducing the original or historical meaning attached to a norm in favour of a contemporary reading" ${ }^{447}$, in order to permit a treaty to be "a 'living instrument' which can change its meaning" 448 facing the developments of society, reflecting evolving circumstances. ${ }^{449}$

\footnotetext{
445 For interpretation it is meant «the process of determining the meaning of a text». Harvard Research in International Law, "Draft Convention on the Law of Treaties", 29 AJIL, 1935. In particular, Waldock, as Special Rapporteur of the ILC on the law of treaties defined interpretation in these terms «the process of interpretation, rightly conceived, cannot be regarded as a mere mechanical one of drawing inevitable meanings from the words in a text, or of searching for and discovering some preexisting specific intention of the parties with respect to every situation arising under a treaty [...] In most instances interpretation involves giving a meaning to a text». Yearbook of ILC, p. 53, para 1, (1964) [quoting Part III of the Harvard Draft Convention...Supp 653, p. 946].

${ }^{446}$ Helmersen, Sondre Torp, "Evolutive Treaty Interpretation: Legality, Semantics and Distinctions", , European Journal of Legal Studies Vol. 6, No. 1, (2013) 127-148, p. 128. The author also specifies that the term "evolutive interpretation" is used as a synonymous with "dynamic interpretation", note 1 .

447 Kolb, Robert, "Evolutionary Interpretation in International Law: Short and Less than Trail-Blazing Reflections", in Abi-Saab, Georges, Keith, Kenneth, Marceau, Gabrielle and Marquet, Clément, Evolutionary Interpretation and International Law, Hart Publishing, Oxford, 2019, p. 16.

${ }^{448}$ Bernhardt, Rudolf, "Evolutive Treaty Interpretation, Especially of the European Convention on Human Rights, German Yearbook of International Law", Vol. 42, No. 11, (1999) 11-25, p. 12.

449 In defining evolutive interpretation, the International Court of Justice referrers to "situations in which the parties' intent conclusion of the treaty was, or may be presumed to have been, to give the term used - or some of them - a meaning or content capable of evolving, not one fixed once and for all, so as to make allowance for, among other things, developments in international law". ICJ Dispute Regarding Navigational and Related Rights, 242, para 64. The opposite approach of evolutive interpretation is the contemporaneity approach. The definition
} 
As argued above, the concept of honour does not have a fixed meaning. It should thus be assessed whether the vagueness of this concept "reflects its actual condition of growth" ${ }^{450}$ In particular, the concept of honour seems to have a content broad enough to fit in the box of the so called "generic terms", namely terms whose meaning "has changed as a consequence of an evolution in language". ${ }^{451}$ The jurisprudence of the ICJ contains a number of references to generic terms. In certain cases, they have influenced the process of treaty interpretation given by the Court. ${ }^{452}$

In its advisory opinion in Namibia case, the Court had to interpret Article 22 paragraph 1 of the Covenant of the League of Nations. While having in mind "the primary necessity of interpreting an instrument according to the intentions of the parties at the time of its conclusion", the Court considered that the concepts "strenuous conditions of the modern world", the "well-being and development of such peoples" and "sacred trust" embodied in Article 22 of the Covenant "were not static, but were by definition evolutionary". ${ }^{453}$ This led the Court to recognize that "the parties to the Covenant must consequently be deemed to have accepted them as such". ${ }^{454}$ In the judgement related to the Aegean Sea case, after qualifying the term "territorial status" as used in the Greece's reservation to the General Act of 1929 as a generic term, the Court stated that "the presumption necessarily arises that its meaning was

of the contemporary approach can be found in Gerarld Fitzmaurice's VI rule of treaty interpretation, which states: «the terms of a treaty must be interpreted according to the meaning which they possessed, or which would have been attributed to them, and in the light of current linguistic usage, as at the time when the treaty was originally concluded». Fitzmaurice, Gerald, "The law and procedure of the International Court of Justice 1951-4: treaty interpretation and other treaty points", Br Yearb Int Law, Vol. 33, (1957) 203-247. For an explanation of the origins of the concept of contemporaneity, its distinction from intertemporal law, and a review of benefits and problems of the contemporaneity approach, see Triantafilou, Epaminontas E., "Contemporary and Evolutive Interpretation under the Vienna Convention on the Law of Treaties", ICSID Review, Vol. 32, No. 1, (2017) 138169.

${ }^{450}$ Gallie expresses the idea of a link between the vagueness of a concept and its condition of growth with regard to the concept of democracy, in order to justify its inclusion among the category of the "essentially contested concepts". Gallie, Walter Bryce, "Essentially Contested Concepts", Proceedings of the Aristotelian Society New Series, Vol. 56, (1955 - 1956) 167-198, p. 184.

451 Palchetti, Paolo, 'Interpreting 'Generic Terms': Between Respect for the Parties' Original Intention and the Identification of the Ordinary Meaning”, in Boschiero, Nerina, Scovazzi, Tullio, Pitea, Cesare and Ragni, Chiara (eds.), International Courts and the Development of International Law Essays in Honour of Tullio Treves, Springer, The Hague, 2013, p. 96.

${ }^{452}$ For a list of cases in which the International Court of Justice decided not to apply the evolutive interpretation method despite the recognition of the existence of generic terms, see Bjorge, Eirik, Evolutionary Interpretation and Intention of the Parties, Oxford University Press, Oxford, 2014, p. 125.

${ }^{453}$ ICJ, Legal Consequences for States of the Continued Presence of South Africa in Namibia (South West Africa) notwithstanding Security Council Resolution 276 (1970), Advisory Opinion, (21 June 1971), para. 53.

${ }^{454}$ Ibid. A critic of the reasoning of the Court in Namibia case has been raised by Thirlway, who sustains the inexistence of evidences that, at the time of the conclusion of the treaty, the parties' intent was to evaluatively interpret the concepts. Thirlway, Hugh, "The Law and Procedure of the International Court of Justice 1960-1989 Part One”, British Yearbook International Law Vol. 60, No. 1, (1989) 1-157, p. 137. 
intended to follow the evolution of the law". ${ }^{455}$ In the Dispute regarding Navigational and Related Rights, the Court established once again a presumption of evolutive interpretation with regard to the term "comercio" in the 1858 Treaty of Limits between Costa Rica and Nicaragua. ${ }^{456}$ Generic terms also have a role in the interpretation process of the case law of other international jurisdictional organs. ${ }^{457}$

If it is followed the view along with generic terms are treaty terms $[\ldots]$ intended to evolve in response to changes in legal and social concepts" ${ }^{\prime 58}$, not only legal terms, but also other open terms can be categorized as generic terms for the purpose of treaty interpretation. ${ }^{459}$ In this sense, also the term honour, which is hardly definable as a legal term, can be classified as a generic term.

The categorization of the term honour as a generic term has significant legal consequences. In particular, this category of terms could give rise to a presumption of evolutionary interpretation, reflecting the meaning of the term at the time of the application of the treaty. In other words, the fact that the parties chose to use a generic term in a treaty means that

the parties necessarily having been aware that the meaning of the terms was likely to evolve over time, and where the treaty has been entered into for a very long period or is 'of continuing

${ }^{455}$ ICJ, Aegean Sea Continental Shelf (Greece v. Turkey), Judgment (19 December 1978), para. 77.

${ }^{456}$ ICJ, Dispute Regarding Navigational and Related Rights (Costa Rica v. Nicaragua), Judgment (13 July 2009), para 67. Dawidowicz criticized the legal reasoning of the Court sustaining the Separate Opinion of Judge Skotnikov, who stated that it cannot be proved that the parties indented the term "comercio" to be qualified in contemporaneous terms, nor it was possible to presume in favour of an evolutive interpretation of the treaty terms. Dawidowicz, Martin, "The Effect of the Passage of Time on the Interpretation of Treaties: Some Reflections on Costa Rica V. Nicaragua”, Leiden Journal of International Law, Vol. 24, No 1, (2011) 201-222, pp. $221-222$.

${ }^{457}$ Generic terms have been used to legitimate an evolutive interpretation by the WTO Appellate Body. See Nolte Georg, "Subsequent practice as a means of interpretation in the jurisprudence of the WTO appellate body", in Cannizzaro, Enzo (ed.), The Law of treaties beyond the Vienna Convention, Oxford University Press, Oxford, 2011, p. 143.

458 Waldock, Humphrey, "The Evolution of Human Rights concepts and the Application of the European Convention of Human Rights", in Mélanges offerts à Paul Reuter-Le droit international: unite et diversité, Pedone, Paris, 1981, p. 536.

459 It is here sustained the idea of Palchetti, according to whom problems of inter-temporality in treaty interpretation raise not only with regard to international law developments, but also in case of changes in conventional language. A presumption of evolutive interpretation could thus concern with both legal generic terms and non-legal generic terms Palchetti, Paolo, "Interpreting 'Generic Terms'..., p. 96. In the same vein, PierreMarie Dupuy sustains that "[a]ccording to the current state of positive international law, the ICJ only allows for a dynamic interpretation of a treaty where justified by notions and concepts in the terms of the treaty from which it may be inferred that the text is open to considerations of factual or legal evolution after the conclusion of the treaty". Dupuy, Pierre-Marie, "Evolutionary interpretation of treaties: between memory and prophecy", in Cannizzaro, Enzo (ed.), The law of treaties beyond the Vienna Convention. Oxford University Press, Oxford, 2011, p. 131. 
duration', the parties must be presumed, as a general rule, to have intended those terms to have an evolving meaning. ${ }^{460}$

In order to understand whether a presumption of evolutionary interpretation can be raised with regard to the generic term "honour", one needs to have recourse to the means of interpretation set forth in the Vienna Convention on the Law of Treaties of 1969 "with a view to establishing the objectivized intention of the parties", ${ }^{461}$ which is the purpose of treaty interpretation. Indeed, it has been argued that "the reference to these rules provides greater legitimacy than the invocation of the presumed intention of the parties". ${ }^{462}$ The Vienna Convention does not apply per se to the Geneva Conventions but, in any case. Anyway, the Geneva Conventions are governed by the general norms of international law which are encapsulated in the Vienna Convention. Of course, this is true with regard to the norms of the Vienna Convention related to the interpretation of a treaty, Articles 31-33, which embody principles reflecting customary international law. ${ }^{463}$

The relevant rule applicable in case of interpretation of generic terms whose meaning has evolved over time is the general rule set forth in Article 31.1. ${ }^{464}$ The norm states that a treaty

${ }^{460}$ ICJ, Dispute Regarding Navigational and Related Rights (Costa Rica v. Nicaragua), Judgment (13 July 2009), para. 63. On this statement, Julian Arato:

Arguably this dictum indicates that the Court would be more willing to interpret a term as evolutive due to its generality where there was some further indication that the term was supposed to connote a perpetual obligation whose meaning would have to be keyed to changing factual or legal circumstances to remain relevant as a right over time. Arato J., "Subsequent practice and evolutive interpretation: techniques of treaty interpretation over time and their diverse consequences", The Law and Practice of International Courts and Tribunals, Vol. 9, No. 3, (2010) 443-494, p. 471.

${ }^{461}$ Bjorge, Eirik, "Time Present and Time Past: The Intention of the Parties and the Evolutionary Interpretation of Treaties", in Abi-Saab, Georges, Keith, Kenneth, Marceau, Gabrielle and Marquet Clément, Evolutionary Interpretation and International Law, Hart Publishing, Oxford, 2019, pp. 37-38.

462 Palchetti, Paolo, "Interpreting 'Generic Terms'...p. 104. Conversely, Georges Abi-Saab sustains that "the rules of interpretation, as codified in VCLT Articles 31 and 32, play a positive, persuasively directive, moderate role, by providing a logical, though standard, road map, with flagging out major stations. But they are far from being determinative of the final interpretation". Abi-Saab, Georges, "Introduction: A Meta-Question", in Abi-Saab, Georges, Keith, Kenneth, Marceau, Gabrielle and Marquet Clément, Evolutionary Interpretation and International Law, Hart Publishing, Oxford, 2019, pp. 9-10.

${ }^{463}$ The International Court of Justice expressed the position along with the principles embodied in Articles 31-33 of the Vienna Convention reflect customary international law in Libya v. Chad, ICJ Reports (1994), p. 6, para. 21; Kasikili/Sedudu Island (Botswana v. Namibia) ICJ Reports (1999), p.1045, para. 18. For the same view, see also Arbitration regarding the Iron Rhine (“IJzeren Rijn") Railway (Belgium/Netherlands), Award of 24 May 2005 , p. 23, para. 45 .

${ }^{464}$ It must be specified that the doctrine of evolutive interpretation has foundations also in Article 31.3.c on the interpretation of a treaty in light of the changing applicable rules of international law. This view has been sustained by the Study Group on Fragmentation established by the International Law Commission. Indeed, when studying Article 31.3.c, the Study Group also considers that in cases of interpretation of "open or evolving concepts" used in a treaty, «rules of international law subsequent to the treaty to be interpreted may be taken into account». International Law Commission, Fragmentation of International Law: Difficulties Arising from The Diversification and Expansion of International Law, in Report of the International Law Commission on the work of its sixty-first session (2006), UN doc. A/61/10, p. 415. Anyway, if one considers the evolutive interpretation to be ground in Article 31.3.c, it would be supported the idea along with only terms expressing legal concepts are 
must be interpreted "in accordance with the ordinary meaning to be given to the terms of the treaty in their context and in light of its object and purpose". ${ }^{465}$ While many discussions could be raised with regard to the relation between the criteria of interpretation listed by Article 31.1, namely "ordinary meaning" of the term, its "context", the "object" and the "purpose"466 of the treaty, ${ }^{467}$ in this case the three components must be used simultaneously for a contemporary interpretation of the term honour. 468

In particular, the ordinary meaning of the term "honour" can be deduced by a comprehensive analysis of the text of the Convention. Since "the general principle of respect for human dignity is the basic underpinning and indeed the very raison d'être of international humanitarian law", 469 relevance should be attributed to what, in a given society, constitutes the content of dignity. In other words, human dignity being the core principle and the "starting point" of the Geneva Conventions, ${ }^{470}$ each provision and each term of the IHL norms should be read in a way which conforms to the dignity of the person. As Trindade put it:

[t]he prevalence of the principle of the respect of the dignity of the human person is identified with the ultimate aim itself of Law, of the legal order, both national and international. By virtue of this fundamental principle, every person ought to be respected (in her honour and in her belief) by the simple fact of belonging to humankind, irrespective of any circumstance. [...] As to the principles of International Humanitarian Law, it has been convinced argued that one should consider Humanitarian Law treaties as a whole as constituting the expression - and the

susceptible to evolutive interpretation. Since it is here sustained the view according to which also non-legal terms can be generic terms for the purposes of evolutive interpretation, the rule of interpretation taken into account is Article 31.1, which is applicable for both legal and non-legal generic terms. However, it must be recalled that the travaux préparatoires of the Vienna Convention confirm that Article 31 expresses a unique rule of interpretation and not a number of rules. See Sorel, Jean-Marc and Boré-Eveno, Valérie, «Article31», in Corten, Olivier and Klein, Pierre (eds.), The Vienna Conventions on the Law of Treaties: A Commentary, Vol. I, Oxford University Press, Oxford, 2011, pp. 814, 816.

${ }^{465}$ Vienna Convention on the Law of Treaties art. 31(1), May 23, 1969, 1980 U.N.T.S. 332 (Italics of the author).

${ }^{466}$ For a list of cases in which the object and purpose were relevant for the reasoning of the European Court of Human Rights, see Gaja, Giorgio, "Does the European Court of Human Rights use its stated methods of interpretation?", in: Divenire sociale e adeguamento del diritto. Studi in onore di Francesco Capotorti, Giuffrè, Milan, p. 218.

467 For a detailed explanation of the history and preparatory work, the meaning, and the practice relating to "ordinary meaning", "context", and "object and purpose", see Gardiner, Richard, Treaty Interpretation, Oxford University Press, Oxford, 2008, pp. 162-202.

${ }^{468}$ It must be noted that the ordinary meaning, the context, the object and the purpose are not only important to determine the evolutive character of a term, but also to decide the current meaning of the evolving term in a subsequent phase. See Arato, Julian, "Subsequent practice and evolutive interpretation: techniques of treaty interpretation over time and their diverse consequences", Law Pract Int Law Tribunals, (2010), p. 19, note 81.

${ }^{469}$ ICTY, The Prosecutor v Anto Furundžija, Trial Judgment, IT-95-17/1, 10 December 1998, para. 183. David Luban opposes to this idea along with IHL, as with IHRL, was designed to protect human dignity. In particular, he states that IHL has not this purpose, but it was born to reduce human suffering. Then, the concept expressed by the ICTY in Furundžija case would not be wrong, but the expression of the reinterpretative and performative role of the court. Luban, David, "Human Rights Thinking and the Laws of War", in J. D. Ohlin (eds.), Theoretical Boundaries of Armed Conflict and Human Rights, Cambridge University Press, Cambridge, 2016, pp. 45-46. ${ }^{470}$ ICTY, The Prosecutor v Mucic et alii, Appeals Judgment, IT-96-21-A, 20 February 2001, para. 149. 
development - of such general principles, applicable in any circumstances, so as to secure a better protection to those victimized. ${ }^{471}$

At the time of the adoption of Article 27, honour was not only a relevant expression of societal norms and values, but also a constituting attribute of human dignity. With the passage of time, the term lost some of its original importance for signifying human dignity. This assertion could be confirmed by the fact that the term has not been used in subsequent conventions and treaties of international humanitarian law. ${ }^{472}$ With regard to women, acts of sexual violence started to be considered as offences against the person, not against a societal proscription of female chastity and modesty. The Additional Protocols of 1977 to the Geneva Convention endorse this evolution. Indeed, these crimes have been expressly prohibited by Article 75(2)(b) of the Additional Protocol I as follows:

Outrages upon personal dignity, in particular humiliating and degrading treatment, enforced prostitution and any form of indecent assault. ${ }^{473}$

Despite many prosecutions and convictions for crimes of rape and other forms of sexual violence occurred before international criminal tribunal, the term "honour" has not been quoted to designate gender-based indictments. The only reference to the term may be found in Furundžija case, where the ICTY, in justifying the classification of forced oral penetration as rape, referred to the principle of respect for human dignity "whether such outrages are carried out by unlawfully attacking the body or by humiliating and debasing the honour, the selfrespect or the mental well-being of a person". ${ }^{474}$ Far from the traditional meaning, the Court seems to refer here to honour as a cause of serious humiliation, a form of degradation of the person for the mental mortification it causes in addition to physical sufferance. In this way, the Court reads the concept of honour in a modern context, unbound by its original traditional connotations.

In conclusion, the term "honour" in Article 27, paragraph 2 is, at least, "troublesome" 475. Feminist criticism is certainly valid to the extent it flags the use of an old-fashioned and gendered term to cover heinous acts of violence against women. From this perspective, the

\footnotetext{
471 Trindade, Antônio Augusto Cançado, International Law for Humankind. Towards a New Jus Gentium, Brill, Nijhoff, Leiden/Boston, 2020, p. 279.

472 Other conventions protecting honour are: Article 17 of the European Convention of Human Rights; Article 8 of the Charter of Fundamental Rights of the European Union.

473 See also Article 76, Additional Protocol I.

474 Ibid.

${ }^{475}$ Viseur Sellers, Patricia and Rosenthal, Indira, "Rape and other sexual violence", in Clapham, Andrew, Gaeta, Paola, Sassòli, Marco,...p. 350.
} 
term seems to attach more importance to the deplorable societal impact and the moral defamation that women subjected to sexual violence have to face more than to the outrageous physical and mental effects these acts have on the person. In this regard, it has been demonstrated that the use of the term honour causes a symbolic issue. Indeed, even if it would be possible to attach a new meaning to the word, the concept still evokes, and consequently could corroborate and perpetuate, a number of gender stereotypes linked to the traditional codes of honour and patriarchal regimes.

However, from a legal analysis of the term seems to guarantying a gateway from this impasse. It has been asserted that a proper reading of the term honour does not reduce the legal protection of women in warfare: all forms of conflict-related sexual violence can be covered under Article 27, paragraph 2 of the Fourth Geneva Convention. Indeed, on the one hand, it has been said that only a very strict interpretation of the term could eventually, and very improbably, leave a space of non-protection for women subjected to sexual violence during the warfare. On the other hand, it has been suggested that the traditional meaning of honour may have its own relevance still today, especially in societies where the original connotation of the term still seems to prevail. In these cases, the lack of recognition of the relevance of the term honour could rather lead to the opposite results, to a misrepresentation of the events and, subsequently, to a misinterpretation of the relevant legal issues and the applicable legal categories. Finally, it has been proposed that the term honour is a generic term. The recognition of the term honour as a generic term eventually guarantees that an evolutive interpretation is warranted. This method of interpretation would lead to a contemporary understanding of the term, less detached from the traditional association to the female chastity and purity and more connected to the concept of human dignity.

That said, it should be recognized that «fundamental changes of values and societal norms» significantly reduced "the connection between sexual violence and honour". ${ }^{476}$ In particular, the very limited use of the term in subsequent IHL conventions and jurisprudence on the one hand, and the fact that IHL has to be informed by the principle of respect for human dignity on the other hand may lead one to interpret the term in a way which is more conform to the current understanding of the phenomenon of violence against women in armed conflicts.

\footnotetext{
${ }^{476}$ Gaggioli, Gloria, "Sexual violence in armed conflicts: A violation of international humanitarian law and human rights law”, International Review of the Red Cross, Vol. 96, No. 894, (2014) 503-538, p. 512.
} 


\subsection{The crime of rape}

After examining the concept of honour and its applicability to cases of violence against women in armed conflict, this Section will turn to the first crime identified as "act against honour" by Article 27 paragraph 2, namely rape. The nature of the crime of rape in the international legal system has been the object of many doctrinal and jurisprudential discussions and it is probably the most important of those listed in Article 27 paragraph 2 in practical, symbolic and doctrinal terms. In order to properly deal with this issue, three problems will be considered. After a brief examination of the IHL norms which prohibit rape (3.3.1), special emphasis will be given on the problems concerning with the identification of an international definition of rape. To this end, an overview of the international ad hoc tribunals and the international criminal court's jurisprudence is necessary (3.3.2.-3.3.4). Once a common international definition of rape is given, the essence of the crime will be explored, in particular the question of whether the crime of rape can be considered a grave breach under international humanitarian law (3.3.5).

\subsubsection{IHL rules prohibiting rape}

Article 27 is the first provision that contains an express reference to rape. ${ }^{477}$ This is not to say that women were not considered as victims of such kind of wartime violence before, ${ }^{478}$ but this norm embodies the first international prohibition of the act. Apart from Article 27, rape is now

\footnotetext{
477 The statement only considers international conventions. Otherwise, the first universal prohibition of rape was recognized in the context of the American Civil War in the General Order n. 100 promulgated by the Union government, commonly known as Lieber Code of 1863. Article 44 stated: "All wanton violence committed against persons in the invaded country, all destruction of property not commanded by the authorized officer, all robbery, all pillage or sacking, even after taking a place by main force, all rape, wounding, maiming, or killing of such inhabitants, are prohibited under the penalty of death, or such other severe punishment as may seem adequate for the gravity of the offense". For a full historical framework of the conception of sexual violence during wartime, see Khushalani, Yougindra, The Dignity and Honour of Women As Basic and Fundamental Human Rights, Martinus Nijhoff Publishers, 1982; Viseur Sellers, Patricia, 'The context of sexual violence: sexual violence as violations of international humanitarian law', in Gabrielle Kirk McDonald and Olivia Swaak-Goldman, Substantive and Procedural Aspects of International Criminal Law. The Experience of International and National Courts, Kluwer Law International, The Hague Vol. I, 2000.

${ }^{478}$ Bassiouni supports the idea that the law of war has prohibited rape for centuries. Bassiouni, M. Cherif, Crimes Against Humanity in International Criminal Law, Kluwer Law International, Leiden, 1999, p. 348. The idea along with violent attacks on non-combatants women were considered illegal for centuries is also sustained by Meron. Meron, Theodor, "Shakespeare's Henry the Fifth and the Law of War", American Journal of International Law, Vol. 86, No. 1, (1992) 1-45. Askin gave evidences that the first recorded war crimes trial which included rape goes back to 1474. Askin, Kelly, War Crimes against Women: Prosecution in International War Crimes Tribunals, Martinus Nijhoff, The Hague, 1997, p. 202-203.
} 
a well-established act in violation of international humanitarian law $^{479}$, both in international and non-international armed conflicts. Rape is also explicitly prohibited at any time and in any place whatsoever as act against the persons by Article 4 paragraph 2 of the Additional Protocol II. Moreover, Article 76 paragraph 1 lists rape as one of the acts from which women shall be especially protected. ${ }^{480}$ Implicit prohibition of rape can also be found in Article 4 paragraph 1 of the Additional Protocol II, which states that all persons are entitled to respect for their person and honour, and in Article 46 of the 1907 Hague Convention (IV), which introduces protection for family honour and rights. Furthermore, rape is considered an "outrage upon personal dignity", specifically prohibited by common Article 3 of the Geneva Conventions and by Article 75 paragraph 2 of the Additional Protocol I.

Neither the Geneva Conventions of 1949 nor the Additional Protocols of 1977 provide for a definition of rape. Since IHL has not its own international judicial body with the specific function to interpret, investigate, prosecute and enforce the Geneva Conventions of 1949 and the Additional Protocols of 1977, the interpretation of IHL rules have been a task especially for the recently established international criminal law bodies. In particular, the problem of the identification of an international definition of the crime of rape originally emerged with the jurisprudence of the ad hoc international criminal tribunals, when the judges needed a common meaning of the concept in order to prosecute the conduct of military personnel for this specific form of violence and to distinguish it from sexual violence.

In order to understand the centrality of an international definition of the crime of rape one may refer to the "iconic triumvirate" 481 of cases which "most extensively developed the law on gender-related crimes", ${ }^{482}$ namely the Akayesu case, the Furundžija case and the Kunarac case. The analysis will firstly focus on the methods that the Courts, the ICTR and the ICTY, used to

\footnotetext{
479 Meron, Theodor, "Rape as a Crime Under International Humanitarian Law", Amsterdam Journal of International Law, Vol. 87, No. 3, (1993) 424-428.

${ }^{480}$ Article 76 (1), AP II: Women shall be the object of special respect and shall be protected in particular against rape, forced prostitution and any other form of indecent assault.

${ }^{481}$ Sellers, Patricia Viseur, "(Re)Considering Gender Jurisprudence”, in Ní Aoláin, Fionnuala, Cahn, Naomi, Haynes, Dina Francesca, and Valji, Nahla (eds.), The Oxford Handbook of Gender and War, Oxford University Press, Oxford, 2017, p. 214. The author includes the three cases among the "narrow jurisprudence approach", that is international criminal law decisions challenging redress of sexual assault under ICL and IHL. In contrast, the "panoramic" view of gender jurisprudence highlights factual elements in judgments that show the inter- twined fate of men and women.

482 Askin, Kelly, "Prosecuting wartime rape and other gender-related crimes under International Law: Extraordinary Advances, Enduring Obstacles”, Berkeley Journal of International Law, Vol 21, No. 2 (2003) 288349 , p. 317.
} 
identify the definition of rape, and, secondly, on the different definitions they provided for the crime.

\subsubsection{Akayesu case}

The judgment of the trial Chamber I of the ICTR in Akayesu case, delivered in September 2, 1998, is a leading decision in international law. It is the first individual conviction for the crime of genocide based on the definition of the crime given by the Genocide Convention and after a trial before an international tribunal. In addition, it was the first conviction for rape as crime against humanity and the first judicial recognition that rape and sexual violence can constitute acts of genocide. The decision is also relevant for its identification of forced nudity as a form of sexual violence, which can constitute a crime against humanity as inhuman act. It is important to notice that the original indictment against Akayesu did not contain any count of rape and sexual violence. ${ }^{483}$ The gender-sensitive approach in the case was the result of accidental events combined with the impetus of civil society ${ }^{484}$ and the awareness of judge Navanethem Pillay over such crimes. ${ }^{485}$

For our purposes, this judgment is significant as it is the first international attempt to address the issue of the identification of a legal definition of rape. Noting that "there is no commonly accepted definition of [rape] in international law" ${ }^{486}$, and given the general principle of nullum crimen sine lege, the ICTR felt obliged to define a crime which, to certain extend, can also constitute crime against humanity under its Statute. Before giving a definition of rape, the

\footnotetext{
${ }^{483}$ For the original indictment, submitted by the Prosecutor on 13 February 1996 and confirmed on 16 February 1996, see ICTR, The Prosecutor v Jean-Paul Akayesu, Trial Judgment, ICTR-96-4-T, 2 September 1998, para. 6. The initial inertial attitude of the ICTR with regard to crimes of sexual violence against women is testified by the Special Rapporteur Radhika Coomaraswamy, who complained the fact that, despite the existence of an "extensive legal framework" and "the creative jurisprudence developed by the ICTY", the OTP is not pro-active. Coomaraswamy R., Report of the mission to Rwanda on the issue of violence against women in situations of armed conflict, U.N. Doc. E/CN.4/1998/54/Add.1 (1998), para. 45 ss.

${ }^{484}$ In particular, it is referred to the effort of women's human rights activists, human rights organizations, scholars, and lawyers who asked the Tribunal to prosecute gender-based crimes. The NGO Coalition for Women's Human Rights in Conflict Situations filed an amicus curiae calling upon the Prosecutor to amend the indictment against Jean-Paul Akayesu to charge rape or other serious acts of sexual violence as crimes within the competence of the Tribunal, available at https://4genderjustice.org/ftp-files/legal-filings/Prosecutor v Akayesu ICTR.pdf [last visited, 27 September 2019].

${ }^{485}$ On the role of Judge Navanethem Pillay, see Global Justice Centre, Written Submission on the General Recommendation on "Access to Justice", February 1, 2013, p. 4, available at: http://globaljusticecenter.net/blog/23-publications/un-submissions/515-written-submission-on-the-generalrecommendation-on-access-to-justice [last visited, 23 September 2019].

486 Ibid. para. 598.
} 
Chamber specified that "the central elements of the crime of rape cannot be captured in a mechanical description of objects or body parts", ${ }^{487}$ supporting the idea that

[r]ape in war is not merely a matter of chance, of women victims being in the wrong place at the wrong time. Nor is it a question of sex. It is rather a question of power and control which is 'structured by male soldiers' notions of their masculine privilege, by the strength of the military's lines of command and by class and ethnic inequalities among women. ${ }^{488}$

Given the complexity of this form of aggression, the Court preferred not to define rape through a list of specific possible acts, but rather using the "conceptual frame work of state sanctioned violence". ${ }^{489}$ This approach permitted the Court to identify some similarities between the crime of rape and the crime of torture as defined by the United Nations' Torture Convention. ${ }^{490}$ Just like torture, rape can have an intimidating, degrading, humiliating, discriminatory, punitive, controlling or destructive purpose and it constitutes a violation of personal dignity. Some scholars contested this method of the Court. In particular, it has been stated that the model of the Torture Convention could be helpful only for a recognition of the concept of protection of human rights against torture, but it does not give a formulation of the actus reus based on concrete acts and it attributes relevance to the particular purpose of the perpetrator for the identification of the criminal conduct. ${ }^{491}$ In this respect, it has been criticized that the Court failed "to follow two international norms in identifying the content of international law namely, the application of the nullum crimen sine lege principle, and the identification of the proper sources of international law". ${ }^{492}$

The ICTR defined the crime of rape as "a physical invasion of a sexual nature, committed on a person under circumstances which are coercive". ${ }^{493}$ The Court said nothing about the method it used to get to this definition, so that it is possible to sustain the idea that it represents an "an archetypal example of judicial creativity". ${ }^{494}$ Two aspects are critical in this definition. First, it

\footnotetext{
${ }^{487}$ Ibid. para.

${ }^{488}$ Chinkin, Christine " Rape and sexual abuse of women in international law", European Journal of International Law, Vol. 5, No.3, (1994), p. 326, 328.

${ }^{489}$ ICTR, The Prosecutor v Jean-Paul Akayesu,...para. 597.

${ }^{490}$ Convention against Torture and Other Cruel, Inhuman or Degrading Treatment or Punishment 1984, 1465 UNTS 85.

491 Alexandra Adams, "The Legacy of the International Criminal Tribunals for the Former Yugoslavia and Rwanda and Their Contribution to the Crime of Rape", European Journal of International Law , Vol. 29, No. 3, (2018), p. 761.

492 Cole, Alison, "Prosecutor v Gacumbitsi: The New Definition for Prosecuting Rape Under International Law" ICLR, Vol. 8, No. 55, (2008), p. 77.

${ }^{493}$ ICTR, The Prosecutor v Jean-Paul Akayesu,...para. 598.

${ }^{494}$ Hayes, Niamh, "Creating a Definition of Rape in International Law: The Contribution of the International Criminal Tribunals", in Darcy, Shane and Powderly, Joseph, Judicial Creativity at the International Criminal Tribunals, Oxford University Press, Oxford, 2010.
} 
is a very general definition, which leaves open some aspects, such as the identification of the body parts that could be invaded and the meaning of "sexual nature". Secondly, the definition is based on the concept of coercion, even if

[...] coercive circumstances need not be evidenced by a show of physical force. Threats, intimidation, extortion and other forms of duress which prey on fear or desperation may constitute coercion, and coercion may be inherent in certain circumstances, such as armed conflict or the military presence of Interahamwe among refugee Tutsi women at the bureau communal. ${ }^{495}$

The Akajesu definition of rape was adopted in three other judgments of the ICTR. ${ }^{496}$

\subsubsection{Furundžija case}

Turning to the ICTY, the Furundžija case constitutes the leading case with regard to the jurisprudence of the ad hoc tribunals related to rape and sexual violence. ${ }^{497}$ On 10 December 1998, the First Trial Chamber found Anto Furundžija guilty for torture as a co-perpetrator in the rape of a Bosnian Muslim woman during an interrogation and for aiding and abetting in outrages upon personal dignity, including rape. ${ }^{498}$

The Trial Chamber of the ICTY devoted a specific section of the judgment - from paragraph 174 to paragraph 186 - to "the definition of rape". This choice is supported by the fact that, since "no definition of rape can be found in international law", the Court has to identify one during the trial. After referring, among others, to Article 27 paragraph 2 of the Geneva Convention IV to sustain that rape is considered the most serious manifestation of sexual assault, ${ }^{499}$ the Court mentions the definition given in Akayesu case to underline the idea that

no elements other than those emphasized [by the ICTR] may be drawn from international treaty or customary law, nor is resort to general principles of international criminal law or to general principles of international law of any avail. ${ }^{500}$

\footnotetext{
${ }^{495}$ ICTR, The Prosecutor v Jean-Paul Akayesu,...para. 688.

${ }^{496}$ ICTR, Prosecutor v. Musema, Trial Chamber I Judgment, ICTR-96-13-T, 27 January 2000, paras. 220-229; ICTY, Prosecutor v. Mucić, Trial Chamber Judgment, IT-96-21-T, 16 November 1998, paras. 478-479; ICTR, Prosecuto v. Niyitegeka, Trial Chamber I Judgment, ICTR-96-14-T, 16 May 2003, paras. 455-458.

${ }^{497}$ On the importance of the case, see Askin, Kelly, "The international war crimes trial of Anto Furundžija: A Mayor Progress Toward Ending the Cycle of Impunity for Rape Crimes", Leiden Journal of International Law, Vol. 12, No. 4, (1999) 935-955.

${ }^{498}$ For the first time in the history of international tribunals, a case has been brought exclusively for crimes of sexual violence and the resulting sentence gave a notable contribution to the confirmation of rape as a war crime and the recognition of rape as a form of torture if the requisite elements are met. The relevance of the ruling can be also traced in the recognition of the application of the principle of universal jurisdiction for the crime of torture. ICTY, Prosecutor v. Furundžija, Trial Chamber Judgment, IT-95-17/1-T, 10 Dec. 1998, paras 156-157.

${ }^{499} \mathrm{Ibid}$. para. 175.

${ }^{500}$ Ibid. para. 177
} 
In so doing, the Court recognized that the exclusive reference to the international law norms and principles is not sufficient to identify an "accurate" international legal definition of rape which satisfies the "criminal law principle of specificity". ${ }^{01}$ For this reason, the Court resorted to the principles of criminal law common to the major legal systems of the world, in accordance with Article 38(1)(c) of the ICJ Statute. ${ }^{502}$ In particular, it used the method of the "common denominators", which consists of an examination of different national legislations and caselaw to identify the common principles shared by the majority of legal systems. ${ }^{503}$ Under this approach, the international legal relevance of a national provision derives from its identity/similarity with norms of other national legislations. In any case, this horizontal comparison among domestic legislations ${ }^{504}$ must consider the specific characteristics of the international criminal regime. ${ }^{505}$

To this end, the Trial Chamber compared 19 domestic criminal codes on the crime of rape. ${ }^{506}$ Despite some "inevitable discrepancies" on the elements of the crime, most jurisdictions consider rape as a violent sexual penetration of the human body, in particular the vagina or the anus, by the penis or other objects forcible inserted ${ }^{507}$ Relevant inconsistencies were found with regard to the qualification of oral sex, classified as rape by some national legislations or

\footnotetext{
501 Ibid.

${ }^{502}$ A general assertion specifying when the recurrence on general principles of criminal law of the major legal systems is admissible has been expressed by the ICTY in Kupreskic: "any time the Statute does not regulate a specific matter, and the Report of the Secretary- General does not prove to be of any assistance in the interpretation of the Statute, it falls to the International Tribunal to draw upon (i) rules of customary international law or (ii) general principles of international criminal law; or, lacking such principles, (iii) general principles of criminal law common to the major legal systems of the world; or, lacking such principles, (iv) general principles of law consonant with the basic requirements of international justice". ICTY, Prosecutor v. Kupreskic, Judgment, IT-9516, 14 January 2000, para. 591.

${ }^{503}$ ICTY, Prosecutor v. Furundžija,...para. 178.

This is one of the few cases in which an international Court makes recourse to general principles for the identification of a primary norm, namely here the definition of the international crime of rape. For an overview of the kinds of international norms deduced from the recourse to general principles, see Bonafè, Beatrice Ilaria, Palchetti, Paolo, "Relying on General Principles in International Law", in Research Handbook on the Theory and Practice of International Lawmaking, Edward Elgar Publishing, Cheltenham, 2016, p. 173.

504 The comparative analysis can be also led down using "une confrontation verticale", which consists of a comparison between an internal criminal norm and an international criminal norm. The aim of this kind of comparison is to determine the compatibility of the first norm with the international legal regime. The national provision could be used at international level only if it is compatible with the international criminal norm. For an extensive analysis of the two mechanisms used by the courts, see: Fronza, Emanuela, Guillou, Nicolas, "Les dynamiques d'élaboration des norms pénales internationals: une analyse à partir de la jurisprudence sur le viol et la participation criminelle", in Chiavario, Mario, La justice pénale international entre passé et avenir, Giuffrè Editore, Milan, 2003, pp. 39-41.

${ }^{505}$ ICTY, Prosecutor v. Furundžija,... para. 178.

${ }^{506}$ In particular, the Court compared the domestic legislations of Chile, China, Germany, Japan, ex-Yugoslavia, Zambia, Austria, France, Italy, Argentina, Pakistan, India, South Africa, Uganda, New South Wales, Netherlands, England, Wales, Bosnia and Herzegovina.

${ }^{507}$ Ibid. para. 181.
} 
as the less serious crime of sexual assault, in others. For this reason, the Trial Chamber resorted to general principles of $1 \mathrm{aw}^{508}$, in particular to the general principles of international criminal law and the general principles of international law. ${ }^{509}$ This latter distinction has been criticized for lack of clarity. In particular, it would seem difficult to conceive a specific category of general principles of international criminal law different from the principles derived from the common law traditions of domestic legal systems. ${ }^{510}$

The Court referred to the principle of respect for human dignity in order to overcome the discrepancies over the legal qualification of oral sex and to justify a broader definition of rape. The legal reasoning of the Court starts from the recognition that oral sex represents a humiliating and degrading outrage to human dignity. Since the respect of human dignity is recognized as the "basic underpinning" of international humanitarian law and human rights law, the extreme gravity of forced oral penetration permits to classify the act as rape. ${ }^{511}$ Therefore, the Trial Chamber identified a definition of rape as:

(i) the sexual penetration, however slight:

(a) of the vagina or anus of the victim by the penis of the perpetrator or any other object used by the perpetrator; or

(b) of the mouth of the victim by the penis of the perpetrator;

(ii) by coercion or force or threat of force against the victim or a third person. ${ }^{512}$

\footnotetext{
508 The notion of general principles of law is controvert. In particular, the expression can assume two different conceptions: a. general principles which underpin the international legal system; b. principles which are found to be in common in the majority of national legislations and are transposed to the international legal system. The nature of the general principles of law in international regime has been analysed by Vitanyi, Béla, "Les positions doctrinales concernant le sens de la notion de «principes généraux de droit reconnus par les nations civilisées», in Revue Générale de droit international public, 1982, p. 48 ss. See O'Keefe, Roger Michael, "Recourse by the ad hoc Tribunals to general principles of law and to human rights law', in Delmas Marty, Mirelle, Fronza, Emanuela and Lambert-Abdelgawad, Elisabeth (eds), Les Sources du Droit International Pénal: L'experience dea tribuneax pénaux internationaux et le statut de la Court penale internationale, Société de législation compårée, Société de Législation Comparée, Paris, 2004. Recently, the ILC drafted the first Report on general principles of law. The document describes the previous work of the Commission on the topic, it explains the development of general principles of law over time and analyses the elements and origins of general principles of law. In the end, it gives proposals for three draft conclusions. See Vázquez-Bermúdez Marcelo, Special Rapporteur, First report on general principles of law, 2019, A/CN.4/732, available at http://legal.un.org/docs/?symbol=A/CN.4/732 [last visited, 23 March 2021].

${ }^{509}$ ICTY, Prosecutor v. Furundžija,... para. 182.

${ }^{510}$ Akande, Dapo, "Sources of International Criminal Law", in Cassese, Antonio (ed.), The Oxford Companion of International Criminal Justice, Oxford University Press, Oxford, 2009, p. 52.

The Statute of the ICC seems to confirm the existence of only two categories of general principles. In order to list the sources of law applicable to the Court, Article 21 of the Rome Statute makes reference to "principles of international law" (para. 1, b)) and "general principles of law derived by the Court from national laws of legal systems of the world" (para. 1, c)).

${ }^{511}$ This qualification would not violate the general principle of legality because the act was already criminalised by domestic criminal legislations. In additions, forced oral sex committed during war constitutes an aggravated sexual assault against defenseless civilian population, so that it falls into the category of war crime and crime against humanity. ICTY, Prosecutor v. Furundžija,... paras. 183-184.

512 Ibid. para. 185 .
} 
Apparently, this definition of rape differs significantly from the one given by the ICTR in Akayesu. The Akayesu definition's "invasion of a sexual nature" is so broad that is can encapsulate a number of sexual conducts. The vague description of the crime is the result of the method adopted by the ICTR. Indeed, the lack of a comparative analysis among the domestic criminal legislations leads the ICTR to an elusive definition of rape. The association of the crime of rape with the crime of torture probably better responds to a human rights approach - focused on the declaration of inviolability of a human right and the protection of the human being - but it does seem to violate the criminal law principle of legal certainty. ${ }^{513}$

On the contrary, the definition offered by the Trial Chamber of the ICTY in Furundžija case clearly identifies the elements of the crime of rape, thus being more specific and detailed. This result is obtained through the comparative analysis of many domestic legislations over the crime of rape. On this basis it emerges a precise and defined description of the criminalized conduct, which better responds to the criminal law principle of nulla poena sine lege than the one offered by ICTR in Akayesu. ${ }^{514}$

Finally, both definitions are based on the civil law approach, which builds the concept of rape on the commission through force or threat of force, instead of using the common law criterium of the lack of consent. The reference to "under circumstances which are coercive" in the Akayesu definition and the more explicit condition "by coercion or force or threat of force" used by the ICTY in Furundžija case clearly suggest the adoption of a civil-law perspective. This fundamental point was critical in the third milestone case on the topic, the Kunarac case.

\subsubsection{Kunarac case}

The Kunarac case establishes a third definition of rape. The name of the case originates from one of three Serbian defendants - Dragoljub Kunarac, Radomir Kovač, Zoran Vuković 515 accused by the Prosecutor of violating the customary laws of war and committing crimes

\footnotetext{
513 Adams, Alexandra, "The First Rape Prosecution before the ICC: Are the Elements of Crimes Based on a Source of International Law?", ICLA Vol. 15, No. 6, (2015) 1098-1121, p. 1114.

${ }^{514}$ It can also be noted that the concept of "invasion" of the Akayesu sentence was substituted by the idea of "sexual penetration by and of body parts".

${ }^{515}$ Kunarac was the leader of a reconnaissance unit and soldier who had access to the highest military command in the Foča area. Radomir Kovač and Zoran Vuković were members of a military unit known as the "Dragan Nikolić Unit".
} 
against humanity, such as rape, torture, slavery and outrages upon personal dignity. The judgment was issued by the Chamber of First Instance of the ICTY on 22 February $2001 .^{516}$

Kunarac is considered a landmark case for at least two reasons. For the first time, an international criminal tribunal judged exclusively on crimes of sexual violence. In addition, it was the first conviction of rape as a form of torture and sexual enslavement ${ }^{517}$ and as a crime against humanity.

Despite the general appreciation of the Furundžija's definition of rape, the Trial Chamber asserts that the classification of the constituent elements of rape as described in the previous ICTY judgment was restrictive, compared to that provided for by international law.

In particular, the Court criticized the elements described in paragraph (ii) of the Furundžija's definition, namely the requirement of "coercion or force or threat of force against the victim or a third person". Indeed, defining the act of sexual penetration as legally relevant for the qualification of rape only if accompanied by force, coercion or the threat of the use of force against the victim or a third person, "the Furundžija definition does not refer to other factors which would render an act of sexual penetration non-consensual or non-voluntary on the part of the victim". ${ }^{518}$ In other words, the Court in Kunarac states that force, coercion and threat of force are relevant but not exhaustive elements to define the crime of rape, and that "a wider or more basic principle of penalising violations of sexual autonomy" is the true common denominator of the various national systems. ${ }^{519}$ In so doing, the Court makes a significant change in the material elements of the offence compared to Furundžija. Indeed, the legally

\footnotetext{
${ }^{516}$ ICTY, Prosecutor v. Kunarac, Judgment, IT-96-23 \& IT-96-23/1-T, 22 Feb. 2001.

517 It should be noted that the Statute of the International Criminal Tribunal for the former Yugoslavia does not specifically include the crime of sexual slavery. Article 5 of the Statute - which deals with the identification of crimes against humanity - lists rape and slavery as two of the acts prosecuted by the Court as crimes against humanity. Consequently, the submission of girls and women to sexual servitude was prosecuted and condemned according to the provisions of the Statute of the ICTY, by granting jurisdiction to the Court over the crimes of rape and slavery as crimes against humanity. Sexual slavery takes is a particular crime in which two forms of enslavement are combined: slavery and forced labor. The exploitation of a person's body without his valid and genuine consent for the sexual satisfaction of another person reduces the person to mere property. The sexual performances that the subject is forced to render nullify his physical, mental and spiritual integrity so as to undermine his dignity. The actus reus of the crime of sexual slavery consists in the exercise of some or all the powers related to the right of property on a subject, through the control of his sexuality or the deprivation of his sexual autonomy. The mens rea is the intentional exercise of these powers. See in this regard, Argibay Carmen M., "Sexual slavery and the "comfort women" of World War II" Berkeley Journal of international Law, Vol. 21, No. 6, (2003) 375-389, pp. 383-384.

${ }^{518}$ ICTY, Prosecutor v. Kunarac, Judgment, IT-96-23\& IT-96-23/1-T, 22 Feb. 2001, para. 438.

519 Ibid. para. 440.
} 
protected interest of the international norm criminalizing rape is no longer the physical and moral integrity (alone), but the concept of sexual autonomy.

On the basis of this statement, the Court identifies three categories of factors which, in many jurisdictions, categorize a sexual act as rape:

(i) the sexual activity is accompanied by force or threat of force to the victim or a third party;

(ii) the sexual activity is accompanied by force or a variety of other specified circumstances which made the victim particularly vulnerable or negated her ability to make an informed refusal; or

(iii) the sexual activity occurs without the consent of the victim. ${ }^{520}$

After this classification, the Trial Chamber turns to an extensive comparative analysis ${ }^{521}$ of national legislations in order to "identify certain basic principles [...] in those legal systems which embody the principles which must be adopted in the international context". ${ }^{522}$ In this case, the crime of rape is described as

the sexual penetration, however slight:

(a) of the vagina or anus of the victim by the penis of the perpetrator or any other object used by the perpetrator; or

(b) of the mouth of the victim by the penis of the perpetrator; where such sexual penetration occurs without the consent of the victim. ${ }^{523}$

One element sounds innovative with regard to the previous definitions of rape. Although the Court follows the descriptive method of Furundžija for a precise definition of the crime of rape, it chooses a common law approach based on the concept of the lack of consent. ${ }^{524}$ The Trial

${ }^{520}$ Ibid. para. 442.

521 The Court compared 26 domestic legislations.

${ }^{522}$ ICTY, Prosecutor v. Kunarac, Judgment, ... para. 439.

${ }^{523}$ ICTY, Prosecutor v. Kunarac, Judgment,... para. 460.

524 The civil law approach builds the definition of rape on the notion of force or threat of force. On the contrary, the common law approach uses the concept of non-consent where consent was presumed in the absence of proof of physical resistance, so when the use or threat of force could not be proven. On the distinction between civil law approach and common law approach on the definition of rape, see Boon, Kristen, "Rape and Forced Pregnancy under the ICC Statute: Human Dignity, Autonomy, and Consent", Columbia Human Rights Law Review, Vol. 32, No. 3. (2001) 625-675, p. 655. The concept of consent in cases of sexual violence has been investigated by many scholars. In particular, on the difficulties in applying the domestic law assumptions of autonomy and consent in cases in which sexual violence is committed during armed conflict, see Schomburg, Wolfgang and Peterson, Ines, "Genuine Consent to Sexual Violence under International Criminal Law", American Journal of International Law, Vol. 101, No. 1, (2007) 121-140, pp. 125-131. On the concept of consent as an expression of the power inequalities between the parties, see MacKinnon, Catharine A., "Defining Rape Internationally: A Comment on Akayesu", Columbia Journal of Transnational Law, Vol. 44, No. 3, (2005) 940-958, p. 951. For a critique of the use of consent rather than coercion as the central element of the crime of rape under international criminal law, see Hayes, Niamh, "Creating a Definition of Rape in International Law: The Contribution of the International Criminal Tribunals", in Darcy, Shane and Powderly, Joseph, Judicial Creativity at the International Criminal Tribunals, Oxford University Press, Oxford, 2010. The author suggests that the element of non-consent not only presupposes a degree of sexual autonomy, but also focuses the attention of the acts and thoughts of the victim instead of those of the perpetrator. Instead, the concept of coercion would imply a lack of consent (pp. 151-152). 
Chamber focuses on domestic jurisdictions in which the absence of genuine and freely given consent is considered the discriminative element to qualify a sexual act of penetration as rape. In this sense, force or threat of force can be evidence of the lack of consent but do not exhaust the category of acts that can be perpetrated without consent.

The "lack of consent" requirement has been criticized because, if considered alone, it could violate the principle of certainty. Indeed, it would be hard to prove when a lack of consent exists and the final evidence usually pays particular attention to the victim's behavior before the sexual attack. ${ }^{525}$ Moreover, the examination of the national regimes made by the Trial Chamber was criticized as an ex-post comparison. According to this view, the Court firstly identified a general legal principle and, subsequently, it found it in the analysed domestic legislations. In this sense, the comparative examination would be functional to the judges' margin of appreciation of the norms and it would have the aim to legitimize a predetermined legal solution. ${ }^{526}$ This attitude would show an undeniable discretion of the judges, probably beyond the inevitable need to cover legislative lacunas in international criminal law. Despite these criticisms, the Kunarac definition is an important step in the development of the international concept of rape. By making the lack of consent the central element of the definition of rape it takes into consideration the fact that female vulnerability does not only derive from coercion or force or threat of force, especially in the context of war. As many scholars hoped, ${ }^{527}$ the Kunarac definition of rape has been subsequently adopted in many other

\footnotetext{
${ }^{525}$ Adams, Alexandra, "The Legacy of the International Criminal Tribunals for the Former Yugoslavia and Rwanda...p. 765.

526 Caligiuri, Andrea, "La ricostruzione dei principi generali di diritto da parte dei tribunali penali internazionali”, Rivista di diritto internazionale, No. 90, (2007), p. 1088. In this regard, «i principi generali del diritto finiscono spesso per essere ricostruiti utilizzando i riferimenti normativi presenti in quei soli ordinamenti nazionali che contengono la nozione della fattispecie criminale scelta dal giudice internazionale». The same position is expressed by Delmas-Marty, Mireille "L'influence du droit comparé sur l'activité des Tribunaux pénaux internationaux", in Cassese, Antonio, Delmas-Marty, Mireille (eds.), Juridictions nationals et crimes internationaux, Presses Universitaires de France, Paris, 2002, p. 95ss, 106; Fronza, Emanuela and Guillou, Nicolas, "Les dynamiques d'élaboration des norms pénales internationals: une analyse à partir de la jurisprudence sur le viol et la participation criminelle", in La justice pénale internationale entre passé et avenir, p. 27, pp. 48-52. ${ }^{527}$ Mertus, Julie, "Judgment of Trial Chamber II in the Kunarac, Kovac and Vukovic Case", American Society for International Law, Vol. 6, No. 6, (2001), p. 5.
} 
judgments of the ICTY and the ICTR, ${ }^{528}$ and it has also been influential in the jurisprudence of other international criminal law tribunals. ${ }^{529}$

The analysis of the most relevant jurisprudential definitions of the crime of rape reveals, firstly, the absence of a single international definition of rape. As it has been noted, Article 27, paragraph 2 of the Fourth Geneva Convention has the merit to be the first norm which expressly prohibits rape in contexts of armed conflict. But the identification of a common meaning of the crime is a process which started much later and involved the active contribution of the international criminal tribunals. This means that a profound legal reflection on the qualification of this systematic conduct of war became an urgent issue only in the late 1990s.

Furthermore, the long jurisprudential procedure to identify a legal definition of rape permits to reflect on the methods used by the international criminal courts for the interpretation of imprecise and vague legal provisions and for the elaboration of more detailed norms. In particular, on the basis of Article 38(1)(c) of the Statute of the International Court of Justice, both ad hoc tribunals made a comparative analysis of the domestic criminal regimes in order to discover common principles applicable at international level for the definition of the crime of rape. The way the comparative analyses has been conducted affected the final definition of rape. As it had been noted, the Furundžija's "horizontal comparison" used the common denominator standard, which lead to a definition of the crime based on the requirement of force or threat of force. On the contrary, the Trial Chamber in Kunarac case introduced the conditions of the lack of consent and the perpetrator's knowledge of the lack of consent, through adopting

\footnotetext{
528 ICTY, Prosecutor v. Kvočka et al. IT-98-30/1-T (Judgment, 2 November 2001), paras. 177-179; ICTR, Prosecutor v. Laurent Semanza ICTR-97-20-T (Judgment, 15 May 2003), paras. 344-346; ICTR, Prosecutor v. Juvénal Kajelijeli ICTR-98- 44A-T (Judgment, 1 December 2003), para. 915; ICTR, The Prosecutor v. Jean de Dieu Kamuhanda ICTR-95-54A-T (Judgment, 22 January 2004), paras. 709-710; Gacumbitsi ICTR-2001-64-T, para. 325; ICTR, Prosecutor v. Sylvestre Gacumbitsi ICTR-2001-64-A (Judgment, 28 September 2004), para. 152; ICTY, Prosecutor v Zelenović, Judgment (IT-96-23/2-S), Trial Chamber I, 4 April 2007, para. 36; ICTY, Prosecutor v. Haradinaj, Judgment (IT-04-84-T), Trial Chamber III, 3 April 2008, paras. 129-130; ICTR, Prosecutor v. Bagosora, Judgment (ITCR-98-41-T), Trial Chamber I, 18 December 2008, paras. 2199-2200; ICTY, Prosecutor v Milutinović et al., Judgment, (IT-05-87-T), Trial Chamber II, para. 203; ICTR, Prosecutor v. Renzaho, Judgment, (ICTR-97-31-T), Trial Chamber II, 14 July 2009, paras. 791-792; Judgment, Prosecutor $v$. Hategekimana (ICTR- 2000-55B-T), Trial Chamber II, 6 December 2010, paras. 723-724; ICTY, Prosecutor v. Dordević, Judgment, (IT-05-87/1-T), Trial Chamber II, 23 February 2011, para. 1766; ICTR, Ndindiliyimana et al., Judgment, (ICTR-2000-56-T), Trial Chamber II, 17 May 2011, para. 2121; ICTR, Prosecutor $v$. Nyiramasuhuko et al., Judgment, (ICTR-98-42-T), Trial Chamber II, 24 June 2011, para. 6075; ICTR, Prosecutor v. Karemera et al., Judgment, (ICTR-98-44-T), Trial Chamber III, 2 February 2012, para. 1676; ICTR, Prosecutor v. Ngirabatware, Judgment, (ICTR-99-54-T), Trial Chamber II, 20 December 2012, para. 1381; ICTY, Prosecutor v. Prlić et al., Judgment, (IT-04-74-T), Trial Chamber III, 29 May 2013, para. 69; Prosecutor v. Karadžićc, (IT95-5/18-T), Trial Chamber III, 24 March 2016, para. 511.

${ }^{529}$ See for example, SCSL, Prosecutor v. Charles Taylor, Trial Chamber Judgment, SCSL-03-01-T, 18 May 2012, para. 415.
} 
a "vertical" comparative method, namely a comparison between a national criminal law norm and an international law norm.

A third consideration relates to the relevance of the jurisprudence of the ICTY and the ICTR for the work of the Preparatory Commission of the ICC in the identification of a definition of rape in the Elements of Crime (EOC) of the Rome Statute. ${ }^{530}$ In considering both the requirement of force or threat of force and the incapacity of giving a genuine consent, the Statute of the ICC seems to have combined the Furundžija and the Kunarac's definitions of rape:

(i) The perpetrator invaded ${ }^{531}$ the body of a person by conduct resulting in the penetration, however slight, of any part of the body of the victim or of the perpetrator with a sexual organ, or of the anal or genital opening of the victim with any object or any other part of the body.

(ii) The invasion was committed by force, or by threat of force or coercion, such as that caused by fear of violence, duress, detention, psychological oppression or abuse of power, against such person or another person, or by taking advantage of a coercive environment, or the invasion was committed against a person incapable of giving genuine consent ${ }^{532} .533$

The ICC also quotes the ICTY and the ICTR for interpreting the elements of the crime. For example, the Court referred to the Akajesu case for the interpretation of the "coercive environment". 534

In conclusion, the definition of rape encapsulated in the EOC of the Rome Statute represents the most recent effort to define the crime at international level and it has been adopted in the subsequent jurisprudence of the Court. ${ }^{535}$

Finally, it should be noted that the definition(s) of rape identified by the case law of the ICTY and the ICTR has been frequently evoked by regional international human rights courts. In

\footnotetext{
${ }^{530}$ Clamberg, Mark (ed.), Commentary on the Law of the International Criminal Court, Torkel Opsahl Academic EPublisher, Brussels, 2017. «The definition of rape found in the Elements of Crimes is heavily influenced by the legal reasoning in cases regarding rape of the ICTY and the ICTR» (p. 50).

531 The concept of 'invasion' is intended to be broad enough to be gender-neutral.

${ }^{532}$ It is understood that a person may be incapable of giving genuine consent if affected by natural, induced or age-related incapacity.

${ }^{533}$ Rome Statute of the International Criminal Court (Rome Statute) 1998, 2187 UNTS 90, Art. 7(1) (g)-1, Art. 8(2)(b)(xxii)-1, Art. 8(2)(e)(vi)-1 (elements of crime [EOC]).

${ }^{534}$ In Prosecutor v. Katanga, the Chamber stated that "threats, intimidation, extortion and other forms of duress which prey on fear or desperation may constitute coercion, and coercion may be inherent in certain circumstances, such as armed conflict or military presence", ICC, Prosecutor v. Katanga, PT. Ch. I. Decision on the Confirmation of Charges, ICC-01/04-01/07-717, (30September 2008), para. 440. It referred to ICTR, Prosecutor v. Akayesu, Trial Judgment, ... para. 688).

${ }^{535}$ For a list of the cases of the ICC on the criminalization of rape, see Schabas, William A., The International Criminal Court: A Commentary on the Rome Statute, Oxford University Press, Oxford, 2016.
} 
particular, some judgments are based on the Akayesu definition of sexual violence ${ }^{536}$ and the comparison the ICTR made between rape and torture. ${ }^{537}$ The Inter-American Court of Human Rights has also recalled the Kunarac's definition of rape, not only in contexts of internal armed conflicts but also in peaceful situations. ${ }^{538}$ In other cases, the definitions given by the ad hoc tribunals were used as a point of departure for the identification of the elements of the crime of rape. ${ }^{539}$ Thus, it is clear that the jurisprudence of the ad hoc tribunals with respect to the identification of an international definition of rape transcended the IHL regime. The question, therefore, arises not so much with regard to the impact that IHL has had or will have to "both the prohibition of rape and its definition in international law" 540 , but with the possibility of a harmonisation of the definition of rape in international law or, conversely, with the opportunity which could derive from the existence of different definitions of rape.

\subsubsection{Is the crime of rape a "grave breach" under the Geneva Conventions?}

After illustrating the basic steps towards an international definition of rape, the analysis turns on the doctrinal dispute regarding the non-inclusion of the crime of rape in the list of grave breaches under the Geneva Conventions and the Additional Protocols of $1977 .{ }^{541}$ Given that grave breaches are particularly serious violations that give rise to specific obligations of repression for States, ${ }^{542}$ it has been argued that the fact that rape and other forms of sexual

\footnotetext{
${ }^{536}$ See IACtHR, Rosendo Cantu v. Mexico, Judgment, (31August 2010), para. 109; IACtHR, Fernández Ortega y otros v. México, (30 August 2010), para. 127.

${ }^{537}$ Ibid. para. 117.

${ }^{538}$ See IACtHR, Fernández Ortega y otros v. México, (30bAugust 2010), para. 115; IACtHR, Women Victims of Sexual Torture in Atenco c. Mexico, (28 November 2018), para. 182.

539 ECtHR, M.C. v. Bulgaria, (application no. 39272/98), judgment, (4 December 2003), para. 102-107. In particular, the Court recalled the different definitions of rape given by the ICTY in Furundžija case and in Kunarac case.

${ }^{540}$ Eriksson, Maria, Defining Rape...p. 493.

541 The set of violations recognized as grave breaches are enlisted in Articles GCI, 50; GCII, 51; GCIII, 130; GCIV, 147; PI, 11/4; PI, 85.

542 The signatory States of the Geneva Conventions are compelled to provide penal sanction for such acts under domestic law and to prosecute perpetrators of grave breaches or to extradite them to another State at its request, under the principle aut dedere aut iudicare. See Uhler, Oscar M., Coursier, Henri, Commentary. IV Geneva convention...vol. 4, 1958, p. 59. In other words, grave breaches must be prosecuted by High Contracting Parties on the basis of the principle of universal jurisdiction. The existence of universal jurisdiction also provides a legal rationale for trying such crimes before an international tribunal and for the obligation of states to cooperate. Roling well explains that «in case of non-grave breaches the State shall take measures necessary for the suppression of such acts (the right to punish, but not the duty)». Roling, Bert V. A., "Criminal Responsibility for Violations of the Laws of War", Belgian Review of International Law, Vol. 12, No. 1, (1976), p. 13. Together with other serious violations of IHL, grave breaches constitute war crimes. On the relationship between the category of war crimes and the one of grave breaches, see Schwarz, Alexander, "War Crimes", in Lachenmann, Frauke and Wolfrum, Rüdiger (eds.), The Law of Armed Conflict and The Use of Force. Max Planck Encyclopedia of Public International Law, Thematic Series, Vol 2, Oxford University Press, Oxford, 2017, p. 1305. For a discussion on
} 
violence are not listed among the crimes amounting to grave breaches would appear to give these crimes a lesser status within the strict hierarchy of war crimes. ${ }^{543}$ How can thus one determine whether rape amounts to a grave breach?

First, the list of grave breaches taken from the articles of the Geneva Conventions of 1949 and the Additional Protocols of 1977 is not illustrative but exhaustive. ${ }^{544}$ This means that only conducts included in the list are subject to universal jurisdiction. However, some types of conduct is described in a very general manner, so that they could include different crimes. Thus, one may ask whether it is possible to consider the crime of rape as being included in one of the general types of conduct enlisted as grave breaches.

Some scholars have argued that the specific reference to rape in Article 27, paragraph 2, but not in the specific Articles in the conventions defining grave breaches would seem to argue against a broad interpretation. ${ }^{545}$ In this sense, it has been stated that

[i]t seems that "inhuman treatment" was included to cover possibilities that had not been seen by the drafters of the Convention. If this interpretation is warranted it is very difficult to maintain that rape is covered by this phrase as it was already a well-established practice in warfare. $^{546}$

In the same vein, Christine Chinkin underlined that the list of grave breaches contained in Protocol I of the Geneva Conventions includes "degrading practices involving outrages upon personal dignity based upon racial discrimination" but "makes no reference to gender discrimination". 547

Conversely, in 1992 the ICRC recognized that the act of "willfully causing great suffering or serious injury to body or health", classified as a grave breach under Article 147 of the Fourth Geneva Convention and under the respective Articles of the other Geneva Conventions and Additional Protocol I, comprises the crime of rape. ${ }^{548}$ Nowadays, the ICRC has made it clear

\footnotetext{
the use of the phrase "grave breach" during the 1949 Geneva Diplomatic Conference, see Solf, Waldemar A. and Cummings, Edward R., "A Survey of Penal Sanctions under Protocol I to the Geneva Conventions of August 12, 1949”, Case Western Reserve Journal of International Law, Vol. 9, No. 2, (1977) 205-252, p. 239.

${ }^{543}$ See e.g. Charlesworth, Hilary, "Symposium on Method: Feminist Methods", American Journal of International Law, Vol. 93, No. 2, (1999), 379-394 ; Copelon, Rhonda, "Surfacing Gender: Re-engraving Crimes Against Women in Humanitarian Law",...p. 250; Gardam and Jarvis, Women,...p. 74.

${ }^{544}$ ICRC, Commentary on the First Geneva Convention: Convention (I) for the Amelioration of the Condition of the Wounded and Sick in Armed Forces in the Field, Cambridge University Press, Cambridge, 2016, Article 50, para. 2906, available at https://ihl-databases.icrc.org/ihl/full/GCi-commentary [last visited 23 March 2021].

545 Gardam, Judith, "Women and the Law of Armed Conflict: Why the Silence?"...p. 75.

546 Ibid. p. 76.

${ }^{547}$ Chinkin Christine, Rape and sexual abuse of women in international law,...p. 332.

${ }^{548}$ ICRC, Aide-Memoire (Dec. 3, 1992) [quoted in Meron, Theodor, "Rape as a Crime Under International Humanitarian Law"...note 20]. The ICTY, in its Judgment concerning the Furundzija case, refers that the same
} 
that rape constitutes grave breach also as "inhuman treatment". ${ }^{549}$ Indeed, the Commentary to Rule 156 ("Definition of War Crimes") of the ICRC's Study on Customary IHL states

\begin{abstract}
Although rape was prohibited by the Geneva Conventions, it was not explicitly listed as a grave breach either in the Conventions or in Additional Protocol I but would have to be considered a grave breach on the basis that it amounts to inhuman treatment or willfully causing great suffering or serious injury to body or health.
\end{abstract}

Similarly, one should recall that rape may amount per se to torture, one of the enlisted grave breaches. Thus, when it satisfies the actus reus of the crime of torture, rape is a grave breach. ${ }^{550}$

The argument against the treatment of rape as grave breach, based on the lack of a specific reference to rape in the list of grave breaches, is thus addressed by the interpretation offered by Courts, scholars, and some States, which expressly recognize that rape falls under one or more of the categories of grave breach. The ICTY acknowledged that any form of sexual violence can constitute a grave breach as inhuman treatment, ${ }^{551}$ and a formal recognition of the classification of rape as a grave breach also came from the United Nations. ${ }^{552}$ In the same vein, the concept was expressed by the U.S. Department of State in the Letter from Robert A. Bradtke, Acting Assistant Secretary for Legislative Affairs, to Senator Arlen Specter ${ }^{553}$ and by the United Kingdom in the Declaration on Preventing Sexual Violence in Conflict, adopted in

position was expressed by the ICRC in its recommendations to the Conference on the Establishment of an International Criminal Court in Rome, July 1998. See ICTY, Prosecutor v. Furundžija,...p. 67, note 192.

${ }^{549}$ For a definition of "inhuman treatment" and the distinction between "human treatment" and "wilfully causing great suffering or serious injury to body or health", see ICRC, ICRC, Commentary on the First Geneva Convention: Convention (I)...Article 50, para. 2979-2983. The ICTY also dealt with the identification of a definition of "human treatment". See in particular, Ĉelebići Appeals Judgment, para. 426; Naletilić Judgment, para. 246; ICTY, Prosecutor v. Prlić, Trial Judgment, No. IT-04-74-T (2013), para. 113.

${ }_{550}$ See, among others, ICTY, Prosecutor v. Delalic, Judgment, No. IT-96-21/T (1998), paras. 7-25; ICTY, Prosecutor v. Furundzija, Judgment, No. IT-95-17/IT (1998); ICTY, Prosecutor v. Kunarac et al., Judgment, No. IT-96-23/T (2001).

${ }^{551}$ ICTY, Prosecutor v. Prlić, Trial Judgment, No. IT-04-74-T (2013), para. 116. The Tribunal stated "in keeping with the case-law of the Tribunal, any sexual violence inflicted on the physical and moral integrity of a person by means of threat, intimidation or force, in such as a way as to degrade or humiliate the victim, may constitute inhuman treatment under Article 2(b) of the Statute. Rape is thereby prohibited, as well as all forms of sexual violence not including penetration".

552 See, e.g., Letter from the Secretary- General to the President of the Security Council transmitting the final report of the Commission of Experts, Dec. 9, 1994, para. 141, U.N. Doc. S/1405, reprinted in The United Nations and Rwanda 1993-1996 415, 430 (1996).

553 The letter is quoted in Meron, Theodor, "Rape as a Crime Under International Humanitarian Law"...

We believe that there is no need to amend the Geneva Conventions to accomplish the objectives stated in your letter, however, because the legal basis for prosecuting troops for rape is well established under the Geneva Conventions and customary international law . . . all parties to an international conflict (including all parties to the conflict in the former Yugoslavia) are required either to try persons alleged to have committed grave breaches or extradite them to a party that will. In our reports to the United Nations on human rights violations in the former Yugoslavia, we have reported sexual assaults as grave breaches. We will continue to do so and will continue to press the international community to respond to the terrible sexual atrocities in the former Yugoslavia. 
London on 11 April 2013 as part of the initiative to end sexual violence in armed conflict. ${ }^{554}$ Along with the ICC Statute, the category of war crimes includes grave breaches of the Geneva Conventions and "other serious violations of the laws and customs applicable in international armed conflict". ${ }^{555}$ Sexual violence is comprised in the definition of "other serious violations".

Apart from the possible inclusion of the crime of rape in the list of the grave breaches through the subsumption of the conduct under the acts of "inhuman treatment", "willfully causing great suffering or serious injury to body or health", and "torture", one may ask whether the crime of rape can be considered, alone, a grave breach. It has been assumed that the lack of explicit recognition in the list of grave breaches "does not mean that other breaches cannot also be subject to universal jurisdiction by reason of customary or treaty law". ${ }^{556}$ In this regard, it could be posited that the categorization of rape as grave breach could also derive from sources other than the Geneva Conventions of 1949 and the Additional protocols of 1977, namely other international conventions or customary rules. ${ }^{557}$

In any case, the non-categorization of the crime of rape as grave breach was not an obstacle for the prosecution of single-episodes of rape by the international criminal tribunals. Since Furundžija case, it was clear that also isolated acts of rape could be prosecuted and this seems to be confirmed by the ICC Prosecutor that, in her 2014 Policy Paper on Sexual and GenderBased Crimes, noting that

[i]n certain circumstances, the Office will also prosecute middle- or even low-ranking officers or individuals, the extent of whose participation and responsibility for particularly serious or notorious crimes, including sexual and gender-based crimes, justifies prosecution, in order to

\footnotetext{
${ }^{554}$ The Declaration on Preventing Sexual Violence in Conflict states in paragraph 4: «Ministers recalled that rape and other forms of serious sexual violence in armed conflict are war crimes and also constitute grave breaches of the Geneva Conventions and their first Protocol. States have an obligation to search for and prosecute (or hand over for trial) any individual alleged to have committed or ordered a grave breach regardless of nationality». The Declaration is available at https://www.mofa.go.jp/mofaj/gaiko/files/g8fmm2013 03.pdf [last visited 7 February 2020]. Theo Rycroft expresses the view along with the use of the verb "recall" in the Declaration would suggest that the Parties didn't want to add a new category of grave breaches, but they merely considered rape within the existing categories of grave breaches. See Rycroft, Theo, "Criminalization and Prosecution of Sexual Violence in Armed Conflict at the Domestic Level: Grave Breaches and Universal Jurisdiction", in Vulnerabilities in Armed Conflicts: Selected Issues, Proceedings of the 14th Bruges Colloquium, 17-18 October 2013, College of Europe/ICRC, Collegium No. 44, Autumn 2014, pp. 73-82.

${ }_{555}^{50 m e}$ Statute for the ICC, Art. 8(2)(a) and (b).

${ }_{556}$ Pilloud, Claude, Sandoz, Yves, Swinarski, Christophe, and Zimmermann, Bruno, Commentary on the Additional Protocols: of 8 June 1977 to the Geneva Conventions of 12 August 1949, Martinus Nijhoff Publishers, Geneva, 1987, p. 976, note 11.

${ }^{557}$ In this respect, Mitchell recalls two domestic cases in which gender-based crimes were redressed in application of the principle of universal jurisdiction. Mitchell, David S., "The prohibition of rape in IHL as a norm of jus cogent: clarifying the doctrine", Duke Journal of Comparative \& International Law, Vol 15, (2005) 219-258, pp. 249 ss.
} 
give full effect to the object and purpose of the Statute and maximize the deterrent impact of the Court's work. ${ }^{558}$

Although some scholars have argued that explicitly including rape as a grave breach "would have been an important step in providing specificity on this matter rather than leaving it up to interpretation", ${ }^{559}$ it seems clear that the categorization of rape as grave breaches has gained acceptance at international level even without change of the wording of the relevant provisions. This development is another example of how the interpretation of current norms of IHL can reflect gender perspectives and contemporary insights about the female experience of war, especially with regard to violence against women.

\subsection{Concluding remarks}

Article 27, paragraph 2 of the IV Geneva Convention is indisputably a controversial norm. Indeed, both its formulation and its applicability are objects of many discussions. It is true that “Article 27 paragraph 2 GC IV uses dated, sexist, and legally imprecise language”, but this "should not inhibit its progressive interpretation". ${ }^{560}$ The specific analysis of the most disputed concepts of the norm, namely "honour" and "rape", has raised many problems. On the one hand, the term honour, evoking a traditional connection of sex with morality, seems inadequate to describe the different forms of conflict-related sexual violence to whom women are subject. Still attached to an old conception of women's chastity, the term risks to misrepresent and distort the experience of violence committed against women in situations of conflict. On the other hand, the crime of rape suffers from both the lack of an international definition and the non-explicit classification as grave breach. In sum, Article 27, paragraph 2 of the IV Geneva Convention constitutes the litmus test of the representation of the conflict-related sexual violence in IHL. It must be recognized a general difficulty in dealing with the matter, not because of a presumed "silence" 561 of the law of armed conflict, but because of a misleading approach to the issue.

\footnotetext{
558 Office of the Prosecutor, Policy Paper on Sexual and Gender-Based Crimes, June 2014, para. 23.

559 Steains, Cate, "Gender Issues", in Roy S. Lee (ed.), The International Criminal Court: The Making Of The Rome Statute: Issues, Negotiations, Results, Kluwer Law International, The Hague, 1999, 362-63.

${ }^{560}$ Viseur Sellers, Patricia and Rosenthal, Indira, 'Rape and other sexual violence',...2015, p. 344

${ }^{561}$ See Gardam, Judith, “Women and the Law of Armed Conflict: Why the Silence?”...
} 
Nevertheless, it is here argued that an evolutive understanding of the provision is possible. The argument has been supported that Article 27, paragraph 2 of the IV Geneva Convention has served as starting point for a great evolution on the protection of women in war. This evolution demonstrates that the limits of the norm can be overcome by means of interpretation. Thus, the given analysis of Article 27, paragraph 2 of the IV Geneva Convention demonstrates the great potential deriving from the (re)interpretation of the existing IHL norms informed by the insights offered by gender perspectives. The suggested evolutive interpretation of the term honour and the jurisprudential developments in defining the term rape are "a testament to this process". ${ }^{562}$ And, what is more, the great effort for a gender-sensitive interpretation of the norm had two other main effects. First, it shows how international courts and scholars were involved in refining the function of interpretative methods and the scope of application of general principles $^{563}$. The second effect was a concrete centralization and refocusing on the value of human dignity as the main principle informing the regime of IHL.

\footnotetext{
${ }^{562}$ Gardam, Judith, “The Silences of the Rules", in Ní Aoláin, Fionnuala, Cahn, Naomi, Haynes, Dina Francesca, Valji, Nahla (eds.) The Oxford Handbook of Gender and Conflict, Oxford University Press, Oxford, 2018, p. 43. 563 The ILC considered, among others, the use of general principles of law to establish certain elements of the definition of rape in the Furundžija case and Kunarac case to support the idea that general principles of law as a source of international law can arise from national legal systems. See Vázquez-Bermúdez Marcelo, Special Rapporteur, First report on general principles of law...paras. 215-218.
} 


\section{PART II}

The first two Chapters of this thesis have addressed the issue of conflict-related violence against women from the perspective of general and special IHL rules. There, certain central rules of ius in bello have been analyzed in order to investigate to what extent IHL accommodates or may accommodate a gender-sensitive approach.

Chapters 4 and 5 now turn to the post bellum phase, namely the phase after the cessation of the hostilities and until a formal settlement. Legal questions regarding wartime violence against women emerges also in relation to this post-conflict phase, particularly in the context of post bellum enforcement and implementation of IHL with regard to actions or omissions committed during the armed conflict and violating rules protecting women in the warfare. What happens in post bellum if IHL rules protecting women in the warfare have been violated by the Parties to the conflict? What happens if a group of female civilians is unlawfully killed during the warfare or a female detainee subjected to sexual violence during her detention by the enemy armed forces?

IHL treaties expressly recognize an obligation to respect IHL. ${ }^{564}$ Unlike domestic law, however, IL (and, thus, IHL as a branch of IL) does not have a centralized system of implementation and enforcement. Many legal mechanisms have been designed to ensure respect to IL and IHL rules. ${ }^{565}$ While most of these mechanisms are general IL implementation mechanisms, some of them are specific to IHL. Examples of the IHL specific implementation mechanisms include, among others, peacetime measures, as the dissemination and training of IHL at national level; ${ }^{566}$ the obligation to respect IHL and to ensure its respect; ${ }^{567}$ international

564 The obligation of the Parties to respect, applicable both in international and non-international armed conflict, is set up under common Article 1(1) of the four Geneva Conventions:

The High Contracting Parties undertake to respect and to ensure respect for the present Convention in all circumstances.

(Article 1 common to the Geneva Conventions; Article 1, para. 1, AP; ICRC, Customary IHL, Rule 139). For a recent research on the current debates on ensuring respect for IHL, the nature and scope of the provision and relevant examples of its interpretation and application today, see Massingham, Eve and McConnachie, Annabel (eds.), Ensuring Respect for International Humanitarian Law, Routledge, London and New York, 2021.

${ }^{565}$ For an overview of the different lawful reactions to violations of international humanitarian law, see generally, Vöneky, Silja, "Implementation and Enforcement of International Humanitarian Law", in Fleck, Dieter (ed.), The Handbook of International Humanitarian Law, Oxford University Press, Oxford, 2013, pp. 648 ss.

${ }^{566}$ GCs, Common Articles 47,48,127,144; AP I, Articles 83 and 87(2); AP II, Article 19, for NIACs. See also ICRC, Customary IHL, Rules 142 and 143.

${ }^{567}$ Common Article 1 of the 1949 Geneva Conventions. See also, AP I, Article 1(1) and 89; ICRC, Customary IHL, Rule 144. For a debate on the ICRC's interpretation of the "ensure respect" obligation under common Article 1 and its similarities with certain general rules in the law on State responsibility that similarly create obligations 
fact-findings procedures; ${ }^{568}$ the activities of the ICRC; 569 the penal and disciplinary measures; ${ }^{570}$ and the role of protecting powers ${ }^{571}$.

Of this rich palette of instruments, general and IHL-specific, the focus here is on the general system of reparations. The reasons for choosing this mechanism have to do both with the historical relevance of state practice and jurisprudence related to this mechanism and with the concrete impact that reparations could have on individual female victims of IHL violations. Reparations are "technically a consequence" 572 of the IL mechanism of State responsibility for breaches of IL. Thus, as will be specified later on in the Chapter, the law of State responsibility constitutes the legal basis for the system of reparations.

The aim of this Part of the thesis is to analyze the mechanism of reparations from the perspective of female victims of war. In this regard, Chapter 4 will introduce the legal framework of the system of reparations for breaches of IHL provisions and will provide an overview of the feminist accounts on the matter. Chapter 5 will analyze a specific case of conflict-related violence against women, namely the "comfort women" case, which is particularly paradigmatic as for the discussion on the relevance of the forms of reparation with regard to the kind of damage suffered by the survivors.

\footnotetext{
in relation to the conduct of others, see Hill-Cawthorne, Lawrence, "GCIII Commentary: Common Article 1 and State responsibility", ICRC Humanitarian Law \& Policy Blog, (January 28, 2021), available at: https://blogs.icrc.org/law-and-policy/ [last visited, 30 January 2021].

568 International fact-findings are investigations led by an independent, impartial and neutral body to guarantee reliable information on the relevant situation. They can be instituted under the request of a party to the conflict, but, since they parties agreement on the enquiry's process is required, States have never resorted to them so far. GCs, Common Articles 52,53,132,149.

569 The ICRC, established in 1863 as an independent and neutral organisation, guarantees humanitarian protection and assistance to victims of armed conflicts and other situations of violence. It promoted the adoption of the 1864 Geneva Convention. In IACs, IHL confers on the ICRC the right to visit prisoners of war and civilian internees, to interview them without witnesses (GC III, Article 126(5) and GC IV, Article 143(5)), and to bring them humanitarian assistance (GC III, Article 125(3); GC IV, Article 142(3)), as well as the right to obtain official information on prisoners of war and civilian internees and transmit it to the person's nationality country and his/her family (GC I, Article 16(2); GC III, Article 123; GC IV, Article 140; P I, Article 33(3)). In NIACs and in for other activities in IACs, the ICRC is provided the right of humanitarian initiative under Article 3 common to the four GCs. In other situations of internal disturbances and tensions, the ICRC has the right to initiative recognized by the Statutes of the International Red Cross and Red Crescent Movement.

${ }^{570}$ National military law defines whether the conduct must be punished through disciplinary measures or whether a criminal prosecution is necessary. Domestic legislations must provide criminal responsibility for those conducts, namely war crimes, which are criminalized by IHL. The implementation and enforcement of IHL particularly improved through the development of international criminal law and the institution of the post-conflict international criminal tribunals and the ICC.

571 AP I, Article 5.

572 Sassòli, Marco, International Humanitarian Law. Rules, Controversies and Solutions to Problems Arising in Warfare, Edward Elgar Publishing, Cheltenham, 2019, p. 91.
} 


\section{REPARATIONS FOR VICTIMS OF ARMED CONFLICT}

\subsection{Scope of the topic and methodological remarks}

First, this Chapter will give an overview of the State obligation to make reparation in case of non-compliance with the provisions of IHL. Second, and considering the particular relevance of reparations as a remedy for individuals, and, consequently for women victims, the critical issue on the existence of an individual right to reparation for violations of IHL will be discussed. Third, it will present the different forms of reparation, their definition, and their main purposes. Finally, the merits of a gender approach to reparation will be analysed in order to evaluate whether, and eventually how, the category of gender may be of any use for the determination of the most appropriate forms of reparation in cases of conflict-related violence against women. In this context, critical legal studies, and specifically feminist studies, will be used to underscore how gender may help in the choice of the most suitable forms of reparation, especially with regard to cases of conflict-related violence against women.

The purpose of the Chapter is neither to address the primary rules of IHL ${ }^{573}$ nor to tackle the issue of which acts of violence against women constitute violations of international obligations. Rather, the Chapter will deal with secondary rules of international law, namely the rules providing for the consequences of violations of primary rules. ${ }^{574}$ Having regard to the obligation of the States to remove the consequences of the wrongs committed, the principle of State responsibility will be applied with regard to breaches of IHL which have women or groups of women as victims. For the present purpose, the principle of the State responsibility will be addressed as elaborated by the International Law Commission (ILC) in the Draft Articles Responsibility of States for Internationally Wrongful Acts ${ }^{575}$ (therein Articles on State Responsibility).

\footnotetext{
${ }^{573}$ Namely the Geneva Conventions, their Additional Protocols and the customary IHL.

574 The distinction between primary rules and secondary rules may be described referring to the Ago's words:

" $[\mathrm{I}] \mathrm{t}$ is one thing to define a rule and the content of the obligation it imposes [primary rule], and another to determine whether that obligation has been violated and what should be the consequences of the violation [secondary rule]". Yearbook of the International Law Commission, (1970), vol. II, p. 306, document A/8010/Rev.l, para. 66 (c).

${ }^{575}$ International Law Commission, Draft Articles on Responsibility of States for Internationally Wrongful Acts, Report of the Work of its fifty-third session, UN GAOR, 56th Sess., Supplement No. 10 (A/56/10), U.N. Doc. A/56/589 (November 2001), reprinted in Crawford, James, The International Law Commission's Articles on State Responsibility: Introduction, Text and Commentaries, Cambridge University Press, Cambridge, 2002.
} 


\subsection{Reparations for violations of IHL}

4.2.1. The general obligation to make reparation for violations of IHL

Reparation is a well-established mechanism in international law and a deep-rooted practice in post conflict situations. ${ }^{576}$ In its original meaning, "war reparations" exclusively consisted in the monetary compensation or the transfer of goods that usually the defeated State must pay to the victors. ${ }^{577}$ Nowadays, the obligation to make reparation originates from the breach of any international obligation. ${ }^{578}$ It is thus relevant also outside situations of armed conflict. The Permanent Court of International Justice (PCIJ) notably expressed the content and scope of this general obligation in the 1928 Case Concerning the Factory at Chorzow (Chorzow Factory Case), stating that

reparation must, as far as possible, wipe out all the consequences of the illegal act and re-establish the situation which would, in all probability, have existed if that act had not been committed. ${ }^{579}$

The general principle of IL, according to which the commission of an internationally wrongful act creates an obligation to make full reparation for the injuries inflicted, has been endorsed in the 2001 International Law Commission's Articles on State Responsibility. ${ }^{580}$ Under the Articles on State Responsibility, international State responsibility arises when two elements are satisfied: an act is attributable to a State and that act constitutes a breach of an obligation under international law. ${ }^{581}$ Along with the general norm of attribution, a conduct is attributed to the State only when is that of its organs of government acting in their capacity, or of others who have acted under the direction, instigation or control of those organs. ${ }^{582}$ Article 7 of the

\footnotetext{
576 For a discussion on the inconsistent terminology used to analyse the mechanism of reparation, see Wood, Michael, "The Rights of Victims to Reparation: The Importance of Clear Thinking", Heidelberg Journal of International Law, Vol. 78, (2018) 541-543. The author suggests the use of the singular form "reparation" to define the right of the victims, and the plural form, "reparations", to generally refer to the forms of war reparations. ${ }^{577}$ For an historical overview of the normative development of the system of reparation, see Musa, Shava, Victim Reparation Under the Ius Post Bellum, Cambridge University Press, Cambridge, 2019. In particular, Chapter 9 and 10 of the volume explain, respectively, why there is no individual right to reparation for war victims today, and why an inherent right to reparation should exist.

${ }^{578}$ The Permanent Court of International Justice expressed the principle stating: "any breach of an engagement of [international law] involves an obligation to make reparation". PCIJ, The Case Concerning the Factory at Chorzow, Claim for Indemnity (1927) P.C.I.J. Series A, no. 9.

${ }_{579}$ PCIJ, The Case Concerning the Factory at Chorzow, Claim for Indemnity (1927) P.C.I.J. Series A, no. 9, 21. ${ }^{580}$ Article 31, Articles on State Responsibility.

581 Article 2, Draft articles on Responsibility of States for Internationally Wrongful Acts, with Commentaries, 2001

582 The circumstances under which a conduct may be attributed to a State are defined under Chapter II of the Articles on State Responsibility.
} 
Article on State Responsibility specifies that the conduct of a State organ or entity acting in its capacity is considered an act of the State even in case of ultra vires acts, namely acts in excess of authority or contrary to instructions. The international responsibility of a State generates certain legal consequences for the responsible State. The content of these legal consequences - defined in Part Two of the Articles on State responsibility - consists, first, in the cessation of the wrongful conduct and eventually the offer of appropriate assurances and guarantees of nonrepetition, ${ }^{583}$ and, second, in the obligation to make full reparation for the injury caused. Cessation aims at putting an end to the conduct in violation of an international obligation, if still ongoing, while the offer of assurances and guarantees of non-repetition, if requested by the circumstances, is finalized to reassure the injured Party about potential future breaches.

As an "indispensable complement of a failure to apply a convention", ${ }^{884}$ the obligation of the responsible State to make reparation obviously arises also in cases of IHL violations. Responsibility for breaches of IHL obligations is in principle regulated by the general regime established by the 2001 Articles on State Responsibility. The core obligation to make reparation for violations of IHL is also specifically established in Article 91 AP I, which basically reproduces Article 3 of the IV Hague Convention Concerning the Laws and Customs of War on Land of 1907.585 Article 91, AP I reads as follows

A Party to the conflict which violates the provisions of the Conventions or of this Protocol shall, if the case demands, be liable to pay compensation. It shall be responsible for all acts committed by persons forming part of its armed forces. ${ }^{586}$

The provision sets out four aspects of reparations for violations of IHL: the obligated parties, the condition of existence of the obligation, the content of the obligation and the attribution of internationally wrongful acts. The party obligated to make reparation is the responsible State (or armed group), so the State that committed the violation, whether aggressor or defendant, whether victor or vanquished. ${ }^{587}$ For the obligation to make reparation to exist, it is not sufficient that an unlawful act has been committed. In addition, it is necessary that the unlawful

\footnotetext{
${ }^{583}$ Article 30, Articles of State responsibility.

${ }^{584}$ PCIJ, The Case Concerning the Factory at Chorzow, Claim for Indemnity (1927) P.C.I.J. Series A, no. 9, p. 29. The position of the PCIJ was lately confirmed by its successor, the International Court of Justice (ICJ), in LaGrand (Merits) (Germany v. United States of America), 27 June 2001, para. 48.

${ }^{585}$ Art. 3, Hague Regulation IV states: “A belligerent party which violates the provisions of the said Regulations shall, if the case demands, be liable to pay compensation. It shall be responsible for all acts committed by persons forming part of its armed forces".

${ }^{586}$ Article 91, AP I.

${ }^{587}$ Commentary, para. 3652.
} 
act results to a loss or damage. Thus, the sentence "if the case demands" means that the obligation arises only if the violation is the cause of a compensable damage. As for the content of the obligation, the responsible State must provide a "compensation", which usually indicates "the award made to make reparation for a wrong". ${ }^{588}$ As will be explored later in this Chapter, reparations may take different forms, including restitution, compensation, rehabilitation, satisfaction and guarantees of non-repetition.

When stating that a State is responsible for "all acts" of a member of the armed forces, Article 91 appears to establish a special rule which diverges from the general rule codified in the Articles on State responsibility. Going beyond the principle of attribution to the State of ultra vires acts as established in Article 7 of the Articles on State Responsibility, Article 91 AP I extends the attribution of an act to the State also when the conduct is committed by its armed forces not acting in their capacity as organs of the State. ${ }^{59}$ A presumption of strict liability is provided for. ${ }^{590}$

The commentary to the Articles on State Responsibility confirms the applicability of the principle to IHL in considering Article 91 AP I and Article 3 of the IV Hague Convention of 1907 as an expression of the principle of attribution of the conduct of an organ to the State. ${ }^{591}$ The State is responsible of all acts committed by its armed forces. ${ }^{592}$ Thus, in cases of IHL violations the conduct of the members of State's armed forces are always attributable to the State, whether or not the armed force is considered a State organ under the domestic law, and irrespectively of the nature of the armed conflict, whether IAC or NIAC. The general rules of attribution also apply to the members of armed opposition groups if they subsequently become the new Government of the State or succeeds in establishing a new State..$^{593}$

\footnotetext{
588 Commentary, para. 3653.

${ }^{589}$ Article 7, ILC Articles on State Responsibility on Excess of authority or contravention of instructions: "The conduct of an organ of a State or of a person or entity empowered to exercise elements of the governmental authority shall be considered an act of the State under international law if the organ, person or entity acts in that capacity, even if it exceeds its authority or contravenes instructions."

590 This interpretation seems to be confirmed by the jurisprudence of the ICJ in Armed Activities on the Territory of the Congo (Democratic Republic of the Congo v. Uganda), where the Court, in applying Articles 3 of the 1907 Hague Convention IV and Article 91 of the 1977 Additional Protocol I, did not consider the possibility that the act of the members of the Ugandan armed forces may not be attributable to the State on the ground that the organ did not act in its capacity as an organ of the State. See in this regard, Greenwood, Christopher, "The International Court of Justice and International Humanitarian Law", in Cherlor Jalloh, Charles and Elias, Olufemi (eds.), Essays in International Law in Honour of Judge Abdul G. Koroma, Brill, Nijhoff, Leiden, 2015, p. 287.

${ }^{591}$ ILC Articles on State Responsibility, 45-6, paras 3-4 commentary to Art 7.

${ }^{592}$ Articles 4-9, Articles on State Responsibility.

${ }^{593}$ Article 10, Articles on State Responsibility.
} 


\subsubsection{The individual right to reparation for violations of IHL}

Who is the holder of the right to reparation? As explained above, the system of reparation has been conceived as an inter-States mechanism. When the conditions discussed above are fulfilled, it is the State that suffered the damage as result of the illegal act of another State that has the right to reparation. While there is no doubt that the wrongdoer State has an obligation to repair the effects of grave violations committed against the civilians and the military personnel of another State, and that the injured State has a right to reparation for the wrongful act, the question whether individuals are also entitled to a right to reparation for international crimes has been raised by a number of scholars during the last decades. The relevance of the issue goes in parallel with the general question of the position of the individual under current IL.

The right to reparation is a secondary right, stemming from a primary substantive right being violated. The existence of the secondary individual right to reparation depends on the violation of a substantive primary right under IHL, intended as a substantive right of individuals to be treated in accordance with the law of war. Thus, if a primary individual right is not recognized, the secondary individual right cannot exist: the recognition of an individual right to reparation assumes the existence of an individual primary right under IHL. ${ }^{594}$

The issue of whether the IHL regime provides individuals with substantive rights, namely whether individuals are merely beneficiaries of rights owned by their State of nationality or whether they are directly protected by the IHL rules, is much discussed in literature. ${ }^{595}$ On the concrete relevance of the controversy over the existence of IHL rules granting primary rights to individuals for women caught up in the conflict, one may recall Peters's example: "Female inhabitants of occupied territories are protected against enforced prostitution. Do they also have

\footnotetext{
${ }^{594}$ Contrarily, Hill suggests that there is not consistent practice to sustain that the right to reparation is a secondary right under secondary rules on State responsibility, arising from the breach of a primary rule conferring direct rights to individuals. In his view, this position may be bypassed by considering the right to reparation a specific right under IHL "arising where any IHL provision that protects individuals is violated". In so doing, the existence of an individual right to reparation would not be dependent on an individual primary right under substantive rules of IHL. Hill-Cawthorne, Lawrence, "Rights under International Humanitarian Law", European Journal of International Law, Vol. 28, No. 4, (2017) 1187-1215, pp. 1208-1209.

${ }^{595}$ For a discussion on the existence of individual rights at the primary level, see for example Zegveld, Liesbeth, "Remedies for Victims of Violations of International Humanitarian Law", International Review of the Red Cross, Vol. 85, No. 851, (2003) 497-527. For a voice contrary to the existence of primary individual rights under IHL, see Gillard, Emanuela-Chiara, "Reparation for Violations of International Humanitarian Law", International Review of the Red Cross Vol. 85, No. 851, (2003) 529-553.
} 
a right not to be forced to prostitute (see Art. 27 Geneva Convention IV)?". 596 The question will not be addressed here. The focus of this Section will be circumscribed to the secondary individual right to reparation, in so following that part of the scholarship asserting for the possibility of recognizing the existence of certain primary rights under contemporary IHL. The existence of individual substantive rights stemming from IHL is a necessary but not sufficient precondition for a secondary individual right to reparation. ${ }^{597}$ Even if assumed, it leaves open the question of whether an individual has a right to reparation for violations of IHL.

The traditional settlement of war reparations - usually consisting in an interstate agreement including a lump sum settlement and a waiver of individual claims ${ }^{598}$ - has been considered as practice supporting the view according to which IHL does not grant rights directly to individuals. ${ }^{599}$ The question whether contemporary international law confirms the classical view, according to which only the State is entitled to reparation in case of breach of an international obligation by another State, or, conversely, whether new developments of international law point to an emerging individual right to reparation is much debated in literature. ${ }^{600}$ Different fields of international law provide for some developments on the matter. First, legal basis for the obligation to make reparation may be found in international human rights legal documents. Some human rights regimes oblige States to provide effective reparation under domestic law to any person whose rights have been violated; ${ }^{601}$ some also

\footnotetext{
${ }^{596}$ Peters, Anne, "Direct Rights of Individuals in the International Law of Armed Conflict", MPIL Research Paper Series, No. 2019-23, (2019). The author analyses whether and under which conditions IHL generates individual rights, and against whom.

597 "Direct individual rights flowing from the primary norms of IHL are - even if no necessary a pre-condition a facilitator for recognizing rights to reparation in the event of the violation of the concrete primary norm". Peters, Anne, "Right to Reparation as a Consequence of Direct Rights Under International Humanitarian Law", Zeitschrift für ausländisches öffentliches Recht und Völkerrecht, Vol 78, No. 3, (2018) 545-549.

${ }^{598}$ Among the peace treaties with these characters concluded after the World War II: Treaty of Peace with Italy 1947, 49 UNTS 3, Arts 76, 80; San Francisco Treaty of Peace with Japan, supra note 6, Arts 14, 19; Joint Declaration by the Union of Soviet Socialist Republics and Japan 1956, 263 UNTS 99, Art. 6.

599 The non-existence of individual rights under IHL has been sustained, among others, by René Provost. He has argued that "humanitarian law protects the interests of the individual through means other than the granting of rights". Provost, René, International Human Rights and Humanitarian Law, Cambridge University Press, Cambridge, 2002, p. 16.

${ }^{600}$ In favour of the existence of an individual right to reparation for victims of violations of international humanitarian law, see for example: Ferstmann, Carla, "The right to Reparation for Victims of Armed Conflict", in Lattimer, Mark and Sands, Philippe (eds.), The Grey Zone: Civilian Protection Between Human Rights and the Laws of War, Hart Publishing, Oxford, 2018, p. 229. For the contrary perspective, see Tomuschat, Christian, Human Rights: Between Idealism and Realism, Oxford University Press, Oxford, 2003, p. 294.

${ }^{601}$ Article 6, International Convention on the Elimination of All Forms of Racial Discrimination, New York, 7 March 1966, UNTC, vol. 660, p. 195; Article 14, Convention Against Torture and Other Cruel, Inhuman or Degrading Treatment or Punishment, 10 December 1984, UNTC, vol. 1465, p. 85; Article 24(4), International Convention for the Protection of All Persons from Enforced Disappearance, 20 December 2006, UNTC, vol. 2716, p. 3.
} 
recognize an individual right to claim reparation and grant a legal procedure for individual complaints $^{602}$. Leaving apart the issue of the applicability of international human rights law during armed conflicts, ${ }^{603}$ it has been sustained that this developments in human rights instruments have contributed to "the formation of 'a reparations ethos' to the effect that individuals who have been wronged by applicable international human rights standards [...] should be compensated as fully as possible". ${ }^{604}$ This new "reparations ethos" led some authors to argue that

[i]t is difficult to maintain that individual victims of violations of human rights norms, applicable under the specific conditions of the relevant armed conflict, should have an individual claim for reparation, including monetary compensation, against the responsible state, whereas the individual victim of an international humanitarian law norm conferring rights on an individual should not have such a right to claim reparation, including monetary compensation. ${ }^{605}$

International criminal law also points to some developments on the issue, such as the individual mechanism of reparation before the International Criminal Court, defined under Article 75 of the Rome Statute. The possibility for the victims to "seek collective and moral reparations" and seek "appropriate reparation [...] collectively or individually" has been also provided, respectively, by the Internal Rules of the Extraordinary Chambers in the Courts of Cambodia $(\mathrm{ECCC})^{606}$ and by the Kosovo Specialist Chambers ${ }^{607}$ However, the individual claim to reparation in international criminal proceedings represents a different scheme to award reparations to victims, in that it is filed against the person convicted for an international crime

\footnotetext{
${ }^{602}$ Article 41, European Convention on Human Rights (therein ECTR); Article 63(1), Inter-American Convention on Human Rights (therein IACHR); Article 27(1), Protocol to the African Charter on Human and Peoples' Rights on the Establishment of an African Court on Human and Peoples' Rights. On the right to reparation under human rights treaties see also Bank, Roland and Schwager, Elke, "Is there a Substantive Right to Compensation for Individual Victims of Armed Conflict against a State under International Law?", German Yearbook of International Law, Vol. 49, (2006), 367, pp. 398 ss. On the practice of granting reparation before the InterAmerican Court of Human Rights (IACtHR) and European Court of Human Rights (ECtHR), see Sandoval, Clara, "International Human Rights Adjudication, Subsidiarity, and Reparation for Victims of Armed Conflict", in Correa Christiàn, Furuya, Shuichi, and Sandoval, Clara (eds.), Reparation for Victims of Armed Conflict, (Anne Peters and Christian Marxsen series eds.), Vol. 3, Cambridge University Press, Cambridge, 2021, pp. 179-264 (on file with the author).

${ }^{603}$ ICJ, Legality of the Threat or Use of Force of Nuclear Weapons, Advisory Opinion of 8 July 1996, ICJ Reports 1996, para. 25; ICJ, Legal Consequences of the Construction of a Wall in the Occupied Palestinian Territory, Advisory Opinion of 9 July 2004, ICJ Reports 2004, para. 106.

${ }^{604}$ Falk, Richard, "Reparations, International Law, and Global Justice", in de Grieff, Pablo (eds.), The Handbook of Reparations, Oxford University Press, Oxford, 2006, p. 485.

${ }^{605}$ Hofmann, Rainer, "Compensation for Personal Damages Suffered During World War II", in Lachenmann, Frauke and Wolfrum, Rudiger (eds.), Max Planck Encyclopendia of Public International Law. The Law of Armed Conflict and the Use of Force, Vol 2, Oxford University Press, Oxford, (article last updated in 2013) p. 285, para 32.

${ }^{606}$ Rule 23(1)(b) Internal Rules (Rev. 9), Extraordinary Chambers in the Courts of Cambodia.

${ }^{607}$ Art. 22(8) of the Law on Specialist Chambers and Specialist Prosecutor's Office, Law No.05/L-053.
} 
and not against the State. ${ }^{608}$ The ILA Committee recognized at the 2010 Conference in The Hague that there is "no reason why the individual, who already enjoys strong protection under international human rights law", and under international criminal law, "should have a weaker position under the rules of international law applicable in armed conflict". ${ }^{609}$ However, the issue seems far from solved when it comes to the recognition of an individual right to reparation for victims of IHL violations.

Some scholars assert that the individual right to seek remedies for violations of international humanitarian law pre-dates World War II. This position would be supported by the case law of international tribunals. In its 1928 judgment in the Chorzow Factory case, the PCIJ regarded the obligation to make reparation for an international wrongful act as a "principle of international law, and even a general conception of law". ${ }^{610}$ This broad conception of the right of reparation could also encompass the right of individual victims to obtain reparation. ${ }^{611}$

An additional argument for recognizing individual claims for compensation is based on Article 3 of the 1907 Hague Convention ${ }^{612}$ and Article 91 of Additional Protocol I. As asserted by Professor Kalshoven, the purpose of Article 3 of the 1907 Hague Convention IV "was from the outset to provide individual persons with a right to claim compensation for damages they suffered as a result of acts in violation of the Regulations" 613 and "directly from the responsible State" ${ }^{\prime 14}$. However, the ratione personae question, namely whether victims themselves may

\footnotetext{
${ }^{608}$ For traces of advancements in the process of recognition of an individual right to reparation in the practice of the international criminal courts and tribunals, see Furuya, Shuichi, "The Right to Reparation for Victims of Armed Conflict: The Intertwined Development of Substantive and Procedural Aspects", in Correa Christiàn, Furuya, Shuichi, and Sandoval, Clara (eds.), Reparation for Victims of Armed Conflict, (Anne Peters and Christian Marxsen series eds.), Vol. 3, Cambridge University Press, Cambridge, 2021 (on file with the author).

${ }^{609}$ Hofmann, Rainer, "Draft Declaration of International Law Principles on Reparation for Victims of Armed Conflict (Substantive Issues)", Commentary to Article 6, in International Law Association, Report of the SeventyFourth Conference Held in The Hague 15-19 August 2010, London, International Law Association, 2010, 295334.

${ }^{610}$ PCIJ, Chorzów Factory case (Germany v. Poland), 1928, Ser. A, No. 17, para. 29.

${ }^{611}$ MacDougall, Gay J., U.N. Special rapporteur, Final Report on Contemporary Forms of Slavery. Systematic Rape, Sexual Slavery and Slave-like Practices during Armed Conflict, E/CN.4/Sub.2/1998/13, 22 June 1998, Appendix, An analysis of the legal liability of the Government of Japan for "comfort women stations" established during the Second World War, para. 47, p. 39.

${ }^{612}$ Convention IV Respecting the Laws and Customs of War on Land and its annex: Regulations concerning the Laws and Customs of War on Land. The Hague, 18 October 1907.

${ }^{613}$ Kalshoven, Fritz, "Article 3 of the Convention (IV) concerning the Laws and Custom of War on Land, signed at the Hague, 18 October 1907", in "Remembering what we have tried to forget", ASCENT, 1997, p. 11. The use of the term 'compensation' in Article 3 instead of reparation would be another indication that "the drafters of the article had in mind the case of individual persons, victims of the laws of war, who with to bring a claim for the injury or damage they suffered" p. 12.

${ }^{614}$ Kalshoven, Frits, "State Responsibility for Warlike Acts of the Armed Forces: From Art. 3 of Hague Convention IV of 1907 to Art. 91 of Additional Protocol I of 1977 and beyond", International and Comparative Law Quarterly, Vol. 40, No. 4, (1991) 827-858, p. 837.
} 
seek redress relying on Article 3 of the Hague Convention, splits scholars. In other terms, the direct applicability to individuals of Article 3 of the 1907 IV Hague Convention is controversial in doctrine. ${ }^{615}$ Kalshoven argued that the lump-sum reparation regimes established after World War II must not be read as a practice that limits the scope of Article 3 to attribute the right to reparation directly to war victims. ${ }^{616}$ However, the prevailing and more convincing view is that, under the practice generally followed by States, this provision was not understood to provide an individual right to reparation, but to oblige States to pay reparations and not only war indemnities. ${ }^{617}$

Finally, some scholars have suggested that also the ICJ has indirectly recognized an individual right to reparation in its 2004 advisory opinion on the Wall in the Occupied Palestinian Territory, when stating that

Israel has the obligation to make reparation for the damage caused to all the natural and legal persons concerned. [...] The Court considers that Israel also has an obligation to compensate, in accordance with the applicable rules of international law, all natural or legal persons having suffered any form of material damage as a result of the wall's construction. ${ }^{618}$

The consideration of the individuals (the Palestinians) as the holders of the right to reparation stems here from the direct application of the IHL regime, in particular the law of occupation, being Israel the occupying power, and from the inexistence of a recognized State of nationality of the victims which could act on their behalf. Some have interpreted this advisory opinion as clearly recognizing an individual right to reparation, ${ }^{619}$ while others as an unicum, given the impossibility for the Court to refer to a State as the holder of the right in the specific case. ${ }^{620}$

\footnotetext{
615 Professor Kalshoven opinion is supported, for example, by Meron, Theodor, Human Rights and Humanitarian Norms as Customary Law, Oxford University Press, Oxford, 1989; Sassòli, Marco, "State Responsibility for Violations of International Humanitarian Law", International Review of the Red Cross, Vol. 84, No. 846, (2002), 401-434, p. 419; Pisillo Mazzeschi, Riccardo, "Reparation Claims by Individuals for State Breaches of Humanitarian Law and Human Rights: An Overview”, Journal of International Criminal Justice, Vol. 1, No. 2, (2003) 339-347, p. 341.

616 Kalshoven, Fritz, "State Responsibility for Warlike Acts of the Armed Forces...pp. 836-837.

${ }^{617}$ See, representatively, Hofmann, Rainer, "Compensation for Personal Damages Suffered during World War II”, Max Planck Encyclopedia of Public International Law, (2013), p. 278.

${ }^{618}$ ICJ, Legal Consequences of the Construction of a Wall on the Occupied Palestinian Territory, Advisory Opinion, 2004 ICJ Reports 136, 9 July 2004, p. 198, para. 152 f.

619 Marxen, Christian, "Introduction", in Correa Christiàn, Furuya, Shuichi, and Sandoval, Clara (eds.), Reparation for Victims of Armed Conflict, (Anne Peters and Christian Marxsen series eds.), Vol. 3, Cambridge University Press, Cambridge, 2021, pp. 179-264 (on file with the author), p. 10.

${ }^{620}$ D'Argent, Pierre, "Compliance, Cessation, Reparation and Restitution in the Wall Advisory Opinion", in Dupuy, Pierre-Marie at al (eds.), Common Values in International Law. Essays in Honour of Christian Tomuchat, Engel Verlag, Kehl, 2006, p. 475. Against this view, Furuya sustains that "this argument does not explain why only those individuals without a home State can be direct beneficiaries of the reparation that a responsible State
} 
Currently, the majority of international scholars ${ }^{621}$ and domestic courts seem to agree that there is no individual right to reparation for violations of IHL. According to the prevalent view in the case law related to compensation claims for war crimes committed in the World War II, individuals are not the holders of a right to reparation for breaches of international law by a State and only the individual's State of nationality is the holder of the secondary right to claim compensation under Articles 3 of the Hague Convention IV and Article 91 AP I. ${ }^{62}$ As the Federal Constitutional Court of Germany stated in the Distomo case, related to massacres in the Greek village of Distomo by the German army in the World War II,

Irrespective of developments at the level of the protection of human rights, which have led to recognition of a partial international legal subjectivity of the individual and to the establishment of individual complaints procedures set out in treaties, secondary claims for damages arising from acts of a State in violation of international law against foreign nationals continue to be assigned only to the home State in principle. ${ }^{623}$

From a procedural perspective as well, the individual right to reparation encounters significant barriers, both at international and national level. International law does not provide individuals a permanent mechanism to claim reparation. According to the traditional procedure of diplomatic protection, the State of nationality of the injured person may act, in its own name and on its own behalf, to safeguard and obtain reparation for that person. As the holder of the right to exercise diplomatic protection, the State has the discretion to decide whether and how to invoke the right and pursue a claim against the responsible State. ${ }^{624}$ Also at domestic level, individual claims before national courts face procedural hurdles, such as amnesties and statutes

has an obligation to make". Furuya, Shuichi, "The Right to Reparation for Victims of Armed Conflict: The Intertwined Development of Substantive and Procedural Aspects", p. 45.

${ }^{621}$ See Ronzitti, Natalino, Diritto internazionale dei conflitti armati, edn third, Giappichelli, Torino, 2011.

${ }^{622}$ Among the cases in which Japanese courts rejected the individual claims for compensation adducing Article 3 of the Hague Convention IV, see X. et al. v. State of Japan, Tokyo High Court, Judgment of 27 July 1995; X. et al. v. State of Japan, Tokyo District Court, Judgment of 30 November 1998; Henson et al. v. State of Japan, Tokyo District Court, Judgment of 9 October 1998. German courts have expressed the same view in different occasions. See for example the judgment of the German Federal Court of Justice, BGH, Judgment of 2 November 2006 - III ZR 190/05 (Varvarin); and the decision of the German Federal Constitutional Court in BVerfG, 2 BvR 2660/06, inadmissibility decision of 13 August 2013 - Bridge of Varvarin. For other references to the German case law on the matter, see Peters, Anne, Beyond Human Rights. The Legal Status of the Individual in International Law, Cambridge University Press, Cambridge, 2016, pp. 204-207.

${ }^{623}$ Federal Constitutional Court of Germany, BVerfG, 2 BvR 1476/03, Non-admissibility Order of the 1st Chamber of 15 February 2006, Neue Juristische Wochenschrift 59 (2006), para. 21. [English translation in Oxford Public International Law, Oxford Reports on International Law, available at https://opil.ouplaw.com /home/oril]. See Peters, Anne, Beyond Human Rights. The Legal Status of the Individual in International Law, Cambridge University Press, Cambridge, 2016, p. 206.

${ }^{624}$ International Law Commission, Draft Articles on Diplomatic Protection with Commentaries, (2006), Report of the ILC on the Work of Its 58 ${ }^{\text {th }}$ Session (1.5.-9.6.; 3.7.-11.8.2006), UN Doc. A/61/10, available at http://untreaty.un.org/ilc/texts/instruments/english/commentaries/98-2006.pdf [last visited: 21 February 2021]. 
of limitations. In particular, individual claims against the State responsible of violations of IHL before national courts of another State violate the principle of State immunity. ${ }^{625}$

During the last years, a number of cases seeking reparations for offences caused by violations of IHL have been dismissed by domestic courts on the ground of State immunity. Conversely, Italian courts allowed some civil claims to be brought against the Federal Republic of Germany for crimes committed by the Third Reich during the World War II, alleging that the State immunity does not apply to the alleged circumstances because the asserted injuries against Italian nationals constitute violations of jus cogens and war crimes. ${ }^{626}$ In its Judgment Jurisdictional Immunities rendered on 3 February 2012 on the basis of the complaint brought by Germany, the ICJ declared that Italy had violated the Germany's immunity. ${ }^{627}$ Among others, the ICJ rejected the claim of existence of a jus cogens norm granting individuals the right to reparation, stating

Moreover, against the background of a century of practice in which almost every peace treaty or post-war settlement has involved either a decision not to require the payment of reparations or the use of lump sum settlements and set-offs, it is difficult to see that international law contains a rule requiring the payment of full compensation to each and every individual victim as a rule accepted by the international community of States as a whole as one from which no derogation is permitted. ${ }^{628}$

In sum, given the prevailing interpretation of substantive treaty law and the courts' unwillingness in overriding procedural bars, such as State immunity, to let victims seeking compensation before national courts, it seems difficult to support the idea that current international law provides victims of war with an individual right to compensation for offences arising from the violation of IHL's rules. It appears even more difficult to argue that the States' practice on the matter could offer a basis for individual claims under customary international law. ${ }^{629}$

\footnotetext{
${ }^{625}$ The rules of State immunity are international procedural rules that prevent the adjudication of a dispute in a particular forum without speaking to the merits of the claim or absolving any underlying responsibility of the state. In other words, they determine whether or not the courts of one State could exercise jurisdiction in respect of another State.

${ }^{626}$ Italian Court of Cassation, Ferrini v. Federal Republic of Germany, Decision No. 5044/2004, Rivista di diritto internazionale, Vol. 87, 2004, p. 539.

${ }^{627}$ ICJ, Case Concerning Jurisdictional Immunities (Federal Republic of Germany v. Italian Republic), Judgment of 3 February 2012.

${ }^{628}$ ICJ, Jurisdictional Immunities, para 94.

${ }^{629}$ On how the use of different approaches to customary law could influence the issue on the existence of an individual right to reparation, see Marxen Christian, "What Do Different Theories of Customary International Law Have to Say about the Individual Right to Reparation under International Humanitarian Law?", Zeitschrift für ausländisches öffentliches Recht und Völkerrecht, Vol. 78, No. 3, (2018) 581-587.
} 
However, according to a number of authors, the issue of individual right to reparation is not yet fully resolved. "Given that there is still little evidence in customary international law for an individual right to a remedy against, and reparation for, violations of international humanitarian law" ${ }^{630}$, it is often treated in terms of de lege ferenda, ${ }^{631}$ Some recent developments might support this view. First, one may recall the Resolution on Basic Principles and Guidelines on the Right to a Remedy and Reparation for Victims of Gross Violations of International Human Rights Law and Serious Violations of International Humanitarian Law (therein UN's Basic Principles and Guidelines on the Right to a Remedy and Reparation) ${ }^{632}$, adopted by the UN General Assembly (GA) in December $2005 .{ }^{633}$ The Resolution does not address the contentious issue of the individual right to reparation and also underlines that does "not entail new international or domestic legal obligations". ${ }^{634}$ However, it provides for a set of norms to respect, ensure respect and implement human rights law and international humanitarian law on the matter of remedies and reparations for individuals, in so confirming the responsibility of the State to provide its own nationals with remedies and reparation for gross violations. For this reason, it postulates "legal standards in the area of victims' rights". ${ }^{635}$

\footnotetext{
${ }^{630}$ Hofmann, Rainer, "The 2010 International Law Association Declaration of International Law Principles on Reparation for Victims of Armed Conflict", Zeitschrift für ausländisches öffentliches Recht und Völkerrecht, Vol 78, No. 3, (2018) 551-554.

${ }^{631}$ Peters, Anne, Beyond Human Rights. The Legal Status of the Individual in International Law, Cambridge University Press, Cambridge, 2014, p. 210.

${ }^{632}$ The UN's Basic Principles and Guidelines on the Right to a Remedy and Reparation are the result of the UN's efforts to develop the subject of the right to reparation of victims of gross violations of human right and humanitarian law which had been started by Theo van Boven, the then Special Rapporteur of the then SuCommittee on Prevention of Discrimination and Protection of National Minorities. He presented a set of Basic Principles and Guidelines on the Right to Reparation for Victims of Gross Violations of Human Rights and International Humanitarian Law within the 1993 study on the right to restitution, compensation and rehabilitation for victims of gross violations of human rights and fundamental freedoms (UN Doc. E/CN.4/Sub.2/1993/8, 2 July 1993). In 2000, the then UNCHR Special Rapporteur, Cherif Bassiouni, submitted his final report which included the revised version of Basic Principles and Guidelines on the right to a remedy and reparation for victims of violations of International Human Rights and Humanitarian Law (UN Doc. E/CN.4/2000/62, 18 January 2000). ${ }^{633}$ UN GA Res, Basic Principles and Guidelines on the Right to a Remedy and Reparation for Victims of Gross Violations of International Human Rights Law and Serious Violations of International Humanitarian Law, A/RES/60/147, 16 December 2005.

${ }^{634}$ Ibid. p. 3 (emphasis added). According to Furuya, the Basic Principles' aim to implement "existing legal obligations under international human rights law and international humanitarian law" must be read as admitting that "the rights of the victim they set out are not lex ferenda; rather, they are already established in international law". Furuya, Shuichi, "The Right to Reparation for Victims of Armed Conflict: The Intertwined Development of Substantive and Procedural Aspects", p. 32.

${ }^{635}$ Van Boven, Theo, "Victims' Right to a Remedy and Reparation: The New United Nations Principles and Guidelines", in Ferstman, Carla and Goetz, Mariana, (eds.), Reparations for Victims of Genocide, War crimes and Crimes Against Humanity: Systems in Place and Systems in the Making, Brill, Nijhoff, Leiden, 2009, p. 32.
} 
Second, a significant step forward in the discussion on the matter was made in 2010, with the adoption of the International Law Association (ILA) ${ }^{636}$ Declaration of International Law Principles on Reparation for Victims of Armed Conflict (Substantive Issues). ${ }^{637}$ The Declaration, soft law in nature, was the result of a 6-years' work of the ILA's Committee on Reparation for Victims of Armed Conflict chaired by Natalino Ronzitti and started at the Berlin workshop in 2004. The central provision of the Declaration, Article 6, states that "victims of armed conflict have a right to reparation from the responsible parties". While assessing that "until most recently, international law did not provide for any right to reparation for victims of armed conflicts", ${ }^{638}$ the Committee seems to recognize that there is room for an individual right to reparation to develop in the future. Indeed, the Commentary to Article 6 provides for a remarkable trend, both in the state practice and in doctrinal literature, toward the recognition of an individual right to reparation. ${ }^{639}$ Moreover, the Committee encourages to strengthen victim's rights in obliging the Parties to give effects to their rights through the establishment of enforcement mechanisms, ${ }^{640}$ and in promoting a victim-oriented interpretation of any agreement on the matter as well as a progressive development of the principles expressed in the Declaration. ${ }^{641}$

A clear indication of the centrality of the subject is the specific focus on the issue planned by the ILC. ${ }^{642}$ In the Report on the work of its seventy-first session, held in Geneva in 2019, the

\footnotetext{
${ }^{636}$ The International Law Association is an international non-governmental organisation, with consultative status, among others, within a number of the United Nations specialised agencies. Founded in Brussels in 1873, the ILA aims at "the study, clarification and development of international law, both public and private, and the furtherance of international understanding and respect for international law" (see the Constitution of the Association).

${ }^{637}$ ILA, Declaration of International Law Principles on Reparation for Victims of Armed Conflict (Substantive Issues), Res. no 2/2010 on Reparation for Victims of Armed Conflict, The Hague, 2010, available at http://www.ila-hq.org/en/committees/index.cfm/cid/1018 [last visited: 21 February 2021]. The procedural standards needed to enforce the right of the victims of armed conflict to reparation stated in the abovementioned ILA Declaration have been set in another ILA Resolution: ILA, Procedural Principles for Reparation Mechanisms, Res. no 1/2014, Washington, 2014.

${ }^{638}$ Hofmann, Rainer, "Draft Declaration of International Law Principles on Reparation for Victims of Armed Conflict (Substantive Issues)", Preliminary Remarks, in ILA, Report of the Seventy-Fourth Conference Held in The Hague 15-19 August 2010, London, International Law Association, 2010, 295-334.

${ }^{639}$ Ibid.

${ }^{640}$ ILA, Declaration of International Law Principles on Reparation for Victims of Armed Conflict (Substantive Issues), Res. no 2/2010, Article 11.

${ }^{641}$ ILA, Declaration of International Law Principles on Reparation for Victims of Armed Conflict (Substantive Issues), Res. no 2/2010, Article 14.

${ }^{642}$ In general, the ILC demonstrated a particular interest on issues related to the individual in international law in the last years, working, among others, on the topics of "State responsibility of internationally wrongful acts," "Diplomatic protection," "Position of the individual in international law," "Nationality including statelessness," and "Protection of persons in the event of disasters.
} 
Commission decided to include of the topic ${ }^{643}$ of "Reparation to individuals for gross violations of international human rights law and serious violations of international humanitarian law" in its long-term programme of work. ${ }^{644}$ This decision will offer "an opportunity for both the codification and the progressive development of international law"645 on the matter. One specific passage of the Report deserves particular attention. Among the possible specific issues to address for this work, the Commission mentions

(a) The different forms of reparation (e.g. restitution, compensation and satisfaction, guarantees of non-repetition, etc.), their definition, and their main purposes;

(b) The degree of flexibility that States have when choosing between different forms of reparation;

(c) The appropriateness of certain forms of reparation, depending on the circumstances. ${ }^{646}$

As it will be discussed later on in the Chapter, one of the major claims of feminist scholars with regard to the system of reparation is just the non-adequateness of the forms of reparation to the exigencies of the victims, especially women survivors of armed conflicts. Thus, the abovementioned reference could be of particular interest in disclosing a new sensibility or, at least, a new understanding of the relevance of the choice of the form of reparation for the victims of armed conflict.

The fact that the Commission felt the need to intervene with a comprehensive analysis on the matter is of great significance. The Commission recognizes that this is a good moment for taking stock of the shift in views on the legal position of the individual in international law, and, eventually, for the identification of an individual right to reparation for victims of armed

\footnotetext{
${ }^{643}$ The Commission established the criteria for the selection of new topics in its long-term programme of work at its fiftieth session (1998), stating that:

(a) The topic should reflect the needs of States in respect of the progressive development and codification of international law;

(b) The topic should be sufficiently advanced in stage in terms of State practice to permit progressive development and codification;

(c) The topic is concrete and feasible for progressive development and codification.

In this regard, in the selection of new topics, the Commission should not restrict itself to traditional topics, but could also consider those that reflect new developments in international law and pressing concerns of the international community as a whole.
}

Yearbook of the International Law Commission, (1997), vol. II, Part Two, p. 72, para. 238.

${ }^{644}$ Report of the International Law Commission, seventy-first session, A/74/10, (29 April-7 June and 8 July-9 August 2019), available at: https://documents-ddsny.un.org/doc/UNDOC/GEN/G19/243/93/PDF/G1924393.pdf?OpenElement [last visited: 26 November 2020 ]. ${ }^{645}$ Ibid. Annex B, p. 362.

${ }^{646}$ Ibid. Annex B, p. 362. 
conflict. In this sense, the work of the Commission could have a great value for the progressive development of the law of reparation.

The above discussion focused on the existence and future developments of an individual right to reparation for victims of IHL violations committed by persons whose acts are attributable to States, under the rules of State responsibility. However, modern armed conflicts often involve non-State actors and persons directly acting for international organisations within peaceenforcement or peace-keeping operations. As Rainer rightly stated,

If present international law provides for such a right [an individual right to reparation] against the States, it is difficult to maintain that the situation should be different as regards international organisations and non-State actors: If they are subjects of international law and engage in acts which could have been committed, under traditional international law, only by States and, thus, behave as States, then they should, in principle, be held accountable in the same way as States. ${ }^{647}$

If it is true that many advancements on the matter have been made, many challenges seem still unresolved. First, one may recall the practical issue of how to eventually award individual compensation in the very common cases of mass violations. Second, even admitting the existence of an individual right to reparation, it will still be necessary to recognize the tertiary right, namely the procedural right of the victims to take a judicial action against the responsible State before the competent forum or the right of the victim to access an effective reparation mechanism. To conclude, as international law now stands, the prevailing view is that there is no individual right to reparation for IHL violations. However, and regardless of the many remaining challenges, a general tendency toward this direction is detectable.

Notably for our purposes, the above analysis suggests that the efforts to recognize the existence of an individual right to reparation assumes a general trend toward a victims-oriented approach to war reparations. Thus, this approach may be used for the subsequent analysis of the best forms of reparations for harms against women amounting to violations of IHL. In other words, the victims-oriented approach could maybe justify a more flexible States' attitude in the choice of the more adequate form of reparation, privileging the view of the female survivors in the case at hand. In this sense, a gender perspective could confer a substantial contribution to the

${ }^{647}$ Hofmann, Rainer, "Victims of Violations of International Humanitarian Law: Do They Have an Individual Right to Reparation against States under International Law?", in Dupuy, Pierre-Marie at al. (eds.), Common Values in International Law. Essays in Honour of Christian Tomuchat, Engel Verlag, Kehl, 2006, pp. 343-344. 
discussion as an essential paradigm for a holistic understanding of how to approach reparation for victims.

\subsubsection{The forms of reparation}

Article 34 of the Articles on State Responsibility identifies three "forms of reparations": restitution, compensation and satisfaction. ${ }^{648}$ In addition, it considers the cessation of conduct in breach of an international obligation and the assurances and guarantees of non-repetition as separate obligations under Article $30 .{ }^{649}$ The current trend to conflate IHL with IHRL with respect to the issue of reparation led to consider, in certain legal documents, "assurances and guarantees of non-repetition" $" 650$ and "rehabilitation" 651 as autonomous forms of reparation for violations of IHL. ${ }^{652}$ However, it is followed here the tripartition of the forms of reparation identified in Article 34 of the Articles on State Responsibility, ${ }^{653}$ so that "assurances and guarantees of non-repetition" is not considered a form of reparation and "rehabilitation" is

\footnotetext{
${ }^{648}$ Article 34: "Full reparation for the injury caused by the internationally wrongful act shall take the form of restitution, compensation and satisfaction, either singly or in combination, in accordance with the provisions of this chapter".

${ }^{649}$ The assurance of non-repetition consists in a verbal expression, while the guarantee of non-repetition is given through acts other than oral. Articles on State Responsibility, Commentary to Article 30, p. 90, para. 12. The Basic Principles and Guidelines on the Right to a Remedy and Reparation provide a series of examples of the acts which may encompass guarantees of non-repetition:
}

(a) Ensuring effective civilian control of military and security forces;

(b) Ensuring that all civilian and military proceedings abide by international

standards of due process, fairness and impartiality;

(c) Strengthening the independence of the judiciary;

(d) Protecting persons in the legal, medical and health-care professions, the media and other related professions, and human rights defenders;

(e) Providing, on a priority and continued basis, human rights and international humanitarian law education to all sectors of society and training for law enforcement officials as well as military and security forces;

(f) Promoting the observance of codes of conduct and ethical norms, in particular international standards, by public servants, including law enforcement, correctional, media, medical, psychological, social service and military personnel, as well as by economic enterprises;

(g) Promoting mechanisms for preventing and monitoring social conflicts and their resolution;

(h) Reviewing and reforming laws contributing to or allowing gross violations of international human rights law and serious violations of international humanitarian law.

Basic Principles and Guidelines on the Right to a Remedy and Reparation, para. 23.

${ }^{650}$ Articles 1(2), 7-10 of the ILA Declaration of International Law Principles on Reparation for Victims of Armed Conflict (Substantive Issues) mention restitution, compensation, satisfaction, and guarantees and assurances of non-repetition among the forms of reparation.

${ }^{651}$ Rehabilitation is a form of reparation specifically devoted to the recovery of the victims of harms in breach of IHL and it encompasses medical and psychological care as well as legal and social services. Basic Principles and Guidelines on the Right to a Remedy and Reparation, para. 21.

${ }^{652}$ See Rome Statute, Article 75(2).

${ }^{653}$ Some authors sustain that, nowadays, a comprehensive and general notion of reparation should refer to restitution, compensation, satisfaction, rehabilitation, and assurances and guarantees of non-repetition. See Marxen, Christian, "Introduction", in Correa Christiàn, Furuya, Shuichi, and Sandoval, Clara (eds.), Reparation for Victims of Armed Conflict. 
assumed to fall under the notion of "satisfaction". The choice is dictated by the fact that, as discussed above, the legal nature of those documents that have enlarged the forms of reparation, such as the 2005 UN's Basic Principles and Guidelines on the Right to a Remedy and Reparation, is still debated. Moreover, it seems that a gender-oriented interpretation of the reparation system may fill the eventual gaps and limits of the traditional forms of reparation.

Restitution refers to all measures "to re-establish the situation which existed before the wrongful act was committed". ${ }^{654}$ In seeking to re-establish the status quo ante, only the situation that existed prior to the occurrence of the wrongful act is taken into account, in so leaving aside any consideration over the establishment or re-establishment of the hypothetical situation that would have existed if the violation of international law had not been committed. In this sense, the Commentary to the Articles on State Responsibility suggests that compensation may eventually make up for this narrow standard, and, together with restitution, ensure a full reparation. ${ }^{655}$ Restitution has to be made "provided and to the extent that" it is neither materially impossible nor wholly disproportionate, meaning that the benefits for the victim would be disproportionate to its cost to the responsible State or restitution would not be a real benefit for the victim. ${ }^{656}$ In introducing exceptions to the use of restitution, it is also indirectly postulated the primacy of this form of reparation over the others, in that "the most closely conforms" to the general scope of reparation. ${ }^{657}$ Restitution may entail, among others, the restoration of rights and the restitution of property.

The second and most common form of reparation is compensation. It consists of a payment that covers the financial assessable damage suffered by the injured State or its nationals because of the violation of international law. Damage is understood both materially and morally, ${ }^{658}$ and Article 36 of the Articles on State Responsibility specifies that the "financial assessable

\footnotetext{
${ }^{654}$ Article 35, Articles on State Responsibility.

${ }^{655}$ Articles on State Responsibility, Commentary to Article 35, p. 96, para. 2.

${ }^{656}$ Article 35, Articles on State Responsibility.

${ }^{657}$ Articles on State Responsibility, Commentary to Article 35, p. 96, para. 3. This primary of restitution when practicable has been reasserted by the ICJ's Advisory Opinion on Israel's security wall:
}

Israel is accordingly under an obligation to return the land, orchards, olive groves and other immovable property seized from any natural or legal person for purposes of construction of the wall in the Occupied Palestinian Territory. In the event that such restitution should prove to be materially impossible, Israel has an obligation to compensate the persons in question for the damage suffered. The Court considers that Israel also has an obligation to compensate, in accordance with the applicable rules of international law, all natural or legal persons having suffered any form of material damage as a result of the wall's construction.

ICJ, Legal Consequences of the Construction of a Wall on the Occupied Palestinian Territory, para. 153.

${ }^{658}$ Article 31(2), Articles on State Responsibility. 
damage" also covers loss of profit as long as it may be quantified in the given case. Usually entailing a monetary payment, compensation may also take any other form of values. There is not a unified international method to determine the appropriate amount of compensation, so standards for the definition of the due compensation have been defined on a case by case basis. It is worth here to stressing that international courts and tribunals have dealt with the assessment of compensation for personal injury suffered by nationals or officials of the State on numerous occasions. ${ }^{659}$ The concept of "non-material damages" may be particularly relevant for this study. This kind of damages, which encompasses the mental and psychological suffering of victims, as well as injuries to the person's reputation and social status and dishonor, are frequently claimed by women victims that seek redress for damages stemming from violations of IHL norms.

Satisfaction is the third form of reparation. It consists in symbolic acts by the responsible State with the aim to alleviate the inflicted harm. These symbolic acts may entail, among others, the acknowledgment of the breach, an expression of regret, a formal apology, ${ }^{660}$ as well as effective measures for the cessation of continuing violations, commemorations and tributes to the victims, ${ }^{661}$ and administrative or criminal trials of responsible persons ${ }^{662}$. In any case, satisfaction must not a "punitive" character ${ }^{663}$, so it is required to apply the principle of proportionality as well as to choose a non-humiliating form of satisfaction while evaluating the specific case. ${ }^{664}$ The exceptional character of this form of reparation is confirmed by Article 37, paragraph 1 of the Articles on State Responsibility, which limits the recourse to this form of reparation "insofar as it cannot be made good by restitution or compensation". Assurances and guarantees of non-repetition "may be sought by way of satisfaction (e.g. the repeal of the legislation which allowed the breach to occur)", that is why there is a certain overlap between the two in practice. ${ }^{665}$ As it will be discussed later on in this Chapter, satisfaction may be particularly relevant for women victims of armed conflict.

\footnotetext{
659 States started to accept, in a limited way, claims of individual victims of the atrocities of that war after the Second World War. See Hofmann, Rainer, "Compensation for Personal Damages Suffered during World War II". ${ }^{660}$ Article 37(1), Articles on State Responsibility; Article 9, Basic Principles and Guidelines on the Right to a Remedy and Reparation.

${ }^{661}$ Basic Principles and Guidelines on the Right to a Remedy and Reparation, para. 22.

${ }^{662}$ Conference Report to ILA Declaration of International Law Principles on Reparation for Victims of Armed Conflict (Substantive Issues), commentary to Article 9, p. 25.

${ }^{663}$ Crawford, James, The International Law Commission's Articles on State Responsibility, Introduction, Text and Commentaries, Cambridge University Press, Cambridge, 2002, p. 234.

${ }^{664}$ Article 37(3), Articles on State Responsibility.

${ }^{665}$ Articles on State Responsibility, Commentary to Article 30, para 11.
} 
While it is theoretically up to the State to decide which form of reparation to claim, international law provides for a hierarchical order of the forms of reparation. The PCIJ expressed this hierarchy in the Chorzów Factory case, in which it identifies an obligation on the wrongdoing State to "restore the undertaking and, if this be not possible, to pay its value at the time of its indemnification, which value is designed to take the place of restitution which has become impossible". 666 Thus, the Court classifies restitution as the primary form of reparation, followed by compensation. The same approach is apparent in the Articles on State Responsibility, in which it is stated that compensation is applicable only when restitution is not possible, as well as satisfaction should be provided when neither restitution nor compensation are available means of reparation.

\subsection{Gender perspectives on reparations}

\subsubsection{Reparations and 'gender justice'}

The specific effects of war on women have never been better recorded. ${ }^{667}$ It is now wellestablished that women and men experience the conflict in a different way, ${ }^{668}$ that wartime offences against women remain too often invisible and, consequently, unpunished at international level, and that the aftermath of the conflict is a particularly insecure phase for women. ${ }^{669}$ This awareness was the premise for the subsequent debate over the possibility to obtain 'gender justice', meaning redress that takes into account the gender dimension during the peace process and the conflict resolution and includes fairer reparation programs for women. ${ }^{670}$

\footnotetext{
${ }^{666}$ Chorzów Factory (Merits), p. 48.

${ }^{667}$ See, among others, UN SG, Report of the Secretary-General on Conflict-Related Sexual Violence, U.N. Doc. S/2017/249, 15 April 2017; UN SG, Report of the Secretary-General on Conflict-Related Sexual Violence, U.N. Doc. S/2018/250, 23 March 2018; UN SG, Report of the Secretary-General on Conflict-Related Sexual Violence, U.N. Doc. S/2019/280, 29 March 2019; UN SG, Report of the Secretary-General on women and peace and security, U.N. Doc. S/2018/900, 9 October 2018.

${ }^{668}$ UN Security Council, Resolution 1325, S/RES/1325 (2000), October 31, 2000.

${ }^{669}$ Ní Aoláin, Fionnuala. "What Does Post Conflict Security Mean for Women?", in Tripp, Aili Mari and Marx Ferree, Myra and Ewig, Christina (eds.), Gender, Violence and Human Security: Critical Feminist Perspectives, NYU Press, New York, 2013, pp. 33-49, 33, 41.

${ }^{670}$ The Nairobi Declaration on Women's and Girls' Right to a Remedy and Reparation - held in Nairobi from 19 to 21 March 2007 by a women's civil society network of women's rights advocates and activists, as well as survivors of sexual violence in situations of conflict - well represents this acknowledgment of the relevance of the gender in dealing with reparations for female survivors.
} 
Debates about ways to further gender justice through transitional justice mechanisms ${ }^{671}$ cross transversely different approaches to international law, and different perspectives on the role of international law in post conflict situations. There is not a unique solution to the question of how gender justice for women victims of international crimes can be achieved. This is basically due to three main reasons related to the nature and the legal regime of the post-conflict phase. First, the post bellum phase - the period between the cessation of the hostilities and the formal settlement - is not always well-defined in modern conflict situations where "ceasefires are declared and broken, multiple processes of peacemaking commenced and some agreements reached, yet violence continues" and "peace agreements do not hold amid recurring cycles of violence". ${ }^{672}$ In these unconventional and more fluid war settings, violence also results in postconflict "criminality, gang warfare, insurgency and counter-insurgency, gendered violence and outbreaks of overt conflict". ${ }^{673}$ In particular, the forms of violence against women tend to stretch even after the supposed end of the conflict. Second, the post-conflict phase is not only governed by IHL, but also by ICL, IHRL, refugee law, as well as constitutional law when a post-conflict country needs a change in the institutional order. The multitude of legal regimes involved generates a series of different responses to the issue of wartime violence against women. Third, transitional justice mechanisms should take into account different aspects in order to be effective. Social and economic rights, as well as considerations of political economy, for example, should not be underestimated in the development of a transitional mechanism. ${ }^{674}$

\footnotetext{
671 The United Nations' Guidance Note of the Secretary-General: United Nations Approach to Transitional Justice, (10 March 2010) defines transitional justice as the "full range of processes and mechanisms associated with a society's attempt to come to terms with a legacy of large-scale past abuses, in order to ensure accountability, serve justice and achieve reconciliation". These processes and mechanisms may consist in "judicial and nonjudicial processes and mechanisms, including prosecution initiatives, truth-seeking, reparations programmes, institutional reform or an appropriate combination thereof". The text is available at https://www.un.org/ruleoflaw/files/TJ Guidance Note March 2010FINAL.pdf [last visited, 9 December 2020]. See generally, Teitel, Ruti, Transitional Justice, Oxford University Press, Oxford, 2000. For an analysis of the type of legal instruments establishing transitional governance arrangements in peace and transition processes from 1990 to date, see Bell, Christine and Forster, Robert A., "Constituting Transitions. Predicting Unpredictability", in De Groof, Emmanuel H. D. and Wiebusch, Micha, International Law and Transitional Governance. Critical Perspectives, Routledge, London and New York, 2020, pp. 33-57. The chapter aims at demonstrating that the constitutionalization of the transition is not the result of "best legal form" considerations, but rather the interaction between different factors, such as the balance of power between the involved actors and the adequacy of existing constitutional documents relevant for the transition.

${ }^{672}$ Chinkin, Christine and Kaldor, Mary, International Law and New Wars, Cambridge University Press, Cambridge, 2017, p. 340.

${ }^{673}$ Ibid. p. 344.

${ }^{674}$ Rees, Madeleine and Chinkin, Christine, "Exposing the Gendered Myth of Post Conflict Transition: The Transformative Power of Economic and Social Rights", New York University Journal of International Law and Politics, Vol. 48, No. 4, (2016) 1211-1226.
} 
A growing body of research analyses how a gender perspective may inform transitional justice processes, while others focus on certain specific aspects of women's vulnerability in postconflict settings. ${ }^{675}$ This Section provides first an overview of the main gender aspects in the two main phases of the post conflict, and then focuses on the gender perspectives on the (potential) individual right to reparation and on the choice of the forms of reparations. To this purpose, the pertaining post bellum law involved is IHL and international law of state responsibility.

\subsubsection{Gender in post-conflict phases}

Gender justice can be promoted in different post-conflict phases. Each of these phases assumes the involvement of different parties, the use of specific means, and, consequently, it faces different legal challenges. Although there is no bright line to demarcate these phases, for the purposes of this Section one may identify two relevant post-conflict phases: the inter-States phase and the intra-State phase. The inter-States phase is just subsequent to the end of the armed conflict, when the parties engage in peace negotiations ${ }^{676}$ to achieve a peace agreement $^{677}$ related to the substantive issues to resolve the conflict. In NIACs, this phase would be better qualified as inter-parties phase, entailing a non-State armed group and a State or two non-State armed groups that have been fighting each other. For the sake of simplification, the expression "inter-States phase" will be here used for both IACs and NIACs.

The intra-State phase involves the relationship between the injured State (or the rebel group become the governing power in a NIAC) and its own nationals harmed by the wrongdoings in breach of IHL committed by the enemy's armed forces. In this phase, a gender approach has been recalled with regard to the design and the implementation of domestic reparation

\footnotetext{
675 See, among others, Duggan, Colleen and Abusharaf, Adila, "Reparation of Sexual Violence in Democratic Transitions: The Search for Gender Justice", in De Greiff, Pablo (eds.), The Handbook of Reparations, Oxford University Press, Oxford, 2006, pp. 623-649; Biörkdahl, Annika and Mannergren Selimovic, "Gender and Transitional Justice", in Simić, Olivera, An Introduction to Transitional Justice, Routledge, London and New York, 2021, pp. 73-95 (forthcoming).

676 The peace process has been described by Christine Bell as "an attempt to bring political and/or military elites involved in conflict (defined as having caused more than twenty-five battle-related deaths in one calendar year) to some sort of mutual agreement as to how to end the conflict". Bell, Christine, Text and Context: Evaluating Peace Agreements for their 'Gender Perspective [Research Paper], UN Women, (2015), p. 5 https://wps.unwomen.org/pdf/research/Bell EN.pdf [last visited, 22 January 2021].

677 There is not a formal definition of peace agreement. An informal definition of peace agreement can be found at https://www.peaceagreements.org/files/PA X codebook Version1 Feb 20 20.pdf [last visited, 9 December $2020]$.
} 
programs. To limit the field of analysis, and given the fact that the literature have recently paid attention to the other aspects, the focus of this Section will be on a specific gender aspect of the inter-States phase, namely the identification of the best form of reparation for female survivors. However, it would be useful to give a brief overview of the main gender aspects relevant to both phases.

The inter-States phase starts with post-conflict peace negotiations and culminates with the stipulation of a peace agreement. ${ }^{678}$ Peace agreements deal with the war reparations that usually the winning party of the war receives from the defeated State. As it has been explained before, reparation is an inter-State mechanism, but it usually has victims as the ultimate beneficiaries. Thus, the result of the inter-States negotiations for the peace agreement expresses its ultimate effects on the victims of the armed conflict. At this phase, a gender approach sheds light on three grounds: the underrepresentation of women in peace negotiation processes, the inclusion of gender provisions as well as their gender sensitive interpretation, and the identification of the best form of reparation for the case at hand.

With regard to female underrepresentation in the peace negotiation processes, ${ }^{679}$ many scholars have focused on how it affects the substance of peace agreements by shadowing women's voice and limiting their opportunity to express female experience of conflict. ${ }^{680}$ Although there are many reasons for this structural underrepresentation, it is often a consequence of women's virtual absence from the male-dominated military ranks and the other State authorities who are usually the main responsible for conducting peace negotiations. Despite the increased number of UN instruments ${ }^{681}$ containing provisions dealing with the issue of women's inclusion in peace negotiations and peace agreements, ${ }^{682}$ in most peace processes and agreements women

\footnotetext{
${ }^{678}$ On the controversial legal nature of the peace agreements, see Bell, Christine, "Peace Agreements: Their Nature and Legal Status", American Journal of International Law, Vol. 100, No. 2, (2006), 373-412.

${ }^{679}$ Bell distinguishes three phases of the negotiation process: pre-Agreement, Agreement and Implementation phases. Bell, Christine, "Transitional Justice, Interdisciplinarity and the State of the 'Field' or 'Non-Field", International Journal of Transitional Justice, Vol. 3, (2009) p. 56. Nì Aolàin demonstrates that each phase's structure and process contribute to the persistent exclusion of women's issues in transitional justice, with the consequent under-enforcement of gendered concerns. Nì Aolàin, Fionnuala, "Gendered Under-Enforcement in the Transitional Justice Context", in Buckley-Zistel, Susanne and Stanley, Ruth (eds.), Gender in Transitional Justice. Governance and Limited Statehood Series, Palgrave Macmillan, London, 2012.

${ }^{680}$ Bell, Christine, "Women, Peace Negotiations, and Peace Agreements: Opportunities and Challenges", in Ní Aoláin, Fionnuala, Cahn, Naomi, Haynes, Dina Francesca and Valji, Nahla (eds.), The Oxford Handbook of Gender and Conflict, Oxford University Press, Oxford, 2018, pp. 418-429.

681 The legally binding nature of those instruments is not always clear.

${ }^{682}$ See Convention on the Elimination of All Forms of Discrimination Against Women (CEDAW); CEDAW, General Recommendation No. 30 (October 18, 2013) on women in conflict prevention and conflict and postconflict situations; UNSC Resolution on Women, Peace and Security (WPS), 1325 (2000), para. 8; UNSC Resolution 2242 (2015), para. 1; UNSC Resolution 2467 (2019), para. 30.
} 
were underrepresented so far. ${ }^{683}$ As Coomaraswamy put it: "The obstacles to women's participation are political not technical". ${ }^{684}$ In this sense, the common claim to include women in peace negotiations for achieving a more diplomatic settlement and a subsequent durable peace $^{685}$ does not seem to benefit.

The attachment of presumed natural inclinations for peace to women could even result in the request of specific skills and stricter conditions for women to be admitted to the negotiations delegations. In general, the "add and stir" approach, consisting in just increasing the number of women involved in peace negotiations in order to achieve gender equality, is not considered enough to address female survivors' instances because it does not guarantee a female-oriented view in the substance of the agreement. Considering the close link between peace agreements and subsequent institutional agenda, ${ }^{686}$ the marginalization of women in the negotiation phase may well affect not only the outcomes of the negotiations, but also the substance of the subsequent enforcement programmes. ${ }^{687}$ To give an example in this sense, one may recall the case of the post-conflict phase in Bosnia and Herzegovina, where the "manly" approach - both in terms of women underrepresentation and lack of gender clauses - of the Dayton Peace Agreement ${ }^{688}$ has been deemed one of the main causes of the failure of the National Action Plans (NAPs) ${ }^{689}$ in implementing the Women Peace and Security (WPS) agenda in the Bosnia and Herzegovina's transition. ${ }^{690}$ The absence of women among the Dayton's delegations

${ }^{683}$ Christine Bell provides an updated list of peace negotiation examples with low number of women. Bell, Christine, "Women, Peace Negotiations, and Peace Agreements: Opportunities and Challenges"..., p. 418.

684 "If parties refuse women access to the negotiation table and ignore parallel processes, peacemakers may have to think of more creative ways of working with technical teams, friends of the parties and local communities. The WPS agenda must focus on innovative ways to ensure women's participation despite dogmatic practices and resistance. The local must guide the international, especially as peace processes are increasingly complex". Coomaraswamy, Radhika, UNSCR 1325 at 20: Reflections on the Women, Peace and Security agenda, Oslo Forum Paper, Centre for Humanitarian Dialogue, Geneva, (2020), available at: https://www.hdcentre.org/wpcontent/uploads/2020/12/UNSCR-1325-at-20.pdf [last visited 23 January 2021].

${ }_{685}$ See UNSC Resolution on Women, Peace and Security (WPS), 1325 (2000); UNSC Resolution 2242 (2015).

686 Bell, Christine, "Transitional Justice, Interdisciplinarity and the State of the 'Field' or 'Non-Field", International Journal of Transitional Justice.

${ }^{687}$ Nì Aolàin, Fionnuala, "Gendered Under-Enforcement in the Transitional Justice Context".

${ }^{688}$ The General Framework Agreement for Peace in Bosnia and Herzegovina, also known as the Dayton Peace Agreement (DPA), Dayton Accords, Paris Protocol or Dayton-Paris Agreement, is the peace agreement reached at Wright-Patterson Air Force Base near Dayton, Ohio, United States, in November 1995, and formally signed in Paris on 14 December 1995. These set of international agreements - consisting in the General Framework Agreement for Peace in Bosnia and Herzegovina, twelve Annexes and the Agreement on Initialling - put an end to the 3 1/2-year-long Bosnian War, one of the armed conflicts in the former Socialist Federative Republic of Yugoslavia. The current Constitution of Bosnia and Herzegovina is the Annex 4 of the DPA.

689 National Action Plans (NAPs) are a strategic and programmatic means for policymakers to translate the international mandates of the WPS agenda - firstly defined by UN SC Resolution 1325/2000 - and implement it into the domestic context.

${ }^{690}$ In this regard, Hozić, Aida A., "Dayton, WPS and the entrenched 'manliness' of ethnic power-sharing peace agreements", LSE Women, Peace and Security blog, (15 February, 2021), available at 
contributed to obscure women's issues from the negotiations with the consequence of an exclusive focus on ethnic issues ${ }^{691}$ and the subsequent backwards in the institutionalization of gender issues in Bosnian politics, despite the recurring emphasis on participation pillar in the Bosnian WPS Agendas. ${ }^{692}$

The underrepresentation of women voices in peace negotiations is directly connected to the second gender aspect of the inter-States phase: the lack of gender-sensitive provisions in the peace agreements. ${ }^{693}$ According to the Peace Agreement database (PA-X), only 361 of 1868 agreements (19,9 per cent) between 1990 and mid 2020 included provisions addressing women, girls or gender. ${ }^{694}$ The data suggests that the majority of peace agreements do not take into account gender and women's issues, and, among the peace agreements that do it, the references are usually limited to once-off provisions that only consider one gender aspect. ${ }^{695}$ How a gender-sensitive approach may be expressed in the formulation of an agreement is a matter of discussion. For a peace agreement to have not only a gender-sensitive approach but also a female-oriented view, the insertion of neutral equality clauses is not sufficient. ${ }^{696}$ In other words, the generic call upon the prohibition of discrimination on the ground of gender or sex

https://blogs.lse.ac.uk/wps/2021/02/15/dayton-wps-and-the-entrenched-manliness-of-ethnic-power-sharingpeace-agreements/ [last visited, 17 February 2021].

${ }^{691}$ On gender blindness of the Dayton Peace Agreement, gender implications of the Dayton Peace Agreements on the Bosnian post war order and, in particular, on the implementation of the WPS agenda, see Deiana, MariaAdriana, "Navigating Consociationalism's Afterlives: Women, Peace and Security in Post-Dayton BosniaHerzegovina. Nationalism and Ethnic Politics", Nationalism and Ethnic Politics, Vol. 24, No. 1, (2018) 33-49.

${ }^{692}$ Hamilton, Caitlin, Naam, Nyibeny and Shepherd, Laura J., "Twenty Years of Women, Peace and Security National Action Plans: Analysis and Lessons Learned", University of Sydney, (2020), available at https://www.wpsnaps.org/app/uploads/2020/03/Twenty-Years-of-Women-Peace-and-Security-National-ActionPlans_Report_Final_Web.pdf [last visited, 17 February 2021].

${ }^{693}$ Bell, Christine, "Women, Peace Negotiations, and Peace Agreements: Opportunities and Challenges", p. 418. "This absence in turn is translated into peace agreement provisions that largely do not address women's perspectives or concerns". See also Christien, Agathe and Mukhtarova, Turkan, Report: Explaining Trends in the Frequency of Gender Provisions in Peace Agreements, 1990-2019, Georgetown Institute for Women, Peace and Security, (October, 2020), available at https://giwps.georgetown.edu/resource/explaining-trends-in-thefrequency-of-gender-provisions-in-peace-agreements-1990-2019/ [last visited, 17 February 2021]. They have found that women's representation in national parliaments guarantees an increased likelihood of adopting gender provisions in peace agreements. Instead, this is not true in cases of good gender-equality indicators for domestic legislation: equal rights under domestic law does not seem to guarantee the presence of gender provisions in peace agreements.

${ }^{694} \mathrm{PA}-\mathrm{X}$ is a database containing an updated set of peace agreements, 1868 peace agreements, found in more than 150 peace processes between 1990 and mid-2020. The database permits to search agreements using different indicators, such as the geographical region/country of the agreement or the level of the agreements, whether international, national or local. https://www.peaceagreements.org

${ }^{695}$ See Bell, Christine and McNicholl, Kevin, "Principled Pragmatism and the 'Inclusion Project': Implementing a Gender Perspective in Peace Agreements", Feminists @ Law, Vol. 9, No 1, (2019).

${ }^{696} \mathrm{This}$ is not to say that data on the references to women or gender in peace agreements are not important. Instead, they are one of the possible (and ore direct) indicator of the women-centred perspective in peace agreements.

The data underline that the vast majority of agreements do not explicitly address gender equality or the rights of women. (para. 15). 
or "the vague references to participation, or once-off measures for women, such as that women prisoners or 'lactating mothers' be released from detention ahead of men" ${ }^{\text {" }} 97$ would not reflect an effective gender perspective. It is rather important that the agreement includes a holistic gender perspective, meaning the insertion of provisions particularly addressing women's post bellum issues. ${ }^{698}$ For example, Resolution 2467 (2019) requests the parties to conflict to include in the peace agreements provisions "that stipulate sexual violence in conflict and postconflict situations as a prohibited act, particularly in provisions relating to disengagement, ensure further that women are present and meaningfully participate in political pre-negotiation and negotiation processes" and that exclude "sexual violence crimes from amnesty and immunity provisions in the context of conflict resolution processes". ${ }^{699}$ According to the 2016 Report of the Secretary-General on conflict-related sexual violence, only the Columbian postconflict process "has addressed gender concerns in a systematic manner". ${ }^{700}$ The third substantive gender aspect with regard to the inter-States phase, namely the identification of the best form of reparation for female survivors, will be the specific object of analysis of the next Section.

In the intra-State phase, a gender sensitive approach usually consists in the request of specific measures to redress the female victims of the conflict in the domestic reparation programs (DRPs). ${ }^{701}$ DRPs are administrative mechanisms established at national level by a governmental or parliamentary act to remedy the harm suffered by victims of gross human rights violations or serious violations of humanitarian law. ${ }^{702}$ They guarantee the claimants a lower threshold of evidence than judicial procedures together with more relaxed and sensitive process to the harms the victims suffered. Indeed, while judicial processes have usually high costs for the claimants and may lead to a re-traumatization and victimization of the survivors, ${ }^{703}$

\footnotetext{
697 Bell, Christine, Text and Context: Evaluating Peace Agreements for their 'Gender Perspective [Research Paper], p. 18 available at https://wps.unwomen.org/pdf/research/Bell EN.pdf

${ }^{698}$ Bell, Christine, "Women, Peace Negotiations, and Peace Agreements: Opportunities and Challenges".

${ }^{699}$ UNSC Resolution 2467 (2019), para. 30.

${ }^{700}$ Report of the Secretary-General on conflict-related sexual violence, UN Doc. S/2016/361, 20 April 2016, para. 11.

${ }^{701}$ See generally Gilmore, Sunneva, Guillerot, Julie, Sandoval, Clara, \& Moffett, Luke (eds.) (2020). Beyond Silence and Stigma - Crafting a Gender-Sensitive Approach for Victims of Sexual Violence in Domestic Reparation Programmes. Reparations, Responsibility and Victimhood in Transitional Societies, Queen's University Belfast, (March 2020), available at: https://reparations.qub.ac.uk/assets/uploads/QUBSGBV Report English Web.pdf [last visited: 28 February 2021].

${ }_{702}$ Among the State that have already used these mechanisms: Argentina, Colombia, Ecuador, Guatemala, Nepal, Sierra Leone, South Africa and Uruguay.

703 De Greiff, Pablo, Report of the Special Rapporteur on the promotion of truth, justice, reparation and guarantees of non-recurrence, UNGA, A/69/518, 14 October 2014, para. 4.
} 
such programs avoid the typical cross-examination scheme in so limiting this kind of risks. Considering that problems related to an effective access to justice usually affect the most vulnerable groups of victims, such as women and girls, ${ }^{704}$ the institution of DRPs may be of vital importance for women and girls survivors, and especially for those victims of CRSV.$^{705}$ The beneficiaries of these programs and the categories of violations redressed are not always well defined ${ }^{706}$ and, according to Ruth Rubio-Marín, this have mostly affected women survivors. ${ }^{707}$ This is the reason why the way DRPs are designed has a direct influence on the adequateness of the offered measures and treatments in addressing vulnerable groups of victims, such as the female survivors, ${ }^{708}$ and in dealing with gender issues. ${ }^{709}$

Against this background, the next Section overviews and investigates gender perspectives on the potential individual right to reparation and on the forms of reparation for female victims of war. The use of gender as an analytical means brings to the light new questions on the recognition of an individual right to reparation under current IHL as well as on the hierarchy of the forms of reparation as it is conceived under the law of State responsibility. One of these questions is whether the established hierarchy of the forms of reparation in effect is more appropriate for some abuses than for others, so that, in practice, it is more difficult to seek redress for those violations that most affect women. The driving issues here are: are women affected and marginalized by the traditional reparation mechanism? May gender play a role in

\footnotetext{
704 CEDAW Committee, General Recommendation No. 33 On women's access to justice, U.N. Doc. CEDAW/C/GR/33, 3 August 2015.

705 In this sense, Labenski, Sheri, "The Right to Reparation for Sexual and Gender-Based Violence", LSE Reparation Report, (2020), p. 12, available at: https://www.lse.ac.uk/women-peacesecurity/assets/documents/2020/Reparations-Report-online-version.pdf [last visited, 27 January 2021].

${ }_{706}$ Office of the United Nations High Commissioner for Human Rights, Rule-of-Law Tools for Post-Conflict States: Reparation Programmes (United Nations publication, Sales No. E.08.XIV.3), New York and Geneva, 2008, pp. 18 ss.

707 Rubio-Marín, Ruth, "The gender of reparations in transitional democracies", in Rubio-Marín, Ruth, The Gender of Reparations. Unsettling sexual hierarchies while redressing human rights violations, Cambridge University Press, Cambridge, 2009.

708 For a gender and a transformative approach in the design of the DRPs, with particular attention to the formulation of the eligible victims, and the identification of the best reparation measures according to the complexity and the consequences of the harms suffered, see Report of Special Rapporteur on the promotion of truth, justice reparations and guarantees of non-recurrence on Gender perspective in transitional justice processes, UN GA 75 ${ }^{\text {th }}$ session, A/75/174, 17 July 2020, para. 27-40, available at: https://documents-ddsny.un.org/doc/UNDOC/GEN/N20/186/87/PDF/N2018687.pdf?OpenElement [last visited, 27 January 2021].

${ }^{709}$ For a gender-sensitive approach to reparations for redressing conflict-related sexual violence against men in Norther Uganda, see Schulz, Philipp, "'Luk Pe Coo' or Compensation as Dowry? Gendered Reflections on Reparations for Conflict-Related Sexual Violence Against Men”, International Journal of Transitional Justice, Vol 12, (2018) 537-548.
} 
the reparation mechanism? If any, may it also be relevant in the choice of the most adequate form of reparation in cases involving women survivors?

\subsubsection{Gender perspectives and the (potential) individual right to reparation}

The previous Section has introduced the different views, developments, as well as the de lege ferenda proposals regarding the individual right to reparation under IHL. What could be the contribution of a gender perspective to this debate?

A gender approach would offer an additional argument in favour of an eventual emerging individual right to reparation for violations of IHL. In particular, it is here suggested that the specific circumstances related to the vulnerability of certain groups caught up in the conflict, such as women and girls, revealed by a gender-sensitive approach to conflict, make the existence of an individual right to reparation more valuable, and are thus in line with a teleological approach to the IHL system of reparations. At least three reasons may support this view.

First, a gender-sensitive perspective reveals that women suffer more from the deficiencies of a pure inter-State reparation mechanism. First, as explained above, it is difficult for women to be represented and express their voice in the post conflict inter-States phase, from negotiations to the signature of the peace agreement. This is one of the reasons that make conflict-related violence against women underestimated and, consequently, often invisible in the traditional settlements of war reparations. An individual right to reparation would be more in line with the ultimate purposes of the reparation mechanism, as it would decouple the right of individuals from the State level, where some of these individuals (women) are structurally underrepresented.

Second, the inter-State reparation mechanism was conceived to privilege property and land claims, usually associated with men, instead of personal and moral injuries claims, more related to the female civilians. ${ }^{710}$ This is the reason why reparation is usually assimilated to

\footnotetext{
710 "Because property rights are of paramount concern, the language of reparation is not used, and the more common formulations emphasize compensation for the wrongs suffered. The basic direction of these treaty norms [ILC Articles] also derives from international customary law, especially legal doctrine associated with the confiscation of foreign-owned property. The legal formula for overcoming the legal wrong accepted in international law involved "prompt, adequate, and effective compensation". Falk, Richard, "Reparations, International Law, and Global Justice", in de Grieff, Pablo (ed.), The Handbook of Reparations, Oxford University Press, Oxford, 2006, p. 483.
} 
compensation and the material damages, often linked to the loss of property, have the prevalence over non-material damages, connected to personal injuries. An individual right to reparation would guarantee the same relevance to both material and non-material damages, real property claims and personal injuries claims, in so assuring women more chances to obtain redress and justice.

Third, in the now prevailing contexts of non-international armed conflict, it seems even more difficult to imagine the victim's State or the new winning party to prioritize the settlement of reparations for women's survivors. ${ }^{711}$

From a gender perspective, thus, the recognition of an individual right to reparation would be desirable in that it would permit to overcome some of the above deficiencies: female victims could also submit directly reparation claims for IHL violations. Moreover, and maybe most importantly, this would guarantee a full restoration of the dignity of the victims.

\subsubsection{Forms of reparation and transformative justice for crimes against women}

Feminist critique criticizes the traditional reparation mechanism basically on three grounds: the perpetration of the gender stereotypes, the lack of a transformative potential, and in particular the failure to address gender inequalities, and the inadequateness of certain forms of reparation to address harms suffered during the conflict by women. These three interrelated aspects are exposed in the principles of the Nairobi Declaration on Women's and Girls' Right to a Remedy and Reparation (therein Nairobi Declaration). Taken together, they allow addressing under new light the limits and the potential of the forms of reparation used in international large-scale reparations programs defined by inter-States agreements in the context of serious violations of IHL resulting in harms against women. ${ }^{712}$ For a systematic approach to

\footnotetext{
711 This is the main reason that led to the institution of The Global Fund for Survivors of Conflict-Related Sexual Violence. Born as survivor-centric mechanism, the Fund's mission is to ensure survivors of conflict-related sexual violence to have access to reparations and other forms of redress, globally, including where the States or other parties responsible for the violence are unwilling or unable to provide reparations. It addresses a long gap identified by survivors and complements efforts to prevent sexual violence, justice and holistic care, Global Survivors Fund, Concept Paper, prepared by The Mukwege Foundation and Nadia's Initiative (October 2019) https://static1.squarespace.com/static/5da75722ddb2780e221c34a6/t/5db71735ef66873d41033019/1572280131 912/ConceptPaper October2019.pdf [last visited: 21 February 2021].

${ }_{712}$ It needs to be noted that this discussion covers collective reparations as legal consequences of a violation of IL will be the object of discussion, while leaving aside those international assistance programmes consisting in solidarity-based funding mechanisms to communities affected by the conflict. An example of a solidarity-based funding mechanism if the ICC Trust Fund for Victims set up under Article 79 of the Rome Statute to respond to the harm resulting from the crimes under the jurisdiction of the ICC. It works to provide assistance and reparation
} 
the issue, the analysis follows the main critics to each of the forms of reparation from a gender perspective. This will constitute the basis for the case study of the Korean "comfort women", where the potential of symbolic forms of reparation, such as public apology, will be particularly explored.

\subsubsection{Restitution}

Restitution has been specifically criticized by feminist international law scholars for its narrow scope. In the working session of the ILA Committee on reparations for victims of armed conflict, held in Washington in 2014, Professor Nì Aolàin manifested her concern on the absence of a gender approach within the Committee's report, offering succinctly a convincing starting point for addressing the problem. As her position was documented in the report, ${ }^{713}$

she noted that the only reference to gender in the principles is to the possibility that the specific vulnerabilities of women may be considered in context of sexual violence. She felt this to be inadequate. She reminded the session of the ongoing conversation on the topic, along with a soon to be published study by the United Nations High Commissioner for Human Rights on reparations and gender in the context of armed conflict. In the context of this work, she considered a side reference to be insufficient in articulating the complexity of reparations and the specific needs of women victims - not only from sexual harm, but range of harms that differentially reflect women and men in conflict settings.

She emphasized an additional key point which she wished to be reflected in all references to conflict and gender. This was that if the core presumption of reparations is a return to status quo - a concept of restitution - it would be to a position of inequality for women in most societies. She postured that therefore, even the core legal principle of remedy is highly inadequate to remedy the gender inequalities which produce the harms that reparations are intended to resolve. She expressed concern that this isn't addressed by the Committee's principles, especially in its use of the word "restitution". She further suggests that it would be helpful to cross reference the Committee's report with the UN High Commissioner's study on the same topic. ${ }^{714}$

In the first paragraph, Nì Aolàin denounces the inadequateness of the 2014 ILA's report on Procedural Principles for Reparation Mechanisms in dealing with gender issues focusing on the limited consideration of women's experience of the conflict while designing the complex reparations scheme. Nì Aolàin here refers to the general equal treatment and antidiscrimination clause, contained in Principle 3, whose commentary specifies that

to the victims and their families delivering, among others, vital programmes related to mental health, physical rehabilitation, and material support, available at: https://www.trustfundforvictims.org/en [last visited:

21 February 2021].

713 The report at stake would have led to the adoption of the abovementioned ILA Procedural Principles for Reparation Mechanisms, Res. no 1/2014, Washington, 2014.

${ }^{714}$ ILA, Report of the Working Session Committee on reparations for victims of armed conflict, Washington, 9 April 2014, available at: https://www.ila-hq.org/index.php/committees [last visited: 21 February 2021]. 
a reparation mechanism should take gender-sensitive measures to address the obstacles faced by women and girls in seeking access to it, particularly if they are claiming reparation for harm caused by sexual and gender-based violence. ${ }^{715}$

Indeed, the "side reference" to gender issues is not sufficient to adequately represent women's position in the reparation scheme. However, the main problem with the lack of a gender approach in reparations does not seem to be the absence of specific provisions in the document at hand, but, as correctly expressed in the second paragraph of Nì Aolàin's criticism, the main assumption of the reparations system itself, namely the aim of a "return to status quo". This presumption specifically informs the essence of the restitution, as a form of reparation basically devoted to the restoration of the same conditions present if the breach of international law did not occur. Since in the majority of cases the previous conditions of inequality for women are also considered one of the deep-rooted causes of the harms suffered during the conflict, ${ }^{716}$ reparations should, from a feminist perspective, contribute to a process of enhancement of women's condition and subversion of the pre-existing inequalities rather than restoring them. ${ }^{717}$ In this sense, restitution, as conceived by the Articles on State Responsibility, cannot be considered a form of "full reparation" for women survivors, in that it does not guarantee a real response to the entrenched discrimination that affects women's lives. It might perpetuate the reasons why women suffered the specific harms they suffered during the conflict. Behind this conception, there is the idea that "the paradox of violent conflict is that it promotes the possibility of advancing the very human rights that were denied in conduct". ${ }^{718}$ Practically, translated into the reparation mechanism for redressing women's harms amounting to violations of IHL, this insight would mean that, so far as restitution is factually possible, the peace agreement must include provisions requiring to the return of the victim to the same condition she was before the violation took place, as long as the measures do not discriminate women or reproduce pre-existing inequalities that may have caused or contributed to the harm suffered during the conflict. In asking the Parties to take measures that address also the causes of the forms of violence suffered by women survivors, this approach does not simply request

\footnotetext{
715 Shuichi Furuya, "Draft Procedural Principles for Reparation Mechanisms", in ILA, Report of the Seventy-Sixth Conference Held in Washington D.C., London, ILA, 2014, 782-813, commentary to Principle 3.

${ }^{716}$ For feminist analysis on the link between structural pre-conflict violence against women and conflict-related violence against women, see Chapter I.

717 See Report of the Special Rapporteur on violence against women, its causes and consequences, Rashida Manjoo, UN GA 14 ${ }^{\text {th }}$ session, A/HRC/14/22, 23 April 2010.

${ }^{718}$ Mitchell, David S., "The prohibition of rape in IHL as a norm of jus cogent: clarifying the doctrine", Duke Journal of Comparative \& International Law, Vol 15, (2005) 219-258, pp. 220-221.
} 
the return to the status quo ante, but argues in favor of an effort to improve women's condition before the conflict.

While recognizing the great potential of this broad concept of restitution in dealing with crimes against women, it seems difficult that such approach may be feasible in the practice of States for at least three reasons.

First, this approach seems to extend the scope of restitution far beyond the standard identified by the regime of the Articles on State Responsibility. Consistently with the commentary to Article 35 of the Articles on State Responsibility, any consideration on the hypothetical situation in place had the violation of international law not taken place must be rejected. ${ }^{719} \mathrm{On}$ this basis, it seems very difficult to accept the idea that restitution should guarantee a better condition to women than the one existing before the harm was committed.

Second, even admitting a broader concept of restitution, this could not be applied in cases of inter-States reparation claims. Considerations on the consequences of the eventual restoration of the previous gender hierarchy would fall outside the responsible State's obligation to afford reparation to the injured State. In this sense, it would be up to the injured State to decline restoration measures in a way that could not only address the harms suffered by its nationals, but also take into account eventual gender implications in the implementation phase. For example, the inter-State restitution measure in case of a forced displacement involving mainly women and children may consist in the return of that group of persons to their homeland. It is difficult to see eventual gender implications of the measure - such as the women's limited access to lands for unfavorable legal regimes, the stigmatization of victims of sexual and gender-based violence or the community's repudiation of children born of rape - as the object of restitution per se. The Parties should rather consider the specific gender consequences of the suffered harms in, eventually, combining restitution with other forms of reparation, which can make up for the limits of restitution and achieve a full reparation for victims. Eventually, it would be up to the domestic administrative reparations programme to design, adopt and implement measures that face gender discriminations and optimize the victims' rights. ${ }^{720}$ With

\footnotetext{
${ }^{719}$ Articles on State Responsibility, Commentary to Article 35, p. 96, para. 2.

${ }^{720}$ In any case, it seems necessary to point out that the domain of responsibility of the government who designs domestic programs of reparation is limited too. A reparation program has not the same purposes and development capacity as other kinds of programs, such as social or developments plans. As Pablo De Grieff put it, "I am skeptical of the effort to turn a program of reparations into the means of solving structural problems of poverty and inequality", so that "it is worth distinguishing between reparations in their strict sense, and the reparative
} 
regard to the case of forced displacement, the national authority should, for instance, promote a legal framework that assures the access to the real property to women, especially where women were excluded from property rights. ${ }^{721}$

Third, since restitution was conceived to basically address property rights, ${ }^{722}$ it does not seem the best form of reparation to deal with those harms that mostly affect women during conflict situations, such as gender-based violence, for which a return to the status quo ante would be in any case impossible. In this sense, "reintegration and restitution by themselves are not sufficient goals of reparation", ${ }^{723}$ in that they usually cannot grant women survivors a full reparation.

\subsubsection{Compensation}

As explained above, the Articles on State Responsibility qualify compensation as the most appropriate form of reparation so far as restitution is not feasible. Compensation arrangements are not only the most common form of reparation in States' practice, but also the main criteria for evaluating the success of the reparation mechanisms. The idea that "the nature of IHL is such that compensation will often be the principal form of reparation available" 724 assumes a State-centric perspective to reparations that seems to influence all the discussions related to war reparations. In this regard, it is not surprising that the general debate over the existence of an individual right to reparation is often expressed in terms of recognition of individual claims to monetary compensation for violations of IHL. As Peters put it,

Ultimately, however, the discussion about the compensation claims of war victims also manifests the limits of the power of law. In the case of hundreds of thousands or even millions of victims, equal enforcement of the fundamental individual right appears utopian. Against the recognition of individual claims for damages, it is thus argued that this would open the floodgates for legal action. It is argued that payment of compensation to individuals especially in post-conflict States is not practicable on financial and logistical grounds. An international rule should, in fact, be valid both for victims of wars in poor countries with weak rule of law

\footnotetext{
effects of other programs". De Grieff, Pablo, “Justice and Reparations", in De Grieff, Pablo (eds.), The Handbook of Reparations, pp. 470-471.

${ }^{721}$ For instance, in the post-war Bosnia and Herzegovina no attempt was made to promote specific measures for the return to home of women refugees and displaced women. Indeed, Annex 7 of the Dayton Peace Agreement, concerning the "Agreement on Refugees and Displaced Persons", does not contain any specific reference to women, and neither sex nor gender were included among the list of prohibited discriminatory criteria for a safe return (Article 1, para. 2). http://www.ohr.int/dayton-peace-agreement/annex-7-2/ [last visited, 22 February 2021].

${ }^{722}$ Van Houtte, Hans, Das, Hans, Delmartino, Bart and Yi, Iasson, Post-War Restoration of Property Rights under International Law, Vol. I: Institutional Features and Substantive Law, Cambridge University Press, Cambridge, 2008, p. 287.

${ }^{723}$ Nairobi Declaration, p. 2, para. 3.

${ }^{724}$ Hill-Cawthorne, Lawrence, "Rights under International Humanitarian Law", p. 1188, note 4.
} 
and for victims in wealthy regions. However, it does not make sense that the extreme situation should determine the solution. Some of the more recent armed conflicts, such as NATO's Kosovo intervention, have triggered a manageable number of compensation claims. The typical practical difficulties arising from compensation claims - namely that individual claims after armed conflicts are asserted en masse - could be managed with the help of reasonable procedures and international support. The capacity of the State obligor to pay can be taken into account when determining the amount of compensation. ${ }^{725}$

From a certain assimilation of the individual right to reparation with the individual claim to compensation for violations of IHL, it follows, first, that the practical issue of "compensation en masse" becomes one of the biggest procedural (and political) problems to guarantee an equal access to reparations to all victims, without exceeding the responsible State's economic capacity. ${ }^{726}$ Second, the issue of the practicability of the compensation claims in cases involving an elevated number of victims requires a specific attention to the procedures and the criteria for the determination and the distribution of the amount of monetary compensation. The third consequence of this position is the direct link - in the relationship between the State of nationality of the victims and its citizens - between the existence of a sufficient compensation arrangement and the worthiness of the eventual individual claim to compensation. In other terms, it is argued that the individual claim to compensation would be "assertable only if the involved States have not concluded any (or any sufficient) compensation arrangement or if the affected persons do not fall within the scope". ${ }^{727}$ Ultimately, this view assumes that, when restitution is not feasible, the achievement of an adequate compensation is generally the best solution also from a victims-oriented perspective.

From a gender perspective, one may identify at least four reasons that make difficult to award compensation to certain categories of female survivors of IHL violations. First, one should consider that "in many societies only men are paid compensation or given property rights, thus excluding women from effective reparation". ${ }^{728}$ In such regimes, where the patriarchal culture

\footnotetext{
725 Peters, Anne, Beyond Human Rights. The Legal Status of the Individual in International Law, p. 212.

${ }^{726}$ See Hofmann, Rainer, "Draft Declaration of International Law Principles on Reparation for Victims of Armed Conflict (Substantive Issues)", Commentary to Article 6, para. 3 (b), in International Law Association, Report of the Seventy-Fourth Conference Held in The Hague 15-19 August 2010, London, International Law Association, 2010, 295-334. "Due to the large number of victims in the aftermath of many conflicts this obligation might not always be fulfilled. Full and prompt reparation to every victim might surpass the economic capacities of the responsible party. This could have destabilizing effects in the post-conflict phase. Furthermore, an individualized assessment of every victim's case can cause enormous delays and strains on resources".

${ }^{727}$ Peters, Anne, Beyond Human Rights. The Legal Status of the Individual in International Law, p. 212.

${ }^{728}$ Sassoli, Marco, International Humanitarian Law Rules,....p. 96.
} 
is still the norm, the effective beneficiary of the monetary payment may well be the male guardian appointed to the woman and not the actual female victim of the IHL violation. ${ }^{729}$

Besides avoiding outright discrimination, reparations programmes that provide economic compensation to women should consider the formal and informal obstacles that different groups of women face in accessing and keeping money. These include difficulties in having a bank account and formal and informal pressure, including security threats, reprisal or ostracism by the family and the community. ${ }^{730}$

In general terms, compensation may act as a societal sign of recognition of the violence experienced as well as a form of support for the necessary expenses to overcome the psychological traumas suffered and for a new independent life. In concrete, the risk of a second victimization in the family and in the community, due to the lack of an effective access to the compensation awarded, may be elevated.

Second, the fear of social ostracism and exclusion from the community and family for specific harms suffered during the conflict may well discourage women from showing up as victims, in so impeding them to be eligible for compensation. In particular, the dishonor that many societies associate with sexual and gender-based violence makes often very difficult to have a valid perception of the extent and nature of the violence committed as well as the real number of victims involved. This is what happened, for example, in Sierra Leone, where, against a governmental estimated number of around 5,000 victims of sexual violence for the civil conflict taken up from 1991 to 2002, only about 3,000 victims have registered as such for reparations. ${ }^{731}$ A similar situation occurred in Rwanda, where women survivors' groups preferred to ask for monetary reparations as "legitimate" widows and wives instead of urging reparations for gender-based and sexual violence. ${ }^{732}$

Third, it seems difficult to estimate the amount of compensation to award non-material damages, which are particularly relevant in cases of personal injuries resulting in conflict-

\footnotetext{
${ }^{729}$ An example of the discriminated status of women with regard to property and land rights is given by the Constitution of Sierra Leone, whose section 27(4)d admits an exception to the general principle of nondiscrimination (stated in section 27(1)) with regard to provisions regarding "adoption, marriage, divorce, burial, devolution of property on death or other interests of personal law". An updated database with a repository of gender equality related provisions in 194 constitutions from around the world is available at: https://constitutions.unwomen.org/en.

${ }^{730}$ Report of the Special Rapporteur on violence against women, its causes and consequences, Rashida Manjoo, UN GA 14 ${ }^{\text {th }}$ session, A/HRC/14/22, 23 April 2010, para. 53.

${ }^{731}$ Probably, many of the victims of sexual violence preferred to register as war widows to avoid stigma. See https://www.peacewomen.org/content/sierra-leone-apology-women-victims-welcome-step.

732 Rombouts, Heidy, "Women and Reparations in Rwanda", in Rubio-Marin, Ruth (eds.), What Happened to the Women? Gender and Reparations for Human Rights Violations, International Centre for Transitional Justice, New York, 2006, pp. 194-245.
} 
related violence against women. Despite the fact that the amount of compensation covers both material losses and non-material damages and that the latter are not, at least in principle, less valuable and compensable than the first ones, ${ }^{733}$ non-material damages are usually more difficult to quantify. For example, in case of sexual slavery against a group of young women, psychological and mental damages extend well beyond that which may be measured in terms of days of detention or costs of medical treatments. Especially when the State of nationality of the injured persons sought compensation for different heads of damage, the assessment of all the non-material damages for victims of gender-based crimes may result in the settlement of a comprehensive agreement that does not take into account all the specific gender aspects of the case. ${ }^{734}$ This seems even more true if one considers the above typical concerns about the financial sustainability of mass reparations for the economy of the responsible State. ${ }^{735}$

Lastly, when compensation has been awarded through criminal judgements against the individual responsible of the breach of IHL, many difficulties may be raised with regard to the perpetrator's insolvency. ${ }^{736}$ In these cases, if the State did not have a dedicated fund for survivors of crimes under international law, the victim rarely may receive any compensation. This issue is particularly relevant for victims of conflict-related sexual violence (CRSV). For example, after the transfer of many cases related to sexual violence from the ICTY to the domestic courts of Bosnia and Herzegovina in accordance with the ICTY Completion Strategy, ${ }^{737}$ Bosnian authorities have failed to provide survivors of CRSV with adequate compensation because of the nonexistence neither of a fund for compensation of damages nor of a reparation mechanism for victims of war in cases when perpetrators are unable to pay for compensation. ${ }^{738}$ In this regard, in its decision on the case Mrs. A. v Bosnia, the UN Committee

\footnotetext{
${ }^{733}$ See ILC Articles on State Responsibility, commentary to Article 31, paras. 5-6-8.

${ }^{734}$ Historically almost absent from the substantial compensatory terms of the peace agreements, the assessment and the evaluation of damage in gender-based crimes against women has been developed in the parameters used by the jurisprudence of the regional human rights courts.

735 The tension between the obligation to pay compensation to the injured State and the financial capacity of the responsible State may be evident in the peace treaty itself. For example, the 1952 Treaty of San Francisco stated: "It is recognized that Japan should pay reparations to the Allied Powers for the damage and suffering caused by it during the war. Nevertheless, it is also recognized that the resources of Japan are not presently sufficient, if it is to maintain a viable economy, to make complete reparation for all such damage and suffering and at the same time meet its other obligations". Article 14 (a), Treaty of Peace with Japan, UNTS 1952 (reg. No. 1832), Vol. $136,45-164$, pp. 60-61.

${ }^{736}$ The judicial entitlement to compensation is often difficult to enforce where the perpetrator is fugitive, or have transferred his assets, or is declared in bankrupt.

${ }^{737}$ See ICTY, Completion Strategy, available at https://www.icty.org/en/about/tribunal/completion-strategy [last visited: 21 February 2021].

${ }^{738}$ Amnesty International expressed its concerns in its 2009 Report "Whose Justice? The Women of Bosnia and Herzegovina are Still Waiting", available at: https://www.amnesty.org/download/Documents/48000/eur630062009eng.pdf [last visited: 21 February 2021].
} 
Against Torture (CAT), in assessing that the repeated rape to which the claimant was subjected by Mr. Savić, a member of the Vojska Republike Srpske, during the armed conflict in former Yugoslavia, constituted torture, Bosnia and Herzegovina was found in breach of its obligation to provide redress to survivors of torture (under Article 14 of the Convention against Torture). Thus, the Committee required the State to redress Mrs. A. with fair and adequate compensation and with medical and psychological support, but also to institute an effective reparations programme for survivors of war crimes, including survivors of sexual violence at a national level. ${ }^{739}$ The decision, the first CAT decision on CRSV, demonstrates on the one hand the difficulty that victims of CRSV face in obtaining compensation before criminal courts, on the other hand the States indecisiveness in dealing with the phenomenon of CRSV.

The above analysis demonstrates that compensation is not always the best form of reparation for female survivors. This is not to say that compensation is not a relevant form of reparation nor that its use should be discouraged. It is rather to highlight that a victim and gender-oriented approach may bring to the foreground certain aspects that are not usually considered in the choice of the form of reparation as well as in the award of compensation. As it will be explored in the next Chapter, also the way compensation is awarded - for example as part of an ex gratia payment or with the State's admission of responsibility - may play a relevant role in the victims' perception and eventual acceptance of the reparation.

\subsubsection{Satisfaction}

Satisfaction, as a symbolic form of reparation, is considered the last resort, when restitution and compensation are not feasible. The subsidiarity role of satisfaction - clearly expressed under Article 37, paragraph 1 of the Articles on State Responsibility - is confirmed in the commentary of Article 49 of the Articles on State Responsibility, which, after admitting the possibility to direct countermeasures also to ensure reparation, addresses the question of

The sixth periodic report submitted by Bosnia and Herzegovina to the Committee on the Elimination of Discrimination Against Women (CEDAW) in 2018 confirms these deficiencies, reporting the failure to adopt the drafted proposal of the Programme for Victims of Wartime Rape, Sexual Abuse and Torture, and their Families in Bosnia and Herzegovina (2013-2016). See CEDAW, Sixth periodic report submitted by Bosnia and Herzegovina under article 18 of the Convention, CEDAW/C/BIH/6, 11 July 2018, available at: https://documentsdds-ny.un.org/doc/UNDOC/GEN/N18/219/45/PDF/N1821945.pdf?OpenElement [last visited, 28 February 2021].

${ }^{739}$ CAT, Decision adopted by the Committee under article 22 of the Convention, concerning communication No. 854/2017, $\quad$ CAT/C/67/D/854/2017, $11 \quad$ September 2019, available at: https://docstore.ohchr.org/SelfServices/FilesHandler.ashx?enc=6QkG1d\%2fPPRiCAqhKb7yhsuOMGYTziGXu 2yX5ndBaQLvm5Vm8uqG0bWPMVI3cKIhs3d2uk0hBTTopC46F5XuTUZxYMDCA550cdYoJhwAByAdyM XX4x9TGS\%2bPMZudTgy2GtHGt6tNGV04Cdbb\%2fwQ\%2f9tg\%3d\%3d. 
whether countermeasures may be an option also when the responsible State fails to provide satisfaction:

In normal situations, satisfaction will be symbolic or supplementary and it would be highly unlikely that a State which had ceased the wrongful act and tendered compensation to the injured State could properly be made the target of countermeasures for failing to provide satisfaction as well. This concern may be adequately addressed by the application of the notion of proportionality set out in article $51 .{ }^{740}$

Once again, satisfaction is undoubtedly understood as a complement to restitution and compensation, so that the possibility of using countermeasures in order to ensure the respect of the obligation of satisfaction alone is not even contemplated. As Professor Dinah Shelton put it:

Damages fulfill a purely compensatory purpose, excluding exemplary or punitive awards. Guarantees of non-repetition and satisfaction are disfavored, the first because such assurances anticipate future breaches, and thus do not remedy injury already caused, and the second because satisfaction has been used in the past as a punitive measure [...] The more general concern of the international community as a whole to uphold the rule of law [...] does not extend to allowing the injured state to request measures to punish the violation or deter the responsible state from further wrongful acts. ${ }^{741}$

It is here argued that satisfaction may have greater significance than the one usually attributed to it, both from a normative and a gender perspective, especially when female survivors are involved. Under certain conditions, satisfaction may effectively gratify the victims' expectations and overcome some of the above limits of restitution and compensation.

In general, depending on the crime suffered or the category of victims, symbolic forms of reparation may have a stronger reparative effect than monetary compensation. As Manfred Nowak argued with regard to victims of torture,

[they] are not primarily interested in monetary compensation, but in the means of reparation that are best suited to restore their dignity and humanity. A full and impartial investigation of the truth and the recognition of the facts, together with an apology by those individuals and authorities responsible, often provide more satisfaction to the victim than payment of money. ${ }^{742}$

Since, as for the crime of torture, many conflict-related forms of violence against women have usually long-term effects in terms of de-humanization of the person, violation of her dignity as

\footnotetext{
${ }^{740}$ ILC Articles on State Responsibility, commentary to Article 49, p. 286, para 8.

${ }^{741}$ Shelton, Dinah, "Righting Wrongs: Reparations in the Articles on State Responsibility", American Journal of International Law, Vol. 96, No 2, (2002) 833 - 856, pp. 844, 848-49.

${ }^{742}$ Report of the Special Rapporteur on torture and other cruel, inhuman or degrading treatment or punishment, Nowak, Manfred, A/HRC/4/33, 15 January 2007, p. 21.
} 
well as societal ostracism and stigmatization, women survivors may often be more interested in symbolic forms of reparation than compensation. ${ }^{743}$

Satisfaction may take different forms with a high-symbolical truth-telling role, such as the institution of public inquiries mechanisms, such as the truth commissions, the establishment of public memorials, the acknowledgment of the past wrongdoing in history books, the condemnation of the responsible individuals through judicial trials. However, the most powerful forms of satisfaction is probably the public apology. ${ }^{744}$ Public apology unveils the real motivations behind the State's recognition of its misconduct and usually implies a previous effort to inquire over the truth of the past facts as well as an additional subsequent effort to achieve a full reparation. ${ }^{745}$ Of course, in order to be truly effective, it should be the culmination of a process that fully involves the victims. ${ }^{746}$

The 2019 Report on apologies for gross human rights violations and serious violations of international humanitarian law submitted by the Special Rapporteur on the promotion of truth, justice, reparation and guarantees of non-recurrence, Fabián Salvioli, has specifically recognized gender as one of the two perspectives, together with a victim-oriented perspective, to be integrated into the practice of public apologies. In particular, public apology should recognize the gendered nature of the harm and specifically address it; identify the potential risks of perpetrating gender inequalities through the reparation mechanism; and involve women survivors in all phases of the apology process, from the identification of the contents and context to the delivery of apologies. ${ }^{747}$

743 See Report of the Special Rapporteur on violence against women, its causes and consequences, Rashida Manjoo, UN GA 14 ${ }^{\text {th }}$ session, A/HRC/14/22, 23 April 2010.

${ }^{744}$ Public apology may be defined as:

(a) An acknowledgement of a wrong deliberately or negligently inflicted that is named;

(b) A truthful admission of individual, organizational or collective responsibility for that hurt;

(c) A public statement of remorse or regret related to the wrongful act or acts, or omission, that is delivered with due respect, dignity and sensitivity to the victims;

(d) A guarantee of non-recurrence.

Report on apologies for gross human rights violations and serious violations of international humanitarian law, Fabián Salvioli, UN GA A/74/147, 12 July 2019, para 3.

745 Probably the most landmark act of public apology is the West Germany Chancellor's, Willy Brandt, spontaneous kneeling for German Nazi atrocities to Jewish people of the Holocaust at the Warsaw Ghetto on December 7, 1970. "the feeling that I must express the exceptional significance of the ghetto memorial from the bottom of the abyss of German history under the burden of millions of victims of murder, I did what human beings do when speech fails them”. Brandt, Willy, My Life in Politics, Hamish Hamilton Press, London, 1992.

${ }^{746}$ Unluckily, women's organisations and representatives are less likely considered and involved in the process of development of symbolic forms of reparation. See Rubio-Marín, Ruth, "The gender of reparations in transitional democracies".

${ }^{747}$ Report on apologies for gross human rights violations and serious violations of international humanitarian law, Fabián Salvioli, UN GA A/74/147, 12 July 2019, pp. 5-6, para. 7. 
The 2010 public apology of the then President of Sierra Leone, Ernest Bai Koroma, expressing regret for the violation of human rights and IHL committed against women during the civil war that took place between different armed groups from 1991 and $2002^{748}$ has been considered a good example of an "unequivocal apology" marked by a clear gender-oriented approach. ${ }^{749}$

At least four aspects made this apology successful from a gender perspective. First, the choice of a symbolic day, the 27 of March 2010, in occasion of the annual celebration of Women's day, to deliver the public apology showed a particular attention to the persons to whom apology was addressed. Second, all the process of organizing and delivering the public apology engaged groups of women and women's representatives, so that the ceremony resulted in a sincere apology for the survivors. Third, the authority of the person delivering the apology, the President of the Republic of Sierra Leone, made the event remarkable in that he could speak in his capacity as head of the State for the lack of State protection to women, as Commander-inChief of the Armed Forces for the wrongdoings against women committed by the Army and all non-State armed groups, as "Fountain of Honor and Justice" for all violations suffered by women, and finally as Leonean man for the commitment not to make women suffer again the same harms. Fourth, the content of the apology is also noteworthy for two aspects. The public apology has been presented as a national matter, a process without which a real reconciliation of the country would not be possible, in so providing a clear signal of recognition of the past responsibilities and profound respect for the victims:

We will never as a nation move forward if we do not apologize to the women of this country for letting them down during the war; we will never as nation know better days if we do not ask for the forgiveness of our mothers, sisters, partners, and female compatriots for what we let them go through during the war. ${ }^{750}$

Moreover, the President of Sierra Leone gave specific reassurances to the victims, committing himself and the country for a looking-forward better society for the Leonean women. Among the specific measures, he launched the country's National Gender Strategic Plan. ${ }^{751}$

\footnotetext{
${ }^{748}$ For a background of the internal conflict in Sierra Leone, as well as a an examination of Sierra Leone's progress in implementing transitional justice commitments, see International Centre for Transitional Justice (ICTJ), "Submission to the Universal Periodic Review of the UN Human Rights Council 11th Session: May 2011", (November 1, 2010), available at: https://www.ictj.org/sites/default/files/ICTJ-SierraLeone-Periodic-Review2010-English.pdf [last visited, 23 February 2021].

749 The text of the apology may be found at: http://www.awarenesstimes.com/drwebsite/publish/printer 200514972.html [last visited, 23 February 2021]. ${ }_{750}$ Ibid.

751 See International Centre for Transitional Justice, "More than words: apologies as a form of reparation" (December 2015), p. 9, available at: https://www.ictj.org/publication/more-than-words-apologies-form-reparation [last visited, 23 February 2021]. For a critical analysis of the transformative potential of reparations in Sierra
} 
As the example of the apology delivered by the President of Sierra Leone shows, apology may have a normative impact which goes well beyond its wording. In particular, when a State recognizes legal responsibility for its conduct or omission - in the case at hand the omission to protect its female civilians - and specifically commits itself to conform to certain international obligations, the statement may have legal consequences in terms of development of IL or, at least, legitimate expectations of the injured State, the international community and the victims. Indeed, apology may plausibly contribute to "the formation or reinforcement of customary international law", in that it may enlarge the practice of the States in acknowledging a certain wrongdoing as a violation of IL and in perceiving the violated norm as mandatory. Moreover, apology may inform treaty interpretation, in establishing a certain interpretation of the obligations under a convention, and "perhaps 'estop' a state from challenging the existence of an alleged rule for the "violation' of which it apologized". ${ }^{752}$ Considering that "at present, there is an evident social demand for apologies, which only seems to accelerate", ${ }^{753}$ the impact of apologies with regard to the number of cases of conflict-related violence against women may well be not only symbolical, in terms of political recognition of the victims' suffering by the wrongdoer State, but also normative, that is the corroboration of the customary nature of those rules prohibiting certain forms of violence, such as gender-based violence against women ${ }^{754}$, and the consolidation of a gender-oriented interpretation of treaty law norms.

The apology may also compensate for some of the limits of the other forms of reparation. Considering the abovementioned issues of the financial sustainability of mass reparations for the responsible State, the focus on satisfaction may offer a way out of the impasse that compensation may cause, representing an inviting substitute or at least a valid complementary form of reparation that combines both the victims and the State interests. It is significant that the legal advisor of TRIAL international in Sarajevo, the NGO that provided legal service and

Leone, see Williams, Sarah and Opdam, Jasmine, "The Unrealised Potential for Transformative Reparations for Sexual and Gender-Based Violence in Sierra Leone", The International Journal of Human Rights, Vol. 21, No. 9, (2017) 1281-1301.

752 See Bilder, Richard, "The Role of Apology in International Law and Diplomacy", Virginia Journal of International Law, Vol. 46, No. 3, (2006) 433-474.

${ }^{753}$ Teitel, Ruti, “The Transitional Apology", in Barkan, Elazar and Karn, Alexander (eds.), Taking Wrongs Seriously. Apologies and Reconciliation, Stanford University Press, Stanford, 2006, pp. 101.

${ }^{754}$ A list of opinion juris and state practice that would suggest the evolution of the prohibition of gender-based violence against women into a principle of customary international law is given by General Recommendation No. 35 on gender-based violence against women, updating general recommendation No. 19, CEDAW, 14th July 2017. For an opposite view, see De Vido, Sara, "The Prohibition of Violence Against Women as Customary International Law? Remarks on the CEDAW General Recommendation No. 35", in Diritti umani e diritto internazionale, Vol. 2, (2018), pp. 379-396. 
submitted the communication to CAT in the sub mentioned case Mrs. A. v Bosnia, in asserting the failure of the State of $\mathrm{BiH}$ to implement the CAT's decision after half year, stated: "Presenting an official public apology is easy. It is therefore the bare minimum that Bosnia and Herzegovina must do for this survivor, as soon as possible". ${ }^{755}$ These words underline the symbolic relevance that a public apology could have in advancing the female victims' perception of justice for the past harms suffered. Moreover, satisfaction addresses also to those female victims that, for reasons of social stigma, decide not to speak out about what they suffered during the conflict as well as to those ones that, substantially excluded from land and property rights, may not effectively obtain compensation.

Despite its remarkable aspects, public apology should not be overestimated. Alone, it is difficult to achieve full reparation for the victims. In order to be effective, it should be part of a wider process of reparation including different forms of satisfaction and compensation. ${ }^{756}$ When women's survivors are involved, apology may have an effective normative and symbolic effect only if the circumstances under which it is delivered, its wording, its content, its timing undertake a gender perspective. As it has been demonstrated, the integration of a gender perspective may well lead to the reassessment of the hierarchy of the forms of reparation as it is conceived in the law of State responsibility, so that it is not always satisfaction to complement compensation but compensation to complement satisfaction.

\subsection{Concluding remarks}

The above analysis explores the relevance of each form of reparation for female victims. Ultimately, it seems that, alone, none of the described forms of reparation may provide a full reparation to women subjected to conflict-related violence. The limits of the forms of reparation in dealing with female survivors appear, at first sight, the evident sign of how the system of war reparations may entrench pre-existing layers of gender issues. In other words, the mechanisms devoted to granting reparation for victims of war were not conceived to deal

\footnotetext{
$755 \mathrm{https}$ ://trialinternational.org/latest-post/is-bosnia-turning-a-deaf-ear-to-un-recommendations/.

756 "Apologies should be accompanied, as appropriate, by reparative measures designed to assist those who have been affected by past harms. They may include accepting legal liability, commitment to provide monetary compensation, restoration of the rights of victims and/or appropriate commemorations or acts of memorialization. Reparative measures may also include a commitment to fulsomely and effectively pursue justice, truth and information recovery". Report on apologies for gross human rights violations and serious violations of international humanitarian law, Fabián Salvioli, UN GA A/74/147, 12 July 2019, para 58.
} 
with gender-specific forms of violence against women. This is especially evident in the prevailing hierarchy of the forms of reparation, which privileges restitution and compensation in so assuming that the return to the status quo ante and the monetary payment are the best forms of reparation for the victims. These deficiencies of these two forms of reparation are easily visible when using a gender-sensitive analytical lens.

It is now acknowledged that the appropriateness of certain forms of reparation depends not only on the general circumstances ${ }^{757}$ but also on the victims' perspective. Even assuming the non-existence of an individual right to reparation under current IHL, the injured State has an obligation to act on behalf of its nationals where they result as the final beneficiaries of the reparation claim. ${ }^{758}$ The ILC's draft Articles on diplomatic protection undertakes this view, encouraging States to "take into account, wherever feasible, the views of injured persons with regard to resort to diplomatic protection and the reparation to be sought" ${ }^{759}$ Following this line, the State of nationality of the victims does not seem completely free in the peace negotiation with the responsible State over the choice of the best form of reparation to award to the victims. To the contrary, the decision about the form of reparation to demand requires the consultation with the injured persons. ${ }^{760}$ It is here sustained that the adequacy of the form of reparation should be evaluated also on the basis of the gender of victims. In particular, when women and girls survivors are involved, the specific qualification and quantification of the suffered harm should be determined, considering the eventual gender aspects of the crime as well as the short and long-terms gender consequences of the violation.

Against this background, symbolic forms of reparation, which are generally underrated in the hierarchy of the forms of reparation, may well assume a leading role in achieving a more adequate reparation for the victims. While the relevance of satisfaction, and in particular of public apology, as a form of reparation under the law of State responsibility is generally limited, a gender approach to the choice of the form of reparation may elevate public apology as an important instrument for inter-States reconciliation and restorative justice to victims.

\footnotetext{
${ }^{757}$ Hofmann, Rainer, "Draft Declaration of International Law Principles on Reparation for Victims of Armed Conflict (Substantive Issues)", Commentary to Article 7, para. 3.

${ }^{758}$ Ferstman, Carla, "The Relationship between Inter-State Reparations and Individual Entitlements to Reparation: Some Reflections", Zeitschrift für ausländisches öffentliches Recht und Völkerrecht, Vol 78, No. 3, (2018) 561564.

${ }^{759}$ ILC, Draft Articles on Diplomatic Protection with Commentaries, (2006), Article 19(b).

${ }^{760}$ Ibid. Commentary to Article 19(b), p. 54, para. 4.
} 
To conclude, it is suggested that the analysis of the system of reparations from a gender perspective means more than "add women" to the current understanding of this war settlement mechanism. Instead, it contributes to the recent debate over the nature of reparations, whether only an interstate mechanism or becoming an individual secondary right, it raises relevant questions about the most adequate forms of reparations from a victim-oriented perspective, it opens new vistas over the relevant role of interstate settlements for humanitarian law claims, and, in general, it offers a clear view on the purpose and role of IHL. 


\title{
5. REPARATIONS IN THE CASE OF THE KOREAN “COMFORT WOMEN"
}

The previous Chapter discussed the issue of reparation for international crimes committed during armed conflicts. After a first examination of the general regime of war reparations, the analysis explored the gender perspectives on reparations, particularly focusing on the potential of an individual right to reparation and on the limits of the forms of reparations for redressing women's survivors. This Chapter now turns to one of the most disputed ongoing case of reparation for personal damages suffered by women during an armed conflict, the still ongoing case of the so-called Korean "comfort women".

\subsection{The relevance of the case from a normative and a gender perspective}

\author{
"Comfort women" 761 are the around 200,000 women ${ }^{762}$ who had been tricked or abducted into \\ government-sanctioned military brothels, called "comfort stations", and forced into slavery ${ }^{763}$ \\ for sexual services for Japanese Imperial Army before and during World War II. ${ }^{764}$ These
}

\footnotetext{
761 The term "comfort women" is the English translation of the Japanese "iugun ianfu" and it is largely considered a euphemistic expression which hides the real condition of sexual violence to which women were subject in the hands of Japanese Imperial Army. The Special Rapporteur for the UN Sub-Commission on the Promotion and Protection of Human Rights, Gay McDougall, named the women as "sex slaves" and the military comfort stations as "rape centers" or "rape camps" in her Report titled "Systematic Rape, Sexual Slavery and Slavery-like Practices during Armed Conflict". Despite the possible use of different terminology, this Chapter refers to the women victims of the Japanese military system of sexual slavery as "comfort women" following the terminology used internationally to promote the case, always in quotation marks to underline the euphemistic value of the expression.

${ }^{762}$ The precise number of women remains uncertain because the most relevant documents were destroyed by Japanese government after the defeat. On the method used to calculate the approximate number of comfort women see Chung, Chin-sung, "An Overview of The Colonial and Socio-Economic Background of Japanese Military Sexual Slavery In Korea”, Muse: Journal of Transcultural Prosecution, Vol. 1, No. 3, (1995) 204, p. 212.

${ }^{763}$ The judgment of the Women's International War Crimes Tribunal on Japan's Military Sexual Slavery (2001) suggests that the most appropriate and accurate legal term to define the atrocities committed against comfort women is "sexual slavery". Indeed, the term "forced prostitution" would hide the terrible gravity of the crime. http://www.alpha-canada.org/wp-content/themes/bcalpha-theme/resources/ SexualSlavery/judgment e01 optz.pdf, paras 634-9. In that sense also Coomaraswamy, Radhika, Report on the mission to the Democratic People Republic of Korea, the Republic of Korea and Japan on the issue of military sexual slavery in wartime, U.N. ESCOR, 52nd Sess., Provisional Agenda Item 9(a), U.N. Doc. E/CN.4/1996/53/Add.1 (1996) paras 17-18, U.N. Doc. E/CN.4/1996/53/Add.1.

${ }^{764}$ It is well known that violence - especially sexual violence - against women occurred in almost every conflict in the history of humanity. For an explanation of the specific elements which make violence perpetrated against comfort women different and unparallel in history, see Boling, David, "Mass Rape, Enforced Prostitution, and the Japanese Imperial Army: Japan Eschews International Legal Responsibility?”, Columbia Journal of Transnational Law, Vol. 32, No. 3, (1994-1995) 533-590, p. 540.
} 
women and girls were taken from Japanese military-occupied areas, especially Korea ${ }^{765}$, but also the Philippines, Indonesia, China and Taiwan, and imprisoned in facilities knows as “comfort stations", where they were subjected to daily violence and sexual assaults by soldiers. At the end of the World War II, the few "comfort women" that survived this treatment were killed or abandoned by Japanese soldiers. ${ }^{766}$ Their patriarchal communities subjected those who could return home to ostracism and marginalization. ${ }^{767}$

Despite some evidences of the forcible abduction of women by the Japanese Army were introduced at the International Military Tribunal for the Far East, the judgement in that case did not focus on these crimes. ${ }^{768}$ Only in the 1990s-2000s - during the "second wave" of societal interest in interpreting the outcomes and the deficiencies of the Tokyo Trial and despite the arise of the "neo-nationalist" or "revisionist" movement ${ }^{769}$ - the Japanese military sexual slavery system came to light. This happened through landmark civil actions for compensation filed by some Korean former "comfort women" and submitted to domestic courts in Japan and other states, ${ }^{770}$ such as the class action lawsuit filed by 15 former "comfort women" in September 2000 before the U.S. Court of Appeals for the District of Columbia Circuit in the case Hwang Geum Joo v. Japan. In alleging to have been victims of human trafficking and

\footnotetext{
${ }^{765}$ The preference of the Japanese Imperial Army for Korean women is interpreted as an exercise of colonial and gender power. see Min, Pyong Gap, "Korean 'comfort women': the intersection of colonial power, gender, and class", Gender and Society, Vol. 17, No. 6, (2003) 938-957, p. 944.

${ }^{766}$ Further details of the facts related to the sexual enslavement treatment to which women were subjected in the comfort stations, see Dolgopol, Ustinia and Snehal Paranjape, Comfort Women: An unfinished ordeal. Report of a mission, International Commission of Jurists, Geneva, 1994; Parker, Karen and Chew, Jennifer F., "Compensation for Japan's World War II War Rape Victims", Hastings International \& Comparative Law Review, No. 17, (1993-1994) 497-550.

${ }^{767}$ For some depositions about the marginalization former comfort women experienced in their lives, see War Victimization and Japan: International Public Hearing Report, Executive Committee International Public Hearing, Tōhō Shuppan, Osaka-shi, 1993. For a general overview of consequences women suffer after rape and sexual violence during and after armed conflicts, see Chinkin, Christine, "Rape and Sexual Abuse of Women in International Law", European Journal of International Law, Vol. 5, No.3 (1994) 326-341.

${ }^{768}$ Dolgopol, Ulstina, "Knowledge and Responsibility: The Ongoing Consequences of Failing to Give Sufficient Attention to the Crimes against the Comfort Women in the Tokyo Trial", in Tanaka, Yuki, McCormack, Tim and Simpson, Gerry (eds.), Beyond Victor's Justice? The Tokyo War Crimes Trial Revisited, Martinus Nijhoff Publisher, Leiden-Boston, 2011, pp. 243-261.

${ }^{769}$ Futamura, Madoka, "Japanese Societal Attitude towards the Tokyo Trial: From a Contemporary Perspective", in Tanaka, Yuki, McCormack, Tim and Simpson Gerry (eds.), Beyond Victor's Justice? The Tokyo War Crimes Trial Revisited, Martinus Nijhoff Publisher, Leiden-Boston, 2011, pp. 45-46.

${ }^{770}$ In particular, Korean former comfort women filed lawsuits before US courts. See Arakawa, Maki, "A New Forum for Comfort Women: Fighting Japan in United States Federal Court", Berkeley Journal of Gender, Law. \& Justice, Vol. 16, No. 1, (2001), 174-200. The author provides an overview of the class action lawsuit filed on September 18, 2000 in the United States District Court for the District of Columbia under the Alien Torts Claim Act (ATCA).
} 
endured rape and torture, the former "comfort women" asked Japan for reparation and official apology. ${ }^{771}$

From the perspective of international law, the case of "comfort women" gives rise to two main issues. The first one concerns the then applicable international law, and in particular the question whether international rules protecting civilians in military-occupied areas and prohibiting human trafficking, forced labour and slavery were in force at the time the "comfort women" system was in operation.

The second issue, which is of interest for the present analysis, regards reparation for breaches of international law. In this respect, three specific aspects emerge in the "comfort women" case. First, the complex issue of the existence of an individual right to reparation at the time of World War II under the 1907 Hague Convention and customary international law is in question. Second, there is the procedural issue of whether and to what extent the principle of State immunity may operate also in cases of serious violations of IL applicable to armed conflicts. The third aspect refers to the relationship between the right to reparation owned by the injured State and any individual right to reparation. The Republic of Korea (ROK), the State of nationality of the victims, ${ }^{772}$ has waived any future claims for war reparation through an agreement signed in the aftermath of the World War II. ${ }^{773}$ The key issue raised here is whether, and to what extent, a decision of the injured State to renounce to reparation claims through a peace agreement also on behalf of its nationals has effects on the victim's right to reparation, particularly when the individuals in question are victims of grave international crimes. As it will be shown, a gender perspective helps here in analysing these three aspects, in that it may offer key elements in supported the view according to which reparation should be awarded to "comfort women".

In addition to these three elements, there is also another aspect of the "comfort women" case that makes it an exemplary case for a study on the gender dimensions of IHL. This concerns

\footnotetext{
${ }^{771}$ Legal documents as well as a summary of the background of the case Hwang Geum Joo v. Japan are available at the website of the Center for Justice and Accountability's https://cja.org/what-we-do/litigation/amicusbriefs/hwang-geum-joo-v-japan/ [last visited, 20 February 2021].

772 As specified above, victims of the comfort stations' system were women of different nationalities: Filipino, Indonesian, Chinese and Taiwanese. However, Korean women were far and away the majority of them as well as the first who initiated legal actions before Japanese and US courts. For these reasons, this contribution will address the issue of right to reparation for international crimes only with regard to Korean women case.

${ }^{773}$ For the English version of the Agreement, see Agreement Between Japan and the Republic of Korea Concerning the Settlement of Problems in Regard to Property and Claims and Economic Co-operation, International Legal Materials, American Society of International Law, Vol. 5, No. 1, (January 1966), 111.
} 
the identification of the most suitable forms of reparation in relation to the type of crime committed and to the specific group of victims concerned. The refusal of the former "comfort women" to accept certain forms of reparation, namely an ex gratia monetary compensation, suggests that a victim and gender-oriented approach to the choice of the form of reparation may influence the assessment of the effectiveness of the reparation. Moreover, the former “comfort women's" rejection of many public apologies delivered by Japanese governmental authorities over time raises the question of the relevance of gender considerations for the final acceptance of the apology by victims, and, ultimately, for a peaceful resolution of the interStates dispute over the case.

\subsection{Historical background}

In an era when women were regarded as inferior to men, the expansionary policy of the then Japanese Government set the perfect background for the gross abuse and humiliation of women, initially in the Korean peninsula and later on in the Philippines and other occupied territories. ${ }^{774}$

This statement indicates that the relationship between the Japanese expansionistic policy of the first decades of the XX century and the exacerbation of women condition finds its roots in the patriarchal system of Nipponese society. A better understanding of "comfort women" issue requires thus contextualization and a short illustration of the situation of Japan in the 1930s.

At the beginning of XX century Japan controlled the island of Taiwan and Korea. ${ }^{775}$ Japan aimed at the establishment of an Asiatic empire under its domination, and for this reason it started a war of aggression against China, the so called second Sino-Chinese war, with the invasion of the Chinese region of Manchuria in 1931. One year later, Japan founded the puppet State of Manchukuo in the region. During its continental advance, Japan committed a number of atrocities. In particular, during the well-known "Rape of Nanking" the population was subjected to the most heinous acts, and at least 20.000 women and girls of all ages were raped, while many of them also mutilated and killed. Since the event risked to jeopardize the international reputation of Japan, Emperor Hirohito decided to institutionalize the so called

\footnotetext{
774 Dolgopol, Ustinia and Snehal Paranjape, Comfort women. An Unfinished ordeal, Report of a mission,...p. 29, available at: http://icj.wpengine.netdna-cdn.com/wp-content/uploads/1994/01/Japan-comfort-women-factfinding-report-1994-eng.pdf] [last visited, 23 February 2021].

775 Taiwan was a Japanese colony since 1895; in 1905 Korea became Japanese protectorate and, five years later, it was completely annexed to Japanese empire as a colony.
} 
comfort stations in order to relegate, and so to hide, sexual violence episodes in special buildings, and restore Nipponese Army image at international level. ${ }^{776}$

According to Argibay, at least other three reasons were at the basis of Japanese government choice to build the comfort stations. First, the rapes committed by Japanese troops were generating an anti-Japanese feeling among occupied territories, so that acts of resistance could have threatened Nipponese military advance. The creation of ad hoc buildings to satisfy sexual desires of soldiers would have concealed this practice. Second, the comfort stations were provided with doctors that verified women's health conditions in order to reduce the risk for soldiers to contract venereal diseases. Finally, the isolated status of "comfort women" guaranteed the impossibility of external contacts and the confidentiality of military secrets. ${ }^{777}$

The first comfort station was established in Shanghai in 1932, but, by the end of the 1930ies, the system spread in all the occupied territories of East Asia and Pacific islands: China, Manchuria, Taiwan, Borneo, Malaysia, Philippines, New Guinea, Ryuku, Singapore, Burma, Indonesia, Japan and Korea. ${ }^{778}$ In short, «stations seem to have been found wherever the Japanese army was based». ${ }^{779}$

Since at that time prostitution was legal in Japan, the first of the "comfort women" voluntarily offered themselves to serve in comfort stations. ${ }^{780}$ Given the growing number of soldiers

\footnotetext{
776 Lee, Sue R., "Comforting the Comfort Women: Who Can Make Japan Pay", University of Pennsylvania Journal of International Law, Vol. 24, No. 2, (2003) 509-547, p. 511 at note 17. Behind this decision, the idea according to which rape would be caused by sexual desire or lack of sexual activity. This would justify the nonrecognition of rape as a crime and affirmation of power against women. The words of a former Japanese soldier seem to confirm this conception: "During the battle, which lasted about 50 days, I did not see any women at all. All I knew that as a result of (being without access to women), men's mental condition ends up declining, and that's when I realized once again the necessity of special comfort stations. This desire is the same as hunger or the need to urinate, and soldiers merely thought of comfort stations as practically the same as latrines". Yoshiaki, Yoshimi Comfort women, Columbia University Press, [trans. S. O’Brien], 2000, p. 199.

777 Argibay, Carmen M., "Sexual Slavery and the 'Comfort Women' Of World War II”, Berkeley Journal of International Law, Vol. 21, No. 2, (2003) 375-389, pp. 376-377.

778 Arakawa, Maki, “A New Forum For Comfort Women: Fighting Japan In The United States Federal Court",...pp. 177-178.

Given the inexistence of adequate documentation on comfort women system, there is not a complete list of places in which comfort stations were located. However, Japanese Government confirmed the presence of comfort stations in these countries or regions: Japan, China, Philippines, Indonesia, Malaysia, Thailand, Burma, New Guinea, Hong Kong, Macao, French Indochina. U.N. Economic \& Social Commission on human rights, Japan's policy on the issues against women and "comfort women", in Further promotion and encouragement of human rights and fundamental freedoms, including the question of the programme and methods of work of the Commission 15, U.N. Doc. E/CN.4/1996/137. Evidences of the existence of comfort stations were also found in Singapore, Dutch East Indies, Okinawa, Pacific Island of New Britain and Trobriand. Coomaraswamy, Radhika, Report on the mission to the Democratic People's Republic of Korea...para. 17-18.

${ }^{779}$ Coomaraswamy, Radhika, Report on the mission to the Democratic People's Republic of Korea,...para. 17.

${ }^{780}$ Prostitutes accepted the offer to work for military bases in order to relieve themselves from debts and to have a fixed gain like public servants. Yoshiaki, Yoshimi, Comfort women..., p. 101. Apart from economic advantages,
} 
required to face the exacerbation of the war in the Pacific, however, volunteering prostitutes were not sufficient anymore. For this reason, Nipponese Army started to capture women and girls from occupied territories. At the beginning the recruitment took place by deception: women were engaged in the Women's Voluntary Service Corps ${ }^{781}$ or persuaded with the promise of a better job. ${ }^{782}$ In some situations of extreme poverty, parents or husbands even sold their women to Japanese Army. ${ }^{783}$ When "slave raids" did not have the collaboration of women's families or villages' chief, soldiers took women and girls by the use of force and threats. $^{784}$

In recruiting women domestically to work in the military comfort stations [...] it is feared that some people have claimed to be acting with the military's consent and have damaged the honor of the army, inviting the misunderstanding of the general public [...] There have also been instances where a lack of proper consideration resulted in the selection of inappropriate people to round up women, people who kidnap women and are arrested by the police. There are many things [about the rounding up of comfort women] that require careful attention. In the future, armies in the field will control the recruiting of women and will use scrupulous care in selecting people to carry out this task. This task will be performed in close cooperation with the military police or local police force of the area. You are hereby notified of the order [of the Ministry of War] to carry out this task with the utmost regard for preserving the honor of the army and for avoiding social problems. ${ }^{785}$

This text, part of a document delivered on $4^{\text {th }}$ March 1938 by Japanese Ministry of War, demonstrates that the Government was not only engaged in the recruitment of "comfort women", but it was also guiltily aware of the illicit methods used during such process. Coercive methods were eventually condemned with the only purpose to preserve the honorability of the Army but not with the actual purpose of prohibiting the use of violence against women. ${ }^{786}$

According to the testimony of former "comfort women", the inhuman treatment they were subjected to in the comfort stations included daily sexual abuses and physical tortures undisturbedly committed in segregating places, without any chance to freely move or leave. ${ }^{787}$

Preliminary investigations of governmental and non-governmental organizations revealed the existence of three typologies of comfort stations: the ones under direct management of the

prostitutes also chose to serve the Army because in so doing they were perceived as patriots and admired for their braveness. Hicks, George, The comfort women: Japan's brutal regime of enforced prostitution in the second world war, W. W. Norton, New York, 1994, p. 39.

${ }^{781}$ Coomaraswamy, Radhika, Report on the mission to the Democratic People's Republic of Korea ... para. 15.

${ }^{782}$ Hicks, George, The comfort women: Japan's brutal regime...p. 49.

${ }^{783}$ Yoshiaki, Yoshimi, Comfort women,...pp. 105-106.

${ }^{784}$ Coomaraswamy, Radhika, Report on the mission to the Democratic People's Republic of Korea ... para. 16.

${ }^{785}$ Yoshiaki, Yoshimi Comfort women,...pp. 58-59.

${ }^{786}$ Lee, Sue R., "Comforting The Comfort Women: Who Can Make Japan Pay”,...p. 514.

${ }^{787}$ Coomaraswamy, Radhika, Report on the mission to the Democratic People's Republic of Korea... para 32-33. 
Japanese Army; the ones formally directed by private persons but under substantial control of the army; and the stations administrated by private entities where personnel of the military had access priority. The second typology seems to have been the most common one. ${ }^{788}$ The Japanese Army gave authorizations for the opening of the comfort stations, provided for necessary furniture, established rules for services' prices and «stipulated such matters as precautions for the use of the facilities». ${ }^{789}$ These regulations are relevant evidences of the degree of institutionalization of the "comfort women" system within the Japanese military machinery. ${ }^{790}$

In the aftermath of the war, former "comfort women" suffered post-traumatic stress, depression, insomnia, sexually transmitted diseases, and nervous diseases. In many cases, the psychological trauma was increased by the stigmatization and the marginalization of their families and communities of origin for their non-virtuous past experience. Therefore, former "comfort women" often opted for silence as the only way to avoid social ostracism. ${ }^{791}$

\section{3. "Comfort women" as victims of IHL violations: the basic issues}

The inter-temporal law problem, namely the question as to whether the international law in force at the time of the facts prohibited the "comfort women" system, is a basic preliminary issue for determining the responsibility of Japan. International state responsibility arises when two conditions exist: a conduct, an act or omission, is attributable to a State under international law and that conduct constitutes a breach of an obligation under international law in force at that time. ${ }^{792}$

Regarding the first condition of attribution, after the discovery of official governmental documents of conscription, transportation, placement and management of comfort stations, ${ }^{793}$

\footnotetext{
${ }^{788}$ McDougall, Gay J., U.N. Special rapporteur contemporary forms of slavery, Final Report on systematic rape, sexual slavery and slave-like practices during armed conflict. E/CN.4/Sub.2/1998/13, 22 June 1998, Appendix, An analysis of the legal liability of the government of Japan for "comfort women stations" established during the second world war, para. 8.

${ }^{789}$ Coomaraswamy, Radhika, Report on the mission to the Democratic People's Republic of Korea... para 128.

${ }^{790}$ Lee, Sue R., "Comforting The Comfort Women: Who Can Make Japan Pay”,...p. 517.

${ }^{791}$ Yoshiaki, Yoshimi, Comfort women,...p. 196.

792 Article 2, Draft articles on Responsibility of States for Internationally Wrongful Acts, with Commentaries, 2001.

${ }^{793}$ Yoshiaki, Yoshimi, Comfort women.... See also Argibay, Carmen M., "Sexual Slavery And The 'Comfort Women' Of World War II",...pp. 2-3.
} 
the Japanese government has acknowledged its direct involvement in establishing and supervising the "comfort women" system. ${ }^{794}$ There is therefore no doubt that the relevant acts of Japanese soldiers and officials are to be attributed to the Japanese State according to the relevant rules of international law. With respect to the second criterion - the incompatibility of the act with obligations under treaties or any other applicable rules of international law - the Japanese Government argued that the acts of slavery and rape were not prohibited by the then applicable treaty law and customary international law. Based on this argument, Japan denied international responsibility for this conduct. ${ }^{795}$ Contrary to Japan's assertions, however, many scholars claimed that the Government of Japan could be held responsible for violations of both treaty law and customary international law.

As regard to violations resulting from treaties, Japan was signatory of the 1904 International Agreement for the Suppression of the "White Slave Traffic", which required states parties to prohibit the trafficking of women. ${ }^{796}$ In 1925, Japan ratified the International Convention for the Suppression of the Traffic in Women and Children of 1921, which not only condemns the traffic of women and children, but also imposes on the contracting states to take the necessary measures to prevent it. ${ }^{797}$ The Government of Japan asserted that, pursuant to Article 14 of that Convention, the territory of Korea was not included in the scope ratione loci of its acceptance of the 1921 Suppression Convention. Article 14 allows colonial States to make a reservation on the application of the Convention over their colonies. However, many scholars underlined the inconsistency of Japan's interpretation of Article 14 with the fundamental purpose of that provision, which was to permit States to eliminate gradually these kinds of traffics, not to foster

\footnotetext{
${ }^{794}$ Statement by Chief Cabinet Secretary Koichi Kato on the issue of the so called "Wartime Comfort Women" from the Korean Peninsula, July 6, 1992; Statement by Chief Cabinet Secretary Yōhei Kōno on August 4, 1993, so-called "Kono Statement". It must be underlined that the position of the Japanese government with regard to its involvement in the comfort women system has always been controversial. Official apologies were usually followed by assertions which contradict the previous remorse statement. Prime Minister Abe, for example, announced in 2015 that there was no evidence of forced mobilization of women, Korea Joon Gang Daily, "Abe denies forcing of sex slaves again" (19 January 2016), available at: http://koreajoongangdaily.joins.com/news/article/Article.aspx?aid=3014142 [21 February 2021].

${ }^{795}$ See Coomaraswamy, Radhika, Report on the mission to the Democratic People Republic of Korea ...paras 22 SS.

${ }^{796}$ Many Articles of the Convention deal with the traffic in women. For the official text of the Convention, see https://treaties.un.org/doc/Treaties/1920/09/19200907\%2006-00\%20AM/Ch VII 8p.pdf

${ }^{797}$ Article 2 calls for the States «to take the necessary steps» to find out and persecute people involved in children trafficking. Article 3 states that Parties to the Convention commit themselves «to secure punishment» in case of attempts or preparatory acts to the commission of crimes of prostitution. In addition, Article 4 requires the States parties «to take all measures within their power» to extradite people accused of sex trafficking. At the same time, Article 7 requires the States to adopt all legislative and administrative measures to control trafficking in women and children.
} 
the creation of safe areas for women trafficking. ${ }^{798}$ In that sense, it has been argued that the reservation of the government of Japan should be considered void because contrary to the object and purpose of the treaty. ${ }^{799}$ However, this conclusion does not seem sufficiently convincing for two reasons. First, the provision specifically provides for the possibility of making such a reservation, so it appears difficult to accept the idea that the reservation made by Japan over its past colonies could be considered contrary to the object and purpose of the Convention. Second, at that time, no States objected to the Japanese reservation.

The "comfort women" system also constituted "forced labour". This, in itself, should be sufficient to regard that system as being unlawful as contrary to the obligations stemming from the 1930 International Labour Organisation (ILO) Convention Concerning Forced Labour ${ }^{800}$, ratified in 1932 by Japan. Indeed, the ILO Committee of Experts stated in a Report of 1996 that Article 2(2) of this Convention, which permits compulsory military services, cannot be applied to the "comfort women" system because it was not a work of "purely military character". The ILO Committee also found the inapplicability of the exception under Article 2(d), which allows forced labour in case of emergency, because the "comfort women" system could not find its justification on circumstances that would have endangered "the existence or the well-being of the whole or a part of the population". 801

Moreover, it is generally accepted that at the time the "comfort system" was established, customary international law prohibited slavery and forced labour. The 1926 Slavery Convention is considered declaratory of customary international law. Women forced to provide sexual services in comfort stations were military sexual slaves. ${ }^{802}$ Although Japan did not ratify the 1926 Slavery Convention, it violated the customary international law prohibiting the slave

\footnotetext{
798 Dolgopol, Ustinia and Snehal Paranjape, Comfort Women: An unfinished ordeal. Report of a mission...pp. 157-158.

${ }^{799}$ Article 19 (c), the Vienna Convention on the Law of Treaties of 1969.

${ }^{800}$ Article 2 (1) "For the purposes of this Convention the term forced or compulsory labour shall mean all work or service which is exacted from any person under the menace of any penalty and for which the said person has not offered himself voluntarily".

${ }^{801}$ Report of the Commission of Experts on the application of Conventions and Recommendations, Int'l Lab. Conference, $83^{\text {rd }}$ Session, Report III (Part 4 A), Convention 29 on Japan, Int'l Lab. Organisation (1996).

${ }^{802}$ Article 1 of the 1926 Slavery Convention defines slavery as "the status or condition of a person over whom any or all of the powers attaching to the right of ownership are exercised". The situation of comfort women can easily be subsumed in the legal category of sexual slavery if we consider the indicia identified by the ICTY in Kunarak case: 1) involuntary procurement, 2) treatment as disposable property, 3) restriction of fundamental rights and basic liberties, 4) absence of consent or of conditions under which consent is possible, 5) forced labor, and 6) discriminatory treatment. Prosecutor v. Kunarac, Nos. IT-96-23-T \& IT-96-23/1- T, Judgment (Feb. 22, 2001). However, ... underlines the relevance of the control of sexuality as a criterium which itself constitutes an indicium of enslavement. See Argibay, Carmen M., "Sexual Slavery And The 'Comfort Women' Of World War II",...pp. 11-12.
} 
trade and the practice of slavery. The customary nature of the prohibition of slavery is confirmed by the existence of the 1910 International Convention for the Suppression of White Slavery ${ }^{803}$ and the 1933 International Convention for the suppression of the Traffic in Women of Full Age.

Finally, some scholars argued that, under customary international law, the prohibition of rape in war pre-dates the World War II. ${ }^{804}$ In particular, reference is made to Article 44 of the Lieber Code of 1863, providing for the customary laws of war of the US Army, which stated:

All wanton violence committed against persons in the invaded country, all destruction of property not commanded by the authorized officer, all robbery, all pillage or sacking, even after taking place by main force, all rape, wounding, maiming, or killing of such inhabitants, are prohibited under the penalty of death, or such other severe punishment as may seem adequate for the gravity of the offence.

Despite its domestic legal nature, the Lieber Code had a relevant influence on the subsequent practice of the States and it paved the way for the drawing up of the 1907 Hague Convention ${ }^{805}$ Respecting the Laws and Customs of War on Lands. ${ }^{806}$

By 1911, Japan was also bound by the 1907 Hague Convention IV respecting the Laws and Customs of War on Land and its annex: Regulations concerning the Laws and Customs of War on Land (therein 1907 Hague Convention IV). According to Article 2 of the Convention, its provisions are applicable only if all belligerents are parties to the Convention. Since this criterion was not fulfilled during the World War II, the Convention is not applicable as such. However, the 1907 Hague Convention IV has been recognized as declaratory of customary international law. The specific rule stating the respect of family honour and rights, Article 46 of its Annex of Regulations, is interpreted as to include the right of women not to be subjected to rape, enforced prostitution and other humiliating practices. ${ }^{807}$ However, the 1907 Hague

\footnotetext{
${ }^{803}$ International Convention for the suppression of the white slave traffic, Article 1: "Whoever, in order to gratify the passions of another person, has procured, enticed, or led away, even with her consent, a woman or girl under age, for immoral purposes, shall be punished, notwithstanding that the various acts constituting the offence may have been committed in different countries". Article 2: "Whoever, in order to gratify the passions of another person, has, by fraud, or by means of violence, threats, abuse of authority, or any other method of compulsion, procured, enticed, or led away a woman or girl over age, for immoral purposes, shall also be punished, notwithstanding that the various acts constituting the offence may have been committed in different countries". ${ }^{804}$ See Eriksson, Maria, Defining Rape: Emerging Obligations for States Under International Law, Brill, Nijhoff, 2011, p. 344; Parker, Karen and Chew, Jennifer F., "Compensation for Japan's World War II War Rape Victims",...p. 513.

805 Therein, 1907 Hague Convention IV.

806 Doswald-Beck, Louise and Vité, Sylvaine, "International Humanitarian Law and Human Rights Law", International Review of the Red Cross, No. 293 (March-April 1993), 94.

807 The idea according to which the reference to "religious convictions" sustains an interpretation of the Hague Conventions as prohibiting rape, torture, and forced prostitution during war would be supported by the fact that
} 
Convention IV only applies to occupied or enemy territories. Since the Korean peninsula was a colony of Japan at that time, Korean peoples had the same nationality of the colonial power. As a result, Korean "comfort women" did not come within the scope of that provision. However, if the scope of application of treaty rules were subjected to this limitation, it can be argued that the same limitation did not apply to the corresponding customary rules. In this respect, the International Military Tribunal for the Far East recognized that the Convention was "good evidence of the customary law of nations to be considered by the tribunal, along with all other available evidence, in determining the customary law to be applied in any given situation" ${ }^{808}$ This statement may be regarded as providing a legal argument for considering Article 46 applicable to "comfort women". 809

In sum, a number of treaties and customary law rules prohibiting slavery, including sexual slavery, forced labour and rape, were in force when the "comfort women" system was operative. On this basis, Japan could be deemed responsible under international law for the internationally wrongful acts of sexual slavery. In this sense, it is noteworthy that individuals criminally responsible of the "comfort women" system were not brought to justice and prosecuted by the Allied before the International Military Tribunal for the Far East. From a gender-oriented perspective, this only strengthens the view that the lack for criminal prosecutions was not due to the absence of international norms prohibiting sexual slavery, but to a consideration of crimes against women as second-rate crimes.

\subsection{Issues surrounding the question of reparation for "comfort women"}

\footnotetext{
every major religion condemns rape. See Parker, Karen and Chew, Jennifer F., “Compensation for Japan's World War II War Rape Victims",,...p. 515.

${ }^{808}$ Minear, Richard H., Victor's Justice: The Tokyo War Crimes Trial, Princeton University Press, Princeton-New Jersey, 1971, p. 50.

809 According to some legal scholars, Article 27 of the 1949 Geneva Convention Relative to the Protection of Civilian Persons in Time of War is declaratory of customary international law. The provision states that "women shall be especially protected against any attack on their honour, in particular against rape, enforced prostitution, or any form of indecent assault". T. Murphy, Sanctions and Enforcement of Humanitarian Law of the Fourth Geneva Convention of 1949 and Geneva Protocol I of 1977, (1984), p. 5. For a detailed analysis of Article 27, 1949 Geneva Convention Relative to the Protection of Civilian Persons in Time of War see Viseur Sellers, Patricia and Rosenthal, Indira, "Rape and Other Sexual Violence", in A. Clapham, Andrew, Gaeta, Paola, Sassoli, Marco (eds.), 1949 Geneva Conventions. A Commentary, Oxford University Press, 2015, pp. 343-368.
} 
The commission of an internationally wrongful act involves an obligation to make reparations for the injuries inflicted. ${ }^{810}$ The Japanese Government has denied "comfort women" claims for legal compensation on three grounds. Firstly, it argued that individual victims have no right to such compensation under international law. Alternatively, the Government of Japan also claimed that any individual right that these women may have had for reparation was fully satisfied by peace treaties and international agreements between Japan and other Asian States following the end of the World War II. Finally, the Japanese Government claimed that any civil or criminal cases concerning the "comfort women" system would now be time-barred by applicable statute of limitations provisions. ${ }^{811}$ This last point will not be addressed because it would be impossible to exhaustively deal with it here.

\subsubsection{The existence of an individual right to reparation at the time of World War II}

The first objection opposed by the Government of Japan is that individuals have no right to reparation under international law and that any form of reparation for such breaches applies only in the relations between States. This raises the question whether claims for reparation in case of violations of IL may only be made by States according to the classical view that only States have a right to reparation, or, conversely, whether current international law also provides for an individual right to reparation. The intertemporal law problem arises here again, namely whether an individual right to reparation (even if assumed) already existed at the time when the crimes against "comfort women" had been committed.

As it has been analysed in the previous Chapter, two different views have been advanced in this regard. On the one hand, some scholars sustain that elements evidencing the existence of a rule providing for an individual right to reparation at the relevant time - in particular the PCIJ's 1928 judgement in the Chorzow Factory case, as well as Article 3 of the 1907 Hague Convention and Article 91 of Additional Protocol I - may be traced back before World War II. In particular, the existence of an individual right to reparation under Article 3 of the 1907 Hague Convention has been argued by distinguished international lawyers with regard to the claims of some Allied prisoners of war against the Government of Japan before Japanese courts

\footnotetext{
${ }^{810}$ Article 31, Draft Articles on Responsibility of State for Internationally Wrongful Acts, with Commentaries, 2001.

${ }^{811}$ Dolgopol, Ustinia and Snehal Paranjape, Comfort Women: An unfinished ordeal. Report of a mission...pp. 141-147.
} 
in the $1990 \mathrm{~s} .{ }^{812}$ On the other hand, the majority of international law scholars argue that these arguments are not sufficient for recognizing the right of individuals to directly seek redress from the responsible State. This second views seems to be confirmed by the relevant case law of the States of the case at stake, Japan and the Republic of Korea.

So far, the attitude of Japanese courts, when confronted to this issue, was to reject the "comfort women" claims, on the assumption that individuals are not subjects of international law, so they have no right to obtain governmental redress under international law. ${ }^{813}$ One of the few judgments in which a Japanese court partially accepted Korean "comfort women" claims is the one rendered in the Shimonoseki Branch case. ${ }^{814}$ The court ruled that the government's failure to enact legislation to enable individual reparations was unlawful under the State Compensation Law. However, it is important to note that the ruling was based on domestic tort law, not on international law. Judges also ordered the Government of Japan to pay a symbolic sum of 300,000 yen (USD 2,800) to each of the three plaintiffs as compensation for moral injury. The judgment, delivered by the Yamaguchi District Court on 27 April 1998, was appealed by the women plaintiff to the Hiroshima High Court claiming that the 1998 ruling was an insult to women's suffering and asking for “proper apology and compensation”. The Hiroshima High Court rejected the appeal and overturned the 1998 ruling on 29 March 2001, on the ground that the government's obligation to introduce a law on compensation was not so clearly stated by Japanese Constitution. The Japan's Supreme Court, appealed by two of the former "comfort women" claiming the unconstitutionality of the 2001 Hiroshima High Court's ruling, rejected the appeal and nullified the 1998 ruling on 25 March 2003, in so confirming the 2001 Hiroshima High Court's ruling and dismissing the only Japanese court ruling that had ordered Japan, even if on the basis of domestic tort law, to directly compensate former "comfort women". 815

\footnotetext{
${ }^{812}$ Hisakazu Fujita, Isomi Suzuki and Kantaro Nagao (eds.), War and Rights of Individuals: Renaissance of Individual Compensation, Nippon Hyoron-sha Co., Tokyo, 1999, p. 39 ss. The text contains the expert opinions by Frits Kalshoven, Eric David and Christopher Greenwood.

813 Japanese jurisprudence maintained this line of reasoning also in other judgments related to compensation for war injuries. In particular, in a case concerning 198 Chinese plaintiffs asking Japan to pay damages for the deaths or the injuries caused by bombings conducted by the Japanese armed forces between 1938 and 1943, the Tokyo District Court ruled that Article 3 of the Hague Convention does not entitle individuals to claim compensation directly against the injuring State (Tokyo District Court, Judgment, February 25, 2015). An explanation of the ruling can be found in the Japanese Yearbook of International Law, Vol. 59 (2016), pp. 469 ss.

814 The text of the ruling translated in English is available at https://digital.lib.washington.edu/dspacelaw/bitstream/handle/1773.1/826/8PacRimLPolyJ063.pdf? sequence=1 [last visited, 23 February 2021].

${ }^{815}$ For an explanation of all lawsuits filed against the Japanese government before Japanese courts, see Japutra, Kiki Anastasia, "The Interest of States in Accountability for Sexual Violence in Armed Conflict: A Case Study
} 
This approach seems to be in line with what have been said above about the difficulty of accepting the existence of an individual right to reparation. With regard to the intertemporal dimension of that issue, the analysis of the State practice after the World War II appears to support the view held by Japanese courts and Government. Reparations issues for war-related claims by individuals have been usually settled by the practice of lump-sum settlements concluded by the one-time belligerent States, so that it should be recognized that it is "reconfirmed the wisdom behind the classical rules of international law which place peacemaking into the hands of governments and not of individuals". 816

On balance, the position held by Japanese courts seems to rely on a stronger legal basis. Indeed, it is difficult to accept the view that, at the time when the crimes had been committed, a rule of international law recognizing to individual victims a right of reparation already existed. This finds confirmation in the work of the International Law Association. As stated in the 2010 Report on "Reparation for victims of armed conflict", "until most recently, international law did not provide for any right to reparation for victims of armed conflicts". 817 The Report, which is based on a careful examination of State practice, recognizes instead that international law has since undergone a process of change and it now recognizes an individual right to reparation. The Report's conclusions appear highly persuasive. Indeed, if it is true that nowadays the Basic Principles and Guidelines on the Right to a Remedy and Reparation for the Victims of Gross Violations of International Human Rights Law and Grave Violations of International Humanitarian Law - adopted by Resolution of the UN General Assembly the $21^{\text {st }}$ March $2006^{818}$ and providing for a set of norms to respect, ensure respect and implement human rights law and international humanitarian law on the matter of remedies and reparations for individuals - could be considered "legal standards in the area of victims' rights" ${ }^{19}$, this consciousness was not present before and during the World War II. On this ground, the

of Comfort Women of the Second World War", in Bergsmo, Morten and Tianying, Song (eds.) Military SelfInterest in Accountability for Core International Crimes, Torkel Opsahl Academic EPublisher, Brussels, 2015, pp. $189 \mathrm{ss}$.

${ }^{816}$ Dolzer, Rudolf, “The Settlement of War-Related Claims: Does International Law Recognize a Victim's Private Right of Action - Lessons After 1945”, Berkeley Journal of International Law, Vol. 20, No. 1, (2002), 296, p. 340. Thus "the central lesson from the long-belated end of the World War II peacemaking process is that governments must more effectively, promptly and carefully incorporate the legitimate concerns of groups and individuals particularly affected by a war into the intergovernmental process of making peace".

817 International Law Commission, Report Reparation for victims of armed conflict, 2010, p. 2.

$818 \mathrm{~A} / \mathrm{RES} / 60 / 147$.

819 Van Boven, Theo, "Victims' Right to a Remedy and Reparation: the New United Nations Principles and Guidelines", in Ferstman, Carla, Goetz, Marlana and Stephens, Alan (eds.), Reparations for Victims of Genocide, War crimes and Crimes Against Humanity: Systems in Place and Systems in the Making, Brill, Nijhoff, Leiden 2009, p. 32. 
position of the Government of Japan seems to be more persuasive in arguing the non-existence of an individual right to reparation under international law during World War II, and, subsequently, in claiming the applicability of the fundamental principle of intertemporal law to deny the individual right of the victims to obtain compensation for acts deriving from violations committed during such period.

\subsubsection{The 1965 Settlement Agreement between Republic of Korea and Japan}

The second argument used by the Japanese Government and judiciary to deny its obligation to provide reparation is based on the assertion that the State of Japan has already settled and concluded any claim for reparation through the operation of the peace treaties concluded by Japan at the end of the hostilities. The general legal framework at the basis of the Japanese reasoning was Article 14 (b) of the San Francisco Treaty of $1951,{ }^{820}$ which states:

The Allied Powers waive (d) all reparations claims of the Allied Powers, other claims of the Allied Powers and their nationals arising out of any actions taken by Japan and its nationals in the course of the prosecution of the war, and claims of the Allied Powers for direct military costs of occupation. ${ }^{821}$

With respect to the claims of the ROK, the Government of Japan relied on the 1965 Agreement on the Settlement of Problems Concerning Property and Claims and the Economic Cooperation between Republic of Korea and Japan (therein Settlement Agreement). ${ }^{822}$ In particular, Article 2 (1) of the Settlement Agreement states,

The High Contracting Parties confirm that the problems concerning property, rights and interests of the two High Contracting Parties and their peoples (including juridical persons) and the claims between the High Contracting Parties and between their peoples (...) have been settled completely and finally.

\footnotetext{
${ }^{820}$ Soh, Chunghee Sarah, “The Korean 'comfort women': movement for redress”, Asian Survey, Vol. 36, No. 12 (December, 1996), 1226. Japan also used this argument with regards to claims filed by former Chinese comfort victims, moving from the Article 14 (b) of the San Francisco Treaty of 1951. On this ground, Japanese Supreme Court denied compensation in the cases Nishimatsu Construction Co. v. Song Jixiao et al., Supreme Court of Japan (2nd Petty Bench), 27.4.2007, and Ko Hanako et al. v. Japan, Supreme Court of Japan (1st Petty Bench), 2.4.2007. These cases were similar to the Supreme Court decision of $25^{\text {th }}$ December 2003 in the former Philippine Comfort Women Claiming Compensation case, confirming a Tokyo High Court decision of $6^{\text {th }}$ February 2002; and the Supreme Court decision in Taiwanese Former Comfort Women case, issued the $25^{\text {th }}$ February 2005 and affirming a Tokyo High Court decision of $18^{\text {th }}$ March 2005.

821 Treaty of Peace with Japan, Sept. 8, 1951, Art. 2, 3 UST 3169, 136 UNTS 45. Available at: https://treaties.un.org/doc/Publication/UNTS/Volume\%20136/volume-136-I-1832-English.pdf.

822 Some documents also refer to it as "Claims Agreement". For a historical background of the relations between Japan and the island of Korea from the $19^{\text {th }}$ century until the Agreement between Japan and the Republic of Korea in the aftermath of the Second World War, see Oda, Shigeru, "The Normalization of Relations between Japan and the Republic of Korea”, American Journal of International Law, Vol. 61, No. 1 (1967) 35-56.
} 
The position of Japan on this issue is not entirely persuasive. At least four arguments could be invoked against the Japanese position.

\subsubsection{The historical argument}

Firstly, the crimes against "comfort women" were unknown at the time when the 1965 Settlement Agreement was signed. ${ }^{823}$ The Special Rapporteur on Systematic rape, sexual slavery and slavery-like practices during armed conflict, Ms. Gay J. McDougall, in her 1998 Final Report, asserted that the Japanese's argument is unpersuasive in that the

silence on this point during the period in which peace and reparations agreements between Japan and other Asian Governments were being negotiated following the end of the war must, as a matter of law and justice, preclude Japan from relying today on these peace treaties to extinguish liability in these cases. ${ }^{824}$

The Japanese acknowledgement of its military Army involvement in creating and implementing the "comfort women" system should be understood as a new factual situation which is not considered by the 1965 Settlement Agreement. ${ }^{825}$ In this sense, it could be said that the "comfort women" claim should be considered as falling outside the scope of the 1965 Settlement Agreement.

\subsubsection{The interpretative argument}

Secondly, the reasoning of Japan does not appear entirely convincing also because the aforementioned Agreement was intended to solve economic and civil claims and liabilities between the two States and not to address human rights violations. ${ }^{826}$ Both the Korean

\footnotetext{
${ }^{823}$ Professor Yoshimi explained that the comfort women issue was not discussed during the treaty negotiations leading to the Korean Treaty. Yoshimi, Yoshiaki, "Historical Understandings on the 'Military Comfort women' Issue", speech to the 1992 Public Hearing concerning the Post-War Compensation of Japan, reprinted in Executive Committee International Public Hearing, War Victimisation and Japan, Toho Shuppansha, Tokyo, (1993), 81, p. 87.

${ }^{824}$ McDougall, Gay J., U.N. Special rapporteur contemporary forms of slavery, Final Report on systematic rape, sexual slavery and slave-like practices during armed conflict, E/CN.4/Sub.2/1998/13, 22 June 1998, Appendix, An Analysis of The Legal Liability of The Government of Japan for "Comfort Women Stations" Established During The Second World War, para 68.

${ }^{825} \mathrm{Yu}$, Tong, "Reparation for Former Comfort Women of World War II", Harvard International Law Journal, Vol. 36, No. 2 (1995), 528-540, p. 535. The author refers to the customary law doctrine of rebus sic stantibus, pursuant to which the obligations of the parties under the agreement should be considered to the extent of the state of facts existing at the time the agreement became effective.

${ }^{826}$ Oda, Shigeru, "The Normalization of Relations between Japan and the Republic of Korea", The American Journal of International Law...pp. 46-47. Conversely, Boling sustains the idea that the post war Agreement between Japan and the Republic of Korea effectively precludes a cause of action against the Japanese government because Article 2 specifically mentions the rights of nationals. The author also supports his statement making a comparison between the Korean-Japanese Agreement and the Philippine-Japanese Agreement, arguing that only the second one could, eventually, permit Philippine claims to success because it lacks the language of finality with
} 
Government and courts share this view. ${ }^{827}$ The Korean Government's position is the one expressed in the "Public-Private Joint Committee on the Follow-up Measures After the Public Release of ROK-Japan Negotiations Documents" ${ }^{828}$, that gave its official opinion of 26 August 2005:

the Claims Agreement was not intended to make a claim for compensation for Japan's colonial rule over Korea, but rather to resolve the financial and civil debts/credit relationship between Korea and Japan pursuant to Article 4 of the San Francisco Treaty; that the inhumane and wrongful acts, including the Japanese military comfort women issue, committed by Japanese state authorities should not be deemed to be settled by the Claims Agreement. ${ }^{829}$

The same conclusion has been achieved by the Supreme Court of South Korea ${ }^{830}$ in its 2012 decision in the case Compensation for Forced Labor, ${ }^{831}$ concerning some Korean victims of forced labor - who had to work for Japanese munitions companies for the production of weapons during the colonial era - that filed a suit against the New Nippon Steel Corporation. ${ }^{832}$ The Court held that the compensation claims of the plaintiffs were not subject to the 1965 Settlement Agreement in that the compensation claims for forced labour originated from the illegality of the Japanese colonization, while the peace agreement between the two States concerned only the financial relationship between Korea and Japan. Thus,

respect to individual claims. Boling, David, "Mass Rape, Enforced Prostitution, and the Japanese Imperial Army: Japan Eschews International Legal Responsibility?”, ...pp. 564-566.

${ }^{827}$ For an overview of the Korean legal system and some of the most useful resources of web-based databases for research on Korean law, see Hyeon-Cheol, Kim and Inyoung, Cho, "South Korean Law Research on the Internet", New York University School of Law, New York, (2017), available at: https://www.nyulawglobal.org/globalex/South_Korea.html [last visited, 03 March, 2021].

${ }_{828}$ The "Public-Private Joint Committee on Follow-up Measures After the Public Release of ROK-Japan Negotiations Documents" was the governmental result of the persistent requests to disclosure documents related to the negotiations over the Claims Agreement as well as the institutional response to the 2004 judgment of the Seoul Administrative Court ruling supporting the disclosure. The ruling at stake is Seoul Administrative Court, 2002 Gu-Hap 33943, Decided on Feb. 13, 2004. See Lee, Seokwoo and Seryon, Lee, "Yeo Woon Taek v. New Nippon Steel Corporation”, American Journal of International Law, Vol. 113, Issue 3, (2019), 592.

${ }^{829}$ References to the content of the Committee's statement may be found in Supreme Court of Korea, 2013 Da 61381, Decided on Oct. 30, 2018 (S. Kor.), p. 9-10. The English translation of the judgment is available at Korean Journal of International \& Comparative Law, Vol 7, Issue 88 (2019).

830 The Supreme Court of South Korea has final appellate jurisdiction over all cases.

831 Supreme Court of South Korea, 2009 Da 68620, decided on May 24, 2012. The English translation of the ruling is available at: Korean Journal of International \& Comparative Law, Vol 2, Issue 2, (2014), (editorially noted and translated by Seokwoo Lee). For an analysis of the Court ruling and a discussion on the "judicial activism" of the Court in this case, see Lee, Seokwoo, and Youngkwan, Cho, "Historical Issues between Korea and Japan and Judicial Activism: Focus on the Recent Supreme Court Decision on Japanese Forced Labor", Korean Journal of International and Comparative Law, Vol. 2, No. 1, (2014) 5-26.

${ }^{832}$ The plaintiffs had previously brought a lawsuit against the New Nippon Steel Corporation in Japan to seek compensation for damages. However, after the entire court proceedings, the Supreme Court of Japan finally brought the case to an end and dismissed it in 2003. On February 28, 2005, the plaintiffs filed a suit before the Seoul Central District Court in Korea against the New Nippon Steel Corporation. However, both the Seoul District Court and the Seoul High Court, following the reasoning of the Japanese courts, dismissed the case on the grounds of res judicata. Thus, the plaintiffs decided to appealed to the Supreme Court of South Korea. 
it is difficult to conclude that the right to compensation for crimes against humanity where state power was directly involved in, or crimes directly connected to colonization, was included in the scope of application of the Claims Agreement. Therefore, the individual rights to claim compensation for forced labor were not extinguished by the Claims Agreement, and neither were Korea's rights to diplomatic protection of its nationals. ${ }^{833}$

The case was thus remanded to the Seoul High Court, ${ }^{834}$ which, in upholding the 2012 Supreme Court of South Korea's decision, ordered New Nippon Steel Corporation to compensate the former forced labors with a payment of 100 million won per each. ${ }^{835}$ The defendant appealed the Seoul High Court's decision to the Supreme Court of South Korea, which finally ruled on the case Yeo Woon Taek v. New Nippon Steel Corporation on October 30, 2018.836 After applying the general principles of treaty interpretation set forth in the Vienna Convention on the law of treaties and extensively analyzing the preparatory work and the relevant circumstances throughout the conclusion of the Settlement Agreement, the Supreme Court confirmed once again the position of the Korean judiciary on the matter. The Supreme Court held that the Settlement Agreement was a postwar reparations settlement for matters concerning financial, civil debts and credit relations between Korea and Japan and not for claims for compensation for damages derived from inhuman acts committed during the unlawful Japanese colonial regime in Korea. ${ }^{837}$

The reasoning of the Korean courts in the case concerning the Korean victims of forced labor may be also applied to the "comfort women" case against the Japanese argument according to which individual claims for reparation, including claims by "comfort women", must be considered within the scope of the Settlement Agreement and thus already settled by the peace agreement. Therefore, it is here suggested that Article 2(1) of the Settlement Agreement was not drafted to cover reparation claims for the harms caused by Japanese military sexual slavery.

It should be noted that the "judicial activism" over the interpretation of the scope of the Settlement Agreement was not counterbalanced by an effort to settle the dispute on the matter.

\footnotetext{
833 Ibid. p. 104.

${ }^{834}$ The questions examined by the High Court concerned: 1. whether the Old Nippon Steel New, responsible of the forced labour complaint by the plaintiffs, has the same legal personality of the New Nippon Steel Corporation, born from the merger and annexation of the previous one; 2 . whether the compensation claims of the forced labours were within the scope of the Claims Agreement; and 3. whether the compensation claims had expired under the statute of limitations.

${ }^{835}$ Seoul High Court, Case $2012 \mathrm{Na}$ 44947, Judgment, rendered on July 10, 2013.

836 Supreme Court of South Korea, Case 2013 Da 61381, Final Judgment, decided on October 30, 2018. The English translation of the ruling is available at: Korean Journal of International \& Comparative Law, Vol. 7 , (2019), (editorially noted and translated by Seokwoo Lee and Seryon Lee).

${ }^{837}$ For an analysis of the ruling, see Lee, Seokwoo, and Seryon Lee, "Yeo Woon Taek v. New Nippon Steel Corporation.” American Journal of International Law, Vol. 113, Issue 3, (2019) 592-599.
} 
One could ask whether the two States did their best to solve the interpretative dispute on Article 2 (1) of the Settlement Agreement using the channels provided for by the Agreement. In particular, given the failure of diplomatic efforts for a common interpretation of the treaty, the Parties could have settled the interpretative dispute through an ad hoc arbitration board under Article 3 of the Settlement Agreement. ${ }^{838}$

The Korean governmental "inertia" to solve the dispute with Japan regarding the interpretation of Article 2(1) of the Settlement Agreement has been the specific object of the 2011 decision of the Constitutional Court ${ }^{839}$ of Korea in the case Challenge against the Act of Omission Involving Article 3 of "Agreement on the Settlement of Problem concerning Property and Claims and the Economic Cooperation between the Republic of Korea and Japan". ${ }^{840}$ The Court was questioned by some former "comfort women" over the constitutionality of the Korea's omission to act to resolve, according to Article 3 of the Settlement Agreement, the dispute with Japan over the interpretation of whether the former "comfort women's" reparation claims against Japan could be considered extinguished under Article 2(1) of the Settlement Agreement. The Court, in confirming the existence of the interpretative dispute between Japan and South Korea over Article 2(1), has stated that the Korean Ministry of Foreign Affairs is in

\footnotetext{
838 "It is agreed that any dispute between the two States concerning the interpretation and implementation of the Agreement shall be settled, firstly, through diplomatic channels, otherwise shall be referred for decision to $a$ hoc arbitration board composed of three arbitrators: one to be appointed by each country party, and the third arbitrator chosen by the two arbitrators so selected or to be appointed by the government of a third country agreed upon by the two arbitrators". Article 3, Agreement on the settlement of problems concerning property and claims and on economic co-operation (with Protocols, exchanges of notes and agreed minutes). Signed at Tokyo, on 22 June 1965.

Along with McDougall, the question to submit to the ad hoc arbitration board could have been, “'“Whether the claims of the victims of 'military sexual slavery' perpetrated by the military of Japan during World War II have been extinguished or satisfied by operation of the Agreement on the Settlement of Problems Concerning Property and Claims and the Economic Cooperation between the Republic of Korea and Japan (1965)." McDougall, Gay J., "Addressing State Responsibility for the Crime of Military Sexual Slavery during the Second World War: Further Attempts for Justice for the "Comfort Women"', Korean Journal of International and Comparative Law, Vol. 1, No. 2, (2013) 137-165.

${ }^{839}$ The Korean judicial system is based on the three instances trial system, which is composed of district courts, the high courts and the Supreme Court. The Constitutional Court, established in 1988, is the guardian of the constitutional order. It protects the people's fundamental rights through impartial interpretations of the Constitution, and fulfils its role of safeguarding constitutional ideologies and values.

In accordance with Article 111 Section 1 of the Constitution, the Constitutional Court has jurisdiction over five areas: a) judicial review of statutes requested by ordinary courts, b) impeachment, c) dissolution of a political party, d) competence dispute between state agencies and local governments, and e) constitutional complaints (seeking remedy against the exercise or non-exercise of the public power or challenging the constitutionality of a statute as an appeal against an ordinary court's decision).

${ }^{840}$ Constitutional Court of Korea, 23-2(A) KCCR 366, 2006 Hun-Ma 788, August 30, 2011. Annual 2012, Decisions of the Constitutional Court Korea (2011), online English version available at:

https://library.ccourt.go.kr/site/conlaw/download/case publications/decision(2011).pdf [last visited, 23 February 2021].
} 
violation of the Constitution ${ }^{841}$ for its failure to solve the dispute according to Article 3 of the 1965 Settlement Agreement. Since such State's inaction is not just related to the block of an individual compensation claim, but also "directly associated with the infringement of fundamental dignity and value of human beings", 842 the respondent [ROK] cannot discretionary decide not to "take action and cannot be deemed to have fulfilled its duty of action to take dispute settlement procedures under Article 3 of the Agreement". 843 Thus, the Constitutional Court of Korea identified not only a general governmental duty to act through diplomatic channels in cases that involve constitutional rights of individuals, but also a specific duty to refer a dispute to an arbitration board according to Article 3(2) of the Settlements Agreement, in so finding insufficient the diplomatic channels pursued until then by the Korean government. However, opposite conclusions were reached by the same Court in its 2019 decision in the case Omission of Dispute Settlement under Article III of the Agreement on the Settlement of Problems Concerning Property and Claims and on the Economic Cooperation between the Republic of Korea and Japan ${ }^{844}$ Called to pronounce on the same matter by some former forced labour victims in Sakhalin during the Japanese colonial rule, this time the Court dismissed the case on the ground that Article 3 of the Settlement Agreement cannot be interpreted as containing "the 'duty' to seek diplomatic settlement procedures or the 'duty' to seek arbitration proceedings when a dispute cannot be settled diplomatically". ${ }^{845}$

\subsubsection{The argument of the limited scope of the waiver clause}

Apart from the interpretative issue, Article 2(1) of the Settlement Agreement raises also a more general legal question: whether a State could waive its right to reparation for crimes committed against its civilians. Japan and South Korea's positions are split also on the issue of the waiver of the right to reparation. First of all, it must be underlined that, in principle, any waiver contained in a peace agreement must be interpreted in strict sense. ${ }^{846}$ As Anzilotti put it,

\footnotetext{
${ }^{841}$ The Court specifically recalled the Preamble and Article 2 Section 2 and Article 10 of the Constitution of the Republic of Korea.

${ }^{842}$ Ibid. p. 150

${ }^{843}$ Ibid. p. 152.

844 Constitutional Court of Korea, 2012 Hun-Ma939, December 27, 2019. Annual 2020 Decisions of the Constitutional Court Korea (2019), online English version available at:

https://library.ccourt.go.kr/site/conlaw/download/case publications/DECISIONS 2019.pdf [last visited, 23 February 2021].

845 Ibid, p. 87.

${ }^{846}$ Campbell (United Kingdom v. Portugal), Award, 10 June 1931:

Attendu qu'il est de principe, admis par le droit de tous les pays, que les renonciations ne se présument jamais et que, constituant des abandons d'un droit, d'une faculté ou même d'une espérance, sont toujours de stricte interprétation;
} 
la rinuncia è, sì, contenuta in un atto bilaterale, ma costituisce fondamentalmente un atto unilaterale consistente nel "volontario abbandono di un diritto". Anzitutto [...] si richiede la volontà di abbandonare: non basta quindi la semplice inerzia, il non esercizio del diritto, perché tutto ciò non implica necessariamente la volontà di abbandono, mentre poi, [...] il solo decorso del tempo non ha l'efficacia di estinguere i diritti. In secondo luogo, la rinuncia, come non si presume, così si deve ammettere soltanto nei precisi limiti in cui risulta effettivamente voluta, $\mathrm{e}$, in caso di dubbio, piuttosto nei limiti più ristretti che di quelli più ampi consentiti dall'interpretazione: quindi, per esempio, la rinuncia ad esercitare alcune facoltà che fanno parte di un determinato regime giuridico, non importa anche alle altre, se queste possono sussistere indipendentemente da quelle a cui si è rinunciato; fra la rinuncia allo esercizio temporaneo di un diritto e la rinuncia al diritto stesso, devesi ritenere piuttosto la prima cosa che la seconda; una rinuncia condizionata a certi vantaggi, è, nel dubbio, da ritenersi voluta a preferenza di una rinuncia pura e semplice; e via dicendo. ${ }^{847}$

Japan's position with regard to the scope of the 1965 Settlement Agreement is clear. First, the eventual individual right to claim reparations for injuries caused by Japanese Army during WWII would fall within the scope of the application of the Settlement Agreement. Second, and consequently, the peace treaty would encompass not only the right to diplomatic protection owned by the State, but also the individual right to reparation, that is thus fully extinguished. ${ }^{848}$ However, it is interesting to note that the Japanese government assumed the contrary position when its own nationals sued post-war reparations claims. In these cases, Japan argued that the

Attendu qu'en admettant même qu'une renonciation puisse être tacite, encore ne peut-elle s'induire que de faits non susceptibles d'une autre interprétation dans les circonstances de l'affaire ;

Attendu que la portée d'une renonciation doit être restreinte à l'objet précis que la renonciation a eu en vue (para. 1156).

847 "The waiver is, yes, contained in a bilateral act, but it is fundamentally a unilateral act consisting in the "voluntary abandonment of a right". First [...] the will to abandon is required: therefore simple inertia, the nonexercise of the right, is not enough, because all this does not necessarily implies the will of abandonment, while then, $[\ldots]$ the mere course of time does not have the effectiveness to extinguish the rights. Secondly, the waiver, as it is not supposed, so it must be admitted only to the precise extent to which it is actually intended, and, in case of doubt, rather within the narrower limits than the wider limits allowed by the interpretation: therefore, for example, the waiver of certain powers that are part of a given legal regime, does not include also the other powers, if these latter ones may exist independently of those waived; between the waiver of the temporary exercise of a right and the waiver of that right, one must consider the first thing rather than the second; a conditional waiver of certain advantages, is, in doubt, to be considered preferred to a pure and simple renunciation; and so on". (English translation by the author) Anzilotti, Dionisio, Corso di diritto internazionale, Volume primo, Introduzione Teorie generali, IV edizione, Ceda, Padova, 1955, pp. 296-297.

${ }^{848}$ See Nishimatsu Construction Co. v. Song Jixiao et al., Supreme Court of Japan (2nd Petty Bench), 27.4.2007, and Ko Hanako et al. v. Japan, Supreme Court of Japan (1st Petty Bench), 02.04.2007. Both cases - the first one brought by kidnapped Chinese victims of forced labor for the Nishimatsu Company close to Hiroshima, and the second one brought by kidnapped Chinese victims former comfort women in Shanxi Province, in northern China - were dismissed by the two different panels of the Japanese Supreme Court on the ground of the same legal reasoning. The Court held that the 1952 Peace agreement with the Republic of China included individual claims, and that the terms of the Japan-China Joint Communique of 1972, as basically part of the Framework of the San Francisco Peace Treaty, clearly waives all claims deriving from the war, including individual claims for compensation. For an analysis of the two cases, see Levin, Mark A., "Comfort Women: Case Comment: Nishimatsu Construction Co. v. Song Jixiao Et Al., Supreme Court of Japan (2d Petty Bench), April 27, 2007, and Ko Hanako Et Al. V. Japan, Supreme Court of Japan (1st Petty Bench), April 27, 2007 (January 1, 2008)”, American Journal of International Law, Vol. 102, No. 1, (2008), 148. 
waiver clause included in peace agreements was only a waiver of diplomatic protection that did not preclude individual right to reparation. ${ }^{849}$

For its part, the Korean judiciary stated that the renunciation clause included in a peace treaty cannot waive an individual right of its citizens to make a claim for compensation. In the above 2012 decision in the case Compensation for Forced Labor, the Korean Supreme Court argued that a State may abandon the right to diplomatic protection through a waiver clause contained in a treaty, but it cannot extinguish in the same way the individual right to claims without the consent of its nationals. For this reason,

Even if it were to be permissible under international law for a state to extinguish by treaty the individual rights of its nationals to make claims, it would not be possible to conclude that a treaty can extinguish not only a state's right to diplomatic protection but also the people's individual rights without clear provisions in the treaty, considering that a state and its peoples are independent legal subjects. The Claims Agreement does not have sufficient evidence to show that there was a consensus of the two governments concerning the extinction of individual rights to claims; and the fact that immediately following the conclusion of the Claims Agreement, Japan domestically enacted a Property Rights Measures Law regarding the rights of Korean peoples against Japan and its peoples, is premised on the fact that the Claims Agreement alone does not extinguish the individual rights of the Korean people to make claims. Taking these points into consideration, even if the claims of the above Plaintiffs were to be included within the scope of application of the Claims Agreement, the individual rights themselves cannot be seen as being automatically extinguished by the Claims Agreement alone. ${ }^{850}$

According to some scholars, evolutionary trends in international law would limit the power of the State to waive reparation claims arising from war crimes and crimes against humanity, ${ }^{851}$ especially when the waiver is contained in lump-sum agreements. ${ }^{852}$ In support of this view, reference is being made to the common provision of the four Geneva Conventions of 1949, Article 51 of the GC I, ${ }^{853}$ which establishes that no State is authorized "to absolve itself or any other High Contracting Party of any liability incurred by itself or by another High Contracting Party" in case of grave violations of the norms of the Conventions. The interpretation of the International Committee of the Red Cross seems to confirm that this common provision is

\footnotetext{
${ }^{849}$ Victims of atomic bomb v. Japan, Tokyo District Court, 7 December 1963. For other examples, see Bong, Shin Hae, "Compensation for Victims of Wartime Atrocities. Recent Developments in Japan's Case Law", Journal of International Criminal Justice, Vol. 3, No. 1, (2005) 187-206, p. 201.

${ }^{850}$ Supreme Court of South Korea, 2009 Da 68620, decided on May 24, 2012, p. 105.

${ }^{851}$ On the matter see Bufalini, Alessandro, "On the Power of the State to Waive Reparation Claims Arising from War Crimes and Crimes Against Humanity", Zeitschrift für ausländisches öffentliches Recht und Völkerrecht, Vol. 77, (2017) 447-470.

${ }^{852}$ Sassòli, Marco, "State Responsibility for Violations of International Humanitarian Law", International Review of the Red Cross, Vol. 84, No. 846, (2002), 401-434, p. 419.

${ }^{853}$ Geneva Convention I, Art. 51; GC II, Art. 52; GC III, Art. 131; GC IV, Art. 148.
} 
aimed at avoiding the possibility that a State responsible for international crimes absolves itself from its responsibility through the use of an armistice or a peace agreement. ${ }^{854}$

Traces of this trend may be also found in the words of some international judges. In his dissenting opinion to the ICJ Judgment in the case Jurisdictional Immunities, Judge Cançado Trindade completely subverted the Kelsenian approach ${ }^{855}$ stating that "a State can waive only claims on its own behalf, but not claims on behalf of human beings pertaining to their own rights, as victims of grave violations of international law". 856

One could therefore argue that the waiver clause contained in the 1965 Settlement Agreement between Japan and ROK must be interpreted in accordance with this general obligation not to absolve a State which has committed grave breaches of humanitarian law from its responsibility, including from its obligation to make reparation. This would reinforce the view that the waiver clause contained in Article 2(1) of the Settlement Agreement does not cover questions of reparation for serious breaches of humanitarian law committed against the "comfort women" by the Japanese Army.

A different line of reasoning was followed by the Women's International War Crimes Tribunal 2000, the peoples' tribunal established in Tokyo to consider the Japanese military activity in the Asia Pacific region in the 1930s and 1940s. ${ }^{857}$ This Tribunal stated that "the Peace Treaties [were] not applicable in the current context as states cannot agree by treaty to waive the liability of another state for crimes against humanity." In the view of the Tribunal, under international law a subsequent treaty cannot trump a claim based on a violation of jus cogens norms. Following this reasoning, the Settlement Agreement between ROK and Japan would be void for violation of Article 53 of the Vienna Convention, which states the invalidity of a treaty that,

\footnotetext{
${ }^{854}$ See Pictet, Jean S. (ed.), The Geneva Conventions of 12 August 1949, Commentary, Volume I, First Geneva Convention for the Amelioration of the Condition of the Wounded and Sick in Armed Forces in the Field, Geneva, 1952, Article 51.

${ }^{855}$ Along with the premise that only the State has a right to reparation and may dispose of its claims accordingly to its treaty making power, Kelsen stated "Rights of individuals not only may be established but also be abolished by a treaty. Since the state under general international law has lawmaking power with respect to its nationals, it may, in a treaty concluded with another state, dispose of the rights, especially of the property rights of its nationals". Kelsen, Hans, Principles of International Law, The Lawbook Exchange, Clark, New Jersey, 2003 (reprint), p. 145.

${ }^{856}$ ICJ, Jurisdictional Immunities of the State (Germany v. Italy, Greece intervening), Judgment of 3 February 2012, ICJ Reports, 2012, Dissenting Opinion of Judge Cançado Trindade, para. 71.

${ }^{857}$ For details on the history of the establishment, the composition, the relevant characteristics and the importance of the Women's International Tribunal on Japanese Military Sexual Slavery, see Chinkin, Christine, "Women's International Tribunal on Japanese Military Sexual Slavery", American Journal of International Law, Vol. 95, No. 2, (2001) 335-341.
} 
at the time of its conclusion, conflicts with a peremptory norm of general international law. Even considering the apparent inexistence of the concept of ius cogens at the time of the commission of the facts, ${ }^{858}$ the analysis of the Tribunal would lead to the invalidity of the 1965 Settlement Agreement for violation of Article 64 of the Vienna Convention. However, the reasoning of the Tribunal does not seem persuasive in that it considers the waiver to reparation for war crimes and crimes against humanity to be in contrast with jus cogens norms. There is no doubt that the norms protecting human rights (primary norms) are peremptory norms, and «no waiver of the breach itself is possible in cases of breach of an obligation arising under ius cogens». ${ }^{859}$ However,

Il n'y a aucune nécessité juridique à considérer que la créance qui nait par l'effet des règles supplétives de la responsabilité international devrait emprunter le caractère indérogeable de la norme dont la violation suscita leur mise en œuvre. ${ }^{860}$

Thus, it is more difficult to claim the jus cogens nature of the norm providing for reparation (secondary norm).

The judgement of the International Court of Justice (ICJ) in the case Jurisdictional Immunities confirms the idea that the obligation to make reparation does not have a peremptory nature. The Court states that, considering the long-established practise of the States to conclude peace treaties or post-war settlements through decisions not to require payments of reparations or using lump-sum settlements,

it is difficult to see that international law contains a rule requiring the payment of full compensation to each and every individual victim as a rule accepted by the international community of States as a whole as one from which no derogation is permitted. ${ }^{861}$

In this sense, the waiver to reparation for the crimes committed against the "comfort women" cannot be considered a violation of a ius cogens norm.

\footnotetext{
${ }^{858}$ See ICL, Draft Articles on the Law of Treaties, in ILCYB, 1966, Vol. II, UN Doc. A/CN.4/SER.A/1966/Add.1, 247 ss.

859 Talmon, Stefan A. G., "Ius Cogens after Germany v. Italy: Substantive and Procedural Rules Distinguished", Leiden Journal of International Law, Vol. 25, No. 4, (2012) 979-1002, p. 997. See generally the ILC commentary of Article 29 on the consent to the wrongful act:

In the case of peremptory rules of international law which, as such, permit of no derogation by agreement of the parties, the consent of the State whose subjective right has been infringed cannot remove, even in a single instance, an obligation created by those rules and thus preclude the wrongfulness of an act not in conformity with that obligation.

International Law Commission, Report to the General Assembly on the on the work of its Thirty-first session, A/34/10, Yearbook of the International Law Commission, Vol. II, Part 2, 1979, p. 110.

${ }^{860}$ D'Argent, Pierre, Les Réparations de Guerre en Droit International Public. La responsabilité internationale des états à l'épreuve de la guerre, Bruylant, Bruxelles, 2002, p. 769.

${ }^{861}$ ICJ, Jurisdictional Immunities of the State (Germany v. Italy, Greece intervening), para. 94.
} 
To conclude, the second argument of Japan for denying its obligation to provide reparation, grounded on the assertion that the peace treaty between the State of Japan and the Republic of Korea has already settled and concluded any claim for reparation, including individual claims, is unpersuasive. Indeed, historical and interpretative arguments seem to lead to the opposite view. Moreover, recent case law and scholarship's trends indicate that the State has not the discretionary power to waive reparation claims where serious violations of IHL are involved. In this sense, the 1965 Settlement Agreement could not be invoked as a waiver of any future claims for reparation arising from war crimes and crimes against humanity committed against the "comfort women".

\subsubsection{The 2015 Agreement between Japan and ROK}

Since Japan has never recognized its legal responsibility for the acts committed, former "comfort women" have always continued efforts to obtain forms of reparation. The establishment of the "Asian Women's Fund” by the Government of Japan in 1995 has been criticized because it was a private structure financed by private donors, ${ }^{862}$ even if the misleading word "atonement money" were used. Unconvincing are also the official letters of apology, not sent to all survivors, as well as the non-transparency in managing the donors' money. ${ }^{863}$ Ultimately, Japan could avoid the risk that the Fund would be perceived as a form of reparation and, consequently, as an implicit admission of its legal responsibility. ${ }^{864}$

On 28 December 2015, an agreement between the Foreign Ministers of Japan and South Korea for the compensation of the few surviving women has been concluded. ${ }^{865}$ The Agreement established a new fund - managed by the Reconciliation and Healing Foundation established by the Government of the Republic of Korea - which corrected the previous situation in that it

\footnotetext{
862 For a gender-oriented criticism to the Asian Women's Fund, see, among others, Gini, Silvia, "Il Fondo nazionale per le donne asiatiche in Giappone: una lettura di genere", Deportati Esuli Profughi, n.15, (2011), 1824. The author, in exploring the nature and contents of Fund and the debates generated by its activities among Korean and Japanese women movements, defines the fund "an ambiguous means of corruption".

${ }^{863}$ Kim, Puja, "The failure of the Asian Women's Fund: the Japanese government's legal responsibility and the colonial legacy", in Nishino, Rumiko, Kim, Puja and Onozawa, Akane (eds.), Denying the Comfort Women The Japanese State's Assault on Historical Truth, Routledge, Abington, New York, 2018, p. 97

${ }^{864}$ Lee, Sue R., "Comforting The Comfort Women: Who Can Make Japan Pay”,...p. 523. On the limits and lacks of the system of the Asian Women Fund, see An NGO Shadow Report to CEDAW 44th Session 2009, New York, Violence against women (Japan's military sexual slavery/ the "Comfort Women" issue), available at: http://www2.ohchr.org/english/bodies/cedaw/docs/ngos/ComfortWomen Japan cedaw44.pdf [last visited, 23 February 2021].

865 The joint press conference of the south Korean and Japanese foreign ministers is available at https://www.youtube.com/watch?v=qrd6wLi-utY; for the final Announcement see: "Le règlement du différend entre la République de Corée et le Japon au suet des Dames de réconfort" at www.sentinelle-droit-international.fr.
} 
launched a public mechanism of reparation. ${ }^{866}$ The Japanese Government engaged in providing a one-time contribution of one billion yen (US\$ 8.3 million) to the fund. It is, anyway, an ex

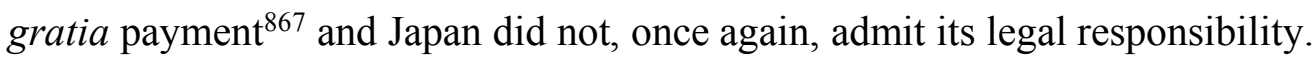

The legal nature of the agreement, consisting of two, oral, and separate statements read by each foreign minister, is under discussion. The fact that the Announcement was not a joint statement represents an obstacle to the understanding of the intention of the parties and permits the two Governments to give different interpretation of the two versions of the declarations. ${ }^{868}$ What can be said however is that this Fund has not been intended as a form of reparation.

In its 2019 final judgment in the case on Announcement of Agreement on the "Comfort Women Issue, ${ }^{869}$ the Constitutional Court of Korea, requested by some former "comfort women" to pronounce on the unconstitutionality of the 2015 Agreement, had to rule on its legal nature in order to assess whether some parts of the agreement violate the Complainants' human dignity and value. After extensive analysis of the 2015 Agreement, the Court concluded that the 2015 Agreement "is hardly considered a legally binding agreement".870 The Court based this conclusion on the absence of the essential elements for an agreement to be considered a treaty under international law. In particular, the Court noted many deficiencies in the 2015 Agreement, such as the lack of a written text and a title, and the discrepancy in expression between the oral statement and the statement published on the official websites. ${ }^{871}$ Moreover, neither States pursued their relevant constitutional procedures to enter a treaty, nor they included any specific rights and obligations upon the Parties as well as explicit legal

\footnotetext{
866 The Foundation, founded using Japanese funding to settle disputes regarding wartime sex slavery issues, has been dissolved and started a liquidation process on 5 July 2019. The Korea Times, "Japan-funded wartime sex slavery victim's foundation dissolved" (05.07.2019), available at: http://www.koreatimes.co.kr/www/nation/2019/07/356 271819.html?fb comment id=2535643713127166 253 6952226329648 [last visited, 23 February 2021].

867 In Latin, "ex gratia" means "by favour". An ex gratia payment is a voluntary payment made to an individual by an organization, government, or insurer for damages or claims, but it does not require the admittance of liability by the party making the payment. In other words, the party making the payment is not obligated to compensate the individual. Examples of ex gratia payments can be found in negotiations of the States following diplomatic attacks to the embassy causing property or personal injuries. See Articles on State Responsibility, commentary to Article 36, para. 12, p. 101.

$868 \mathrm{http}: / /$ www.straitestimes.com/asia/east-asia/historic-south-korea-japan-deal-strumbles-over-comfort-womanstatue [last visited, 23 February 2021].

${ }^{869}$ Constitutional Court of Korea, 2016Hun-Ma253, December 27, 2019. The English version of the ruling is available at: https://library.ccourt.go.kr/site/conlaw/download/case publications/DECISIONS 2019.pdf [last visited, 23 February 2021].

870 Ibid. p. 104.

871 The English translation of the Japanese version of the Agreement is available at: https://www.mofa.go.jp/a o/na/kr/page4e 000364.html [last visited, 23 February 2021].
} 
implications in case of infringements. ${ }^{872}$ Thus, the Court dismissed the case on the basis that the Agreement, which "falls within the realm of politics", has not created legal rights and obligations, and, consequently, is not "able to infringe on the basic rights of the victims, such as their claims for damages". 873

The Court's position seems to be well-founded. Indeed, despite the proclaims of a "final and irreversible" resolution of the matter, the subsequent conducts of the two Governments do not confirm the coherent intentions of the Parties and an authentic and genuine will to reach a real conclusion of the dispute. ${ }^{874}$ Moreover, as it will be analysed later in this Chapter, the Parties also completely lacked a gender-oriented approach that would have been essential for an effective resolution of the "comfort women" issue. Thus, the 2015 Agreement may not be considered as providing a binding solution for the settlement of the "comfort women" case.

\subsection{The 2021 Judgement of the Seoul Central District Court as a turning point}

All the previous issues acquire a prominent relevance in the judgement in issued by the Seoul Central District Court on January 8, 2021 in the case Kwak Ye-Nam et. al. v. Japan, which represents a turning point in the "comfort women" case.

In August 2013, the survivors of the military sexual slavery applied for mediation with the Government of Japan at the House of Sharing. However, the subsequent exclusion of the former "comfort women" from the process of the 2015 Agreement as well as the failure of the two governments to achieve a settlement recognized by the victims was the main basis to convert the mediation in the two lawsuits filed before Korean courts, considered the "last chance for justice for 'comfort women", ${ }^{875}$ Two claims were filed before Korean courts by

\footnotetext{
${ }^{872}$ Ibid. p. 101-104.

${ }^{873}$ Ibid. p. 105.

${ }^{874}$ For an explanation of the series of the two States' conducts contradicting the 2015 Agreement, see Hyun-Soo Lim, "Not 'Final and Irreversible': Explaining South Korea's January 2018 Reversal on the 'Comfort Women' Agreement", Yale Journal of International Law Blog, (February, 2018), available at: https://www.yjil.yale.edu/not-final-and-irreversible-explaining-south-koreas-january-2018-reversal-on-thecomfort-women-agreement/ [last visited, 25 February 2021].

875 Amnesty International, "South Korea: Lawsuits against Japanese government last chance for justice for 'comfort women"”, (12 August 2020), available at: https://www.amnesty.org/en/latest/news/2020/08/south-korea-lawsuits-against-the-japanese-government-lastchance-for-justice-for-comfort-women/ [last visited, 25 February 2021].
} 
former "comfort women" and some bereaved family members representing other victims seeking compensation from the Japanese government. ${ }^{876}$ The ruling of the first claim has been delivered on 8 January 2021, while the other has been postponed to the end of March 2021. 877

On 8 January 2021, the Korea's Seoul Central District Court delivered its judgement ${ }^{878}$ in the case Japanese Military “Comfort Women”, upholding the claims of all plaintiffs and ordering Japan to pay a compensation of $100,000,000 \mathrm{KRW}$ (won), about 75,000 euro, to each of the twelve Korean former "comfort women". For the first time the Japanese government was brought before a Korean court and found responsible for IHL violations resulting in international crimes committed during the WWII. The decision has been already considered a "historical ruling" and a potential "bill of rights" $" 879$ for war crimes victims throughout the world.

The ruling is remarkable for a number of reasons. First, it offered a qualification of the acts in violation of IHL committed by the Japanese Army against the "comfort women". In the examination of the facts, the Court properly underlined that the forms of violence to which "comfort women" were subjected encompassed forced mobilization, forced transport of women, detainment in "comfort stations", systematic sexual violence, beating, surveillance, forced sterilization and pregnancy, and post-war disturbances such as severe psychological damages and social ostracism. After finding Japanese Army's conduct in violation of a number of international conventions at the time of the commission of the acts - Article 3 of the 1907 Hague Convention and Article 46 of the annex to the Convention; the International Convention for the Suppression of the White Slave Traffic; the International Convention for the Suppression in the Traffic of Women and Children; the Convention to Suppress the Slave Trade

\footnotetext{
876 The second group of victims decided to file a formal lawsuit after recognizing the inaction of the government of Korea on the matter. This second lawsuit was filed on December 28, 2016.

${ }^{877}$ Korea Joon Gang Daily "Court makes landmark ruling that Japan is responsible for compensating comfort women victims" (08 January 2021), available https://koreajoongangdaily.joins.com/2021/01/08/national/socialAffairs/comfort-women-Japan-Seoul-CentralDistrict-Court/20210108125300714.html.

878 Seoul Central District Court, Case no.: 2016 Ga-Hap 505092, Compensation for Damage (Others), delivered on January 8, 2021. The English version of the ruling, translated by the Woohee Kim for the Korean Council for Justice and Remembrance for the Issues of Military Sexual Slavery by Japan, is available at: https://womenandwar.net/kr/wp-content/uploads/2021/02/ENG-2016 Ga Hap 505092 23Feb2021.pdf [last visited, 25 February 2021].

${ }^{879}$ Lee, Sang-hee "A Universal Judgment Based on Universal Human Rights", Booklet of the International Symposium Korean Court's Historic Ruling on Japanese Military 'Comfort Women': Restoring the Right to Justice and Truth held on February 26, 2021, p. 67, available at: https://womenandwar.net/kr/korean-courtshistoric-ruling-on-japanese-military-comfort-women-restoring-the-right-to-justice-and-truth/ [last visited, 25 February 2021]. The video of the international symposium is also available on YouTube at: https://youtu.be/oD1ZzNnh7u4 [last visited, 25 February 2021].
} 
and Slavery; the ILO Forced Labour Convention; and the 1946 Charter of the International Military Tribunal for the Far East - the Court qualified the illegal acts committed systematically and extensively by Imperial Japan as "crimes against humanity in violation of international jus cogens against the Plaintiffs". ${ }^{880}$ From a gender perspective, this qualification of the harms suffered by "comfort women" represents a confirmation of the illegality of genderbased violence against women even under applicable international law at the time of the acts of the case.

Second, the Court ruled on the matter of the relationship between inter-State war settlement and the individual claims to reparation. Responding to the Defendant's claim that the victims' right to claim reparations is expired due to the conclusion of the 1965 Settlement Agreement first, and the 2015 Agreement then, the Court stated that the Plaintiffs' right is not extinguished because it was not included in the scope of application of the two agreements. In confirming that the 2015 Agreement is a nonbinding agreement, ${ }^{881}$ the Court specified that the parties "failed to include reparations for individuals" that "do not have negotiation power or political power", ${ }^{882}$ and in any case, "the state cannot dispose of individual rights without separate delegation or provisions of laws and regulation". ${ }^{883}$ Thus, the Court upheld the view that the State can dispose of its right to diplomatic protection by treaty, but cannot also extinguish the individual right to claim without the consent of its individual citizens - especially the most vulnerable ones.

Third, and probably the most significant aspect of the decision, the Court did not recognize Japan's jurisdictional immunity, typically enjoyed before a national court by foreign States under international law. ${ }^{884}$ Despite the recognition that, in principle, the jurisdiction of the courts of South Korea does not extend to sovereign acts of foreign States in accordance to treaty and customary international law by virtue of the principle of state immunity, ${ }^{885}$ the Court applied an exception and stated its jurisdiction in the case at hand. The exception was justified by the fact that, given the "crimes against humanity committed systematically and extensively

\footnotetext{
${ }^{880}$ Seoul Central District Court, Case no.: 2016 Ga-Hap 505092, Compensation for Damage (Others), delivered on January 8, 2021, p. 26.

${ }^{881}$ Ibid. pp. $30-40$.

882 Ibid. p. 29.

883 Ibid. p. 39.

${ }^{884}$ For a critical analysis of the issue of state immunity in the ruling at stake, see Franchini, Daniel, "South Korea's denial of Japan's immunity for international crimes", Völkerrechtsblog, (18 January 2021), available at: https://voelkerrechtsblog.org/de/south-koreas-denial-of-japans-immunity-for-international-crimes/ [last visited, 25 February, 2021].

${ }^{885}$ Seoul Central District Court, Case no.: 2016 Ga-Hap 505092, p. 24, 26.
} 
by Imperial Japan in violation of international jus cogens against the Plantiffs", ${ }^{886}$ resulting in the destruction of "universal values of the international community", and also considering that the chosen forum represented "the last resort" for the victims, the exemption of Japan from Korean jurisdiction would be "unreasonable and unjust". ${ }^{887}$ The legal basis for the jus cogens exception to the principle of State immunity is the Korean constitutional order, in particular Article 27(1) of the Constitution of South Korea, which states the right of access to courts. ${ }^{888}$ In the Court's reasoning,

[e]ven though state immunity is a customary international law that has become established through customs, if customary law is applied to exempt the Defendant from jurisdiction even in cases where the Defendant has committed grave crimes against humanity, it would be impossible to sanction a state for violating international conventions that prevent it from committing grave crimes against humanity against citizens of another state, thereby depriving victims of their right of access to courts guaranteed by the Constitution and not providing a remedy for their rights. Such results are unreasonable and unjust as they are not in accordance with the overall legal order that positions the Constitution as the highest norm. Thus, customary international law that applies state immunity is not effective in such cases. ${ }^{889}$

The similarity of the Korean District Court's legal reasoning on the matter with the 2004 judgment of the Italian Supreme Court of Cassation in Ferrini case ${ }^{890}$ is undeniable. Both courts applied an exception to the principle of state immunity on the basis of the peremptory nature of the violations committed ${ }^{891}$ by the respective former occupying power - Japan in the case at hand, and Germany in Ferrini case - during the World War II. However, it is remarkable that this decision arrived after the 2012 ICJ judgement in the case Jurisdictional Immunities, which clearly stated the irrelevance of the peremptory character of the claimed breaches for the application of state immunity. In other words, according to the ICJ, the violation of serious international human rights or IHL norms cannot be held to deny state immunity to the wrongdoer State, because "rules of State immunity are procedural in character" and

\footnotetext{
${ }^{886}$ Ibid. p. 26.

${ }^{887}$ Ibid. p. 28.

888 Ibid. p. 26.

${ }^{889}$ Ibid. p. 29.

${ }^{890}$ Italian Supreme Court of Cassation (Unified civil Sections), Ferrini v Federal Repubblic of Germany, judgment No 5044 of 6 Nov. 2003, registered 11 Mar. 2004, Rivista diritto internazionale, Vol. 87, (2004), 539. The original version of the ruling is available at: https://www.jolau.com/wp-content/uploads/2018/10/SentenzaFerrini-5044-04-2.pdf [last visited, 23 February 2021].

${ }^{891}$ For a critical view of the denial of the jurisdictional immunity of the State for violations of international jus cogens, see Zimmermann, Andreas, "Sovereign Immunity and Violations of Jus Cogens - Some Critical Remarks", Michigan Journal of International Law, Vol. 16, No. 2 (1995), 433-440. The author sustains that the denial of State immunity in cases of purported violations of international human rights should be avoided because contrary to the basic principle enshrined under the State immunity principle, namely the principle of sovereign equality between the States. Moreover, denying sovereign immunity to foreign States also leads to a distortion of the "social fabric of international relations", made of international relations among States (p. 439).
} 
independent from the substantial issue of the responsibility of the State. ${ }^{892}$ Moreover, the ICJ rejected the "last resort" argument stating that there is no State practice in support of the view that customary international law provides for an exception in the state immunity principle in case of lack of effective alternative means of redress for the victims. ${ }^{893}$ In this sense, the Seoul Central District Court's decision reopened a discussion that seemed settled about the tension between serious breaches of human rights and compliance with the general IL principles of state immunity. What is especially relevant for the purposes of this dissertation is that this discussion reopens at a case dealing with women's claims arising from in conflict situations.

On its side, the Korean Court had the (only) example of the Italian Constitutional Court's decision 238/2014, which, by refusing to implement the 2012 ICJ judgment, declared the inconsistency of the rule of state immunity with the basic values of respect for human dignity and right to access to justice under the Italian constitutional order. ${ }^{894}$ Again, constitutional values are used by a domestic court to limit the applicability of state immunity. ${ }^{895}$

Moreover, the Korean Court reached its findings by referring to the customary rule of state immunity, along with "the doctrine of state immunity is not permanent nor static", 896 but "it continuously evolves in accordance with the changes in the international order" ${ }^{897}$ In this sense, the Court concluded that the application of state immunity cannot lead to the State absolution in cases of jus cogens violations resulting in the evasion to make reparation to the victims affected by harms derived from the illegal acts. ${ }^{898}$

\footnotetext{
${ }^{892}$ ICJ, Jurisdictional Immunities of the State (Germany v. Italy, Greece intervening), para 93. https://www.icjcij.org/en/case/143.

${ }^{893}$ ICJ, Jurisdictional Immunities of the State (Germany v. Italy, Greece intervening), para 101.

${ }^{894}$ For a critic of the paucity of the legal reasoning of the Italian Constitutional Court in balancing the right to jurisdictional protection with the compliance to the principle of State immunity, see Palchetti, Paolo, "Can State Action on Behalf of Victims Be an Alternative to Individual Access in Case of Grave Breaches of Human Rights?", The Italian Yearbook of International Law, Vol. 24, (2014), 53. The author sustains that the Italian Constitutional Court completely missed the opportunity to consider alternative non-judicial forms of protection of the right to the victims, in particular through an evolving interpretation of the right to diplomatic protection, that could have avoided to sacrifice the compliance with general principles of international law.

${ }^{895}$ For an overview of the attitude of States towards customary international law and general principles of international law, see Bartolini, Giulio, "A Universal Approach to International Law in Contemporary Constitutions: Does It Exist?”, Cambridge Journal of International and Comparative Law, Vol. 3, No. 4, (2014), $1287-1320$.

${ }^{896}$ Korean courts are not new to the idea that the sovereign immunity, far from written in stone, is a continuously evolving doctrine. See Supreme Court decision 17 December 1998, 97 Da 39216. See also Kim Do-Hyoung, "Practices on State Immunity at Korean Courts", Seoul International Law Journal Vol. 22, No. 2, (December 2015), 115. For a recent work on the matter, Hwang Myoung-jun, "Recent Discourse on Overcoming Sovereign Immunity: Focusing on the Italian Constitutional Court Decision No. 238 (2014) and subsequent discussions thereof', Seoul International Law Journal Vol. 25, No. 1, (June 2018), 1.

${ }^{897}$ Seoul Central District Court, Case no.: 2016 Ga-Hap 505092, p. 27.

${ }^{898}$ Ibid. p. 29.
} 
The Seoul Central District Court set a judicial precedent in favor of recognizing an exception to the principle of state immunity when serious human rights and IHL violations are involved and when the lawsuit represents the last resort for the victims. Undoubtedly, it is an historical ruling in that it recognized that the claim to reparations of former "comfort women", since arising from the crime of sexual slavery, may overcome the traditional procedural hurdle of state immunity. The decision has been welcomed as a human rights-centred ruling by international lawyers and activists supporting the "comfort women" case, ${ }^{899}$ in that it stated the prevalence of the substantive human rights of the victims and the right to trial over the procedural principle of state immunity. However, considering the Japanese hard critics to the decision, ${ }^{900}$ one may ask whether the ruling could have real chances to be executed in so ensuring effective reparations to former "comfort women".

From a gender perspective, the judgement is a turning point in the case of "comfort women" and offers precious insights on a number of issues. First, the judgment of the Central District Court of Seoul offered a symbolic contribution. In opening with a series of testimonies, the decision gave voice to the former "comfort women". In this sense, the trial represented probably the last occasion for the survivors to have a legitimized space for testifying their memories and to relate their past experiences. By detailing the testimonies of these women in the judgment, the court gave dignity to each of the survivor, in so assuming a victim-oriented and gender-based approach. Second, in the examination of the facts, the Court properly underlined all the forms of violence to which "comfort women" were subjected and qualified the offences caused to this group of persons as jus cogens violations, in so matching the aspirations of the feminist-oriented movements in support of "comfort women's" claims..$^{901}$

\footnotetext{
899 Lee, Sang-hee, “A Universal Judgment Based on Universal Human Rights”, Booklet of the International Symposium Korean Court's Historic Ruling on Japanese Military 'Comfort Women': Restoring the Right to Justice and Truth held on February 26, 2021, p. 67, available at: https://womenandwar.net/kr/korean-courtshistoric-ruling-on-japanese-military-comfort-women-restoring-the-right-to-justice-and-truth/ [last visited, 23 February 2021]. See also the Global Jurists Statement in support of the Seoul Central District Court decision of Japanese Military "Comfort Women" Victims v. Japan case, available at: https://docs.google.com/forms/d/e/1FAIpQLSdEJ1JxFz5ltTRhEK4-X6BAruPIPE9mwUPa2LXsZYIgR4OTQ/viewform [last visited, 23 February 2021].

$900 \quad$ https://english.kyodonews.net/news/2021/01/131a29c7f880-breaking-news-japan-lodges-protest-with-skorea-envoy-over-comfort-women-ruling.html [last visited, 23 February 2021].

901 Prosecutor and Peoples of Asia Pacific Region v. Hiroshito; Prosecutor and Peoples of Asia Pacific Region the government of Japan, The Women's International War Crimes Tribunal for the Trial of Japan's Military Sexual Slavery, Judgment on the common indictment and the application for restitution and reparation, Case PT-2000-1T, 4 December 2001. The judgment may be found at: https://archives.wam-peace.org/wt/wpcontent/uploads/2020/03/Judgment.pdf. See also Amnesty International's Submission to the Honorable Judges of The Seoul Central District Court Concerning the Case of Kwak Ye-Nam Et. Al. v. Japan (2016 Ga-Hap 580239), available at: https://amnesty.or.kr/wp-content/uploads/bcp-attach/Amnesty-Submission-to-the-HonorableJudges-of-the-Seoul-Central-District-Court 12-11-2019 final-1.pdf [last visited: 21 February 2021].
} 
Moreover, the decision permitted to reflect on the relevance of the regime of state responsibility in cases of war crimes and crimes against humanity committed against women.

However, Chinkin argues that the Seoul Central District Court failed to "provide a full gender analysis", specifying that the crime of sexual slavery was directed to women as women, and to focus on the gender nature of the crimes. Moreover, she sustains that the decision could have provided the normative framework on gender equality and prohibition of violence against women developed in the last decades. ${ }^{902}$ This assertion seems even more plausible if one considers that the human rights discourse informed almost every part of the Court's legal reasoning, especially while operating an exception to the general IL principle of state immunity for serious violations of human rights and international humanitarian law. In this sense, a gender analysis of the case at stake would have reinforced the Court's decision, in confirming the illegality of the Japanese conduct under international law standards and in underlining the necessity to guarantee an effective right of access to justice to those individuals, women and girls, usually more vulnerable and discriminated.

By bringing a full gender perspective in the judgment, the Court could also have added considerations on the role that a sincere public apology from Japan could have had for the redress of "comfort women". In so doing, it could have given its contribution to the discussion about a gender-oriented approach to the choice of the best form of reparation.

\subsection{Public apology and memorials as reparation for "comfort women" and their potential for gender crimes}

The 2021 Seoul Central District Court judgment is the outcome of Japan's failure to provide former "comfort women" a form of reparation that could really reflect the State's taking responsibility as well as its sincere remorse over the issue. In particular, a sincere public apology, accompanied by uncontroversial acts of regret and reparation, would have been of great significance and would have probably avoided the long-term tension between the two States.

\footnotetext{
902 Chinkin, Christine, "The significance of this ruling to women's human rights, expand the meaning of state immunity in relation to gender and human rights perspectives", Booklet of the International Symposium Korean Court's Historic Ruling on Japanese Military 'Comfort Women': Restoring the Right to Justice and Truth held on February 26, 2021, p. 79.
} 
The issue of reparations for "comfort women" raises the question of the best form of reparation for the case at hand and the relevance of symbolic forms of reparations for gender crimes. As the "most organized and well-documented movement for reparations for women", since the late 1980s former "comfort women"

have come forward to bear witness and mobilize international public opinion, asking for an official apology and reparation. Survivors have rejected financial aid gestures as inadequate and reiterated their desire for a formal apology and individual compensation through public funds rather than a welfare- or benevolence-type of assistance based on socio-economic needs. As victims of sexual crimes, they do not want to receive economic compensation without an official apology and official recognition of State responsibility. ${ }^{903}$

The thirty-years history of former "comfort women" movement for obtaining reparations from the Japanese government shows the recurrence of three specific aspects. The first aspect is the survivors' expectations, consisting in the strong wish to obtain a formal apology and, at the same time, their reluctance to accept monetary payments, especially if not accompanied by assumption of responsibility by Japan. The second aspect entails the Japanese ambiguous position with respect to the matter, consisting in a number of incoherent statements from different governments but sharing the same lack of formal recognition of legal responsibility. The third aspect involves the inter-States ruinous attempts to solve the issue, which were the main reasons for the victims to file multiple lawsuits before Japanese, third States' as well as Korean courts. The three aspects are strictly linked one to the other.

The requests of former "comfort women" have always been clear. Korean survivors are fighting for a resolution of the Japanese military sexual slavery issue that could assure the restoration of their dignity and guarantee the non-recurrence of such a heinous crime in the future. ${ }^{904}$ Given the interests at stake, the survivors have always privileged symbolic reparations as primary forms of reparation. This raises both legal and gender issues.

From a legal perspective, the survivors' predilection for symbolic reparations could seem in conflict with the hierarchy of the forms of reparation as described in the regime of State responsibility analyzed in Chapter IV. In particular, the prevalence for compensation envisaged under the 2001 Articles on State Responsibility, when applied to the context of post-war settlements, seems to respond more to the traditional idea of war reparations as post war

903 Report of the Special Rapporteur on violence against women, its causes and consequences, Rashida Manjoo, UN GA A/HRC/14/22, 23 April 2010, para. 71, available at: https://documents-ddsny.un.org/doc/UNDOC/GEN/G10/131/09/PDF/G1013109.pdf?OpenElement [emphasis added].

904 See generally the work of the Korean Council for Justice and Remembrance for the Issues of Military Sexual Slavery by Japan, https://womenandwar.net/kr/about-us/ [last visited: 21 February 2021]. 
mechanism to make the vanquished State responsible for the overall war rather than an instrument to redress victims for specific IL violations. However, the general trend of proliferation of specific mechanisms, such as the claims commissions, to redress victims in accordance with an emerging individual rights lens ${ }^{905}$ suggests that a victim-oriented perspective is currently at the basis of the choice of the form of reparation to redress individual victims of international crimes.

In asking how a full reparation for a gender crime, sexual slavery in the case at hand, should look like and why apology is so important for the "comfort women", one should think before at the harms suffered and the protected right offended. This process implied a deep gender analysis for a full understanding of the victims' perspective and, consequently, for an effective reparation.

If the paramount value of human dignity is at stake, dignity of "comfort women" has been violated twice: in the "comfort stations" first, and in the subsequent ostracism dimension to which survivors were subjected at the end of the war. Sincere public apology could highlight the political dimension of the violence suffered by "comfort women", in so fighting the stigma attached to the victims throughout decades. The "comfort women's" refusal of compensation through ex gratia monetary payments by the Japanese government clearly shows their willingness to search for a restoration of dignity, not to fell again "victims of a crime that is still seen as private and apolitical". 906

It is submitted that the apparent deficiencies of the Japanese government's attitude to the "comfort women" issue have a clear gender dimension whose main evidence is reflected in the ineffective attempts to express a public apology considered genuine by the victims and in the contrast to other possible forms of symbolic reparation, such as memorials and statues.

5.6.1. The ambiguous Japanese apologies from the Kato Statement to the 2015 Agreement

\footnotetext{
${ }^{905}$ Furuya, Shuichi, "The Right to Reparation for Victims of Armed Conflict: The Intertwined Development of Substantive and Procedural Aspects", in Correa Christiàn, Furuya, Shuichi, and Sandoval, Clara (eds.), Reparation for Victims of Armed Conflict, (Anne Peters and Christian Marxsen series eds.), Vol. 3, Cambridge University Press, Cambridge, 2021 (on file with the author).

906 Hamber, Brandon and Palmary, Ingrid, "Gender, Memorialization, and Symbolic Reparations", in RubioMarin, Ruth (ed.), The Gender of Reparations: Unsettling Sexual Hierarchies while Redressing Human Rights Violations, Cambridge University Press, Cambridge, 2009, p. 344.
} 
The scars I got from the Japanese government will never fade away, but a sincere apology will help me rest in peace. If Japanese government has any conscience, they should investigate the truth and let me rest in peace. ${ }^{907}$

As the words of this former "comfort woman" testifies, sincere apology and truth would be the most significant achievements for a "rest in peace". These words give the measure of the former "comfort women" fight for justice. Thus, it seems relevant to provide an excursus of the main expressions of apologies that the Japanese government gave on the issue, in order to understand why former "comfort women" have never accepted them.

On January 1992, the Japanese Government spoke for the first time of the "comfort women" issue through the expression of apology and remorse of the then Prime Minister, Kiichi Miyazawa, in a press conference. ${ }^{908}$ It was the 1992 Statement by Chief Cabinet Secretary, Koichi Kato, to recognize for the first time the Japanese's government involvement in the establishment, construction, management and maintenance of the "comfort stations", as well as the recruitment and control of the "comfort women". 909

However, the real turning point in Japanese's attitude toward "comfort women" issue was in August 1993, with the Statement by the Chief Cabinet Secretary Yohei Kono (therein Kono Statement). In this occasion, the Japanese Government not only officially recognized the extensive governmental mechanism of the "comfort stations", and offered "sincere and apologies and remorse" to "comfort women", but also expressed its "firm determination never to repeat the same mistake by forever engraving such issues in our memories through the study and teaching of history". 910

Following the establishment of the AWF in 1995, ${ }^{911}$ the Japanese Prime Minister Tomiichi Murayama defined the "comfort women" issue as a "scar" for Japan and the Fund as "an

907 Message from one former "comfort woman, Gil Won-ok, available at: https://womenandwar.net/kr/testimonies/?ckattempt=1 [last visited: 21 February 2021]

908 See Japanese Government Statements and Ministry of Foreign Affairs Statements, available at: https://kls.law.columbia.edu/content/japanese-government-statements-and-ministry-foreign-affairs-statements [last visited: 21 February 2021]

${ }^{909}$ Statement by Chief Cabinet Secretary Koichi Kato on the Issue of the so-called "Wartime Comfort Women" from the Korean Peninsula, 6 July 1992, available at: https://www.awf.or.jp/e6/statement-01.html [last visited: 21 February 2021].

910 Statement by Chief Cabinet Secretary Yohei Kono on the Result of the Study on the Issue of "Comfort Women", 4 August 1993, available at: https://www.awf.or.jp/e6/statement-02.html [last visited: 21 February 2021].

911 For a Japanese perspective on the exchanges between Japan and ROK on the "comfort women" issue, see Details of Exchanges Between Japan and the Republic of Korea (ROK) Regarding the Comfort Women Issue From the Drafting of the Kono Statement to the Asian Women's Fund, available at: https://www.mofa.go.jp/files/000042171.pdf [last visited: 21 February 2021]. 
expression of atonement on the part of the Japanese people" for those women affected "in their honor and dignity" by such a "inexcusable" Japanese conduct. ${ }^{912}$ It is worth noting that the definition of the Fund as "expression of atonement" clearly shows the humanitarian scope of the mechanism: the Fund was intended as a charitable means and not as a form of reparation. This also reveals the long-term Japanese approach to the issue, consisting in a full awareness of "its moral responsibilities" $" 913$ while firmly denying any legal responsibility on the matter.

Consistently with the above apologies, the text of the Japanese statement during the joint conference for the 2015 Agreement refers to the "comfort women" issue as a "grave affront to the honor and dignity" of women. ${ }^{914}$ As correctly pointed out by Hamber and Palmary, if it is true that the emphasis on the concept of "dignity" may well fit with the survivors' request of restoration of their dignity, a deeper eye cannot miss to notice the link of "honor and dignity" with the traditional view of sexual harms against women as harms against women's virginity and pureness. ${ }^{915}$ This view seems also supported by the genericity of all statements, which completely lack any reference to the concrete harms suffered by the victims, in particular the missing mentioning of sexual slavery. The non-naming of the crimes committed against "comfort women" seem to respond to a double scope. On the one hand, this attitude tends to minimalize the gravity of the military acts committed against comfort women, in so reinforcing the idea that Japan is still not completely aware of the seriousness of its violations. On the other hand, the non-mention of the crimes aims at avoiding the shame attached to victims of sexual and gender-based crimes. This last point would strengthen the idea of a deep gendered approach towards crimes committed against women, still considered stigmatizing offences for women.

On January 9, 2018, the Korean Minister of Foreign Affairs, Kang Kyung-wha, in recognizing that "what the victims have consistently wished for is a voluntary and sincere apology", admitted the lack of a victim-oriented approach to the "comfort women" issue in the 2015 Agreement between ROK and Japan because of its failure to "appropriately reflect consensus

\footnotetext{
912 Statement by Prime Minister Tomiichi Murayama on the occasion of the establishment of the "Asian Women's Fund", available at: https://www.mofa.go.jp/a o/rp/page25e 000354.html [last visited: 21 February 2021].

${ }^{913}$ Letter from Prime Minister Junichiro Koizumi to the former comfort women, 1 January 20021, available at: https://www.mofa.go.jp/a o/rp/page25e 000352.html [last visited: 21 February 2021].

914 For the English version of the Agreement translated by Japan, see https://www.mofa.go.jp/a o/na/kr/page4e 000364.html. [last visited: 21 February 2021].

${ }^{915}$ Hamber, Brandon and Palmary, Ingrid, “Gender, Memorialization, and Symbolic Reparations”, ...pp. $370-371$.
} 
of the victims". Therefore, the minister declared that the 2015 Agreement does not represent "a genuine resolution" of the issue, ${ }^{916}$ in so effectively nullifying the Agreement. ${ }^{917}$

The same position was assumed by the Constitutional Court of Korea in its 2019 decision in the case Announcement of Agreement on the "Comfort Women Issue. With regard to the Japanese apologies expressed in the 2015 Agreement, it stated

Regarding the part of the Agreement in which Japanese Prime Minister expresses apologies and remorse to "comfort women" victims, it is uncertain whether this part is aimed toward providing remedies for the infringements of their rights, making it difficult to determine its legal implications. $^{918}$

The Court added that, since Japan's apology did not clearly specify the cause of damages, the Japanese military coercive and illegal involvement, as well as the State's responsibility for the issue of "comfort women" because considered solved by the 1965 Settlement Agreement, "the aforementioned expression of apologies can hardly be viewed as legal measures to redress harm inflicted upon "comfort women" victims". 919

Various UN agencies argued that the 2015 Agreement did not incorporated a victim-oriented approach. The UN Committee on the Elimination of Discrimination against Women in its 2016 concluding observations on the combined seventh and eighth periodic reports of Japan, ${ }^{920}$ while considering the 2015 bilateral Agreement between Japan and ROK, urged the State party to "ensure that its leaders and public officials desist from making disparaging statements regarding responsibility, which have the effect of re-traumatising victims". ${ }^{921}$ In the same vein, the UN Committee on the Elimination of Racial Discrimination (CERD), in its concluding observations of 2018 on the combined tenth and eleventh periodic reports ${ }^{922}$ of Japan, sustained that "the surviving comfort women were not adequately consulted and that this solution did not

\footnotetext{
916 Announcement of the Republic of Korea's Position Regarding the ROK-Japan Agreement on the "Comfort Women" Issue (January 9, 2018), integral English version of the statement available at: http://www.mofa.go.kr/eng/wpge/m 4903/contents.do [last visited: 21 February 2021]

917 McCurry, Justin, "In 2018, South Korea nullified the 2015 agreement, saying it did not reflect survivors' opinion", The Guardian, (21 November 2018), available at: https://www.theguardian.com/world/2021/jan/08/seoul-court-orders-japan-to-pay-damages-over-wartimesexual-slavery [last visited: 21 February 2021]

918 Ibid. pp. 108-109.

919 Ibid.

920 CEDAW, CEDAW/C/JPN/Q/7-8/Add.1, para 51, available at: https://documents-ddsny.un.org/doc/UNDOC/GEN/N16/023/87/PDF/N1602387.pdf?OpenElement [last visited 3 March 2021].

921 CEDAW, Concluding observations on the combined seventh and eighth periodic reports of Japan, CEDAW/C/JPN/CO/7-8, para 29(a). Available at: https://tbinternet.ohchr.org/Treaties/CEDAW/Shared\%20Documents/JPN/CEDAW C JPN CO 7821666 E.pdf [last visited 3 March 2021].

${ }^{922} \mathrm{CERD}, \mathrm{CER} / \mathrm{C} / \mathrm{SR} .2662$ and 2663.
} 
acknowledge unequivocal responsibility for the human rights violations committed against these women by the Japanese military before and during the Second World War". ${ }^{223}$ Moreover, the CERD Committee expressed its concerns regarding the negative impact of discordant statements of public officials that seem to minimize Japan's responsibility on the "comfort women" issue and recommended a victim-centred approach to "ensure a lasting solution to the issue". ${ }^{924}$ The same view has been expressed by the ILO's Committee of Experts on the Application of Conventions and Recommendations (therein CEACR):

The Committee notes from the "Report on the Review of the Korea-Japan Agreement of 28 December of 2015 on the Issue of 'Comfort Women Victims", published by the Ministry of Foreign Affairs of the ROK, that the victim-centred approach was not sufficiently incorporated in the course of the "comfort women" consultation process, and that as long as a resolution is not accepted by the victims as was the case with the 2015 Agreement, the "comfort women" issue will continue to be raised as an unresolved issue, even if the two Governments declare that it is "finally and irreversibly resolved". ${ }^{925}$

What appears clear so far is the failure of the Japanese government to make a trustworthy apology to former "comfort women". The lack of a victim-centered and gender-sensitive approach in a number of its apology statements undermines the credibility of Japanese's attempts to solve the issue.

\subsubsection{Memorialization}

"Comfort women" case also raises the question of a gender approach to memorialization of war atrocities as well as the role of satisfaction as a symbolic form of reparation for genderbased crimes. Satisfaction may assume various forms other that public apology, such as the building of memorials and statues, the education of history at school and other forms of memorialization. Japan has always been skeptical as for the use of these forms of memorialization with regard to the "comfort women" case. In its 2001 judgement, the Women's International War Crimes Tribunal for the Trial of Japan's Military Sexual Slavery underlined the negative Japanese attitude towards these forms of reparation stating

The state of Japan's failure to face the truth of its past crimes is reflected in the dearth of official memorials, research institutions, cultural explorations, and special medical and rehabilitative services and programs and institutes for the survivors and their families. It is also reflected,

\footnotetext{
$923 \quad \mathrm{CERD}, \quad \mathrm{CERD} / \mathrm{C} / \mathrm{JPN} / \mathrm{CO} / 10-11, \quad$ para $27, \quad$ available https://tbinternet.ohchr.org/Treaties/CERD/Shared\%20Documents/JPN/CERD C JPN CO 101132238 E.pdf [last visited: 3 March 2021].

924 Ibid. para 27-28.

925 https://www.ilo.org/dyn/normlex/en/f?p=1000:13100:0::NO:13100:P13100 COMMENT ID:3958065
} 
perhaps most pointedly in the inadequate treatment of the history of the "comfort women" in the school textbooks approved by the Japanese Ministry of Education and used in Japanese schools. $^{926}$

This Japanese approach has been maintained in the following years. In December 2011, the peace monument appeared before the Japanese Embassy in Seoul with the inscription: "This peace monument reflects people's genuine desire to learn from history and remember the past on the occasion of the 1,000th weekly protest against Japan's atrocities by comfort woman forced into sexual slavery".927 However, former "comfort women" have been always discouraged from installing statues remembering the violations committed against them, and the Japanese government's pressure for the removal of the existing statues has been object of diplomatic tensions in many occasions. One may quote here two specific events in this sense. First, in the 2015 Agreement between Japan and ROK, the Korean government specifically committed to "appropriately address the concern" of the memorial statue placed before the Embassy of Japan in Seoul. Second, Japan engaged in a struggle for the demolition of the "Statue of Peace" from cities around the world. One of the last examples of these attempts happened in 2020, when the Japanese government asked for the removal of the statue dedicated to "comfort women" in Berlin. 928

Considering that memorials are usually used to uphold a masculine idea of the conflict representing valorous and intrepid men, ${ }^{929}$ the installation of statues for the "comfort women" would have a great value not only as a symbolic redress for victims, but also as a means to subvert the traditional exclusively male narrative of the conflict. In this sense, Japanese efforts in abolishing memorials has not only the legal value of avoiding the recognition of a legal responsibility over the issue, but also a gender-specific value, in that it is an attitude that undermines the historical transmission and the future prevention of conflict-related and genderbased violence committed against women. It is argued that the Japanese denial of symbolic

\footnotetext{
${ }^{926}$ Prosecutor and Peoples of Asia Pacific Region v. Hiroshito; Prosecutor and Peoples of Asia Pacific Region the government of Japan, The Women's International War Crimes Tribunal for the Trial of Japan's Military Sexual Slavery, Judgment on the common indictment and the application for restitution and reparation, Case PT-2000-1T, 4 December 2001, para 1014, available at: https://archives.wam-peace.org/wt/wpcontent/uploads/2020/03/Judgment.pdf [last visited, 23 February 2021].

927 For a list of the "comfort women" memorials around the world, see https://peace.maripo.com/p comfort women.htm [last visited, 23 February 2021].

${ }^{928}$ For the video of the installation of the "statue of peace" in Berlin, see https://www.dw.com/en/south-koreancourt-orders-japan-to-pay-damages-to-comfort-women/a-56165321 [last visited, 23 February 2021].

${ }^{929}$ For examples of the traditional representation in the memorials of war, with the exaltation of the characters associated with the male soldier, see Hamber, Brandon and Palmary, Ingrid, "Gender, Memorialization, and Symbolic Reparations", ...pp. 358-360.
} 
forms of reparation that focus on memorialization of the past undermines the Japanese credibility over a sincere remorse about the issue. Moreover, it demonstrates, once again, the Japanese failure to assume a gender-oriented perspective that would lead to a resolution of the case.

The recent regression in Japanese position with regard to the issue of "comfort women" is well resumed in an official document titled "The Issue of Comfort Women", published on the official website of the Ministry of Foreign Affairs website and updated on February 1, 2021. Three passages of the document are particularly relevant:

- 'Forceful taking away' of comfort women by the Japanese military and government authorities could not be confirmed in any of the documents that the Government of Japan was able to identify.

- The expression 'sex slaves' contradicts the facts so that it should not be used. This point was confirmed with the ROK at the occasion of the Japan-ROK Agreement in December 2015 and the expression 'sex slaves' is not used in the agreement.

- The figure '200,000 persons' lacks concrete evidence. ${ }^{930}$

The recent denial of acknowledged historical outcomes regarding the "comfort women" case, recently also reinforced by some scholars' denialism, ${ }^{931}$ shows an ongoing failure to eradicate a certain tendency to consider conflict-related violence against women as inevitable effect of the war and to undermine victim's sufferance. Moreover, this recent governmental statement shows again the incoherent Japanese remorse over the issue, resulting in a lack of trust of the victims with respect to the authenticity of the previous attempts of apology.

"Comfort women" case properly demonstrates that the achievement of full reparation when serious crimes against civilians have been committed encompasses a series of acts and procedures that, in order to be effective, must directly involve the victims. There is no full reparation without acknowledgement of the facts by the wrongdoer State, there is no genuine

930 https://www.mofa.go.jp/files/000473133.pdf [last visited, 23 February 2021].

931 The emergence of historical denialism in academia about the "comfort women" issue was particularly evident in the Harvard Law School Japanese legal studies Professor J Mark Ramseyer "incident". Professor Ramseyer's paper "Contracting for Sex in the Pacific War" claims that the Imperial Japanese Army did not use sexual slaves but recruited, contracted sexual workers during World War II. The work was immediately criticized by the majority of scholars for distorting historical truth and an international academic movement mobilized to debunk his denialism. The online version of the paper is available at: http://chwe.net/ramseyer/ramseyer.pdf. For a list of resources on the "incident", see https://chwe.net/irle/, and also https://sites.google.com/view/feministsonramseyer/resources [last visited, 23 February 2021]. 
acknowledgement of the facts without public apology, and, vice versa, a public apology must include acknowledgment of facts. ${ }^{932}$

Moreover, the analysis of the "comfort women" issue also shows the gender-specific connotations usually connected with gender-based violence against women in conflict. Only by assuming a gender perspective to the "comfort women" case and considering the specific aspects of the gender crime a full reparation for the few survivors will be possible.

\subsection{Excursus: the influence of international human rights law in the "comfort women" case}

Although outside the realm of IHL, an issue that deserves particular attention is the relationship between the development of the human rights regime and the emergence of a new international consciousness about the heinous acts of violence against comfort women. In particular, it can be argued that international human rights law influenced the legal conceptualization of the "comfort women" case and paved the way for their individual claims before national courts.

The issue is an aspect of the well-known question of the interplay between IHL and IHRL. ${ }^{933}$ Since it is not possible to cover this highly debated topic here, reference is only made to the development of a particular field of human rights law, namely women's human rights. ${ }^{934}$ This discourse contributed substantially in bringing the case of comfort women to the diplomatic and legal foreground and has substantial potential to assist in interpreting IHL norms.

As it has been explained above, "comfort women" system came to light only many decades after the World War II. While many reasons could be found to explain the silence on the

\footnotetext{
932 See Report on apologies for gross human rights violations and serious violations of international humanitarian law, Special Rapporteur on the promotion of truth, justice, reparation and guarantees of non-recurrence Fabián Salvioli, UN GA A/74/147, 12 July 2019.

${ }^{933}$ On the relationship between IHL and IHRL, see, for example, Jinks, Derek, "International Human Rights Law in Time of Armed Conflict", in Clapham, Andrew and Gaeta, Paola (eds.), The Oxford Handbook of International Law in Armed Conflict, Oxford University Press, Oxford, 2014. On the concept of "Humanisation" of international humanitarian law and the influence of the human rights regime on international humanitarian law, see Meron, Theodor, The Humanization of International Law, Martinus Nijhoff, Leiden, 2006.

${ }^{934}$ A distinction has been made between women's rights and women's human rights. Women's rights are defined as rights specifically connected to women, such as, the rights associated with reproductive and maternity choice and the right to a minimum wage for domestic work; vice versa, women's human rights are the general norms of human rights applicable to women in specific contexts. This distinction has been studies by N. Borrows, 'International law and human rights: the case of women's rights' in Campbell, Tom, Goldberg, David, McLean, Sheila and Mullen, Tom (eds.) Human rights: from rhetoric to reality, Basil Blackwell, New York, 1986, pp. 80, 89-96.
} 
issue, ${ }^{935}$ the causes that permitted an international debate over it to spread at international level are well documented. The bilateral compensation dispute between the Republic of Korea and Japan became an international affair_through the submission of a petition by Lee Hyo-chae, the then co-chair of the KCWS (the Korean War and the Korean Comfort Women Station System), to the U.N. Human Rights Commission, on 4 March 1992. ${ }^{936}$ The petition requested the Commission to investigate the heinous acts committed by Japanese Army against Korean comfort women during World War II and to press the Government of Japan to pay reparation to women who individually had filed suits. In August 1992, the UNHRC put the issue on its agenda and, by then on, it started a series of hearings and launched their own investigationsassigning Special Rapporteurs. The UNHRC's Sub-commission for the Prevention of Discrimination and Protection of Minorities described the comfort women system as a «crime against humanity that violated the human rights of Asian women». ${ }^{937}$

The interest for an analysis of the historical facts and the legal issues related to the comfort women case is particularly expressed in two main reports prepared by the Special Rapporteurs Radhika Coomaraswamy and Gay McDougall, respectively in 1996 and 1998. Coomaraswamy was appointed to write the Report on the mission to the Democratic People's Republic of Korea the Republic of Korea and Japan on the issue of military sexual slavery in wartime within a study on "violence against women: its causes and consequences" promoted by the UNCHR.938 McDougall's work was the result of a specific interest of the UNHCR's Sub-commission on Prevention of Discrimination and Protection of Minorities toward contemporary forms of enslavement. Appointed by the Sub-commission with Decision 1997/114, McDougall wrote the Report on systematic rape, sexual slavery and slave-like practices during armed conflict. ${ }^{939}$

\footnotetext{
${ }^{935}$ In particular, Hicks hypothesizes that the attitude of indifference toward the issue could be traced back to a series of causes that interacted with each other. The civil conflict in which Korea fell at the end of the World War II, followed by the Korean War in the early 1950ies, certainly contributed to obscure the problem. It can also be added that the investigation over facts committed against the humblest sections of the population was not, probably, among the priorities of the upper class at that time. However, Hicks underlines that the unfavourable historical context and the low social status of the women involved were not the only causes which led to the irrelevance of the problem. Also, another reason could be found in the general conception of rape and sexual violence as inevitable and collateral effects of the war. Hicks, George, The comfort women: Japan's brutal regime...pp. 172-173.

${ }_{936}$ Soh, Chunghee Sarah, “The Korean 'Comfort Women': Movement for Redress”,...pp. 1234-1235.

937 Ibid.

${ }^{938}$ Coomaraswamy, Radhika, Report on the mission to the Democratic People Republic of Korea, the Republic of Korea and Japan on the issue of military sexual slavery in wartime, U.N. ESCOR, 52 nd Sess., Provisional Agenda Item 9(a), U.N. Doc. E/CN.4/1996/53/Add.1 (1996).

${ }_{939}$ McDougall, Gay J., U.N. Special rapporteur contemporary forms of slavery, Final Report on systematic rape, sexual slavery and slave-like practices during armed conflict, E/CN.4/Sub.2/1998/13, 22 June 1998, Appendix, An analysis of the legal liability of the government of Japan for "comfort women stations" established during the second world war.
} 
The Report has a specific section on comfort women issue: the case was indeed the main reason which motivated the Sub-commission to delegate this work. Both Reports introduce comfort women case as a human rights issue. In this sense, the "violence against women" discourse is useful to the U.N. understanding of the case within the women's rights framework. ${ }^{940}$ Comfort women system started to be described as a case of sexual slavery and comfort stations as rape centers. This characterization was part of the superior effort to consider women's rights as human rights and to recognize violence against women as an international law issue. ${ }^{941}$ These U.N. documents allowed "comfort women" case to be regarded not only as a collateral effect of war but also as a dramatic event raising important human rights issues.

The influence of human rights law over the issue of the "comfort women" system is particularly evident in two aspects analysed above. First, the question as to whether the Four Geneva Conventions of 1949 contain norms granting rights to individuals. Second, the question of whether it is possible to interpret post-war peace treaties in light of the subsequent human rights treaties.

With regard to the first issue, the evaluation of the existence of international humanitarian law norms which encapsulate individual human rights is strictly connected to the question of whether an individual right to reparation can be attributed to victims of violations of international humanitarian law. In particular, using the paradigm of the international responsibility of the State, it could be said that existence of individual substantive rights stemming from IHL is a necessary, even if not sufficient, precondition for a secondary individual right to reparation to exist. This concept is expressed by Professor Peters, who states that

Direct individual rights flowing from the primary norms of IHL are - even if no necessary a pre-condition - a facilitator for recognizing rights to reparation in the event of the violation of the concrete primary norm. ${ }^{942}$

The identification of an individual right from the primary norms of IHL generates "as a matter of principle" an individual "secondary" right to reparation in case of breach of the specific

\footnotetext{
${ }^{940}$ For a critic of the use of the human rights framework in analyzing the "comfort women" case, see Lee, Elisa, "Behind the Mask of Human Rights: 'Comfort Women', Heteronormativity, \& Empires", Tapestries: Interwoven voices of local and global identities, Vol. 4, Issue 1, No. 4, (2015) 1-10.

${ }^{941}$ Ueno, Chizuko, Nationalism and Gender, Trans Pacific Press, Melbourne, 2004, [Translation by Beverly Yamamoto], p. 88.

942 Peters, Anne, "Right to Reparation as a Consequence of Direct Rights Under International Humanitarian Law", Zeitschrift für ausländisches öffentliches Recht und Völkerrecht, Vol. 78, No. 3, (2018), 545.
} 
primary norm. ${ }^{943}$ In this sense, the new awareness introduced by the human rights discourse leads to reconsider the extent of applicability of international humanitarian law norms. In particular, some provisions of IHL would be applicable not only to States, but they should be also interpreted as to recognize substantial rights to individuals. ${ }^{944}$ The identification of individual rights in IHL norms could, consequently, justify the idea of an individual right to reparation in case of violation of these rights. This reasoning could be helpful to comfort women's claims of reparation. Indeed, whether the comfort women system constitutes a violation of one or more primary norms of the 1949 Geneva Conventions encapsulating an individual right, a right to reparation to comfort women could be recognized.

As regards the second issue, namely an interpretation of post-war peace treaties in accordance with subsequent human rights Conventions, one may ask whether it is possible to interpret the 1965 Settlement Agreement Between Japan and the Republic of Korea using the lens of women's rights Conventions.

Considering that the 1965 Settlement Agreement was adopted in a period in which women's rights were not recognized to the same degree as they are today, should current national courts interpret the norms of the Agreement evaluating which would have been the intention of the parties if they had been conscious of the recent human rights regime applicable to comfort women ${ }^{945}$ In particular, one may refer to the Convention on the Elimination of All Forms of Discrimination Against Women (CEDAW), to which both Japan and Korea are parties, which states that the Parties to the Treaty shall ensure to guarantee the legal protection and the same opportunities to women. ${ }^{946}$ The comfort women system, as a scheme of women sexual enslavement which was not considered during the negotiations for the peace treaties in the aftermath of the War, would be considered nowadays a violation of the CEDAW. While it could be difficult to interpret the 1965 Settlement Agreement in accordance with the CEDAW in order to grant an individual right to reparation to former comfort women, however it could be said that victims of the comfort stations system are not restricted by the 1965 Settlement

\footnotetext{
${ }_{943}$ Ibid. p. 549.

${ }^{944}$ Scholarship is split on the question of whether IHL encapsulates rights of individual. According to some scholars, IHL norms merely introduces standards of protection for individuals so that IHL is a not-rights-basedconstruction. In this sense, Provost, René, International Human Rights and Humanitarian Law, Cambridge University Press, Cambridge, 2002, pp. 26-34.

${ }^{945}$ For the interpretation of a peace agreement of the WW II in the light of the subsequent IHRL treaties signed by the parties, see: Kwon, Jennifer, "The Comfort Women Litigation and the San Francisco Treaty: Adopting a Different Principle of Treaty Interpretation", George Washington Law Review, Vol. 73, No. 3, (2005) 649-667. ${ }^{946}$ Convention on the Elimination of All Forms of Discrimination Against Women, December 18, 1979, 1249, U.N.T.S. 13 [hereinafter: CEDAW].
} 
Agreement because of the lack of Parties' intent to consider their rights during peace negotiations. In this sense, the waiver clause contained in the 1965 Agreement between Japan and Korea would be interpreted as to apply only to the original issues contemplated by the parties in order to exclude its application for comfort women claims. In other terms, an interpretation of the 1965 Agreement between Japan and Korea in light of the CEDAW would support the idea that the waiver clause does not cover the issue of reparation for the breaches of humanitarian law committed against the comfort women. ${ }^{947}$

\subsection{Concluding remarks}

To sum, the real problem with the "comfort women" case is the result of a State-centric approach to reparations, where the form of reparation chosen, the context, the language used, do not consider the specific group of victims in the process for the development of a full reparation.

On the one hand, Japanese incapacity to recognize its legal responsibility has as main consequence the victim's rejection of any form of ex gratia payment and the non-recognition of public remorse statements as official and sincere apologies. It is true that the position of Japan on the matter seems in line with the "mainstream" nationalist revisionism of Japanese political discourse that tends to minimize the crimes the State committed in the World War II in favour of a victimhood narrative. ${ }^{948}$ However, Japanese long and impervious process of reparation to comfort women seems to go further this revisionist wave and to assume a gender character. In particular, Japan encounters the deep difficulties that States have in order to recognize, first, the international relevance of international crimes against women, and, consequently, their dignity for awarding redress. It is argued that gender category cannot be dissociated from the study of this case, not only for the gender form of violence that hurt former

\footnotetext{
947 The idea of the interpretation of the 1965 Settlement Agreement in light of the CEDAW is in line with the recent question of whether it is possible to interpret past treaties and Conventions in accordance with the current view of the individual in international law and, consequently, whether or not IHL norms are directly applicable to individuals so that individuals may invoke IHL norms for their compensation claims. With regard to "comfort women", the issue is discussed in Boling, David, "Mass Rape, Enforced Prostitution, and the Japanese Imperial Army: Japan Eschews International Legal Responsibility?",...pp. 562-563.

${ }_{948}$ Milanovic, Marko, "Courting Failure: When Are International Criminal Courts Likely to be Believed by Local Audiences?", in Heller, Kevin, Mégret, Frédéric, Nouwen, Sarah, Ohlin, Jens and Robinson, Darryl, The Oxford Handbook of International Criminal Law, Oxford University Press, Oxford, 2020, pp. 276-277.
} 
"comfort women", but also for the way the relevant States, both the responsible and the injured one, managed with the case at hand.

On the other hand, the weak diplomatic position of the Korean Government seems to be counter-balanced by the vigorous attitude of the South Korean courts, which have intervened in different occasions to settle relevant questions on the matter, such as the interpretation of the Claims Agreement so as to clarify that the rights of the "comfort women" to claim reparation is outside the scope of such treaty, and the relevance of the State immunity principle when serious violations of IHL are involved as in the case at stake.

In this context, the development of the human rights regime and its contribution to the reach of a new awareness on women's rights seem to give some other chances to the victims of the comfort women system. Indeed, the women's human rights system not only played an important role on the worldwide recognition of the issue of comfort women, but, as the 2021 Seoul Central District Court's decision demonstrated, it also had a relevant function in the legal understanding of the issue. 


\section{CONCLUSIONS}

During the last decades, significant progress in the study of conflict-related violence against women as violations of IHL prepared the ground for the prosecution of crimes against women both at the national and the international level. Yet, notwithstanding these advances, international legal scholars, especially feminist scholars, criticize the IHL regime for failing to adequately respond to the numerous ongoing crimes committed against women in the warfare. This criticism has often structural characteristics: it is claimed that IHL is irreversibly biased against women, in a way that cannot be remedied through interpretation. The present research aimed at addressing this question and contributing to this literature. It sought to offer a coherent overview of the basic IHL rules addressing wartime violence against women and their potential in addressing some of the questions set by contemporary gender studies.

The object of this thesis was the study of IHL rules addressing conflict-related violence against women as well as the relevant rules on reparations. Around this object of investigation, two basic lines of enquiry has been pursued, as grounding themes throughout this work. The first is the relevance of the category of gender for the study of humanitarian law dealing with wartime violence against women. This basic theme brings into the analysis elements of other disciplines, calling for an interdisciplinary approach. Concretely the thesis had recourse to gender studies and feminist critiques to international law, which offer important insights for understanding the contemporary position of women in armed conflict. The second line of enquiry of this investigation was to form a view on the adequateness of the IHL regime in bello and the post bellum applicable rules on reparation, in addressing conflict-related violence against women. This theme was closely linked to the radical gender critique to the applicable rules, which argues that the rules governing violence against women are irreversibly biased and thus the legal treatment of women caught in conflict can never truly account for their specific vulnerabilities. From this perspective, this thesis investigated whether a genderoriented interpretation of IHL is possible and whether this interpretation could reflect the particular condition of women in war, as revealed by modern feminist studies, and thus ultimately guarantee a better protection of women. These objectives and basic themes were pursued in two Parts. 
Part One of the thesis demonstrated that many of the valid feminist critiques with regard to basic jus in bello IHL rules can be addressed by a gender-oriented reinterpretation of the current rules of IHL; a complete overhaul of the regime is neither necessary nor desirable.

Chapter 1 set the scene, providing a general picture of the main feminist engagements with international law and with IHL in particular. This Chapter reflected on the theoretical background of wartime violence against women, introducing the basic issues. For this purpose, it used insights from other disciplines, in particular gender studies. This discussion had a twofold purpose, semantic and methodological. First, considering that language is at the basis of the analysis of any human phenomenon including its legal understanding, the analysis of the legal terminology led to a reflection on the most accurate legal language to address wartime violence against women. This Chapter demonstrated why "gender", a concept going beyond 'sex' to cover the social attributes and opportunities associated with being male and female and the relationships between women and men, is also useful in the context of armed conflict and IHL. Having regard also to this concept of gender, a definition of "conflict-related violence against women" was then offered. Conflict-related violence against women was defined as violence that occurs against female subjects - girls and women - during or in the immediate aftermath of armed conflict, international or not, and which has a specific nexus with the conflict. $^{949}$ This definition also demarcated the scope of research. The second basic contribution of Chapter 1 was the analysis of the limits of IHL in the legal protection of women. This provided a critical lens that was used throughout the thesis. As the overview of the basic elements of the feminist approaches to international law showed, reading international law and IHL from a gender-sensitive perspective reveals a number of critical issues that might otherwise remain obscure. For example, the use of concepts such as "sovereignty", "the use of force" and "military necessity" gets some additional (or even alternative) significance if seen also from the perspective of women. The concept of "military necessity", for instance, could have as implication that women's life and interests, as predominantly civilians, will always rank after the target of military victory of the State and its pursuance by (male) combatants.

But how radical are the implications of such feminist critiques? According to some authors, they are so important that even to label IHL as 'humanitarian law' would be a misnomer.950

\footnotetext{
949 On the type of nexus, see under 1.2.2.

950 Gardam, Judith, "A Feminist Analysis of Certain Aspects of International Humanitarian Law", Australian Yearbook of International Law, Vol. 12, (1992) 265-278, p. 267.
} 
This thesis did not find sufficient grounds for this radical approach. Instead of following the "revisionist" approach, namely the view according to which IHL would be an irreversible male regime that would need to be rewritten to accommodate a female perspective, this thesis has accepted that a gender-oriented interpretation may be sufficient to address many of the concerns of feminist critics. Ultimately, this approach positions the work in a perspective that constructively understands the flexibility of IHL and its inherent potential to be interpreted as to enhance the protection of women in conflict.

Starting from these premises, Chapters 2 and 3 turned to some of the most female-relevant rules of the Geneva Conventions. From a descriptive-doctrinal perspective, this part of the thesis offered and overview of some of the most important rules applicable to women in armed conflict. From a more analytical-critical perspective, it investigated whether a gender-sensitive interpretation allows to overcome certain limitations that seem to derive from the text of the norms. This part concluded that, despite the existence of some limits in the text of the IHL rules, which often reflect an outdated idea of women or the use of narrow and biased concepts, there is important flexibility inherent in most IHL norms relevant for women. This flexibility allows taking into account specific female considerations. This IHL flexibility proves particularly relevant with regard to the principle of non-discrimination, the norms guaranteeing specific care for pregnant women caught up in the conflict, and the regime for differentiated treatment for interned women and women POWs.

Especially the principle of non-discrimination may allow for a great degree of flexibility. Tested in the context of the law of occupation, this principle can provide answers to some of the basic legal challenges deriving from contemporary forms of occupation, such as long-term occupation, and in some of the specific problems that women face in such contexts. The specific norms related to the medical care for pregnant women caught up in the conflict have also been "put to the test". In that case, the critical question was whether these rules also provide for an obligation for the Parties to the conflict to guarantee abortion services for survivors of wartime rape. The analysis concluded that the generality of the norms of specific care for pregnant women, read in light of their essential humanitarian purpose, leave important room for a legal interpretation that accounts for women's medical needs in this context. In this sense, an interpretation of the norms that excludes abortion services to raped survivors would seem contrary to the spirit of the norms. The same can be said in relation to the IHL norms providing a regime of differentiated treatment for interned women and women POWs. Here a basic question was whether IHL may be read as to cover the issue of foreign minor brides - a 
problem that is unfortunately of great relevance in some contemporary conflicts. Although the regime was neither originally designed to face this specific problem nor it provides specific guarantees to women deprived of their liberty in NIACs, the analysis concluded that the status of civilians, as regulated under the IV Geneva Convention, would guarantee women their release or repatriation.

Two general conclusions may be drawn from these observations. First, some of the feminist critiques should be read as part and parcel of the more general approach towards a humanitarian-oriented reinterpretation of IHL. In this sense, the overall process towards humanization of IHL may both reinforce and benefit from feminist approaches, which have provided important insights on the issues of protection of women in conflict. Second, the specific issue of conflict-related violence against women has given the author the opportunity to reflect upon some of the most critical contemporary issues of IHL. Ultimately, it has been shown that some of the difficulties and limits that IHL faces with regard to conflict-related violence against women are closely connected with some of the broader challenges that IHL faces in modern wars. Certain general issues of IHL, such as the extent of application of its norms to cases of long-term occupation or the outdated distinction between IACs and NIACs, are directly linked to the protection afforded to women. The general gaps in the application of IHL to long-term occupations or the deficient normative framework applicable in NIACs are particularly evident if one applies a gender lens. In other words, the general problems that IHL faces in current conflicts have greater negative implications in the protection of women in situations of conflict. Female vulnerabilities magnify and reinforce legal issues of broader relevance.

Of course, this is not to say that there are no specific IHL challenges with regard to the protection of women from conflict-related violence. The most pertinent example is the controversial interpretation and applicability of Article 27, paragraph 2 of the IV Geneva Convention. The analysis of the most disputed terms of this norm, namely "honour" and "rape", showed two main problems with the women's treatment under IHL. The first problem is the outdated perception of conflict-related sexual violence against women as an attack to women's honour and morality, rather to her as individual. This is an approach attached to an old conception of women's chastity, rather than a violation of women's physical and sexual integrity. The second problem is the only partial recognition of the gravity of the acts of violence committed against women during conflict. The lack of a single international definition of the crime of "rape" by the jurisprudence of the ad hoc tribunals as well as its non-inclusion 
in the category of acts constituting grave breaches are indicative of the legal complexities surrounding this issue. However, this thesis suggested that an evolutive interpretation of the norm is possible through a gender-oriented understanding of Article 27 paragraph 2. Chapter 3 explained in detail how gender perspectives can be indeed reflected in the interpretation of this norm. Moreover, it has been argued that this reinterpretation of Article 27 paragraph 2 was not only serving women's protection in the warfare, but it was also a means to put the value of human dignity at the centre of IHL.

Part Two turned to the post bellum phase. The basic object of the analysis was the reparation mechanism and its potential to provide redress to women subjected to conflict-related violence. To address the topic, the analysis focused on the study of the law of State responsibility.

Chapter 4 revealed that there are limits in the different forms of reparations when it comes to dealing with female survivors. These limits are basically the result of a general lack of a gendersensitive reflection in the overall design and the traditional application of the system of war reparations. Since women were not the usual beneficiaries of the system of reparations, their specific needs were not envisaged by the mechanism. This is particularly the case with regard to the hierarchy of the forms of reparation reflected under the Articles on State responsibility, which assume that restitution and compensation are the best forms of reparation for the victims and downgrade symbolic forms of reparation. This thesis has used a gender perspective to show that the latter forms of reparation may have a higher value for women and are usually particularly appreciated by female victims. It has been suggested that this needs to be reflected in the application of the law of responsibility.

This discussion about a gender-approach to reparations may indeed contribute to the recent debate on the degree of flexibility that the States have in the choice of the forms of reparation, ${ }^{951}$ especially when individuals are the final beneficiaries of the reparation claim. It was here suggested that gender should be one of the parameters to contemplate when considering the appropriateness of certain forms of reparation, having due regard to the nature of the violation committed and the category of victims to be redressed. Indeed, the gendered aspects of the crime and the gender of the victims play a relevant role in the adequacy of the form of reparation and its subsequent effectiveness.

\footnotetext{
${ }^{951}$ Report of the International Law Commission, seventy-first session, A/74/10, (29 April-7 June and 8 July-9
} August 2019) The Report of the ILC's seventy-first session, Annex B, p. 362. 
In Chapter 4 it has been claimed that a broader understanding of the potential residing in the choice of the different forms of reparation and how they may affect the reparation system into a more transformative mechanism is a key aspect in addressing the redress for conflict-related violence against women. In operating with female survivors, the narrowness of a rigid concept of reparation becomes evident, in particular the assumptions that accompany the implicit hierarchy of the forms of reparation and the State-centric approach.

Against this general background, Chapter 5 turned to the analysis of the ongoing Korean "comfort women" case. This case was selected and discussed in great extent as a particularly paradigmatic example of the relevance of a gender approach when choosing the best form of reparation for female survivors. The Korean "comfort women" case, characterized by specific gender-sensitive aspects such as the injured group and the crimes to which it was subjected, provided a vivid example of the relevance of symbolic forms of reparation for restoring the victims. In particular, former "comfort women" considered satisfaction, in the forms of request of an official apology and memorialization, as the best form of reparation to restore their dignity. However, the lack of a gender-sensitive approach to reparations in the Japanese stance affected the victim's perception and acceptance of the diplomatic efforts undertaken and the inter-States negotiations on the issue, thus undermining a possible settlement on this longstanding dispute.

Recent developments, and in particular the 2021 Seoul Central District Court's judgment, offered a turning point in the "comfort women" case. These developments, on which the thesis focused in detail, revealed the real potential of a gender-oriented perspective in the analysis of cases of conflict-related violence against women, and, ultimately, in the development of general IL. In this fundamental judgment, by denying the general IL principle of state immunity for a case of military sexual slavery, the Court granted redress and justice to the victim. At the same time, it set an important precedent which is in line with the broader direction advocated by gender-oriented scholarship, namely the direction that privileges the centrality of the human being considered in his/her integrality and gender connotations in the interpretation of international law.

This recent decision confirmed one of the thesis' basic standpoints, in that it used a case of conflict-related violence against women for making a decisive step within the path of evolution of international law towards a greater centrality of the individual. The search for an effective legal protection of women under the IHL regime offered the occasion not only to realize the 
victims' claims, but also to make a step towards the advancement of international law standards of protection for individuals.

Finally, this thesis addressed the overall question whether there is lack of a coherent legal framework in the protection of women from conflict-related violence. The analysis of the IHL rules and the law of responsibility suggested two things. First, that these separate rules need to be read systematically as a separate sub-field of research of international rules governing armed conflict. Second, that the limits associated with some seemingly outdated concepts of this regime may be overcome through the use of a gender-sensitive lens and the appropriate means of interpretation.

This conclusion should be put in the context of some broader questions. Which could be the best way to enhance the treatment of women under IHL? In other words, how could IHL develop as to offer better protection for women in conflict and post-conflict situations? What should be the way ahead for the international law of armed conflict and the position of women in it?

As already argued, the evolutive interpretation of the existing IHL norms is an essential means for a renewed, gender-oriented understanding of the protection of women accorded under IHL. The updated Commentaries to the 1949 Geneva Conventions, prepared by eminent scholars under the auspices of the ICRC, may have a crucial role in this direction. The first updated Commentaries to the Geneva Conventions I, II and III ${ }^{952}$ have already moved towards "an important shift in underpinning gender assumptions", ${ }^{953}$ thus supporting the main argument of this thesis. It is suggested that this potential is even greater with regard to an updated Commentary to the Geneva Convention IV. In particular, an updated renewed interpretation of Article 27, paragraph 2 of the Geneva Convention IV may provide significant insights as for a definitive overcoming of the traditional and outdated focus on protecting women's modesty and honour rather than her as an individual. Moreover, this step could dissolve any reservation over the classification of rape and other serious forms of sexual violence as grave breaches of IL. Furthermore, an updated Commentary to the Geneva Convention IV could better specify the guarantees accorded to female civilians under the Convention, also considering the

\footnotetext{
952 See https://www.icrc.org/en/icrc-databases-international-humanitarian-law.

953 O’Rourke, Catherine, “Geneva Convention III Commentary: What Significance for Women's Rights?”, Just Security, (October 21, 2020), available at: https:/www.justsecurity.org/72958/geneva-convention-iiicommentary-what-significance-for-womens-rights/?fbclid=IwAR1XN2u-P8ZcLruDJlx7Fk6DG9X9cGz0qENM2 FRC4E-djo6Ho6-Hdp5L0 [Last visited, 28 February 2021].
} 
increased recognition of the different experiences of women in conflict as well as the various forms of violence to which they are subjected.

There are two main reasons to privilege the update of IHL Commentaries rather than amending the rules. ${ }^{954}$ First, updated Commentaries permit to modernize IHL without risking to erode its international legitimacy or putting into question previous efforts to solve specific women's issues through the existing IHL norms. Second, updated Commentaries take into account developments of other emerging fields of IL in order to provide for a comprehensive understanding of the Conventions' norms.

Nevertheless, given the magnitude and gravity of the forms of violence committed against women in conflict, one may ask whether there is still a need to consider new rules altogether, such as the introduction of a specific convention against the most recurrent gender-based forms of violence against women, namely rape and sexual violence. In this regard, it seems still unresolved the question of whether a unique statutory definition of rape and sexual violence would reinforce the criminalization of these offences as well as whether a specific convention on the matter could really have a deterrent effect on the Parties. One could even think that this would lead to a specific understanding prevailing over the others - that can even be the minimum common denominator to which the States can agree rather than what real reflects women's needs. The analysis above showed that international tribunals, despite the difficulties and unavoidable inconsistencies, may help to read legal concepts like rape in a way that takes into account modern ideas about female physical and sexual integrity. Another quite unexplored possibility of treaty reform could be the drafting of a fourth Additional Protocol to the Geneva Conventions specifically dealing with the protection of women in conflict. ${ }^{955}$

In any case, whatever way is chosen, of interpretation or of a new legal instrument, IHL will never be sufficient alone. Despite the opportunity to interpret applicable rules in a gendersensitive way or the possibility of introducing new norms, it is ultimately up to the international and national actors to implement them. IHL is a valid instrument to guide the conduct of the Parties in conflict. However, one cannot ignore the enforcement problem and the risk that the Parties decide to ignore IHL, or the risk of "politicized interpretations and implementation of

\footnotetext{
${ }^{954}$ For an overview of the feminist suggestions to solve gender deficiencies identified in IHL, see Bennoune, Karima, "Do We Need New International Law to Protect Women in Armed Conflict?", Case Western Reserve Journal of International Law, Vol. 38, No. 2 (2007), 363-392, pp. 387-391.

955 For a discussion on this proposal, see Gardam, Judith, "Women and the Law of Armed Conflict: Why the Silence?”, International and Comparative Law Quarterly, Vol. 46, No. 1 (1997) 55-80.
} 
its rules". 956 These risks pose some outer limits to the potential of IHL to address violence against women. In these cases, the Parties maintain the legal and moral responsibility over their acts, which cannot be attributable to an alleged failure of IHL rules.

In sum, this thesis has demonstrated that the analysis of the IHL regime from a gender perspective is both possible and means more than just addressing women's interests. This reading brings women-relevant rules together in a holistic body and informs its interpretation. A gender perspective may be more than that, however. It can contribute to the general debate on the nature, role and purpose of IHL. After all, a gender sensitive approach to the international law norms relevant for armed conflict - in particular a gender sensitive approach to the interpretation of the IHL provisions on the one hand, and to the reparation mechanism on the other hand - may be regarded as inspired by the overriding principle of humanity, which informs the 1949 Geneva Conventions and their Additional Protocols of 1977.

IHL is intrinsically victim-oriented. Indeed, IHL regime as a whole has been rightly qualified as the expression of some basic general principles, such the principle of humanity. ${ }^{957}$ The present thesis argued that these principles and their concrete expression in gender terms can and should be used as interpretative guides to address the specific condition of women in war. At the same time, taking seriously the specific experience of women in war means focusing on the individual as ultimate addressee of all law, including international law. From this perspective, a (re)interpretation of IHL norms from a gender perspective is not only about women. It is a part of the broader enterprise of humanization of IHL and international law in general.

\footnotetext{
${ }^{956}$ ICRC, International humanitarian law and the challenges of contemporary armed conflicts, Vol. 89, No. 867 (2007), p. 720. Available at: https://www.icrc.org/en/doc/assets/files/other/irrc-867-ihl-challenges.pdf

${ }^{957}$ Abi-Saab, Rosemary, "Les 'Principes généraux' du Droit humanitaire selon la Cour Internationale de Justice", Revue internationale de la Croix-Rouge, Vol. 79, Issue 766, (1987), pp. 386, 389.

The author, with regard to the obiter dicta of the ICJ in the Nicaragua v United States case (1986), stated: "Pour la Cour en effet, il ne s'agit pas, comme ont essaye de le faire certains experts, de rechercher dans les Conventions de Genève celles de leurs dispositions qui pourraient être qualifiées de principes généraux s'imposant en toute circonstance, mais d'envisager les Conventions elles-memes comme des instruments qui ne font qu'exprimer ou developper ces principes généraux" (p. 386).

"l'appartenance au droit international general des principes generaux de base du droit humanitaire, c'est-a-dire leur applicability en toute circonstance, afin de mieux assurer la protection des victimes" (p. 389).
} 


\section{BIBLIOGRAPHY}

Adams, Alexandra, "The First Rape Prosecution before the ICC: Are the Elements of Crimes Based on a Source of International Law?", International Criminal Law Review, Vol. 15, No. 6, (2015) 1098-1121

Adams, Alexandra, "The Legacy of the International Criminal Tribunals for the Former Yugoslavia and Rwanda and Their Contribution to the Crime of Rape", European Journal of International Law, Vol. 29, No. 3, (2018) 749-769

Akande, Dapo, "Classification of Armed Conflicts", in Saul, Ben and Akande, Dapo (eds.), The Oxford Guide to International Humanitarian Law, Oxford University Press, Oxford, 2020

Akande, Dapo, "Sources of International Criminal Law", in Cassese, Antonio (ed.), The Oxford Companion of International Criminal Justice, Oxford University Press, Oxford, 2009

Allen, Louise and Shepherd, Laura J., "In pursuing a new resolution on sexual violence Security Council significantly undermines women's reproductive rights", LSE Women, Peace and Security blog, 25 April, 2019, available at: https://blogs.lse.ac.uk/wps/2019/04/25/in-pursuing-a-new-resolution-on-sexualviolence-security-council-significantly-undermines-womens-reproductive-rights/

Amaya Castro, Juan M., "Feminism and International Law: 20 years after Charlesworth, Chinkin and Wright", Runnymede Lecture, Universiteit van Amsterdam, 9 June 2011, available at: https://papers.ssrn.com/sol3/papers.cfm?abstract_id=2314504

Amnesty International, “'Our Job Is to Shoot, Slaughter and Kill': Boko Haram's Reign of Terror in North-East Nigeria", 14 April 2015, available at: https://www.amnesty.org/en/documents/afr44/1360/2015/en/

Amnesty International, "Nigeria: Security forces failed to act on warnings about Boko Haram attack hours before abduction of schoolgirls", 20 March 2018, available at: https://www.amnesty.org/en/latest/news/2018/03/nigeria-abduction-of-schoolgirlssecurity-forces-failed-to-act-boko-haram/

Amnesty International, "South Korea: Lawsuits against Japanese government last chance for justice for 'comfort women"”, (12 August 2020), available at: https://www.amnesty.org/en/latest/news/2020/08/south-korea-lawsuits-against-thejapanese-government-last-chance-for-justice-for-comfort-women/

Amnesty International, Report "Whose Justice? The Women of Bosnia and Herzegovina are Still Waiting", 30 September 2009, available at: https://www.amnesty.org/download/Documents/48000/eur630062009eng.pdf

Amnesty International's Submission to the Honorable Judges of The Seoul Central District Court Concerning the Case of Kwak Ye-Nam Et. Al. v. Japan (2016 Ga-Hap 580239), available at: https://amnesty.or.kr/wp-content/uploads/bcp-attach/Amnesty- 
Submission-to-the-Honorable-Judges-of-the-Seoul-Central-District-Court 12-112019 final-1.pdf

Anzilotti, Dionisio, Corso di diritto internazionale, Volume primo, Introduzione - Teorie generali, IV edizione, Ceda, Padova, 1955

Appiah, Kwame Anthony, The Honor Code: How Moral Revolutions Happen, Norton, New York, 2010

Arai-Takahashi, Yutaka, "War Crimes relating to child soldiers and other children that are otherwise associated with armed groups in situations of non-international armed conflict. An incremental step toward a coherent legal framework?", Questions of International Law, 23 September, 2019, available at: http://www.qil-qdi.org/warcrimes-relating-to-child-soldiers-and-other-children-that-are-otherwise-associatedwith-armed-groups-in-situations-of-non-international-armed-conflict-anincremental-step-toward-a-coherent-legal/

Arai-Takahashi, Yutuka, The Law of Occupation: Continuity and Change of International Humanitarian Law, and Its Interaction with International Human Rights Law, Martinus Nijhoff, Leiden-Boston, 2009

Arakawa, Maki, “A New Forum for Comfort Women: Fighting Japan in United States Federal Court”, Berkeley Journal of Gender, Law. \& Justice, Vol. 16, Issue 1, (2001), 174200

Arato, Julian, "Subsequent practice and evolutive interpretation: techniques of treaty interpretation over time and their diverse consequences", The Law and Practice of International Courts and Tribunals, Vol. 9, No. 3 (2010) 443-494

Argibay, Carmen M., “Sexual Slavery and the 'Comfort Women' Of World War II”, Berkeley Journal of International Law, Vol. 21, No. 2, (2003) 375-389

Askin, Kelly, "Prosecuting wartime rape and other gender-related crimes under International Law: Extraordinary Advances, Enduring Obstacles", Berkeley Journal of International Law, Vol 21, No. 2 (2003) 288-349

Askin, Kelly, "The international war crimes trial of Anto Furundžija: A Mayor Progress Toward Ending the Cycle of Impunity for Rape Crimes", Leiden Journal of International Law, Vol. 12, No. 4 (1999) 935-955

Askin, Kelly, "Women and International Humanitarian Law", in Askin, Kelly and Koenig, Dorean (eds.), Women and International Human Rights Law, Vol. 1, Transnational Publishers, New York, 1999

Askin, Kelly, War Crimes against Women: Prosecution in International War Crimes Tribunals, Martinus Nijhoff, The Hague, 1997

Bank, Roland and Schwager, Elke, "Is there a Substantive Right to Compensation for Individual Victims of Armed Conflict against a State under International Law?", German Yearbook of International Law, Vol. 49 (2006), 367

Bartlett, Katharine T., "Feminist Legal Methods”, Harvard Law Review, Vol. 103, (1989) 829 
Bartolini, Giulio, "A Universal Approach to International Law in Contemporary Constitutions: Does It Exist?", Cambridge Journal of International and Comparative Law, Vol. 3, Issue 4 (2014), 1287

Baumeister, Hannah, Sexualised Crimes, Armed Conflict and the Law. The International Criminal Court and the Definitions of Rape and Forced Marriage, Routledge, Abingdon, 2018

Bell, Christine and Forster, Robert A., "Constituting Transitions. Predicting Unpredictability", in De Groof, Emmanuel H. D. and Wiebusch, Micha, International Law and Transitional Governance. Critical Perspectives, Routledge, London and New York, 2020

Bell, Christine and McNicholl, Kevin, "Principled Pragmatism and the 'Inclusion Project': Implementing a Gender Perspective in Peace Agreements”, Feminists @ Law, Vol. 9, No. 1 (2019), 1-51

Bell, Christine and O'Rourke, Catherine, "Peace Agreements or Pieces of Paper? The Impact of UNSC Resolution 1325 on Peace Processes and Their Agreements", International \& Comparative Law Quarterly, Vol. 59, No. 26 (2010), 941-980

Bell, Christine, "Peace Agreements: Their Nature and Legal Status", American Journal of International Law, Vol. 100, No. 2 (2006), 373-412

Bell, Christine, "Transitional Justice, Interdisciplinarity and the State of the 'Field' or 'NonField"”, International Journal of Transitional Justice, Vol. 3, No. 1 (2009), 5-27

Bell, Christine, "Women, Peace Negotiations, and Peace Agreements: Opportunities and Challenges", in Ní Aoláin, Fionnuala, Cahn, Naomi, Haynes, Dina Francesca and Valji, Nahla (eds.), The Oxford Handbook of Gender and Conflict, Oxford University Press, Oxford, 2018

Bell, Christine, Text and Context: Evaluating Peace Agreements for their 'Gender Perspective, UN Women Research Paper, (2015), available at https://wps.unwomen.org/pdf/research/Bell_EN.pdf

Bennoune, Karima, "Do We Need New International Law to Protect Women in Armed Conflict?”, Case Western Reserve Journal of International Law, Vol. 38, No. 2 (2007), 363-392

Benshoof, Janet, "The Other Red Line: The Use of Rape as an Unlawful Tactic of Warfare", Global Policy, Vol. 5, No. 2, (2014) 146-158

Benvenisti, Eyal, The International Law of Occupation, Oxford University Press, Oxford, 2012

Bernhardt, Rudolf, "Evolutive Treaty Interpretation, Especially of the European Convention on Human Rights, German Yearbook of International Law", Vol. 42, No. 11 (1999) $11-25$

Bianchi, Andrea, International Law Theories. An Inquiry into Different Ways of Thinking, Oxford University Press, Oxford, 2017 
Bilder, Richard, "The Role of Apology in International Law and Diplomacy", Virginia Journal of International Law, Vol. 46, No. 3, (2006) 433-474

Biörkdahl, Annika and Mannergren Selimovic, "Gender and Transitional Justice", in Simić, Olivera, An Introduction to Transitional Justice, Routledge, London, New York, 2021

Bjorge, Eirik, Evolutionary Interpretation and Intention of the Parties, Oxford University Press, Oxford, 2014

Black, Donald, Moral time, Oxford University Press, New York, 2011

Bohrer, Ziv, "Divisions over Distinctions in Wartime International Law", in Bohrer, Ziv, Dill, Janina and Duffy, Helen, (eds.), Law Applicable to Armed Conflict, Max Planck Trialogues on the Law of Peace and War (Anne Peters and Christian Marxsen series eds.), Vol. 2, Cambridge University Press, Cambridge, 2020

Boisson de Chazournes, Laurence and Condorelli, Luigi, "Common Article 1 of the Geneva Conventions revisited: Protecting collective interests", International Review of the Red Cross, Vol. 82, No. 837, (2000) 67-87

Boling, David, "Mass Rape, Enforced Prostitution, and the Japanese Imperial Army: Japan Eschews International Legal Responsibility?", Columbia Journal of Transnational Law, Vol. 32, No. 3, (1994-1995) 533-590

Bonafè, Beatrice Ilaria and Palchetti, Paolo, "Relying on General Principles in International Law", in Research Handbook on the Theory and Practice of International Lawmaking, Edward Elgar Publishing, Cheltenham, 2016

Bong, Shin Hae, "Compensation for Victims of Wartime Atrocities. Recent Developments in Japan's Case Law”, Journal of International Criminal Justice, Vol. 3, No. 1, (2005) 187-206

Boon, Kristen, "Rape and Forced Pregnancy under the ICC Statute: Human Dignity, Autonomy, and Consent", Columbia Human Rights Law Review, Vol. 32, No. 3. (2001) 625-675

Bradley, Samantha Frances, "Protection of Detainees from Sexual Violence under International Humanitarian Law”, Journal of Conflict \& Security Law, Vol. 25 No. 3, (2020) 381-422

Braidotti, Rosi, "The Uses and Abuses of the Sex/Gender Distinction in European Feminist Practice", in Griffin, Gabriele and Braidotti, Rosi, Thinking Differently, A Reader in European Women's Studies, Zed Books, London, 2002, 286-306

Brandt, Willy, My Life in Politics, Hamish Hamilton Press, London, 1992

Bufalini, Alessandro, "On the Power of the State to Waive Reparation Claims Arising from War Crimes and Crimes Against Humanity", Zeitschrift für ausländisches öffentliches Recht und Völkerrecht, Vol. 77, (2017) 447-470

Buss, Doris E., "Rethinking 'Rape as a Weapon of War'”, Feminist Legal Studies, Vol. 17, No. 2 (2009), 145-163 
Buss, Doris E., "Sexual Violence, Ethnicity, and the Limits of Intersectionality in International Criminal Law" in Grabham, Emily, Cooper, Davina, Krishnadas, Jane, Herman, Didi (eds.), Intersectionality and Beyond Law, Power and the Politics of Location, Routledge-Cavendish, Abingdon, 2008

Buss, Doris E., "The Curious Visibility of Wartime Rape", Windsor Yearbook of Access to Justice, Vol. 25 (2007), 3-22

Caligiuri, Andrea, "La ricostruzione dei principi generali di diritto da parte dei tribunali penali internazionali", Rivista di diritto internazionale, Vol. 90, No. 4 (2007), 1079

Campbell, Tom, Goldberg, David, McLean, Sheila and Mullen, Tom (eds.) Human rights: from rhetoric to reality, Basil Blackwell, New York, 1986

Cane, Peter and Conaghan, Joanne (eds.), The New Oxford Companion of Law, Oxford University Press, Oxford, 2008

Cassese, Antonio, "The nexus requirement for war crimes", Journal of International Criminal Justice, Vol. 10, No. 5 (2012), 1395-1417

Cassese, Antonio, "The Status of Rebels under the 1977 Geneva Protocol on Non-International Armed Conflict", International \& Comparative Law Quarterly, Vol. 30, (1981) 416

Cassese, Antonio, Five Masters of International Law: Conversations with R-J Dupuy, E Jiménez de Aréchaga, R Jennings, L Henkin and O Schachter, Hart, Oxford, 2011

Charlesworth, Hilary and Chinkin, Christine, "The Gender of Jus Cogens", Human Rights Quarterly, Vol. 15, No. 1 (1993), 63-76

Charlesworth, Hilary and Chinkin, Christine, The Boundaries of International Law. A Feminist Analysis, Manchester University Press, Manchester, 2000

Charlesworth, Hilary, "Feminist Methods in International Law", American Journal of International Law, Vol. 93, No. 2 (1999), 379-394

Charlesworth, Hilary, "Foreword", in Harris Rimmer, Susan, and Ogg, Kate (eds.), Research Handbook on Feminist Engagement with International Law, Edward Elgar Publishing, Cheltenham, 2019

Charlesworth, Hilary, "Law-Making and Sources", in Crawford, James and Koskenniemi, Martti (eds), The Cambridge Companion to International Law, Cambridge University Press, 2012

Charlesworth, Hilary, "Not Waving but Drowning: Gender Mainstreaming and Human Rights in the United Nations", Harvard Human Rights Journal, Vol. 18, No. 1, (2005) 1-18

Charlesworth, Hilary, "The sex of the State in international law", in Naffine, Ngaire and Owens, Rosemary J. (eds.), Sexing the subject of law, Law Book Company, Sydney, 1997

Charlesworth, Hilary, "The Women Question in International Law", Asian Journal of International Law, Volume 1, No. 1, (2011) 33 - 38 
Charlesworth, Hilary, “Transforming the United Men's Club: Feminist Futures for the United Nations", Transnational Law \& Contemporary Problems, Vol. 4, No. 2, (1994) 421454

Charlesworth, Hilary, "Words Apart: Public/Private Distinctions in International Law", in Thornton, Margaret (eds.), Public and Private: Feminist Legal Debates, Oxford University Press, Oxford, 1995

Charlesworth, Hilary, Chinkin, Christine and Wright, Shelley, "Feminist Approaches to International Law", American Journal of International Law, Vol. 85, No. 4, (1991) 613-645

Charlesworth, Hilary, Chinkin, Christine and Wright, Shelley, "Looking back on Feminist Approaches", (October, 2012)

Cherif Bassiouni, Mahmoud, Crimes Against Humanity in International Criminal Law, Kluwer Law International, The Hague, 1999

Cherif Bassiouni, Mahmoud, Crimes Against Humanity: Historical Evolution and Contemporary Application, Cambridge University Press, Cambridge, 2011

Chinkin, Chinkin, "Rape and Sexual Abuse of Women in International Law, Symposium: The Yugoslav Crisis: New International Law Issues", European Journal of International Law, Vol. 5, (1994) 326

Chinkin, Christine and Kaldor, Mary, International Law and New Wars, Cambridge University Press, Cambridge, 2017

Chinkin, Christine and Lees, Madelaine, Commentary on Security Council Resolution 2467. Continued State Obligation and Civil Society Action on Sexual Violence in Conflict, Centre for Women Peace and Security, London School of Economics and Political Science, London, (2019), available at: https://www.un.org/sexualviolenceinconflict/wpcontent/uploads/2019/09/report/commentary-on-security-council-resolution2467/19_0496_WPS_Commentary_Report_online.pdf

Chinkin, Christine and Neenan, Joanne, "International Law and the Continuum of Genderbased Violence", LSE Women, Peace and Security Working Paper Series, (2017)

Chinkin, Christine, "A Gendered Perspective to the International Use of Force", Australian Yearbook of International Law, Vol. 12, No. 1 (1992) 285-286

Chinkin, Christine, "Feminism, Approach to International Law", in Wolfrum, Rüdiger (ed.), The Max Plank Encyclopedia of Public International Law, Oxford University Press, 2010

Chinkin, Christine, "Gender and Armed Conflict", in Clapham, Andrew and Gaeta, Paola, The Oxford Handbook of International Armed Conflict, Oxford University Press, Oxford, 2014

Chinkin, Christine, "Gender-Based Crimes", in Wolfrum, Rüdiger (ed.), The Max Plank Encyclopedia of Public International Law, online version available at: 
https://opil.ouplaw.com/view/10.1093/law:epil/9780199231690/law9780199231690-e1729

Chinkin, Christine, "Rape and Sexual Abuse of Women in International Law", European Journal of International Law, Vol. 5, No.3 (1994) 326-341

Chinkin, Christine, "The significance of this ruling to women's human rights, expand the meaning of state immunity in relation to gender and human rights perspectives", Booklet of the International Symposium Korean Court's Historic Ruling on Japanese Military 'Comfort Women': Restoring the Right to Justice and Truth held on February 26,2021

Chinkin, Christine, "Women's International Tribunal on Japanese Military Sexual Slavery", American Journal of International Law, Vol. 95, No. 2, (2001) 335-341

Chinkin, Christine, International Law and New Wars, Cambridge University Press, Cambridge, 2017

Christien, Agathe and Mukhtarova, Turkan, Report: Explaining Trends in the Frequency of Gender Provisions in Peace Agreements, 1990-2019, Georgetown Institute for Women, Peace and Security, (October, 2020), available at https://giwps.georgetown.edu/resource/explaining-trends-in-the-frequency-ofgender-provisions-in-peace-agreements-1990-2019/

Chung, Chin-sung, "An Overview of The Colonial And Socio-Economic Background Of Japanese Military Sexual Slavery In Korea", Muae: Journal of Transcultural Prosecution, Vol. 1, No. 3, (1995) 204

Cicero, Tusculanae Disputationes II.58 [translation Olsthoorn, Peter, Honor in Political and Moral Philosophy, SUNY Press, 2015

Clamberg, Mark (ed.), Commentary on the Law of the International Criminal Court, Torkel Opsahl Academic EPublisher, Brussels, 2017

Cockburn, Cynthia, "The Continuum of Violence: A Gender Perspective on War and Peace", in Wenona Giles and Jennifer Hyndman (eds), Sites of Violence: Gender and Conflict Zones, University of California Press, Berkeley and Los Angeles, 2004

Cole, Alison, "Prosecutor v Gacumbitsi: The New Definition for Prosecuting Rape Under International Law" ICLR, Vol. 8, No. 55, (2008)

Collins, Randall, Violence: A Micro-sociological Theory, Princeton University Press, Princeton 2008

Conaghan, Joanne, Law and Gender, Oxford University Press, Oxford, 2013

Connell, Raewyn W., Gender and Power, Stanford University Press, Stanford, 1987

Coomaraswamy, Radhika, "UNSCR 1325 at 20: Reflections on the Women, Peace and Security agenda", Oslo Forum Paper, Centre for Humanitarian Dialogue, Geneva, (2020)

Coomaraswamy, Radhika, Report on the mission to the Democratic People Republic of Korea, the Republic of Korea and Japan on the issue of military sexual slavery in wartime, 
U.N. ESCOR, 52nd Sess., Provisional Agenda Item 9(a), U.N. Doc. E/CN.4/1996/53/Add.1 (1996), U.N. Doc. E/CN.4/1996/53/Add.1

Copelon, Rhonda, "Gender crimes as war crimes: integrating crimes against women into International Criminal Court”, McGill Law Journal, Vol. 46, (2000) 217-240

Copelon, Rhonda, "Surfacing Gender: Re-engraving Crimes Against Women in Humanitarian Law”, Hastings Women's Law Journal, Vol. 5, No.2, (1994) 243-266

Cossman, Brenda, "Gender performance, sexual subjects and international law", Canadian Journal of Law and Jurisprudence, Vol. 15, No. 2, (2002) 281-296

Crawford, Emily, "The Temporal and Geographical Reach of International Humanitarian Law", in Saul, Ben and Akande, Dapo (eds.), The Oxford Guide to International Humanitarian Law, Oxford University Press, Oxford, 2020

Crawford, Emily, The Treatment of Combatants and Insurgents Under the Law of Armed Conflict, Oxford University Press, Oxford, 2010

Crawford, James, The International Law Commission's Articles on State Responsibility, Introduction, Text and Commentaries, Cambridge University Press, Cambridge, 2002

Crowe, Anna, "'All the regard due to their sex': Women in the Geneva Conventions of 1949", Harvard Research Working Paper Series, HRP 16-001, (2016), available at: http://hrp.law.harvard.edu/wp-content/uploads/2016/12/Anna-Crowe HRP$\underline{16 \text { 001.pdf }}$

D'Argent, Pierre, "Compliance, Cessation, Reparation and Restitution in the Wall Advisory Opinion”, in Dupuy, Pierre-Marie at al (eds.), Common Values in International Law. Essays in Honour of Christian Tomuchat, Engel Verlag, Kehl, 2006

D’Argent, Pierre, Les Réparations de Guerre en Droit International Public. La responsabilité internationale des états à l'épreuve de la guerre, Bruylant, Bruxelles, 2002

David, Erik, Principes de droit des conflits armés, Bruylant, Bruxelles, 2012

Davies, Margaret, "Taking the inside out sex and gender in the legal subject", in Naffine, Ngaire and Owens, Rosemary J. (eds.), Sexing the subject of law, Law Book Company, Sydney, 1997

Dawidowicz, Martin, "The Effect of the Passage of Time on the Interpretation of Treaties: Some Reflections on Costa Rica V. Nicaragua", Leiden Journal of International Law, Vol. 24, No 1, (2011) 201-222

De Brouwer, Anne-Marie, Supranational Criminal Prosecution of Sexual Violence: The ICC and the Practice of the ICTY and the ICTR, Intersentia, Antwerp, 2006

De Grieff, Pablo, "Justice and Reparations", in De Grieff, Pablo (eds.), The Handbook of Reparations, Oxford University Press, Oxford, 2006

De Vido, Sara, "The Prohibition of Violence Against Women as Customary International Law? Remarks on the CEDAW General Recommendation No. 35", Diritti Umani e Diritto Internazionale, Vol. 12, Issue 2, (2018) 379-396 
Deiana, Maria-Adriana, “Navigating Consociationalism's Afterlives: Women, Peace and Security in Post-Dayton Bosnia-Herzegovina. Nationalism and Ethnic Politics", Nationalism and Ethnic Politics, Vol. 24, No. 1, (2018) 33-49

Delmas-Marty, Mireille "L’influence du droit comparé sur l'activité des Tribunaux pénaux internationaux", in Cassese, Antonio, Delmas-Marty, Mireille (eds.), Juridictions nationals et crimes internationaux, Presses Universitaires de France, Paris, 2002

Deteseanu, Daniela-Anca, "La protection des femmes en temps de conflit armé", in Sorel, JeanMarc, and Popescu, Corneliu-Liviu (eds.), La protection des personnes vulnérable en temps de conflit armé, Bruylant, Bruxelles, 2010

Dinstein, Yoram, "Legislation Under Article 43 of the Hague Regulations: Belligerent Occupation and Peacebuilding”, Harvard University, Occasional Papers Series, No. $1,(2004)$

Dinstein, Yoram, "The Principle of Distinction and Cyber War in International Armed Conflicts", Journal of Conflict \& Security Law, Vol. 17, No. 2, (2012) 261-277

Dixon, Rosalind, "Rape as a crime in International Humanitarian Law: where to from here?", European Journal of International Law, Vol. 13, No. 3, (2002) 697-720

Dolgopol, Ulstina, "Knowledge and Responsibility: The Ongoing Consequences of Failing to Give Sufficient Attention to the Crimes against the Comfort Women in the Tokyo Trial", in Tanaka, Yuki, McCormack, Tim and Simpson, Gerry (eds.), Beyond Victor's Justice? The Tokyo War Crimes Trial Revisited, Martinus Nijhoff Publisher, Leiden-Boston, 2011

Dolgopol, Ustinia and Snehal Paranjape, Comfort Women: An unfinished ordeal. Report of a mission, International Commission of Jurists, Geneva, 1994

Dolzer, Rudolf, "The Settlement of War-Related Claims: Does International Law Recognize a Victim's Private Right of Action - Lessons After 1945", Berkeley Journal of International Law, Vol. 20, Issue 1, (2002), 296

Dörmann, Knut, Lijnzaad, Liesbeth, Sassòli, Marco, and Spoerri, Philip (eds.), Commentary on the First Geneva Convention: Convention (I) for the Amelioration of the Condition of the Wounded and Sick in Armed Forces in the Field, Cambridge University Press, Cambridge, 2016 [Commentary I, 2016]

Dörmann, Knut, Lijnzaad, Liesbeth, Sassòli, Marco, and Spoerri, Philip (eds.), Commentary on the Second Geneva Convention: Convention (II) for the Amelioration of the Condition of Wounded, Sick and Shipwrecked Members of Armed Forces at Sea, Cambridge University Press, Cambridge, 2017, [Commentary II, 2017]

Dörmann, Knut, Lijnzaad, Liesbeth, Sassòli, Marco, and Spoerri, Philip (eds.), Commentary on the Third Geneva Convention: Convention (III) relative to the Treatment of Prisoners of War. Geneva, 12 August 1949, Cambridge University Press, Cambridge, 2020, [Commentary III, 2020]

Doswald-Beck, Louise and Vité, Sylvaine, "International Humanitarian Law and Human Rights Law”, International Review of the Red Cross, No. 293, (March-April 1993) 94 
Duggan, Colleen and Abusharaf, Adila, "Reparation of Sexual Violence in Democratic Transitions: The Search for Gender Justice", in De Greiff, Pablo (eds.), The Handbook of Reparations, Oxford University Press, Oxford, 2006

Dupuy, Pierre-Marie, "Evolutionary interpretation of treaties: between memory and prophecy", in Cannizzaro, Enzo (ed.), The law of Treaties beyond the Vienna Convention, Oxford University Press, Oxford, 2011

Durham, Helen and O'Byrne, Katie, “The Dialogue of Difference: Gender Perspectives on International Humanitarian Law", International Review of the Red Cross, Vol. 92, No. 877, (2010) 31-52

Durham, Helen, "International Humanitarian Law and The Protection of Women", in Helen and Gurd, Tracey (eds.), Listening to the Silence: Women and War, Koninklijke Brill, Leiden, 2005

Eboe-Osuji, Chile, International Law and Sexual Violence in Armed Conflicts, Martinus Nijhoff Publishers, Leiden, 2012

Engle, Karen, "A Genealogy of the Centrality of Sexual Violence to Gender and Conflict", in Ní Aoláin, Fionnuala, Cahn, Naomi, Haynes, Dina Francesca, and Valji, Nahla (eds.), The Oxford Handbook of Gender and War, Oxford University Press, Oxford, 2018

Engle, Karen, "Feminism and Its (Dis)contents: Criminalizing Wartime Rape in Bosnia and Herzegovina", American Journal of International Law, Vol. 99, No. 4, (2005) 778816

Eriksson Baaz, Maria and Stern, Maria, Sexual Violence as a Weapon of War? Perceptions, Prescriptions and Problems in the Congo and Beyond, Zed Books, London and New York, 2013

Eriksson, Maria, Defining Rape: Emerging Obligations for States Under International Law, Brill, Nijhoff, Leiden/Boston, 2011

Evans, Mary (ed.), Feminism. Critical concepts in literary and cultural studies, Routledge, London, New York, 2001

Falk, Richard, "Reparations, International Law, and Global Justice", in de Grieff, Pablo (ed.), The Handbook of Reparations, Oxford University Press, Oxford, 2006

Fenrick, William J. "The Rule of Proportionality and Protocol I in Conventional Warfare", Military Law. Review, Vol. 98, No. 1, (1982) 91-127

Ferraro, Tristan (ed.), ICRC Expert Meeting, 'Occupation and Other Forms of Administration of Foreign Territory’ ICRC, Geneva, 2012

Ferraro, Tristan, "The Law of Occupation and Human Rights Law: Some Selected Issues", in Kolb, Robert and Gaggioli, Gloria (eds.), Research Handbook on Human Rights and Humanitarian Law, Edward Elgar, Cheltenham, 2013,

Ferstman, Carla, "The Relationship between Inter-State Reparations and Individual Entitlements to Reparation: Some Reflections", Zeitschrift für ausländisches öffentliches Recht und Völkerrecht, Vol 78, No. 3, (2018) 561-564 
Ferstman, Carla, "The Right to Reparation for Victims of Armed Conflict", in Lattimer, Mark and Sands, Philippe (eds.), The Grey Zone: Civilian Protection Between Human Rights and the Laws of War, Hart Publishing, Oxford, 2018

Fitzmaurice, Gerald, "The law and procedure of the International Court of Justice 1951-4: treaty interpretation and other treaty points", British Yearbook of International Law, Vol. 33, (1957) 203

Flax, Jane, "Postmodernism and gender relations in feminist theory", Signs, Vol. 12, (1987) $621-643$

Fleck, Dieter, "The Law of Non-International Armed Conflict", in Fleck, Dieter, The Handbook of International Humanitarian Law, Oxford University Press, Oxford, 2013

Flores, Marcello (ed.), Stupri di Guerra. La Violenza di Massa contro le Donne nel Novecento, FrancoAngeli, Milano, 2010

Fowler's Dictionary of Modern English Usage, Oxford University Press, Oxford, 1940

Franchini, Daniel, "South Korea's denial of Japan's immunity for international crimes", Völkerrechtsblog, (18 January 2021), available at: https://voelkerrechtsblog.org/de/south-koreas-denial-of-japans-immunity-forinternational-crimes/

Fronza, Emanuela, Guillou, Nicolas, "Les dynamiques d'élaboration des norms pénales internationals: une analyse à partir de la jurisprudence sur le viol et la participation criminelle", in Chiavario, Mario, La justice pénale international entre passé et avenir, Giuffrè Editore, Milan, 2003

Furuya, Shuichi, “The Right to Reparation for Victims of Armed Conflict: The Intertwined Development of Substantive and Procedural Aspects", in Correa Christiàn, Furuya, Shuichi, and Sandoval, Clara (eds.), Reparation for Victims of Armed Conflict, (Anne Peters and Christian Marxsen series eds.), Vol. 3, Cambridge University Press, Cambridge, 2021 (on file with the author)

Futamura, Madoka, "Japanese Societal Attitude towards the Tokyo Trial: From a Contemporary Perspective", in Tanaka, Yuki, McCormack, Tim and Simpson, Gerry (eds.), Beyond Victor's Justice? The Tokyo War Crimes Trial Revisited, Martinus Nijhoff Publisher, Leiden-Boston, 2011

Gaggioli, Gloria, "Is There a Right to Abortion for Women and Girls Who Become Pregnant as a Result of Rape? A Humanitarian and Legal Issue", Vulnerabilities in Armed Conflicts: Selected Issues, 14 ${ }^{\text {th }}$ Bruges Colloquium - October 17 and 18, (2013), available at: https://www.icrc.org/en/doc/assets/files/2013/abortion-sexual-violencebruges-10-2013-2.pdf

Gaggioli, Gloria, "Sexual violence in armed conflicts: A violation of international humanitarian law and human rights law", International Review of the Red Cross, Vol. 96, No. 894, (2014) 503-538 
Gaja, Giorgio, "Does the European Court of Human Rights use its stated methods of interpretation?", in: Divenire sociale e adeguamento del diritto. Studi in onore di Francesco Capotorti, Giuffrè, Milan, 1999

Gallie, Walter Bryce, "Essentially Contested Concepts", Proceedings of the Aristotelian Society New Series, Vol. 56, (1955 - 1956) 167-198

Gardam, Judith and Charlesworth, Hilary, "Protecting Women in Armed Conflict" Human Rights Quarterly, Vol. 22, No. 1, (2000) 148-166

Gardam, Judith and Jarvis, Michelle, Women, Armed Conflict and International Law, Kluwer Law International, 2001

Gardam, Judith, "A Feminist Analysis of Certain Aspects of International Humanitarian Law", Australian Yearbook of International Law, Vol. 12, No. 1, (1992) 265-278

Gardam, Judith, "The Neglected Aspect of Women and Armed Conflict-Progressive Development of The Law", Netherlands International Law Review, Vol. 52, No. 2, (2005) 197-219

Gardam, Judith, "The Silences in the Rules That Regulate Women during Times of Armed Conflict", in Ní Aoláin, Fionnuala, Cahn, Naomi, Haynes, Dina Francesca, and Valji, Nahla (eds.), The Oxford Handbook of Gender and War, Oxford University Press, Oxford, 2018

Gardam, Judith, "The Silences in the Rules", in Clapham, Andrew, and Gaeta, Paola (eds.), The Oxford Handbook of International Armed Conflict, Oxford University Press, Oxford, 2014

Gardam, Judith, "Women and Armed Conflict: The Response of International Humanitarian Law" in Durham, Helen and Gurd, Tracy (eds.), Listening to the Silences: Women and War, Martinus Nijihoff Publishers, Leiden, 2005

Gardam, Judith, "Women and the Law of Armed Conflict: Why the Silence?", International and Comparative Law Quarterly, Vol. 46, No. 1 (1997) 55-80

Gardam, Judith, "Women, Human Rights and International Humanitarian Law", International Review of the Red Cross, Vol. 38, Special Issue No. 324, (1998) 421-432

Gardam, Judith, and Charlesworth, Hilary, "Protection of Women in Armed Conflict", Human Rights Quarterly, Vol. 22, No. 1, (2000) 148-166

Gardiner, Richard, Treaty Interpretation, Oxford University Press, Oxford, 2008

Gill, Terry, "Chivalry: A Principle of the Law of Armed Conflict?", in Matthee, Mariëlle, Toebes, Brigit, Brus M.M.T.A. (eds.), Armed Conflict and International Law: In Search of the Human Face, T.M.C. Asser Press, The Hague, 2013

Gillard, Emanuela-Chiara, "Reparation for Violations of International Humanitarian Law", International Review of the Red Cross Vol. 85, No. 851, (2003), 529-553

Gilligan, Carol, In a different voice: psychological theory and women's development, Harvard University Press, Cambridge, 1982 
Gilmore, Sunneva, Guillerot, Julie, Sandoval, Clara, \& Moffett, Luke (eds.), "Beyond Silence and Stigma - Crafting a Gender-Sensitive Approach for Victims of Sexual Violence in Domestic Reparation Programmes. Reparations", Responsibility and Victimhood in Transitional Societies, Queen's University Belfast, (March 2020), available at: https://reparations.qub.ac.uk/assets/uploads/QUB-SGBV_Report_English_Web.pdf

Goldstein, Joshua, War and Gender: How Gender Shapes the War System and Vice Versa, Cambridge University Press, Cambridge, 2001

Gordon, Gregory S., "The Trial of Peter von Hagenbach", in Heller, Kevin and Simpson, Gerry, The Hidden Histories of War Crimes Trials, Oxford University Press, Oxford, 2013

Greenwood, Christopher, "Scope of Application of Humanitarian Law", in Fleck, Dieter (eds.), The Handbook of International Humanitarian Law, Oxford University Press, 2008

Greenwood, Christopher, "The International Court of Justice and International Humanitarian Law", in Cherlor Jalloh, Charles and Elias, Olufemi (eds.), Essays in International Law in Honour of Judge Abdul G. Koroma, Brill, Nijhoff, Leiden, 2015

Gross, Aeyal, The Writing on the Wall: Rethinking the International Law of Occupation, Cambridge University Press, Cambridge, 2017

Grossman, Nienke, "Feminist Approaches to International Adjudication", in Ruiz Fabri, Hélène (eds.), Max Planck Encyclopedia of International Procedural Law, Oxford University Press, Oxford, 2019

Grossman, Nienke, "The effect of the participation of women judges on the legitimacy of international Courts and Tribunals", Proceedings of the American Society of International Law Annual Meeting, Vol. 105, (2011) 452 - 455

Gutteridge, Joyce A.C., “The Geneva Conventions of 1949”, British Yearbook of International Law, Vol. 26, (1949) 294

Hagemann, Karen and Campbell, D’Ann, “Post-1945 Western Militaries, Female Soldiers, and Gay and Lesbian Rights", in Hagemann, Karen, Dudink, Stefan and Rose Sonya O. (eds.), The Oxford Handbook of Gender, War, and the Western World since 1600, Oxford University Press, Oxford, 2020

Hamber, Brandon and Palmary, Ingrid, "Gender, Memorialization, and Symbolic Reparations", in Rubio-Marin, Ruth (ed.), The Gender of Reparations: Unsettling Sexual Hierarchies while Redressing Human Rights Violations, Cambridge University Press, Cambridge, 2009

Hamilton, Caitlin, Naam, Nyibeny and Shepherd, Laura J., "Twenty Years of Women, Peace and Security National Action Plans: Analysis and Lessons Learned", University of Sydney, (2020), available at https://www.wpsnaps.org/app/uploads/2020/03/TwentyYears-of-Women-Peace-and-Security-National-ActionPlans_Report_Final_Web.pdf

Harris Rimmer, Susan, and Ogg, Kate, Feminist Engagement with International Law, Edward Elgar Publishing, Cheltenham, 2019 
Hatzimihail, Nikitas E., "Reconstructing Mixity: Sources of Law and Legal Method in Cyprus", in Palmer, Vernon Valentine, Mattar, Mohamed Y. (eds.), Mixed Legal Systems, East and West, Routledge, New York, London, 2016

Hayes, Niamh, "Creating a Definition of Rape in International Law: The Contribution of the International Criminal Tribunals", in Darcy, Shane and Powderly, Joseph, Judicial Creativity at the International Criminal Tribunals, Oxford University Press, Oxford, 2010

Heathcote, Gina, Feminist Dialogues on International Law: Success, Tensions, Futures, Oxford University Press, Oxford, 2019

Heathcote, Gina, The Law on the Use of Force. A Feminist Analysis, Routledge, London, New York, 2012

Helmersen, Sondre Torp, "Evolutive Treaty Interpretation: Legality, Semantics and Distinctions”, European Journal of Legal Studies Vol. 6, No. 1, (2013) 127-148

Henckaerts, Jean-Marie and Doswald-Beck, Louise (eds.), Customary International Humanitarian Law: Volume 1, Rules/Volume 2, Practice, Cambridge University Press, 2005

Hill-Cawthorne, Lawrence, "Rights under International Humanitarian Law", European Journal of International Law, Vol. 28, No. 4, (2017) 1187-1215

Hill-Cawthorne, Lawrence, "GCIII Commentary: Common Article 1 and State responsibility", ICRC Humanitarian Law \& Policy Blog, (January 28, 2021), available at: https://blogs.icrc.org/law-and-policy/

Hisakazu Fujita, Isomi Suzuki and Kantaro Nagao (eds.), War and Rights of Individuals: Renaissance of Individual Compensation, Nippon Hyoron-sha Co., Tokyo, 1999

Hodson, Loveday and Lavers, Troy (eds.), Feminist Judgements in International Law, Hart, Oxford, 2019

Hofmann, Rainer, "Compensation for Personal Damages Suffered During World War II", in Lachenmann, Frauke and Wolfrum, Rudiger (eds.), Max Planck Encyclopendia of Public International Law. The Law of Armed Conflict and the Use of Force, Vol 2, Oxford University Press, Oxford, 2013

Hofmann, Rainer, "Draft Declaration of International Law Principles on Reparation for Victims of Armed Conflict (Substantive Issues)", Commentary to Article 6, in International Law Association, Report of the Seventy-Fourth Conference Held in The Hague 15-19 August 2010, London, International Law Association, 2010

Hofmann, Rainer, "Draft Declaration of International Law Principles on Reparation for Victims of Armed Conflict (Substantive Issues)", in ILA, Report of the SeventyFourth Conference Held in The Hague 15-19 August 2010, London, International Law Association, 2010

Hofmann, Rainer, "The 2010 International Law Association Declaration of International Law Principles on Reparation for Victims of Armed Conflict", Zeitschrift für ausländisches öffentliches Recht und Völkerrecht, Vol 78, No. 3 (2018) 
Hofmann, Rainer, "Victims of Violations of International Humanitarian Law: Do They Have an Individual Right to Reparation against States under International Law?", in Dupuy, Pierre-Marie at al. (eds.), Common Values in International Law. Essays in Honour of Christian Tomuchat, Engel Verlag, Kehl, 2006

Hozić, Aida A., "Dayton, WPS and the entrenched 'manliness' of ethnic power-sharing peace agreements", LSE Women, Peace and Security blog, (15 February, 2021), available at https://blogs.1se.ac.uk/wps/2021/02/15/dayton-wps-and-the-entrenched-manlinessof-ethnic-power-sharing-peace-agreements/

Hwang Myoung-jun, "Recent Discourse on Overcoming Sovereign Immunity: Focusing on the Italian Constitutional Court Decision No. 238 (2014) and subsequent discussions thereof", Seoul International Law Journal, Vol. 25, No. 1, (2018) 1

Hyeon-Cheol, Kim and Inyoung, Cho, "South Korean Law Research on the Internet", New York University School of Law, New York, (2017), available at: https://www.nyulawglobal.org/globalex/South_Korea.html

Hyun-Soo Lim, 'Not 'Final and Irreversible': Explaining South Korea's January 2018 Reversal on the 'Comfort Women' Agreement", Yale Journal of International Law Blog, (February, 2018), available at: https://www.yjil.yale.edu/not-final-and-irreversibleexplaining-south-koreas-january-2018-reversal-on-the-comfort-women-agreement/

International Center for Transitional Justice, "When No One Calls It Rape: Addressing Sexual Violence Against Men and Boys in Transitional Contexts", (2016), available at https://www.ictj.org/sites/default/files/ICTJ_Report_SexualViolenceMen_2016.pdf

International Centre for Transitional Justice, "More than words: apologies as a form of reparation" (2015), available at: https://www.ictj.org/publication/more-than-wordsapologies-form-reparation

International Committee of the Red Cross, Special Appeal 2020. The ICRC's Response to Sexual Violence, Geneva, March 2020, available at: https://www.icrc.org/sites/default/files/wysiwyg/Activities/Sexualviolence/2020_specialappeal_sv.pdf

International Law Commission, Report to the General Assembly on the on the work of its Thirty-first session, A/34/10, Yearbook of the International Law Commission, Vol. II, Part 2, 1979

Japutra, Kiki Anastasia, "The Interest of States in Accountability for Sexual Violence in Armed Conflict: A Case Study of Comfort Women of the Second World War", in Bergsmo, Morten and Tianying, Song (eds.) Military Self-Interest in Accountability for Core International Crimes, Torkel Opsahl Academic EPublisher, Brussels, 2015

Jinks, Derek, "International Human Rights Law in Time of Armed Conflict", in Clapham, Andrew and Gaeta, Paola (eds.), The Oxford Handbook of International Law in Armed Conflict, Oxford University Press, Oxford, 2014

Jochnik, Chris and Normand, Roger, "The legitimation of violence: a critical history of the laws of war", Harvard International Law Journal, Vol. 35, No. 1, (1994) 49-96 
Kalshoven, Frits, "Article 3 of the Convention (IV) concerning the Laws and Custom of War on Land, signed at the Hague, 18 October 1907", in "Remembering what we have tried to forget", ASCENT, 1997

Kalshoven, Frits, "State Responsibility for Warlike Acts of the Armed Forces: From Art. 3 of Hague Convention IV of 1907 to Art. 91 of Additional Protocol I of 1977 and beyond", International and Comparative Law Quarterly, Vol. 40, No. 4, (1991) 827858

Kalshoven, Frits, Reflections on the Law of War: Collected Essays, Martinus Nijhof, Leiden, 2007

Kelsen, Hans, Principles of International Law, The Lawbook Exchange, Clark, New Jersey, 2003 (reprint)

Kelsen, Hans, Pure Theory of Law, translation from the Second German Edition by Max Knight, University of California Press, Berkeley, 1967

Khushalani, Yougindra, The Dignity and Honour of Women as Basic and Fundamental Human Rights, Martinus Nijhoff Publishers, 1982

Kim Do-Hyoung, "Practices on State Immunity at Korean Courts", Seoul International Law Journal Vol. 22, No. 2, (2015), 115

Kim, Puja, "The failure of the Asian Women's Fund: the Japanese government's legal responsibility and the colonial legacy", in Nishino, Rumiko, Kim, Puja and Onozawa, Akane (eds.), Denying the Comfort Women The Japanese State's Assault on Historical Truth, Routledge, Abington-New York, 2018

Knebel, Johannes, Chronicle of the Chaplain Johannes Knebel from the Time of the Burgundian Wars, Bahnmaier, 1851

Knop, Karen, "Re/Statements: feminism and state sovereignty in International Law", Transnational Law \& Contemporary Problems, Vol. 3, (1993) 306-307

Kolb, Robert, "Evolutionary Interpretation in International Law: Short and Less than TrailBlazing Reflections", in Abi-Saab, Georges, Keith, Kenneth, Marceau, Gabrielle and Marquet, Clément, Evolutionary Interpretation and International Law, Hart Publishing, Oxford, 2019

Kouvo, Sari and Pearson, Zoe, Gender and International Law. Critical Concepts in Law. Volume II, Doing Gender and International Law: Human Rights, Routledge, London, New York, 2014

Kouvo, Savi and Pearson, Zoe (eds.), Feminist Perspectives on Contemporary International Law: Between Resistance and Compliance, Hart Publishing, 2014

Krill, Françoise, "The Protection of Women in International Humanitarian Law", International Committee of the Red Cross, Vol. 25, No. 249, (1985) 337-363

Kuper, Jenny, International Law Concerning Child Civilians in Armed Conflict, Clarendon Press, Oxford, 1997 
Kwon, Jennifer, "The Comfort Women Litigation and the San Francisco Treaty: Adopting a Different Principle of Treaty Interpretation", George Washington Law Review, Vol. 73, No. 3, (2005), 649-667

La Rocca, Simona, "Le violenze di genere nei conflitti armati: nome e politiche di contrasto", in La Rocca, Simona (eds.), Stupri di guerra e violenza di genere, Ediesse, Roma, 2015

Labenski, Sheri, "The Right to Reparation for Sexual and Gender-Based Violence", LSE Reparation Report, (2020), available at: https:/www.lse.ac.uk/women-peacesecurity/assets/documents/2020/Reparations-Report-online-version.pdf

Lacey, Nicola, "Feminist legal theory and the rights of women", in Knop, Karen (eds.), Gender and human rights, Oxford University Press, Oxford, 2004

Lauterpacht, Hersch, "The Grotian tradition in international law", British Year Book of International Law, Vol. 23, No. 1, (1946) 1-53

Lee, Elisa, "Behind the Mask of Human Rights: 'Comfort Women', Heteronormativity, \& Empires", Tapestries: Interwoven voices of local and global identities, Vol. 4, No. 1, (2015), 1-10

Lee, Sang-hee, “A Universal Judgment Based on Universal Human Rights”, Booklet of the International Symposium Korean Court's Historic Ruling on Japanese Military 'Comfort Women': Restoring the Right to Justice and Truth held on February 26, 2021

Lee, Seokwoo and Seryon, Lee, "Yeo Woon Taek v. New Nippon Steel Corporation", American Journal of International Law, Vol. 113, No. 3, (2019) 592599

Lee, Seokwoo, and Youngkwan, Cho, "Historical Issues between Korea and Japan and Judicial Activism: Focus on the Recent Supreme Court Decision on Japanese Forced Labor", Korean Journal of International and Comparative Law, Vol. 2, No. 1, (2014) 5-26

Lee, Sue R., "Comforting the Comfort Women: Who Can Make Japan Pay", University of Pennsylvania Journal of International Law, Vol. 24, No. 2, (2003) 509-547

Lehr-Lehnardt, Rana, "One small step for women: female-friendly provisions in the Rome Statute of the International Criminal Court", in BYU Journal of Public Law, Vol. 16, (2002) 317-354

Leiby, Michele, "Wartime sexual violence in Guatemala and Peru", International Studies Quarterly, Vol. 53, No. 2, (2009) 445-468.

Levin, Mark A., "Comfort Women: Case Comment: Nishimatsu Construction Co. v. Song Jixiao Et Al., Supreme Court of Japan (2d Petty Bench), April 27, 2007, and Ko Hanako Et Al. V. Japan, Supreme Court of Japan (1st Petty Bench), April 27, 2007 (January 1, 2008)", American Journal of International Law, Vol. 102, No. 1, (January 2008), 148

Lindsey-Curtet, Charlotte, Holst-Roness, Florence Tercier, and Anderson, Letitia, “Addressing the Needs of Women Affected by Armed Conflict. An ICRC Guidance Document", ICRC, (March 2014) 
Lindsey, Charlotte, "The impact of armed conflict on women", in Durham, Helen and Gurd, Tracey (eds.), Listening to the silence: women and war, Brill, Leiden, 2005

Lindsey, Charlotte, "Women and War - An Overview", International Review of the Red Cross, No. 839, (2000), 561-579

Lindsey, Charlotte, Women Facing War: ICRC Study on the Impact of Armed Conflict on Women, ICRC, Geneva, 2001

Linehan, Jan "Women and public international litigation", (2002) background paper prepared for the seminar held by the Project on International Courts and Tribunals and Matrix Chambers, London, July 13, 2001, available at: http://www.pictpcti.org/publications/PICT_articles/Women1.pdf

Luban, David, "Human Rights Thinking and the Laws of War", in J. D. Ohlin (eds.), Theoretical Boundaries of Armed Conflict and Human Rights, Cambridge University Press, Cambridge, 2016

Lubell, Noam, Pejic, Jelena, Simmons, Claire, Investigating Violations of International Humanitarian Law: Law, Policy and Good Practice, September 2019, available at: https://www.icrc.org/en/document/guidelines-investigating-violations-ihl-lawpolicy-and-good-practice

MacKinnon, Catharine, "Rape, Genocide, and Women's Human Rights." Harvard Women's Law Journal, Vol. 17, No. 5, (1994) 5-16

MacKinnon, Catharine, "Defining Rape Internationally: A Comment on Akayesu”, Columbia Journal of Transnational Law, Vol. 44, No. 3 (2005) 940-958

MacKinnon, Catharine, "Feminism, Marxism, method, and the State: toward a feminist jurisprudence”, Signs, Vol. 8, No. 4, (1983) 635-658

MacKinnon, Catharine, Feminist unmodified: discourses on life and law, Harvard University Press, London, Massachusetts, Cambridge, 1987

MacKinnon, Catharine, Toward a Feminist Theory of the State, $2^{\text {nd }}$ edition, Harvard University Press, Cambridge, 1991

Marxen Christian, "What Do Different Theories of Customary International Law Have to Say about the Individual Right to Reparation under International Humanitarian Law?", Zeitschrift für ausländisches öffentliches Recht und Völkerrecht, Vol. 78, No. 3 (2018)

Marxen, Christian, "Introduction", in Correa Christiàn, Furuya, Shuichi, and Sandoval, Clara (eds.), Reparation for Victims of Armed Conflict, (Anne Peters and Christian Marxsen series eds.), Vol. 3, Cambridge University Press, Cambridge, 2021

Massingham, Eve and McConnachie, Annabel (eds.), Ensuring Respect for International Humanitarian Law, Routledge, London, New York, 2021

Mazurana, Dyan, Marshak, Anastasia and Spears, Kinsey, "Child Marriage in Armed Conflict”, International Review of the Red Cross, Vol. 101, No. 911, (2019) 575-601. 
McDougall, Gay J., "Addressing State Responsibility for the Crime of Military Sexual Slavery during the Second World War: Further Attempts for Justice for the "Comfort Women'”, Korean Journal of International and Comparative Law, Vol. 1, No. 2, (2013) 137-165

McDougall, Gay J., U.N. Special rapporteur contemporary forms of slavery, Final Report on systematic rape, sexual slavery and slave-like practices during armed conflict, E/CN.4/Sub.2/1998/13, 22 June 1998, Appendix, An Analysis of The Legal Liability of The Government of Japan for "Comfort Women Stations" Established During the Second World War

Meger, Sara, "The Problematic Evolution of UN Resolutions on Women, Peace and Security", e-International Relations, 1 November 2012, available at: https://www.eir.info/2012/11/01/the-problematic-evolution-of-un-resolutions-on-women-peace-

and-security/

Mégret, Frédéric, "Féminisme et Droit International: Le 'Féminisme de Gouvernance' à l'Epreuve du 'Féminisme Critique", in Tourme Jouannet, Emmanuelle, BourgorgueLarsen, Laurence, Muir Watt, Horatia, and Ruiz Fabri, Hélène (eds.), Féminisme(s) et Droit International. Etudes du Réseau Olympe, Société de legislation compare, Paris, 2016

Meron, Theodor, "Rape as a Crime Under International Humanitarian Law", Amsterdam Journal of International Law, Vol. 87, No. 3, (1993) 424-428

Meron, Theodor, "Shakespeare's Henry the Fifth and the Law of War", American Journal of International Law, Vol. 86, No. 1, (1992) 1-45

Meron, Theodor, "The Humanization of Humanitarian Law", American Journal of International Law, Vol. 94, No. 2, (2000) 239-278

Meron, Theodor, Human Rights and Humanitarian Norms as Customary Law, Oxford University Press, Oxford, 1989

Meron, Theodor, The Humanization of International Law, Martinus Nijhoff, Leiden, 2006

Mertus, Julie, "Judgment of Trial Chamber II in the Kunarac, Kovac and Vukovic Case", American Society for International Law Insights, Vol. 6, No. 6, (2001), available at: https://www.asil.org/insights/volume/6/issue/6/judgment-trial-chamber-ii-kunarac-

kovac-and-vukovic-case

Milanovic, Marko, "Courting Failure: When Are International Criminal Courts Likely to be Believed by Local Audiences?”, in Heller, Kevin, Mégret, Frédéric, Nouwen, Sarah, Ohlin, Jens and Robinson, Darryl, The Oxford Handbook of International Criminal Law, Oxford University Press, Oxford, 2020

Min, Pyong Gap, “Korean 'comfort women': the intersection of colonial power, gender, and class", Gender and Society, Vol. 17, No. 6, (2003) 938-957

Minear, Richard H., Victor's Justice: The Tokyo War Crimes Trial, Princeton University Press, Princeton, New Jersey, 1971 
Mitchell, David S., "The prohibition of rape in IHL as a norm of jus cogent: clarifying the doctrine", Duke Journal of Comparative \& International Law, Vol. 15, (2005) 219258

Moser, O. Caroline, "The Gendered Continuum of Violence and Conflict: An Operational Framework", in Moser, O. Caroline, and Clark, Fiona (eds.), Victims, Perpetrators or Actors? Gender, Armed Conflict and Political Violence, Zed Books, New York, 2001

Moshan, Brook Shari, "Women, war and words: the gender component in the permanent International Criminal Court's definition of crimes against humanity", Fordham International Law Journal, Vol. 22, No. 1, (1998) 154-184

Musa, Shava, Victim Reparation Under the Ius Post Bellum, Cambridge University Press, Cambridge, 2019

Nagel, Joane, "Gender, violence and the military", in Shepherd, Laura J. (eds.), Handbook on Gender and Violence, Edward Elgar Publishing, Northampton, 2019

Ní Aoláin, Fionnuala, "Gendered Under-Enforcement in the Transitional Justice Context", in Buckley-Zistel, Susanne and Stanley, Ruth (eds.), Gender in Transitional Justice. Governance and Limited Statehood Series, Palgrave Macmillan, London, 2012

Ní Aoláin, Fionnuala, "Gendering the Law of Occupation: The Case of Cyprus", Minnesota Journal of International Law, Vol. 27, No. 1, (2018) 107-141

Ní Aoláin, Fionnuala. "What Does Post Conflict Security Mean for Women?”, in Tripp, Aili Mari and Marx Ferree, Myra and Ewig, Christina (eds.), Gender, Violence and Human Security: Critical Feminist Perspectives, NYU Press, New York, 2013

Niarchos, Catherine N., "Women, war, and rape: Challenges facing the International Tribunal for the Former Yugoslavia", Human Rights Quarterly, Vol. 17, No. 4, (1995) 649690

Niemi, Johanna and Verdu Sanmartin, Amalia, "The Concepts of Gender and Violence in the Istanbul Convention", in Niemi, Johanna, Peroni, Lourdes and Stoyanova, Vladislava (eds.), International Law and Violence against Women. Europe and the Istanbul Convention, Routledge, London and New York, 2020

Nolte, Georg, "Subsequent practice as a means of interpretation in the jurisprudence of the WTO appellate body", in Cannizzaro, Enzo (ed.), The Law of treaties beyond the Vienna Convention, Oxford University Press, Oxford, 2011

Nussbaum, Martha C., “Women's Progress and Women's Human Rights”, in Fassbender, Bardo and Traisbach, Knut (eds.), The Limits of Human Rights, Oxford University Press, Oxford, 2019

O'Keefe, Roger Michael, "Recourse by the ad hoc Tribunals to general principles of law and to human rights law', in Delmas Marty, Mirelle, Fronza, Emanuela and LambertAbdelgawad, Elisabeth (eds), Les Sources du Droit International Pénal: L'experience dea tribuneax pénaux internationaux et le statut de la Court penale internationale, Société de législation compårée, Société de Législation Comparée, Paris, 2004

O’Donovan, Katherine, Sexual Divisions in Law, Weidenfeld \& Nicolson, London, 1985 
O'Rourke, Catherine, “Geneva Convention III Commentary: What Significance for Women's Rights?", Just Security, (October 21, 2020), available at: https://www.justsecurity.org/72958/geneva-convention-iii-commentary-whatsignificance-for-womens-rights/?fbclid=IwAR1XN2u-P8ZcLruDJlx7Fk6DG9X9cGz0qENM2_FRC4E-djo6Ho6-Hdp5L0

O'Rourke, Catherine, Women's Rights in Armed Conflict under International Law, Cambridge University Press, Cambridge, 2020

Oda, Shigeru, "The Normalization of Relations between Japan and the Republic of Korea", American Journal of International Law, Vol. 61, No. 1 (1967) 35-56

Oloka-Onyango Joe and Tamale, Sylvia, “"The Personal Is Political” or Why Women's Rights Are Indeed Human Rights: An African Perspective on International Feminism' Human Rights Quarterly, Vol.17 (1995) 691-731

Olsthoorn, Peter, Honor in Political and Moral Philosophy, SUNY Press, New York, 2015

Oosterveld, Valerie, "Feminist Debates on Civilian Women and International Humanitarian Law”, Windsor Yearbook of Access to Justice, Vol. 27, No. 2, (2009) 385-402

Oosterveld, Valerie, "Forced Marriage during Conflict and Mass Atrocity", in Ni Aolain, Fionnuala, Cahn, Naomi, Haynes, Dina Francesca and Valji, Nahla (eds), The Oxford Handbook of Gender and Conflict, Oxford University Press, Oxford, 2018

Otto, Dianne, "Feminist Approaches to International Law", in Orford, Anne, Hoffmann, Florian, The Oxford Handbook of the Theory of International Law, Oxford University Press, 2016

Otto, Dianne, "Women, Peace, and Security: A Critical Analysis of the Security Council's Vision", in Ní Aoláin, Fionnuala, Cahn, Naomi, Haynes, Dina Francesca, Valji, Nahla (eds.), The Oxford Handbook of Gender and Conflict, Oxford University Press, Oxford, 2018

Otto, Dianne, "Women's Rights", in Moeckli, Daniel, Shah, Sangeeta and Sivakumaran, Sandesh (eds.), International Human Rights Law, Oxford University Press, Oxford, 2013

Palchetti, Paolo, "An Interdisciplinary Approach to International Law? Some Cursory Remarks", in Meccarelli, Massimo (ed.), Reading the Crisis: Legal, Philosophical and Literary Perspectives, Editorial Dykinson, Madrid, 2017

Palchetti, Paolo, "Can State Action on Behalf of Victims Be an Alternative to Individual Access in Case of Grave Breaches of Human Rights?", The Italian Yearbook of International Law, Vol. 24, (2014) 53

Palchetti, Paolo, “Interpreting 'Generic Terms': Between Respect for the Parties' Original Intention and the Identification of the Ordinary Meaning", in Boschiero, Nerina, Scovazzi, Tullio, Pitea, Cesare and Ragni, Chiara (eds.), International Courts and the Development of International Law. Essays in Honour of Tullio Treves, Springer, The Hague, 2013

Papanicolopulu, Irini, Gender and the Law of the Sea, Brill/Nijhoff, Leiden, 2019 
Parker, Karen and Chew, Jennifer F., “Compensation for Japan's World War II War Rape Victims", Hastings International \& Comparative Law Review, No. 17, (1993-1994), 497-550

Pellet, Alain, "The Destruction of Troy Will Not Take Place", in Playfair, Emma (ed.), International Law and the Administration of Occupied Territories, Clarendon Press, Oxford, 1992

Peters, Anne, "Direct Rights of Individuals in the International Law of Armed Conflict", MPIL Research Paper Series, No. 2019-23, (2019)

Peters, Anne, "Right to Reparation as a Consequence of Direct Rights Under International Humanitarian Law", Zeitschrift für ausländisches öffentliches Recht und Völkerrecht , Vol 78, No. 3 (2018) 545-549

Peters, Anne, Beyond Human Rights. The Legal Status of the Individual in International Law, Cambridge University Press, Cambridge, 2016

Pictet, Jean S. (ed.), The Geneva Conventions of 12 August 1949, Commentary, Volume III, Third Geneva Convention relative to the Treatment of Prisoners of War, Geneva, 1960, [Commentary, Vol. III]

Pictet, Jean S. (ed.), The Geneva Conventions of 12 August 1949, Commentary, Volume IV, Fourth Geneva Convention Relative to the Treatment of Civilian Persons in Time of War, Geneva, 1958, [Commentary, Vol. IV]

Pictet, Jean S. (ed.), The Geneva Conventions of 12 August 1949, Commentary, Volume I, First Geneva Convention for the Amelioration of the Condition of the Wounded and Sick in Armed Forces in the Field, Geneva, 1952, [Commentary, Vol. I];

Pictet, Jean S. (ed.), The Geneva Conventions of 12 August 1949, Commentary, Volume II, Second Geneva Convention for the Amelioration of the Condition of Wounded, Sick and Shipwrecked Members of Armed Forces at Sea, Geneva, 1960, [Commentary, Vol. II];

Pilloud, Claude, Sandoz, Yves, Swinarski, Christophe, and Zimmermann, Bruno (eds.), Commentary on the Additional Protocols: of 8 June 1977 to the Geneva Conventions of 12 August 1949, Martinus Nijhoff Publishers, Geneva, 1987

Pisillo Mazzeschi, Riccardo, "Reparation Claims by Individuals for State Breaches of Humanitarian Law and Human Rights: An Overview", Journal of International Criminal Justice, Vol. 1, No. 2, (2003) 339-347

Plevri, Anna, "Cyprus", in Ruggeri, Lucia Kunda, Ivana, and Winkler, Sandra (eds.), Family Property and Succession in EU Member States National Reports on the Collected Data, 2019, available at https://www.eurofamily.eu/documenti/news/psefs_e book_compressed.pdf

Program on Humanitarian Policy and Conflict Research, Harvard University, Manual on International Law Applicable to Air and Missile Warfare, 2009

Provost, René, International Human Rights and Humanitarian Law, Cambridge University Press, Cambridge, 2002 
Rees, Madeleine and Chinkin, Christine, "Exposing the Gendered Myth of Post Conflict Transition: The Transformative Power of Economic and Social Rights", New York University Journal of International Law and Politics, Vol. 48, No. 4 (2016) 1211-1226

Rehn Elisabeth and Johnson Sirleaf Ellen, "Women, War and Peace: The Independent Experts' Assessment on the Impact of Armed Conflict on Women and Women's Role in Peacebuilding”, UNIFEM, New York, 2002

Roling, Bert V. A., "Criminal Responsibility for Violations of the Laws of War", Belgian Review of International Law, Vol. 12, No. 1, (1976) 9-26

Romany, Celina, "State responsibility goes private: a feminist critique of the public/private distinction in International Human Rights Law", in Cook, Rebecca (eds.), Human rights of women. National and international perspectives, University of Pennsylvania Press, Philadelphia, 1994

Rombouts, Heidy, "Women and Reparations in Rwanda", in Rubio-Marin, Ruth (eds.), What Happened to the Women? Gender and Reparations for Human Rights Violations, International Centre for Transitional Justice, New York, 2006

Rona, Gabor, and McGuire, Robert J., "The Principle of Non-Discrimination", in Clapham, Andrew, Gaeta, Paola and Sassoli, Marco (eds.), The 1949 GC: A Commentary, Oxford University Press, Oxford, 2015

Ronen, Yael, "Recognition of divorce without recognition of statehood", Cambridge Law Journal, Vol. 63, No. 2, (2004) 268-271

Ronzitti, Natalino, Diritto internazionale dei conflitti armati, 3rd edn, Giappichelli, Torino, 2011

Rubio-Marín, Ruth, "The gender of reparations in transitional democracies", in Rubio-Marín, Ruth, The Gender of Reparations. Unsettling sexual hierarchies while redressing human rights violations, Cambridge University Press, Cambridge, 2009

RULAC (Rule of Law in Armed Conflicts), "Non-International Armed Conflicts in Nigeria, available at: http://www.rulac.org/browse/conflicts/non-international-armed-conflictin-nigeria\#collapse3accord

Rycroft, Theo, "Criminalization and Prosecution of Sexual Violence in Armed Conflict at the Domestic Level: Grave Breaches and Universal Jurisdiction", in Vulnerabilities in Armed Conflicts: Selected Issues, Proceedings of the 14th Bruges Colloquium, 1718 October 2013, College of Europe/ICRC, Collegium No. 44, Autumn 2014

Salvadego, Laura, Struttura e funzioni della necessità militare nel diritto internazionale, Giappichelli, Torino, 2016

Sandoval, Clara, "International Human Rights Adjudication, Subsidiarity, and Reparation for Victims of Armed Conflict", in Correa Christiàn, Furuya, Shuichi, and Sandoval, Clara (eds.), Reparation for Victims of Armed Conflict, (Anne Peters and Christian Marxsen series eds.), Vol. 3, Cambridge University Press, Cambridge, 2021

Sassòli, Marco, "State Responsibility for Violations of International Humanitarian Law", International Review of the Red Cross, Vol. 84, No. 846 (2002), 401 - 434 
Sassòli, Marco, International Humanitarian Law Rules, Controversies, and Solutions to Problems Arising in Warfare, Edward Edgar Publishing, Cheltenham, 2019

Scales, Ann, "Militarism, Male Dominance and Law: Feminist Jurisprudence as Oxymoron", Harvard Women's Law Journal, Vol. 12, (1989) 25-73

Schabas, William A., "International Prosecution of Sexual and Gender-Based Crimes Perpetrated during the First World War", in Martin Böse, Michael Bohlander, André Klip and Otto Lagodny, Justice Without Borders. Essays in Honour of Wolfgang Schomburg, Brill, Nijhoff, Leiden, 2018

Schabas, William A., The International Criminal Court: A Commentary on the Rome Statute, Oxford University Press, Oxford, 2016

Schomburg, Wolfgang and Peterson, Ines, "Genuine Consent to Sexual Violence under International Criminal Law", American Journal of International Law, Vol. 101, No. 1 (2007) 121-140

Schulz, Philipp, “'Luk Pe Coo' or Compensation as Dowry? Gendered Reflections on Reparations for Conflict-Related Sexual Violence Against Men", International Journal of Transitional Justice, Vol. 12, No. 3 (2018) 537-548

Schwarz, Alexander, "War Crimes", in Lachenmann, Frauke and Wolfrum, Rüdiger (eds.), The Law of Armed Conflict and The Use of Force. Max Planck Encyclopedia of Public International Law, Thematic Series, Vol. 2, Oxford University Press, Oxford, 2017

Scott, Joan W., "Gender: a useful category of analysis", American Historical Review, Vol. 91, (1986) 1053-1075

Seifert, Ruth, "War and Rape: A Preliminary Analysis", in Stiglmayer, Alexandra (ed.), Mass Rape: The War against Women in Bosnia-Herzegovina, University of Nebraska Press, Lincoln, 1994

Sellers, Patricia Viseur, “(Re)Considering Gender Jurisprudence”, in Ní Aoláin, Fionnuala, Cahn, Naomi, Haynes, Dina Francesca, and Valji, Nahla (eds.), The Oxford Handbook of Gender and War, Oxford University Press, Oxford, 2017

Sellers, Patricia Viseur, "Gender Strategy is Not Luxury for International Courts", Journal of Gender, Social Policy \& the Law, Vol. 17, Issue 2, (2009) 301-325

Sellers, Viseur Patricia and Rosenthal, Indira, "Rape and Other Sexual Violence", in Clapham, Andrew, Gaeta, Paola and Sassoli, Marco (eds.), 1949 Geneva Conventions. A Commentary, Oxford University Press, 2015

Sellers, Viseur Patricia, "The Context of Sexual Violence: Sexual Violence as Violation of International Humanitarian Law", in Kirk McDonald, Gabrielle and Swaak-Goldman, Olivia (eds.), Substantive and Procedural Aspects of International Criminal Law: The Experience of International and National Courts. Volume I: Commentary, Kluwer Law International, The Hague, 2000

Sharoni, Simona, Welland, Julia, Steiner, Linda and Pedersen, Jennifer (eds.), Handbook on Gender and War, Edward Elgar Publishing, Northampton, 2016 
Shaw, Malcom N., International Law, $8^{\text {th }}$ edition, Cambridge University Press, Cambridge, 2017

Shelton, Dinah, "Righting Wrongs: Reparations in the Articles on State Responsibility", American Journal of International Law, Vol. 96, No 2, (2002) 833 - 856

Shuichi, Furuya, "Draft Procedural Principles for Reparation Mechanisms", in ILA, Report of the Seventy-Sixth Conference Held in Washington D.C., London, ILA, 2014

Sivakumaran, Sandesh, "Sexual Violence Against Men in Armed Conflict", European Journal of International Law, Vol. 18, No. 2, (2007) 253-276

Sjöholm, Maria, Gender-sensitive Norm Interpretation by Regional Human Rights Law Systems, Brill, Leiden, 2018

Sluga, Glenda, "Gender, Peace, and the New Politics of Humanitarianism in the First Half of the Twentieth Century", in Hagemann, Karen, Dudink, Stefan, and Rose, Sonya O., The Oxford Handbook of Gender, War, and the Western World since 1600, Oxford University Press, Oxford, 2020

Soh, Chunghee Sarah, “The Korean 'comfort women': movement for redress”, Asian Survey, Vol. 36, No. 12, (1996) 1226-1240

Solf, Waldemar A. and Cummings, Edward R., "A Survey of Penal Sanctions under Protocol I to the Geneva Conventions of August 12, 1949", Case Western Reserve Journal of International Law, Vol. 9, No. 2, (1977) 205-252

Sorel, Jean-Marc and Boré-Eveno, Valérie, "Article31", in Corten, Olivier and Klein, Pierre (eds.), The Vienna Conventions on the Law of Treaties: A Commentary, Vol. I, Oxford University Press, Oxford, 2011

Spoerri, Philip, "The Law of Occupation", in Clapham, Andrew and Gaeta, Paola (eds.), The Oxford Handbook of International Law in Armed Conflict, Oxford University Press, Oxford, 2014

Steains, Cate, "Gender Issues", in Roy S. Lee (ed.), The International Criminal Court: The Making of The Rome Statute: Issues, Negotiations, Results, Kluwer Law International, The Hague, 1999

Stern, Orly Maya, Gender, Conflict and International Humanitarian Law. A Critique of the "Principle of Distinction”, Routledge, Abingdon-New York, 2019

Stockholm International Peace Research Institute, "World military expenditure grows to $\$ 1.8$ trillion in 2018”, 29 April 2019, available at: https://www.sipri.org/media/pressrelease/2019/world-military-expenditure-grows-18-trillion-2018.

Swaine, Aisling, Conflict-Related Violence against Women: Transforming Transition, Cambridge University Press, Cambridge, 2018

Talmon, Stefan A. G., "Ius Cogens after Germany v. Italy: Substantive and Procedural Rules Distinguished”, Leiden Journal of International Law, Vol. 25, No. 4, (2012) 979-1002 
Teitel, Ruti, "The Transitional Apology", in Barkan, Elazar and Karn, Alexander (eds.), Taking Wrongs Seriously. Apologies and Reconciliation, Stanford University Press, Stanford, 2006

Teitel, Ruti, Transitional Justice, Oxford University Press, Oxford, 2000

Thirlway, Hugh, "The Law and Procedure of the International Court of Justice 1960-1989 Part One”, British Yearbook International Law Vol. 60, No. 1, (1989) 1-157

Thomas, Tracy A., and Boisseau, Tracy Jean (eds), Feminist legal history: essays on women and law, New York University Press, New York, 2011

Touquet, Heleen, "Unsilenced: Male Victims of Sexual Violence in Sri Lanka", International Truth and Justice Project, Johannesburg, 2018

Triantafilou, Epaminontas E., "Contemporary and Evolutive Interpretation under the Vienna Convention on the Law of Treaties", ICSID Review, Vol. 32, No. 1, (2017) 138-169

Trindade, Antônio Augusto Cançado, International Law for Humankind. Towards a New Jus Gentium, Brill, Nijhoff, Leiden/Boston, 2020

Ueno, Chizuko, Nationalism and Gender, [transl. B. Yamamoto] Trans Pacific Press, Melbourne, 2004

Uhler, Oscar M., Coursier, Henri, Commentary. IV Geneva convention relative to the protection of civilian persons in time of war, International Committee of the Red Cross, Geneva, 1958

UNICEF, "In Nigeria's restive northeast, fate of thousands of abducted women remains unknown", 2016, available at: https://news.un.org/en/story/2016/04/526752-nigeriasrestive-northeast-fate-thousands-abducted-women-remains-unknownun\#.VxDC43CQyGB

UNICEF, "Sexual Violence as a Weapon of War", available at: www.unicef.org/sowc96pk/sexviol.htm

Van Boven, Theo, "Victims' Right to a Remedy and Reparation: the New United Nations Principles and Guidelines", in Ferstman, Carla, Goetz, Marlana and Stephens, Alan (eds.), Reparations for Victims of Genocide, War crimes and Crimes Against Humanity: Systems in Place and Systems in the Making, Brill, Nijhoff, Leiden, 2009

Van Houtte, Hans, Das, Hans, Delmartino, Bart and Yi, Iasson, Post-War Restoration of Property Rights under International Law, Vol. I: Institutional Features and Substantive Law, Cambridge University Press, Cambridge, 2008

Vázquez-Bermúdez Marcelo, Special Rapporteur, First report on general principles of law, 2019, A/CN.4/732, available at http://legal.un.org/docs/?symbol=A/CN.4/732

Venturini, Gabriella, "Diritto internazionale umanitario e diritti umani: una prospettiva di genere", in Di Stefano, Adriana and Sapienza, Rosario (eds.), La tutela dei diritti umani e il diritto internazionale. SIDI - XVI Convegno, Catania, 23-24 giugno 2011, Editoriale scientifica, Napoli, 2012 
Vitanyi, Béla, "Les positions doctrinales concernant le sens de la notion de «principes généraux de droit reconnus par les nations civilisées», in Revue Générale de droit international public, Vol 86, (1982) 48-116

Vöneky, Silja, "Implementation and Enforcement of International Humanitarian Law", in Fleck, Dieter (ed.), The Handbook of International Humanitarian Law, Oxford University Press, Oxford, 2013

Waldock, Humphrey, "The Evolution of Human Rights concepts and the Application of the European Convention of Human Rights", in Mélanges offerts à Paul Reuter-Le droit international: unite et diversité, Pedone, Paris, 1981

Wallach, Evan, "Pray Fire First Gentlemen of France: Has 21st Century Chivalry Been Subsumed by Humanitarian Law?", Harvard National Security Journal Vol. 3, (2012), 431-469

Weapons Law Encyclopedia, 'Weapon', available at: http://www.weaponslaw.org/glossary/weapon

Weil, Simone, The Need for Roots. Prelude to a Declaration of Duties towards Mankind, Routledge, London, New York, 2001

Welchman, Lynn and Hossain, Sara (eds), Honour: Crimes, Paradigms and Violence Against Women, Zed Books, London, 2005

West, Robin, “Jurisprudence and gender”, University of Chicago Law Review, Vol. 55, No. 1, (1988) 1-72

WHO, "Safe abortion care: the public health and human rights rationale", in Safe abortion: technical and policy guidance for health systems, 2nd ed., Geneva, 2012, available at: http://apps.who.int/iris/bitstream/10665/70914/1/9789241548434 eng.pdf

Williams, Sarah and Opdam, Jasmine, "The Unrealised Potential for Transformative Reparations for Sexual and Gender-Based Violence in Sierra Leone", International Journal of Human Rights, Vol. 21, No. 9, (2017) 1281-1301

Wiltsher, Anne, Most Dangerous Women: Feminist Peace Campaigners of the Great War, Pandora, London, 1985

Wing, Adrien K., "International Law and Feminism", in West, Robin and Grant Bowman, Cynthia, Research Handbook on Feminist Jurisprudence, Edward Elgar Publishing, Cheltenham, 2019

Women's Initiatives for Gender Justice (WIJG), "Civil Society Declaration on Sexual Violence", 2019

Wood, Elisabeth Jean, "Conflict-related sexual violence and the policy implications of recent research", International Review of the Red Cross (2014), 96 (894), 457-478

Wood, Elisabeth Jean, "Sexual violence during war: variation and accountability", in Smeulers (ed.), Collective Violence and International Criminal Justice, Intersentia, Antwerp 2010 
Wood, Michael, "The Rights of Victims to Reparation: The Importance of Clear Thinking", Heidelberg Journal of International Law, Vol. 78, (2018) 541-543

Yoshiaki, Yoshimi Comfort women, [trans. S. O’Brien], Columbia University Press, New York 2000

Yoshimi, Yoshiaki, "Historical Understandings on the 'Military Comfort women' Issue", speech to the 1992 Public Hearing concerning the Post-War Compensation of Japan, reprinted in Executive Committee International Public Hearing, War Victimisation and Japan, Toho Shuppansha, Tokyo, (1993), 81

$\mathrm{Yu}$, Tong, "Reparation for Former Comfort Women of World War II", Harvard International Law Journal, Vol. 36, No. 2 (1995), 528-540

Žarkov, Dubravka, "Conceptualizing Sexual Violence in Post-Cold War Global Conflicts”, in Hagemann, Karen, Dudink, Stefan and Rose, Sonya O. (eds.), The Oxford Handbook of Gender, War, and the Western World since 1600, Oxford University Press, Oxford, 2020

Žarkov, Dubravka, "From Women and War to Gender and conflict? Feminist Trajectories", in Ní Aoláin, Fionnuala, Cahn, Naomi, Haynes, Dina Francesca, Valji, Nahla (eds.), The Oxford Handbook of Gender and Conflict, Oxford University Press, Oxford, 2018

Zegveld, Liesbeth, "Remedies for Victims of Violations of International Humanitarian Law", International Review of the Red Cross, Vol. 85, No. 851, (2003), 497-527

Zimmermann, Andreas, "Sovereign Immunity and Violations of Jus Cogens - Some Critical Remarks", Michigan Journal of International Law, Vol. 16, No. 2 (1995), 433-440

Borelli, Silvia and Vitucci, Maria Chiara, "From chattel slavery to 'modern slavery': The role for human dignity in the struggle against contemporary forms of human exploitation", Questions of International Law, (December 24, 2019), available at: http://www.qilqdi.org/from-chattel-slavery-to-modern-slavery-the-role-for-human-dignity-in-thestruggle-against-contemporary-forms-of-human-exploitation/

Vitucci, Maria Chiara, "The Protection of Sexual Orientation in International Law: Between the Principles of Non-Discrimination and Human Dignity", Europa Ethnica, Vol. 76, No. 3-4, (2019) 115-119

Marchegiani, Maura, "La condition juridique de la victime à travers le prisme des juridictions pénales internationalisées", in in Kamto, Maurice and Tyagi, Yogesh (eds.), The Access of Individuals to International Justice, Brill Nijhoff, Leiden Boston, 2019 